$$
\begin{aligned}
& \text { Pevista Portuguesa de }
\end{aligned}
$$

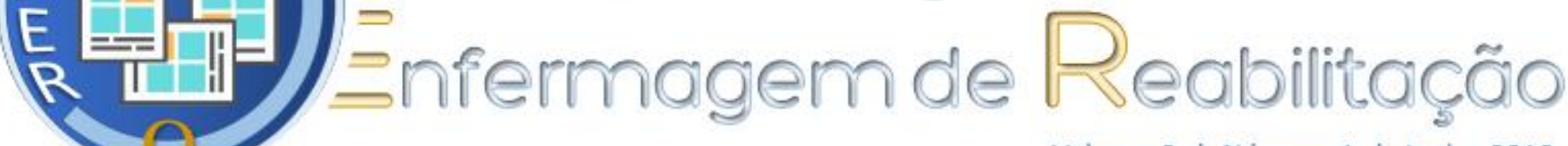

$$
\begin{aligned}
& \text { Volume } 2 \text { | Número } 1 \text { | Junho } 2019
\end{aligned}
$$

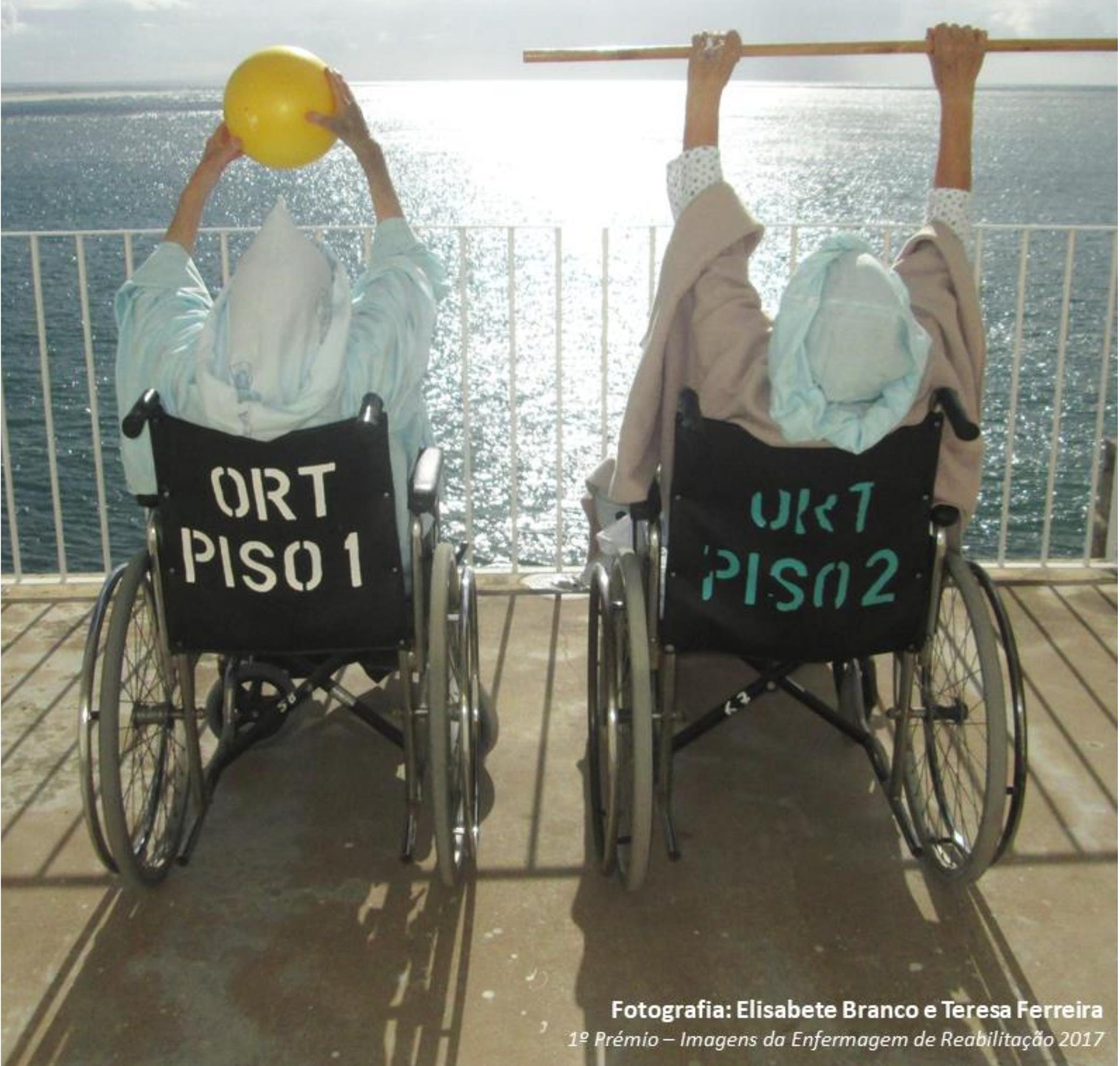




\section{FICHA TÉCNICA}

ISSN: 2184-3023

PROPRIEDADE INTELECTUAL

Associação Portuguesa dos Enfermeiros de Reabilitação

Rua Cassiano Branco 74, $4^{\circ}$ Esq Tras 4250 - 084 Porto - www.aper.pt

E-mail: revista@aper.pt | Contacto telefónico: 931756382

Editor Chefe

Maria Manuela Ferreira Pereira da Silva Martins (i)

PhD - Escola Superior de Enfermagem do Porto, Portugal

Editor Sénior

Fernando Manuel Dias Henriques (i)

Escola Superior de Enfermagem de Coimbra, Portugal

Comissão Editorial

André Filipe Morais Pinto Novo

PhD - Escola Superior de Saúde do Instituto Politécnico de Bragança, Portugal

Luís Manuel Mota Sousa (iD

PhD - Escola Superior de Enfermagem S. João de Deus, Universidade de Évora, Portugal

Edição Gráfica

Rui Pedro Marques da Silva

\section{Comissão Técnica}

Ana Cristina Nunes Mesquita (iD

Ana da Conceição Alves Faria

Bruno Miguel Delgado (iD)

Clara Monteiro

Cristina Maria Medeiros Guedes F. Moura

Dulce Sofia Antunes Ferreira

Eunice Salomé Alves Sobral Sousa

Glória Maria Andrade do Couto

Helena Castelão Figueira Carlos Pestana id

Ivo Cláudio Mendes Lopes (iD

Jacinta Pires Martins

João Pedro Pinto Coelho Oliveira

Joaquim Augusto Gonçalves Simões

José Alberto Teixeira Pires Pereira

José Alexandre Pinto Soares (ii

Júlia da Conceição Marques dos Santos

Liliana Celeste Faria da Silva Ribeiro

Luís Jorge Rodrigues Gaspar (i)

Luís Miguel Ferreira Agostinho

\section{Comissão Científica}

Ana Filipa dos Reis Cardoso (iD)

André Filipe Morais Pinto Novo (iD

Arménio Guardado Cruz (D)

Bárbara Pereira Gomes (i)

Bruna Raquel Figueira Ornelas de Gouveia (i)

Carla Sílvia Fernandes (iD

César João Vicente da Fonseca (iD

Clara de Assis Coelho de Araújo (D)

Cristina Lavareda Baixinho (iD)

Cristina Marques-Vieira (iD)

Élvio Henriques de Jesus (ii)

Fabiana Faleiros Santana Castro (iD

Fernando Alberto Soares Petronilho (it)

José Miguel Santos Castro Padilha (D)

Leonel São Romão Preto (iD
Manuel Barnabé Moura Pinto de Melo

Maria do Carmo Oliveira Cordeiro

Maria de Fátima Sequeira Loureiro

Maria Eugénia Rodrigues Mendes (io

Maria Helena Ferreira de Almeida

Maria José Bule (iD)

Marisa da Glória Teixeira da Cunha

Patrícia Maria Rodrigues Pereira Pires

Raquel Maria dos Reis Marques

Ricardo Jorge Almeida Braga

Rui Pedro Marques da Silva (it)

Rute Salomé Silva Pereira (iD)

Sandy Silva Pedro Severino (iD

Sérgio Alberto Pires Garcia

Sérgio Filipe Alves Vaz

Sónia Alexandra Claro Casado

Teresa Silveira ic

Víctor Jorge Reis Pereira

Virgínia Lucinda de sousa Cruz Pereira

Luís Manuel Mota Sousa (iD

Maria de La Salete Rodrigues Soares (iD

Maria Gorete Mendonça dos Reis (iD

Maria José Almendra Gomes (iD)

Maria José Lopes Fonseca (iD

Maria José Lumini Landeiro (it)

Maria Manuela Martins (iD)

Maria Salomé Martins Ferreira (iD)

Nelson Emidio Henrique Guerra (i0

Olga Maria Pimenta Lopes Ribeiro (ii)

Pedro Migue Santos Dinis Parreira (i]

Rosa Maria Lopes Martins (i)

Soraia Dornelles Schoeller (iD

Vanda Lopes da Costa Marques Pinto

Wiliam C. A. Machado (iD 


\section{ÍNDICE DE CONTEÚDOS}

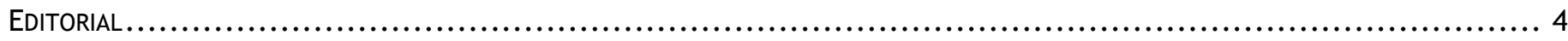

ATIVIDADE FísICA E EXERCícIO FísICO: FUNDAMENTOS E APLICAÇÕES EM ENFERMAGEM DE REABILITAÇÃO ..........................4

EFEITO dA REABILITAÇÃO RESPIRATÓRIA NOS SINTOMAS AVALIAdO PELO CAT E A SUA RELAÇÃO COM A TOLERÂNCIA À ATIVIDADE ............ 6

(D) Luis Gaspar; Paula Martins; Fátima Gomes

ENFERMAGEM DE REABILITAÇÃO NA PREVENÇÃO DE QUEDAS EM IDOSOS NO DOMICÍLIO 11 Jéssica Gomes; Carlos Miguel Soares; (iD Maria José Bule

EXERCíCIO FÍSICO EM PESSOAS COM DIABETES: REVISÃo SISTEMÁTICA DE LITERATURA 18

(Di) Lénia Alexandra Ramos Loureiro; (D) Maria Isabel Vaz Afonso; (D) Patrícia da Silva Ribeiro; (D) Ana Cristina Nunes Mesquita; iD Helena Castelão Figueira Carlos Pestana; iD Luís Manuel Mota de Sousa

EXERCÍCIO FÍSICO NA PESSOA COM DEMÊNCIA: REVISÃO SISTEMÁTICA DE LITERATURA. 27

(D) Diana Vanessa Ferreira Maia; (D) Rui Miguel de Andrade Gaspar; (i) António Manuel Gradíssimo Costa; (D) Filipe Manuel Gonçalves Dias; iD Helena Castelão Figueira Carlos Pestana; iD Luís Manuel Mota de Sousa

EXERCíCIO FÍSICO NA PESSOA COM DEPRESSÃO: REVISÃO SISTEMÁTICA DA LITERATURA 35

(DD Inês de Jesus Rocha; (D) Carla Alexandra Fundevila de Barros; (i) Ana Maria Pinto Mateus; (D) Rosa Cristina Rodrigues Correia; (iD Helena Castelão Figueira Carlos Pestana; Di Luís Manuel Mota de Sousa

FUNCIONALIDADE DE PESSOAS SUBMETIDAS A ARTOPLASTIA TOTAL DO OMBRO POR FRATURAS DO ÚMERO PROXIMAL: ESTUDO RETROSPETIVO .. 43 Carolina Tiago Afonso; Miguel Pinto Freitas; Nuno Gonçalo Pais; Daniel Ramos Pires; (D) André Novo; Afonso Salgado Ruano

MOBILIZAÇÃO PRECOCE EM PESSOAS SUBMETIDAS A VENTILAÇÃO MECÂNICA INVASIVA: REVISÃo INTEGRATIVA DA LITERATURA

(iD Pedro Cerol; (D) Jorge Martins; (D) Luís Manuel Mota de Sousa; (D) Isabel Oliveira; (D) Teresa Silveira

O TREINO DE EXERCÍCIO EM PESSOAS COM DOENÇA RESPIRATÓRIA CRÓNICA ESTABILIZADA : UMA SCOPING REVIEW

(DD Luis Gaspar; Dulce Ferreira; Francisco Vieira; Paulo Machado; (D) Miguel Padilha

O TREINO PROPRIOCETIVO E DE EQUILÍBRIO POSTURAL NO IDOSO PARA A PREVENÇÃO DE QUEDAS: SCOPING REVIEW . 66

Catarina Correia; Liliana Barbosa; Luís Rebelo; Marco Alves; Nuno Pinho; Bruno Magalhães

PREVENÇÃO DAS CONSEQUÊNCIAS DA IMOBILIDADE NA PESSOA EM SITUAÇÃO CRÍTICA 78 Ana Vanessa Barroso Cerqueira; (D) Eugénia Nunes Grilo

INTERVENÇÃO dO ENFERMEIRO ESPECIALISTA EM REABILITAÇÃO NA MOBILIDADE DA PESSOA IDOSA INSTITUCIONALIZADA - PROGRAMA TEIA .. 90 Rita Pires; (D) Maria Manuela Martins; (D) Bárbara Gomes; Clara Monteiro; (D) Olga Ribeiro

IMPACTO DE UM TREINO PROPRIOCETIVO NA CAPACIDADE FUNCIONAL DOS IDOSOS .102

Sérgio Garcia; Marisa Cunha; (D) Eugénia Mendes; (D) Leonel Preto; (iD André Novo 


\section{EDITORIAL}

No momento de apresentar um novo número da revista deparamo-nos com a necessidade de contextualizar a temática pelo que convidados um dos membros da comissão editoral a fazê-lo de forma a explicar a aproximação da temática "atividade física" ao conhecimento teórico e prático de enfermagem.

Selecionamos artigos que percorressem o tema da atividade física com especificidades relacionadas com o desenvolvimento humano, mas também com particularidades de saúde e de programas. Trazemos ainda para a leitura, várias metodologias de pesquisa e de aprofundamento do conhecimento sobre a matéria.

Acreditamos que é uma das áreas de cuidados de enfermagem que, embora faça parte das práticas diárias nos vários contextos, não tem emergido em publicações que representem a carga de trabalho desenvolvido pelos Enfermeiros de Reabilitação.

As intervenções dos Enfermeiros de Reabilitação, em torno da atividade física, revestem-se de particularidades de saberes de áreas afins, mas incorporam o conhecimento específico de enfermagem, pelo que consideramos que os enfermeiros de reabilitação têm competências especificas para intervir nesta área de forma a acrescentar valor à saúde das pessoas, durante o ciclo de vida e nos processos de doença.

Para melhor justificar a importância da atividade física no trabalho dos Enfermeiros de Reabilitação o Professor Doutor Luís Sousa desenvolveu um resumo de introdução à temática.

\section{Prof. DOUTORA MARIA MANUEla MARTINS}

Professora Coordenadora da Escola Superior de Enfermagem. Membro do Grupo de Investigação - NursID: Inovação e Desenvolvimento em Enfermagem - CINTESIS - center for health technology and services research - FMUP. Professora no Mestrado de Enfermagem de Reabilitação, Coordenadora do Mestrado de Direção e Chefia dos Serviços de Enfermagem. Membro da Comissão Ciêntifica do Doutoramento em Ciências de Enfermagem da UP.

\section{ATIVIDADE FíSICA E EXERCíCIO FíSICO: FUNDAMENTOS E APLICAÇÕES EM ENFERMAGEM DE REABILITAÇÃO}

Os modelos de enfermagem onde a atividade física e o exercício físico se enquadram enquanto focos e intervenções de enfermagem são Roper, Logan e Tierney (1995), e o de Orem (2001). A atividade física e o exercício físico estão atualmente regulamentados em duas competências, definidas pela mesa do colégio de enfermagem de reabilitação da Ordem dos Enfermeiros, especificamente, J2.1.2 - Realiza treinos específicos de AVD's, nomeadamente utilizando produtos de apoio (ajudas técnicas e dispositivos de compensação), assim como os treinos inerentes à atividade e exercício físico e J3.1.3 - Ensina, instrui e treina sobre técnicas e tecnologias (incluindo a atividade e o exercício físico) a utilizar para maximizar o desempenho a nível motor, cardíaco e respiratório, tendo em conta os objetivos individuais da pessoa e o seu projeto de saúde.

O exercício físico está definido na Classificação Internacional para a Prática de Enfermagem (CIPE) versão 2011 como a realização do trabalho físico e voluntário dos sistemas musculosquelético e respiratório para a melhoria da forma física, mobilidade e força. E a intolerância à atividade como um status comprometido: falta de capacidade ou energia para tolerar ou completar atividades.

A CIPE versão 2015 apresenta neste âmbito os seguintes diagnósticos/resultados: Adesão ao regime de exercício; Padrão de exercício comprometido; Atitude face ao regime de exercício dificultadora; Capacidade para gerir regime de exercício comprometida; Conhecimento sobre exercício; Conhecimento sobre terapia física; Conhecimento sobre regime de exercício; Intolerância à atividade; Risco de intolerância à atividade; Tolerância à atividade efetiva.

Como intervenções CIPE versão 2015 apresenta: Avaliar evolução da resposta psicossocial à instrução sobre exercício; Avaliar conhecimento sobre terapia física; Avaliar padrão de exercício; Avaliar tolerância à atividade; Monitorizar tolerância à atividade; Ensinar como aumentar a tolerância à atividade; Aumentar a tolerância à atividade; Promover adesão ao regime de exercício; Promover exercício; Promover mobilidade física; Reforçar regime de terapia física e Reforçar técnica de exercício muscular ou articular. E por último estão previstos os seguintes recursos: Técnica de exercício muscular ou articular e Terapia pela atividade.

O exercício terapêutico de acordo com Kisner Colby e Borstad (2017), é caracterizado pelo desempenho sistemático e planeado de movimentos físicos, posturas ou atividades destinadas a fornecer ao doente / cliente os meios para: atenuar ou prevenir deficiências de funções e estruturas do corpo; restaurar ou melhorar a atividade e a 
participação; prevenir ou reduzir os fatores de risco relacionados com a saúde; otimizar a saúde geral e sensação de bem-estar.

As recomendações na prescrição do exercício físico alicerçam-se nos seguintes critérios: Modalidade/ tipo de exercício, intensidade, volume, ordem dos exercícios, duração, frequência e progressão.

Segundo Kisner Colby e Borstad (2017), ao planear o exercício físico tem de se ter em consideração as várias dimensões da função física nomeadamente, desempenho muscular, resistência cardiovascular, mobilidade/flexibilidade, controlo neuromuscular/coordenação, estabilidade e equilíbrio corporal.

Piercy e colaboradores em 2018 referem como benefícios da atividade física e do exercício físico em crianças e adolescentes são: melhoria da saúde óssea (entre 3 e 17 anos); melhoria do peso (idades de 3 a 17 anos); melhoria da aptidão cardiorrespiratória e muscular (idades de 6 a 17 anos); melhoria da saúde cardiometabólica (entre 6 e 17 anos); melhoria da Cognição (idades de 6 a 13 anos); redução do risco de depressão (entre 6 e 13 anos).

A literatura científica (Novo e Paz em 2012; Meneses-Echávez e colaboradores em 2015; Piercy e colaboradores em 2018) refere que em adultos e idosos os benefícios são: menor risco de mortalidade por todas as causas; menor risco de mortalidade por doença cardiovascular; menor risco de doença cardiovascular; menor risco de hipertensão; menor risco de diabetes tipo 1 e 2, com melhoria da sensibilidade à insulina; menor risco de perfil lipídico sanguíneo adverso; menor risco de cancro da bexiga, mama, cólon, endométrio, esôfago, rim, pulmão e estômago; redução da fadiga relaciona com o cancro da mama, melhoria da qualidade de vida e da função física após cancro; melhoria da cognição; risco reduzido de demência (incluindo doença de Alzheimer); melhor qualidade de vida; redução da ansiedade; redução do risco de depressão; melhoria do Sono; redução do peso quando combinada com uma ingestão calórica reduzida; melhoria da saúde óssea; melhoria da função física, menor risco de quedas (idosos); menor risco de lesões relacionadas a quedas (idosos).

Deverão ser utilizadas as estratégias mais apropriadas para aumentar a atividade física assim como do exercício físico (tipo, frequência, intensidade, duração), além disso, estas estratégias terão de ser adaptadas de acordo com as capacidades, necessidades e desejos das pessoas.

Em síntese, os enfermeiros especialistas em enfermagem de reabilitação têm competências e são detentores de conhecimento científico que lhes permite prescrever exercício físico em populações especiais, contribuindo assim para a melhorias dos seus resultados em saúde, no âmbito da atividade física e do exercício físico.

\section{PROF. DOUTOR LUIS SOUSA}

Professor adjunto na Escola Superior de Enfermagem S. João de Deus, Universidade de Évora, Portugal 


\title{
EFEITO dA REABILITAÇÃo RESPIRATÓRIA NOS SINTOMAS AVALIADO PELO CAT E A SUA RELAÇÃO COM A TOLERÂNCIA À ATIVIDADE
}

\author{
EFECTO de LA ReHABILITACIÓN PULMONAR EVALUADOS POR EL CAT Y SU RELACIÓN CON ACTIVIDAD
}

\section{EFFECT OF PULMONARY REHABILITATION ASSESSED BY CAT AND ITS RELATION TO ACTIVITY TOLERANCE}

DOI 10.33194/rper.2019.v2.n1.01.4566 | Submetido 12.03.2019 | Aprovado 27.06.2019

Duis Gaspar ${ }^{1}$; Paula Martins ${ }^{1}$; Fátima Gomes ${ }^{1}$

1 - Centro Hospitalar e Universitário São João

\section{RESUMO}

A Doença Pulmonar Obstrutiva Crónica (DPOC) caracteriza-se por limitação crónica, progressiva e não totalmente reversível do fluxo aéreo, limitando por vezes o autocuidado.

Anteriormente caracterizada pela dispneia, reconhece-se atualmente a necessidade de uma avaliação sintomática mais abrangente recomendando-se entre outros instrumentos o COPD Assessment Test (CAT).

Sendo a Reabilitação Respiratória (RR) o tratamento não farmacológico recomendado neste contexto é objetivo deste estudo perceber qual o seu efeito no CAT e sua relação com a capacidade funcional (CF).

Estudo Quasi-Experimental com programa de Reabilitação Respiratória (PRR) de duração mediana de 13 semanas sendo o efeito no CAT e na CF avaliados no início e no final.

Incluidas 45 pessoas: $80 \%$ homens; idade media 65,82 anos e FEV1\% medio $40 \%$.

Verificou-se melhoria estatística e clinicamente significativas no CAT e na CF existindo entre as duas uma correlação negativa moderada.

Concluímos que este PRR reduziu a sintomatologia e aumentou a capacidade funcional em pessoas com DPOC.

Descritores: Enfermagem de Reabilitação, Reabilitação Respiratória; CAT; Tolerância à atividade; DPOC

\section{RESUMEN}

La Enfermedad Pulmonar Obstructiva Crónica (EPOC) se caracteriza por una limitación crónica, progresiva y no totalmente reversible del flujo aéreo, provocando limitaciones funcionales importantes repercutidas en el autocuidado.

Anteriormente caracterizada únicamente por la disnea se reconoce actualmente la necesidad de una evaluación más amplia de los síntomas y se recomienda entre otros el uso del COPD Assessment Test (CAT).

La Rehabilitación Respiratoria (RR) es el tratamiento no farmacológico recomendado en este contexto, la meta de este estudo es saber cuál es su efecto en el CAT y su relación con la CF.

Estudio Quasi-Experimental con programa de Rehabilitación Respiratoria (PRR) de duración mediana de 13 semanas, 3X semana siendo su efecto en el CAT y en la CF evaluados al inicio y al final.

Se incluyeron a 45 personas: $80 \%$ hombres; edad media 65,82 años y FEV1\% medio de $40 \%$.

Se observó una mejora estadística $(p<0,001)$ y clínicamente significativas en el CAT y en la CF existiendo una correlación negativa moderada.

Concluimos que este programa de RR redujo la sintomatología y aumentó la capacidad funcional en personas con EPOC.

Palabras clave: Enfermería de Rehabilitación; Rehabilitación Pulmonar; CAT; Tolerancia a la actividad; EPOC

\section{ABSTRACT}

Chronic Obstructive Pulmonary Disease (COPD) is a common disease characterized by progressive airflow limitation, causing important functional impairment with repercussions on self-care. Previously characterized only by dyspnea, it is now recognized that a more comprehensive assessment is needed leading GOLD to recommend the COPD Assessment Test (CAT).

Pulmonary Rehabilitation (PR) is the non-pharmacological treatment recommended in this context, and for that reason the goal of this investigation is to understand its effect on CAT as well as its relation with CF.

Quasi-Experimental study that includes COPD patients admitted to PR and the impact of CAT and CF was assessed at the beginning and at the end of the PR program.

Forty five patients were included ( $80 \%$ men), mean age 65.82 years and mean FEV1\% of $40 \%$. 
Statistical and clinically significant improvements were found $(p<0.001)$ in both CAT and CF, with a moderate negative correlation.

We conclude that this PR program reduces symptoms and increases functional capacity in people with COPD.

Key words: Rehabilitation Nursing; Pulmonary Rehabilitation; CAT; Exercise tolerance; COPD

\section{INTRODUÇÃOO}

A doença pulmonar obstrutiva crónica (DPOC) caracteriza-se por uma limitação persistente do fluxo aéreo.

Nos últimos anos tem-se assistido ao aumento da mortalidade e morbilidade sendo calculado que será a terceira causa de morte em 2020. (1) (2)

Em Portugal comparando os registos de utentes entre 2011 e 2017 assistiu-se a um aumento da 54.000 para 136.958 casos, sendo que a prevalência atualmente estimada é de $14,2 \%$ para idade superior a 40 anos o que deverá rondas as 800.000 pessoas. (2)

0 grau de obstrução aparece associada a bastantes sintomas da doença, contudo é pouco preditivo quanto à dispneia e à qualidade de vida. (1) (2) (3).

De facto, a função respiratória não explica todos os sintomas da doença, não resultando a intolerância à atividade unicamente da perda de função pulmonar, mas associada a trocas gasosas deficitárias e disfunção muscular periférica causando fadiga muscular (especialmente dos membros inferiores) e dispneia com impacte importante no autocuidado e na qualidade de vida. (3)

Este facto levou a GOLD (Global Iniciative for Chronic Obstructive Lung Disease) a propor desde 2011 uma nova estratificação da doença, combinando o risco de exacerbação, a espirometria e a avaliação sintomática (1).

Os sintomas resultantes da doença, especialmente a dispneia, a intolerância á atividade e a perda de função pulmonar levam ao reconhecimento da Reabilitação Respiratória (especialmente devido à componente de treino de exercício) como tratamento não farmacológico indicado para pessoas com DPOC. (2) (3) (4) (5) Sendo que a intervenção dos Enfermeiros de Reabilitação deve ir ao encontro das necessidades individuais da pessoa aumentando a tolerância á atividade através fundamentalmente do treino de exercício e da componente educacional promovendo desta forma a independência funcional e a adoção de comportamentos em saúde. (4) (5)

Neste contexto, a avaliação inicial dos programas de reabilitação respiratória é fundamental para a determinação do impacte da doença na pessoa. assim como posteriormente perceber qual a resposta individual e quais os ganhos sensiveis aos cuidados de saúde do programa de reabilitação respiratória. (3) (4) (6)

Neste sentido deverão ser avaliados dados sobre dispneia, tolerância à atividade e qualidade de vida que poderão ser facilmente recolhidos usando o COPD Assessment Test (CAT). (4) (5) (6)
Este questionário contém oito questões centrados em dados da função respiratória: tosse, expetoração, dispneia e expansão torácica limitada e também em dados não respiratórios como sendo a intolerância á atividade, distúrbios do sono, e incapacidade de executar atividades de vida diária (3) (4) (7)

o CAT é um instrumento de avaliação curto, de simples quantificação dos vários impactes dos sintomas da doença tendo sido desenvolvido para avaliar o estado de saúde e também para simplificar a comunicação entre a pessoa doente e a equipa de saúde.

Consiste em 8 itens respondidos ao longo de uma escala de Likert de 5 pontos, sendo que o valor máximo da doença é de 40 pontos.

É um questionário de autopreenchimento onde as pontuações variam entre 0 a 10 (leve), 11 a 20 (moderado), 21 a 30 (grave) e 31 a 40 (muito grave). (3) (4) (6) (7)

0 recente relatório de 2019 da GOLD recomenda que pessoas com CAT superior a 10 pontos sejam estratificadas como altamente sintomáticas (2)

Um decréscimo de 2 pontos no questionário CAT é considerado como ganho em saúde relevante fazendo deste valor a mínima diferença clinicamente significativa que é um indicador bastante importante uma vez que traduz ganhos em saúde. (8)

Este estudo teve como objetivo avaliar o efeito de um programa de reabilitação respiratória nos sintomas apercebidos pelas pessoas com DPOC avaliados pelo CAT e perceber qual a sua relação com a tolerância à atividade

Neste sentido, foram duas as questões que orientaram esta investigação:

- Qual o impacte de um Programa de Reabilitação Respiratória sobre os sintomas, a qualidade de vida e a tolerância ao exercício em pessoas com DPOC?

- Qual a relação entre as alterações avaliadas no CAT e a tolerância ao exercício nas pessoas com DPOC submetidas a um Programa de Reabilitação Respiratória?

\section{MÉTODOS}

\section{Tipo de Estudo}

Estudo Quasi-Experimental com programa de reabilitação respiratória com a duração média de 13 semanas, 3 sessões por semana. 
Cada sessão teve a duração média de 1 hora e incluiu treino de exercício. A sessão educacional foi realizada em sala e teve a duração de 60 (9) (Quadro 1).

\section{Amostra}

A técnica de amostragem utilizada foi não probabilística por conveniência tendo sido constituída por pessoas com DPOC que cumpriram o programa de reabilitação respiratória no Sector de Cinesiterapia e Reabilitação Respiratória do Centro Hospitalar e Universitário de São João.

Os critérios de inclusão seguem as recomendações GOLD publicadas em 2019 (1).

Os critérios de exclusões usadas foram o não cumprimento integral do programa de reabilitação respiratória, incapacidade e/ou contraindicação formal para a prática de exercicio físico, doença psiquiátrica ou disfunção cognitiva grave e hipoxia induzida pelo esforço refratário ao oxigénio.

\section{Instrumentos de recolha de dados}

O impacte do programa de reabilitação respiratória nos sintomas foi avaliado através do autopreenchimento do COPD Assessment Test (CAT) antes e após o programa de reabilitação.

A intensidade do treino de exercício foi avaliada pela Prova de esforço Cardio-respiratória e pelo teste de 1 RM de acordo com as linhas de orientação da ERS/ATS (4) (5) (9) (11)

A capacidade funcional foi avaliada no inicio e no final do programa de reabilitação respiratória pela prova de marcha de seis minutos (Variações após intervenção clinica igual ou superior a 25 metros traduzem melhoria clinica). (4) (8)

\section{Análise estatística}

$\mathrm{Na}$ análise e tratamento estatístico dos dados foi utilizada a estatística descritiva e inferencial.

O tratamento estatístico foi efetuado usando um teste não paramétrico para 2 amostras relacionadas (Wilcoxin signed-rank test) para as variáveis em estudo

O tratamento estatístico foi efetuado pelo programa IBM $®$ SPSS $®$ Statistics versão 23.0.

Todos os dados foram expressos com valores médios e desvio padrão (DP) sendo o nível de significância estatística 0,05 para todos os testes estatísticos.
PROGRAMA DE REABILITAÇÃO RESPIRATÓRIA COMPONENTE FISICA

\begin{tabular}{|c|c|}
\hline $\begin{array}{c}\text { Treino de Força } \\
\text { Muscular (30 minutos) }\end{array}$ & $\begin{array}{c}\text { Treino de Endurance (30 } \\
\text { minutos) }\end{array}$ \\
\hline $\begin{array}{l}\text { - Membros Superiores } \\
\text { - Bicipede } \\
\text { - Tricipede } \\
\text { - Deltoide } \\
\text { - Membros Inferiores } \\
\text { - Quadricipede } \\
\text { - Isquiotibial } \\
\text { - Gémeo } \\
\text { - Grande peitoral } \\
\text { - Grande dorsal }\end{array}$ & $\begin{array}{l}\text { - Cicloergómetro } \\
\text { - Membros inferiores } \\
\text { - Membros superiores } \\
\text { - Tapete }\end{array}$ \\
\hline \multicolumn{2}{|c|}{ COMPONENTE EDUCACIONAL } \\
\hline \multicolumn{2}{|c|}{$\begin{array}{l}\text { Sessão educacional ( } 60 \text { minutos) } \\
\text { - Alterações do Processo Respiratório } \\
\text { - Benefícios do exercício físico e na manutenção de } \\
\text { atividade física regular } \\
\text { - Gestão do regime terapêutico } \\
\text { - Técnicas de Gestão de Energia } \\
\text { - Técnicas de ventilação controlada } \\
\text { - Prevenção e tratamento precoce de exacerbações }\end{array}$} \\
\hline
\end{tabular}

Quadro 1 - Programa de Reabilitação Respiratória

Este estudo foi conduzido de acordo com os imperativos éticos exigidos, tendo sido garantidos todos os pressupostos deontológicos inerentes á ética da investigação.

\section{RESULTADOS}

Foram incluídos no estudo 45 pessoas, (71,9\% homens) com idade média de 65,82 anos com FEV1\% medio de 40\%. (Quadro 2).

\begin{tabular}{|c|c|}
\hline $\mathbf{N}$ & 45 \\
\hline Género Masculino & 36 \\
\hline Género Feminino & 9 \\
\hline Idade & $\begin{array}{c}65,82 \text { anos } \\
\text { (Max:83, min:49 Anos) } \\
\text { Desvio Padrão:11,01 }\end{array}$ \\
\hline FEV1\% & $\begin{array}{c}40 \% \\
\text { (Max:70,6; min: 11,2) } \\
\text { Desvio Padrão:17,57 }\end{array}$ \\
\hline $\begin{array}{c}\text { Prova de Marcha de } \\
\text { seis minutos inicial }\end{array}$ & $\begin{array}{c}\text { (Max:504; min: } 0 \text { ) } \\
\text { Desvio Padrão: } 97,5\end{array}$ \\
\hline
\end{tabular}

Quadro 2 - Caracterização da amostra

Os resultados do CAT referem melhoria estatisticamente $(p<0,001)$ no resultado global do teste com variação media de -7,67 (Tabela 1). 


\begin{tabular}{|ccccc|}
\hline & \multicolumn{4}{c|}{ COPD Assessment Test } \\
\cline { 2 - 5 } Media & Inicio & Fim & Valor $\boldsymbol{p}$ & Variação \\
$\min$ & 23,62 & 15,96 & $0,001^{*}$ & $-7,67^{* *}$ \\
Max & 10 & 10 & & \\
DP & 38 & 35 & & \\
\hline * Estatisticamente significativo para $p<0,005$ & \\
** Clinicamente significativo para variação $>2$ pontos \\
\hline
\end{tabular}

Tabela 1 - Resultados CAT

A capacidade funcional obteve variação estatística ( $p$ $=0,001)$ e clinicamente significativa com variação média de 32,4 metros na prova de marcha de seis minutos (Tabela 2).

\begin{tabular}{|ccccc|}
\hline & \multicolumn{4}{c|}{ Prova de Marcha de 6 minutos } \\
\cline { 2 - 5 } Media & Inicio & Fim & Valor $\boldsymbol{p}$ & Variação \\
$\min$ & 357,4 & 389,9 & $0,001^{*}$ & $32.4^{* *}$ \\
Max & 0 & 120 & & \\
DP & 504 & 550 & & \\
\hline * Estatisticamente significativo para $p<0,005$ & \\
** Clinicamente significativo para variação $>$ a 25 metros \\
\hline
\end{tabular}

Tabela 2 - Resultados Prova de marcha 6 minutos

Por fim verificou-se existir uma correlação negativa entre as duas variáveis estudadas mais acentuada nos valores após o programa de reabilitação respiratória (Tabela 3).

\begin{tabular}{|c|c|c|c|}
\hline & \multicolumn{3}{|c|}{ Correlação de Pearson } \\
\hline & $\begin{array}{l}\text { Prova de } \\
\text { Marcha } \\
\text { Inicial }\end{array}$ & $\begin{array}{c}\text { Prova de } \\
\text { Marcha Final }\end{array}$ & $\begin{array}{c}\Delta \text { Prova de } \\
\text { Marcha }\end{array}$ \\
\hline CAT Inicial & $-0,618^{*}$ & & \\
\hline CAT Final & & $-0,744 * *$ & \\
\hline$\triangle \mathrm{CAT}$ & & & $-0,507 *$ \\
\hline \multicolumn{4}{|c|}{ * Correlação moderada $p$ entre $-0,7$ e $-0,5$} \\
\hline \multicolumn{4}{|c|}{ ** Correlação forte $p$ entre $-0,9$ e $-0,7$} \\
\hline
\end{tabular}

Tabela 3 - Correlação entre CAT e Prova de marcha

\section{DISCUSSÃO}

Esta investigação teve como finalidade avaliar qual o impacte de um programa de reabilitação respiratória nos sintomas e perceber qual a sua relação com a tolerância à atividade em pessoas com DPOC.

A nossa investigação obteve resultados sobreponíveis aos encontrados na mais recente evidência científica publicada tendo obtido ganhos clinicamente significativos quer na variável sintomas (avaliado pelo CAT), quer na variável capacidade funcional (avaliado pelo 6MWD).

Verificamos ainda existir uma correlação negativa entre as duas variáveis, mais exacerbada nos resultados após programa de reabilitação o que pode ser explicado pelo facto de o treino de exercício melhorar a capacidade cardiovascular e reduzir o consumo de oxigénio levando á consequente melhoria da dispneia e da tolerância á atividade.

Outro achado importante na nossa investigação corrobora a importância da individualização dos programas de reabilitação uma vez que apesar da variabilidade encontrada o impacte nas atividades de vida diárias e na interação social obteve ganhos clinicamente significativos.

Como referimos anteriormente, a reabilitação respiratória é o tratamento não farmacológico indicado para o tratamento de pessoas com DPOC, sendo uma combinação de intervenções complexas baseadas na avaliação individualizada da pessoa que incluem, mas não se limitam a educação e treino de exercício. (4) (5) (9) (12). O seu sucesso deve-se ao seu efeito na redução da dispneia e fadiga muscular presente em cerca de $68 \%$ das pessoas com DPOC em contexto ambulatório, melhorando a condição física e psicológica e promovendo a aquisição de instrumentos de autogestão da doença. (5) (9)

Neste contexto a avaliação inicial reveste-se de particular importância no sentido de melhor conceber e implementar o programa de treino de exercício.

Da mesma forma é fundamental avaliar o resultado da nossa prática clínica por forma a identificar intervenções com maior benefício clinico assim como conferir mais robustez aos cuidados de enfermagem de reabilitação melhorando desta forma não só a prática clinica como também validando o conhecimento balizado pela teoria de enfermagem.

o CAT emerge neste contexto como um excelente instrumento de avaliação pela sua simplicidade e por traduzir os sintomas que normalmente refletem os problemas da pessoa.

Liu et al (2015) num estudo experimental com grupo de controlo numa amostra de 80 pessoas concluiu que apesar de a função respiratória estar mais comprometida no grupo de intervenção os valores da prova de marcha pós-reabilitação respiratória eram superiores aos do grupo de controlo. Este facto mostra claramente que o CAT é um instrumento bastante válido para avaliar a função respiratória e a tolerância a atividade. (11)

Candemir et al (2015) numa amostra de 40 pessoas com DPOC submetidas a um programa de reabilitação respiratória de 8 semanas relacionou os resultados obtidos pelo CAT com a dispneia (avaliada pela MRC), a qualidade de vida (avaliada pela Saint George Respiratory Questionnaire), as atividades de vida diária (avaliada pela London Chest od daily living) e a tolerância ao exercício (avaliado pelo Incremental Shuttle Walking test e pelo Endurance Shuttle Walking Test) tendo concluído que o CAT correlaciona-se positivamente com a Qualidade de vida, a dispneia e as atividades de vida e negativamente com a tolerância ao esforço. Sugerindo ainda que o CAT é um instrumento robusto para avaliar os resultados dos programas de reabilitação respiratória uma vez que analisa todas as variáveis normalmente usadas como 
indicador de resultado nos programas de reabilitação respiratória. (12)

Dood et al (2015) realizou um estudo quasiexperimental multicêntrico mais alargado com uma amostra de 261 pessoas com DPOC tendo avaliado para além do CAT, a ansiedade, a depressão, a qualidade de vida, a tolerância á atividade e a qualidade de vida tendo concluído ser o CAT um instrumento simples, prático, viável, de fácil preenchimento devendo fazer parte integrante tanto da avaliação inicial como da avaliação final dos programas de reabilitação respiratória. (3)

O mesmo resultado alcançou Houben-Wilke $S$. et al (2018) que realizou um estudo quasi-experimental com 497 pessoas com DPOC e que revelou melhoria significativa dos valores do CAT e da 6MWD após o programa de reabilitação respiratória. (6)

\section{CONCLUSÃO}

A evidência científica atual é unanime ao aceitar o treino de exercício e a educação como pilares fundamentais na reabilitação das pessoas com DPOC reduzindo os principais sintomas da doença (dispneia e fadiga muscular).

O CAT é sensível a esses resultados plasmando os ganhos sensiveis aos cuidados de Enfermagem de Reabilitação devendo ser adotado na avaliação dos programas de reabilitação respiratória.

\section{REFERÊNCIAS BIBLIOGRÁFICAS}

1. GLOBAL STRATEGY FOR THE DIAGNOSIS, MANAGEMENT, AND PREVENTION OF CHRONIC OBSTRUCTIVE PULMONARY DISEASE (2019 REPORT). GLOBAL INITIATIVE FOR CHRONIC OBSTRUCTIVE LUNG DISEASE; 2019.

2. PANORAMA DAS DOENCAS RESPIRATÓRIAS EM PORTUGAL Retrato da saúde 2018 O estado da Saúde em Portugal. OBSERVATÓRIO NACIONAL DAS DOENCSSS RESPIRATÓRIAS; 2018.

3. Ferreira D, Gaspar L, Teodoro A, et al. Guia Orientador de Boa Prática - Reabilitação Respiratória. Ordem dos Enfermeiros ed. Lisboa; 2018.
4. Dood JW, Hogg L, Nolan J, Jefford $H$, et al. The COPD assessment test (CAT): Response to pulmonary rehabilitation. A multicentre prospective study. Thorax. 2011 Março; 66: p. 425429.

5. Spruit MA, Singh SJ, Garvey C, et al. An Official American Thoracic Society/European Respiratory Society Statement: Key Concepts and Advances in Pulmonary Rehabilitation. American Thoracic Society Documents. 2013; 188: p. 13-63.

6. Houben-Wilke S, Janssen SJA, Franssen FM, et al. Contribution of individual COPD assessment test (CAT) items to CAT total score and effects of pulmonary rehabilitation on CAT scores. Health and Quality of life outcomes. 2018.

7. Kim S, Oh J, Kim Yl, et al. Differences in classification of COPD group using COPD assessment test (CAT) or modified Medical Research Council (mMRC) dyspnea scores: a cross-sectional analyses. BMC Pulmonary Medicine. 2013;: p. 13-35.

8. Kon S, Canavan JL, Jones SE, et al. Minimum clinically important difference for the COPD Assessment Test: A prospective analysis. Lancet Respiratory Medicine. 2014;: p. 195-203.

9. Garvey C, Bayles MP, Hamm LF, et al. Pulmonary Rehabilitation Exercise Prescription in Chronic Obstructive Pulmonary Disease: Review of selected guidelines. Journal of Cardiopulmonary Rehabilitation and Prevention. 2016; 36: p. 75-83.

10. M S, F P, al MEe. Pulmonary Rehabilitation and Physical Activity in Patients with Chronic Obstructive Pulmonary Disease. American Journal of Respiratory and Critical Care Medicine. 2015; 192.

11. Gloeckl R, Pitta F, Marinov B. Pratical recommendations for exercise training in patients with COPD. European Respiratory Review. 2013 Junho;: p. 178-186.

12. Gaspar L. Treino aeróbico e de fortalecimento muscular no doente com patologia respiratória. Enfermeiro: Anuário 2017. 2017 Maio;. (Reabilitação Respiratória).

13. Liu J, Meng G, Ma Y, Zhang X, Dingmei C, Chen M. Influence of COPD Assessment text (CAT) evaluation and rehabilitation education guidance on thr respiratory and motor functions of COPD patients. Open Medicine. 2015; 19: p. 394-398.

14. Candemir I, Kaymaz D, Ergun P, Demir N, et al. Assessment of pulmonary rehabilitation efficacy in chronic obstructive pulmonary disease patients using the chronic obstructive pulmonary disease assessment test. Expert Review of Respiratory Medicine. 2015;: p. 487-492. 


\title{
ENFERMAGEM DE REABILITAÇÃO NA PREVENÇÃO DE QUEDAS EM IDOSOS NO DOMICÍLIO
}

\section{ENFERMERÍA DE REHABILITACIÓN EN LA PREVENCIÓN DE CAÍDAS EN ANCIANOS EN EL DOMICILIO}

\section{NURSING REHABILITATION IN THE PREVENTION OF FALLS IN THE ELDERLY AT HOME}

DOI 10.33194/rper.2019.v2.n1.02.4571 | Submetido 24.04.2019 | Aprovado 27.06.2019

\author{
Jéssica Gomes; Carlos Miguel Soares²; (iD Maria José Bule ${ }^{3}$ \\ - ULSLA - Hospital do Litoral Alentejano, Serviço de Ortopedia; \\ 2 - ULSLA - Centro de Saúde de Sines, UCC1; 3 - Universidade de Évora
}

\section{RESUMO}

Objetivo: Identificar fatores intrínsecos e extrínsecos associados ao risco de queda em idosos no domicílio; Analisar o resultado de cuidados de Enfermagem de Reabilitação na diminuição do risco de queda em idosos no domicílio.

Métodos: Estudo de caso descritivo com três participantes que são utentes integrados na Equipa de Cuidados Continuados Integrados de uma Unidade de Cuidados na Comunidade, com alterações do foro neurológico e com alteração do equilíbrio, alvos de cuidados de enfermagem de reabilitação, e com potencial de recuperação.

Resultados: Durante oito semanas de implementação do programa de cuidados de enfermagem de reabilitação verificou-se a diminuição de fatores de risco intrínsecos para queda, relacionados com o equilíbrio, com as transferências e com a mobilidade. Ao avaliar os resultados obtidos é possível observar que todos os participantes obtiveram ganhos. De uma forma geral, em todos os casos houve ganhos na capacidade dos participantes executarem as AVD's (IB) em 45 pontos e um aumento do Equilíbrio (EEB) de 42 pontos. A evolução no grau de dependência ocorreu apenas em um caso, sendo que nos restantes dois manteve-se a dependência grave.

Conclusão: Os cuidados de enfermagem de reabilitação indiciam produzir ganhos no equilíbrio e na capacidade de execução dos autocuidados, o que consequentemente diminui o risco de queda em idosos no domicílio. A enfermagem de reabilitação no domicílio nas fases subagudas da doença neurológica pode potencializar estes resultados.

Descritores: Reabilitação, Idoso, Acidentes por Quedas

\section{RESUMEN}

Objetivo: Identificar factores intrínsecos y extrínsecos asociados a riesgos de caídas en ancianos en el hogar; Analizar el resultado de cuidados de enfermería de rehabilitación en la disminución de los riesgos de caídas de los ancianos en el hogar.

Métodos: Estudio de caso descriptivo con tres participantes que son pacientes que están integrados en el equipo de Cuidados Continuados Integrados de la Unidad de Cuidados de la Comunidad, con alteraciones de origen neurológicos y con alteración del equilibrio, objetivo de cuidados de la enfermería de rehabilitación con potencial de recuperación.

Resultados: Durante ocho semanas de implementación del programa de cuidados de enfermería de rehabilitación se verificó la disminución de factores de riesgos intrínsecos para la caída, relacionados con el equilibrio, las transferencias y la movilidad. Al evaluar los resultados obtenidos es posible observar que todos los participantes obtuvieron ganancias. En general, en todos los casos hubo ganancias en la capacidad de los participantes para ejecutar sus actividades de vida diarias en 45 puntos y un aumento del Equilibrio de 42 puntos. La evolución en el grado de dependencia ocurrió sólo en un caso, siendo que en los restantes dos se mantuvo la dependencia grave.

Conclusión: Los cuidados de enfermería de rehabilitación producen ganancias en el equilibrio y en la disminución de la dependencia, lo que disminuye el riesgo de caída en ancianos en el domicilio. La enfermería de rehabilitación en el domicilio en las fases subagudas de la enfermedad neurológica puede potenciar estos resultados.

Palabras clave: Enfermería de rehabilitación, Anciano, Caídas

\section{ABSTRACT}

Objective: Identify intrinsic and extrinsic factors associated with the risk of fall in the elderly at home; Analyse the result of rehabilitation nursing care on decreasing the risk of fall in the elderly at home.

Methodology: Descriptive case study with three participants who are patients that are integrated into long-term care team unit integrated in the community care, with neurological and balance changes, targets of rehabilitation nursing care with potential for recovery. 
Results: During eight weeks of implementation of the rehabilitation nursing care program, there was a decrease in intrinsic risk factors for falls, related to balance, transfers and mobility. When evaluating the results obtained it is possible to observe that all the participants obtained gains. In all cases there were gains in the ability of the participants to perform your daily living activities the in 45 points and an increase in the Equilibrium of 42 points. The evolution in the degree of dependence occurred only in one case, and in the other two cases, severe dependence was maintained.

Conclusion: The rehabilitation nursing care produce gains in balance and decreased dependency which consequently reduces the risk of fall in the elderly at home. The rehabilitation nursing at home in subacute phases of neurological disease can enhance these results.

Keywords: Rehabilitation nursing, Elderly, Falls

\section{INTRODUÇÃO}

0 Enfermeiro Especialista em Enfermagem de Reabilitação (EEER) é o profissional com competência científica, técnica e humana para prestar cuidados gerais e especializados baseados nos problemas reais e potenciais das pessoas, assim como realizar intervenções terapêuticas ao nível das funções neurológicas, respiratória, cardíaca, ortopédica e outras situações potencializadoras de incapacidade (1). Desta forma, o EEER procura capacitar os idosos para alcançarem o seu potencial máximo para que estes consigam desempenhar as suas atividades diárias, antes limitadas pela incapacidade decorrente da doença (2).

O envelhecimento da população é um fenómeno que se tem vindo a agravar anualmente, o que é demonstrado pelo índice de envelhecimento desde de 1961 com um crescimento de 27,5 para $153,2 \%$ no ano de 2017, o que significa que no ano de 2017 existiam 153,2 idosos por cada 100 jovens (pessoas com menos de 15 anos) ${ }^{(3)}$.

0 processo de envelhecimento acarreta consigo alterações anatómicas e fisiológicas que contribuem para o aumento do risco de queda no idoso. Alterações nos sistemas visual e vestibular; sistema nervoso central; sistema cardiovascular e sistema músculoesquelético, são as que mais contribuem para este aumento. Estas alterações fisiológicas manifestam-se por exemplo no défice de manutenção do equilíbrio corporal e do controlo postural, em atrofia e fraqueza muscular e alterações das funções cognitivas como memória, aprendizagem e consciência, o que contribui quer para o aumento de risco de queda, quer para a diminuição da capacidade para a realização das atividades de vida diárias (AVD's) ${ }^{(4)}$. 0 estudo da funcionalidade dos idosos realizado no Alentejo (903 participantes), concluiu que o declínio da funcionalidade aumenta com a idade mantendo-se algumas funções preservadas até aos 75 anos de idade. Os dados revelaram que cerca de $25 \%$ dos idosos têm alterações da memória que requerem intervenção terapêutica, $15 \%$ necessitam de cuidados dirigidos aos défices auditivos, $58 \%$ têm dor maioritariamente lombar e dos membros inferiores, $11 \%$ necessitavam de ajuda na realização das rotinas diárias e $32,2 \%$ careciam de ajuda para deslocar-se. Ainda no mesmo estudo as necessidades de ajuda para os autocuidados variaram entre $2,8 \%$ e $7,5 \%$ nas atividades de eliminação e vestuário, respetivamente ${ }^{(5)}$.
$\mathrm{Na}$ Europa, as quedas representam umas das principais causas de lesão nos idosos, sendo que em cada ano, um em cada três idosos sofre um acidente doméstico e nos idosos com mais de 80 anos, um em cada dois, sofre uma queda pelo menos uma vez por ano. Aproximadamente, uma em cada cinco destas quedas necessita de cuidados médicos e uma queda em cada vinte resulta em fratura (6). As quedas acarretam consigo consequências responsáveis pela perda de autonomia, ou até mesmo a incapacidade que condicionam de forma significativa a qualidade de vida dos idosos e dos seus cuidadores ${ }^{(7)}$.

A Direção-Geral da Saúde e a Fundação MAPFRE(8) classificam os fatores de risco de quedas em dois: fatores de risco intrínsecos e extrínsecos. Os fatores intrínsecos estão relacionados com a pessoa e o processo fisiológico de envelhecimento e refletem a sua incapacidade de manter ou recuperar o equilíbrio quando existe alteração do centro de gravidade. Os fatores extrínsecos, por sua vez, estão associados ao ambiente doméstico e de lazer em que a pessoa se encontra. Em casa, a presença de iluminação deficiente, tapetes soltos, inexistência de barras de apoio nas casas de banho ou escadas e o pavimento escorregadio são potencializadores da ocorrência de acidentes.

Neste sentido, é fundamental que exista um conjunto de ações preventivas que promova junto da população idosa um programa de reabilitação com medidas preventivas de queda, adequadas a cada utente e às respetivas alterações fisiológicas identificadas. Um programa de exercício físico melhora a performance física e diminui o risco de queda em 23\% numa população idosa ativa ${ }^{(9)}$. Este facto é também corroborado pelos autores Daly et al (10), que demonstram a redução de quedas através de programas de fortalecimento muscular e de equilíbrio, pelo que sugerem a sua implementação a nível comunitário.

A aplicação deste programa de enfermagem de reabilitação emergiu então das necessidades da população alvo e os objetivos do projeto foram: identificar fatores intrínsecos e extrínsecos associados ao risco de queda em idosos no domicílio; analisar o resultado de cuidados de enfermagem de reabilitação na diminuição do risco de queda em idosos no domicílio. 
Estudo de caso múltiplo, descritivo (11). Foi realizado no estágio final do curso de Mestrado em Enfermagem, área de especialização de Enfermagem de Reabilitação no período de setembro a novembro de 2018 numa Unidade de Cuidados na Comunidade (UCC), pertencente à Unidade Local de Saúde do Litoral Alentejano (ULSLA). Os participantes foram selecionados segundo os critérios: ter 70 ou mais anos, ser alvo de cuidados do EEER da UCC, apresentar alterações neurológicas e alteração do equilíbrio.

A recolha de dados foi realizada entre 24 de setembro e 16 de novembro de 2018 e foram recolhidos dados de caracterização sociodemográfica e da condição de saúde/alterações neurológicas dos utentes numa grelha elaborada para este fim através da consulta dos dados dos processos clínicos, observação e entrevista ao utente e ao seu cuidador.

De forma a avaliar os fatores intrínsecos de queda foram utilizados os seguintes instrumentos: o Índice de Barthel (IB) (12) que permitiu avaliar o grau de dependência nas AVD's; a Escala de Equilíbrio de Berg (EEB) ${ }^{(13)}$ para avaliar o equilíbrio funcional dinâmico e estático e prever o risco de queda e uma grelha de observação elaborada a partir da revisão da literatura que permitia auferir alterações existentes na audição, visão e eliminação e recolher dados sobre a medicação habitual e as patologias diagnosticadas que influenciassem o risco de queda.

Os fatores de risco extrínsecos para quedas foram identificados pela Escala Ambiental do Risco de Quedas ${ }^{(14)}$. Esta escala permitia uma avaliação da segurança do domicílio baseada nos seguintes parâmetros: iluminação dentro de casa e no exterior e presença de obstáculos no quarto, casa de banho, cozinha e escadas.

Com base na avaliação diagnóstica foi planeada a intervenção terapêutica ${ }^{(15)}$. 0 programa de intervenção de enfermagem de reabilitação foi implementado durante 8 semanas no domicílio dos utentes em sessões de 30min-1hora duas vezes por semana, sendo que todos eles entraram no programa ao mesmo tempo. O plano foi constituído por intervenções cujo objetivo era aumentar o fortalecimento muscular e o equilíbrio e otimizar o espaço físico do domicílio dos utentes, tal como explicitado mais à frente.

A avaliação de resultados foi realizada com recurso aos instrumentos usados para o diagnóstico.

O projeto de intervenção foi aprovado pela Comissão de Ética da Sub-região onde se insere a UCC ${ }^{(16)}$. Aos utentes foi apresentado o pedido de consentimento à participação, em conformidade com os princípios da Declaração de Helsínquia e com a norma da DGS $(15 ; 16)$.

Foram realizados três estudos de caso adiante designados por A1, A2 e A3. Os dados foram analisados com recurso a técnicas descritivas.

\section{RESULTADOS}

Os participantes são do género feminino com idades de 79, 86 e 90 anos. Duas mulheres são casadas, vivem com o marido e recebem apoio de cuidadores informais. O caso $A 3$, viúva, vive sozinha, recebe o apoio da filha e também de cuidador informal. A baixa escolaridade é comum a todas as participantes. São as duas participantes menos idosas as que têm história de queda e em ambas o acidente ocorreu em casa (Quadro 1).

\begin{tabular}{|c|c|c|c|}
\hline & A1 & A2 & A3 \\
\hline Idade & 79 & 86 & 90 \\
\hline Género & Feminino & Feminino & Feminino \\
\hline Nacionalidade & Portuguesa & Portuguesa & Portuguesa \\
\hline Estado Civil & Casada & Casada & Viúva \\
\hline $\begin{array}{l}\text { Agregado } \\
\text { Familiar }\end{array}$ & $\begin{array}{l}\text { Vive com o } \\
\text { marido e tem } \\
\text { apoio de } \\
\text { cuidadora } \\
\text { informal } \\
\end{array}$ & $\begin{array}{l}\text { Vive com o } \\
\text { marido e tem } \\
\text { apoio de } \\
\text { cuidadora } \\
\text { informal }\end{array}$ & $\begin{array}{c}\text { Vive sozinha } \\
\text { com apoio da } \\
\text { filha e } \\
\text { cuidadora } \\
\text { informal } \\
\end{array}$ \\
\hline \begin{tabular}{|c|} 
Nível de \\
Escolaridade \\
\end{tabular} & $4^{\mathrm{a}}$ classe & $4^{\mathrm{a}}$ classe & \begin{tabular}{|c|} 
Sem \\
escolaridade
\end{tabular} \\
\hline Profissão & Reformada & Reformada & Reformada \\
\hline $\begin{array}{c}\text { Historial de } \\
\text { Quedas }\end{array}$ & $\begin{array}{c}1 \\
\text { Na transferência } \\
\text { da cama para a } \\
\text { cadeira por não } \\
\text { estar travada }\end{array}$ & $\begin{array}{c}1 \\
\text { Na casa de } \\
\text { banho por } \\
\text { desequilíbrio }\end{array}$ & $\begin{array}{c}\text { Sem historial } \\
\text { de quedas }\end{array}$ \\
\hline
\end{tabular}

Quadro 1 - Descrição Sociodemográfica dos participantes

\section{Estudo de caso A1}

No dia 20 de outubro de 2017 a utente foi admitida no Serviço de Urgência por quadro de perda de força no hemicorpo direito e afasia ao acordar. Realizado TACCE (Tomografia Axial Computorizada CrânioEncefálica) que revelou AVC (Acidente Vascular Cerebral) isquémico da Artéria Cerebral Média esquerda. Durante o internamento manteve-se vígil, aparentemente orientada, com hemiplegia à direita e afasia com acompanhamento da Medicina Física e de Reabilitação. No dia 8 de novembro teve alta para o domicílio onde aguardou até 22 de janeiro, vaga na Unidade de Cuidados Continuados de Média Duração e Reabilitação, onde ingressou. Aquando a alta para o domicílio, a utente encontrava-se disártrica, sem disfagia e dependente nas AVD's.

No domicílio, a utente encontra-se motivada para o seu processo de reabilitação. Apresentava hemiparesia à direita, com uma diminuição grave da força no membro superior direito (1/5 Escala de Oxford) e ligeira no membro inferior direito (4/5 Escala de Oxford). Como fatores de risco de queda intrínsecos, apresentava diminuição da audição. Fazia terapêutica indutora de sono e apresentou uma queda no quarto por a cadeira de rodas não estar travada no momento da transferência.

\section{Estudo de caso A2}

No dia 6 de dezembro de 2017 foi admitida no Serviço de Urgência por quadro de perda de força no hemicorpo direito, disartria e desvio da comissura 
labial. Realizado TAC-CE que revelou AVC isquémico frontotemporoinsular esquerdo. Durante o internamento manteve-se vígil, orientada, disártrica e com plegia do membro superior direito e parésia de grau $1 / 5$ (Escala de Oxford) do membro inferior direito. Teve acompanhamento da Medicina Física e de Reabilitação. No dia 16 de janeiro de 2018 teve alta para uma Unidade de Cuidados Continuados de Média Duração e Reabilitação. À data da alta, a utente encontrava-se disártrica, sem disfagia, dependente nas AVD's, com diminuição ligeira da funcionalidade.

No domicílio, a utente encontrava-se motivada para o seu processo de reabilitação. Apresentava hemiparesia à direita, com uma diminuição grave da força no membro superior direito (2/5 Escala de Oxford) e moderada no membro inferior direito (3/5 Escala de Oxford).

Como fatores de risco de queda intrínsecos, apresentava diminuição da audição. Fazia terapêutica indutora de sono, diurética e anti hipertensora e apresentou uma queda na casa de banho por desequilíbrio no momento da transferência, por tentar fazê-lo sem ajuda.

\section{Estudo de Caso A3}

No dia 18 de julho de 2018 foi admitida no Serviço de Urgência com perda de força no hemicorpo esquerdo e afasia. Realizado TAC-CE revelou AVC hemorrágico talâmico no hemisfério direito. Durante o internamento manteve-se vígil, orientada, disártrica e com parésia dos membros superior e inferior esquerdos de grau 3/5 (Escala de Oxford). No internamento foi acompanhada na especialidade de Medicina Física e de Reabilitação. No dia 26 de julho de 2018 teve alta para o domicílio.

No domicílio, a utente encontrava-se motivada para o seu processo de reabilitação. Apresentava paresia do membro superior esquerdo, com uma diminuição ligeira da força no membro superior esquerdo (4/5 Escala de Oxford) e força normal no membro inferior esquerdo (5/5 Escala de Oxford).

Como fatores de risco de queda intrínsecos, apresentava diminuição da audição e da visão, não compensadas e fazia terapêutica anti hipertensora.

\section{Intervenção de enfermagem de reabilitação}

As análises dos dados da avaliação inicial levaram à formulação dos diagnósticos de ER presentes em cada utente (Quadro 2):

\begin{tabular}{|c|l|}
\hline Utentes & \multicolumn{1}{|c|}{ Diagnósticos identificados } \\
\hline A1 & $\begin{array}{l}\text { Dependente em grau elevado no Andar; } \\
\text { Dependente em grau moderado no Transferir-se; } \\
\text { Equilíbrio Corporal comprometido; } \\
\text { Movimento Muscular diminuído; } \\
\text { Risco de Queda Presente, em Grau Moderado }\end{array}$ \\
\hline A2 & Dependente em grau elevado no Andar; \\
\hline
\end{tabular}

\begin{tabular}{|c|c|}
\hline & $\begin{array}{l}\text { Dependente em grau moderado no Transferir-se; } \\
\text { Equilíbrio Corporal comprometido; } \\
\text { Movimento Muscular diminuído; } \\
\text { Risco de Queda Presente, em Grau Elevado }\end{array}$ \\
\hline A3 & $\begin{array}{l}\text { Dependente em grau elevado no Andar; } \\
\text { Dependente em grau elevado no Transferir-se; } \\
\text { Equilíbrio Corporal comprometido; } \\
\text { Movimento Muscular diminuído; } \\
\text { Risco de Queda Presente, em Grau Elevado }\end{array}$ \\
\hline
\end{tabular}

Quadro 2 - Diagnósticos de enfermagem de reabilitação (Fonte: adaptado de Ordem dos Enfermeiros (17))

Relativamente ao andar, todas as utentes apresentavam dificuldade. Em todos os casos foi incentivado e treinado o uso de auxiliar de marcha, nomeadamente do bastão de caminhada nos casos A1 e A2 e andarilho no caso A3. Para além disto, foram treinadas também manobras como o girar, o sentar e o levantar e o contorno de obstáculos presentes nos seus domicílios.

Para as transferências, foram treinadas várias técnicas como o rolamento e o sentar na cama, o equilíbrio estático e dinâmico sentado, a passagem à posição ereta, o giro de $180^{\circ}$ e o sentar com descida controlada na cadeira de rodas.

As participantes apresentavam o equilíbrio corporal comprometido, pelo que foram treinadas técnicas para recuperar o equilíbrio estático e dinâmico, tanto na posição sentada como na posição ereta. O treino era iniciado na posição sentada com os pés apoiados e o tronco livre durante $1 \mathrm{~min}$, seguindo-se 10 repetições com elevação dos membros superiores para a direita e para a esquerda, para a frente e para cima e 10 repetições de balanço do tronco para a frente e para trás. Posteriormente, era treinado o equilíbrio estático na posição ereta: sem apoio durante 20 segundos de olhos abertos, e depois com os olhos fechados; com os pés juntos durante 30 segundos e com um pé à frente do outro em mais 30 segundos. No equilíbrio dinâmico na posição ereta eram treinadas as seguintes técnicas: da posição de sentado passar para a posição de pé e vice-versa; sentar com as costas desapoiadas, com os pés apoiados no chão e inclinarse para a frente com o membro superior estendido. Em todas as técnicas treinadas, foi sempre incentivada a correção postural e o tempo de exercício foi gradualmente aumentado.

Relativamente ao movimento muscular, em todos os casos este encontrava-se diminuído devido às patologias e às limitações associadas. Foram treinadas técnicas de exercício muscular e articular, nomeadamente: mobilizações ativas assistidas e resistidas, sentar-se e levantar-se sem se apoiar mais de 6 vezes; flexão da articulação coxo femoral 6 a 8 vezes; com os pés apoiados, baloiçar mais de 30 segundos; inclinação do tronco com as mãos na cintura para a direita e para a esquerda mais de 20 vezes e exercícios terapêuticos no leito como a ponte, o rolamento para o lado são e para o lado afetado e a rotação controlada da anca. Em todas as técnicas 
treinadas, o tempo de exercício foi aumentando consoante a capacidade dos utentes ${ }^{(18)}$.

Todas as técnicas foram treinadas na presença dos cuidadores, para que estes as pudessem executar e treinar com os utentes de forma segura e eficaz.

Foram incluídas as avaliações dos domicílios das utentes e realizados os ensinos respetivos aos familiares e cuidadores para que estes percebessem a importância da organização do espaço e de manter os acessos livres para aumentar a segurança e diminuir o risco de queda no domicílio.

No domicílio da utente A1, o principal fator externo de queda identificado incidia nas escadas do prédio por não terem corrimão bilateral, nem revestimento antiderrapante. 0 marido fez obras de adaptação na casa de banho e otimizou o restante espaço físico da casa.

Relativamente aos fatores extrínsecos presentes no domicílio da utente $A 2$, o principal problema incidia nas áreas de locomoção que não se encontravam desimpedidas. 0 cuidador foi incentivado a desimpedilas, facilitando a circulação nas áreas da casa. Apesar da casa de banho ter sofrido obras, estas não foram realizadas de forma adequada, uma vez que o corrimão foi colocado no lado oposto e a cabine de duche ficou com elevação relativamente ao solo, o que impedia a utente de se transferir facilmente.

No domicílio da utente $A 3$, o principal problema incidia na casa de banho, por não apresentar barras de apoio facilitadoras à sua transferência e por ter uma banheira que impedia a utente de se transferir facilmente. A família otimizou o restante espaço físico da casa, deixando as zonas de circulação desimpedidas.

\section{DISCUSSÃO}

Seguindo-se a metodologia de estudo de caso de Yin, Robert ${ }^{(11)}$, segue-se a fase de congregar os resultados obtidos através da avaliação dos utentes.

Ao avaliar os resultados obtidos é possível que em todos os casos houve ganhos na capacidade dos participantes executarem as AVD's (IB) em 45 pontos. A evolução entre a primeira e a segunda avaliação encontra-se ilustrada no gráfico 1 .

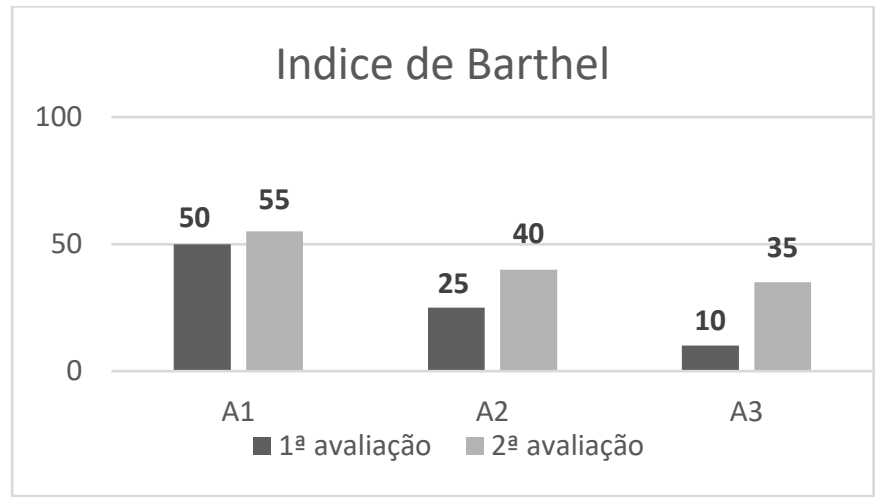

Gráfico 1 - Dependência nas AVD's dos participantes antes e após intervenção de enfermagem de reabilitação
A utente A1 manteve-se com uma grave dependência nos autocuidados, apesar de ter obtido ganhos nas transferências. Também a utente A2 manteve o nível de dependência como grave, apesar de ter obtido ganhos essencialmente nas transferências e na mobilidade. No caso da utente $\mathrm{A} 3$, é possível notar uma evolução positiva de dependência total para uma grave dependência, tendo a maior evolução na mobilidade. Relativamente ao autocuidado andar, todas as utentes conseguiam andar pela casa com o auxiliar de marcha, com supervisão e ajuda ocasional. No caso $A 2$, os resultados foram menos notórios devido à presença de instabilidade articular do joelho do hemicorpo afetado, o que dificultava a marcha. Os resultados obtidos no autocuidado transferir-se foram a independência no sentar com descida controlada e a passagem à posição de pé nos casos $\mathrm{A} 1$ e A2. 0 caso A3 manteve a necessidade de apoio para assumir a posição de pé.

Os resultados obtidos na independência (IB) são corroborados por Hager et al (19), que no seu estudo concluíram também que programas de exercício físico no domicílio para prevenir quedas são efetivos por reduzir os fatores de risco. Para além disso melhoram o equilíbrio, a força e a capacidade funcional dos idosos.

Também Martinez-Velilla et al (20), demonstraram através do seu estudo com 370 idosos que a implementação de um programa de atividade física previne o declínio funcional dos utentes, sendo que houve uma melhoria de cerca de 6.9 pontos no IB no grupo de intervenção (programa de exercício duas vezes por dia), quando comparado ao grupo controlo.

Num outro estudo realizado por Kato et al.(21), foi aplicado um programa de exercício físico durante 12 semanas cujas intervenções eram: sentar e levantar da cadeira e marchar no mesmo lugar. No final da intervenção foi possível obter um ganho de cerca de $11.6 \%$ no IB, quando comparado o grupo de intervenção ao grupo de controlo.

Após a aplicação do programa verificou-se uma diminuição de fatores de risco intrínsecos para queda, relacionados com o equilíbrio, tal como demonstrado no gráfico 2 .

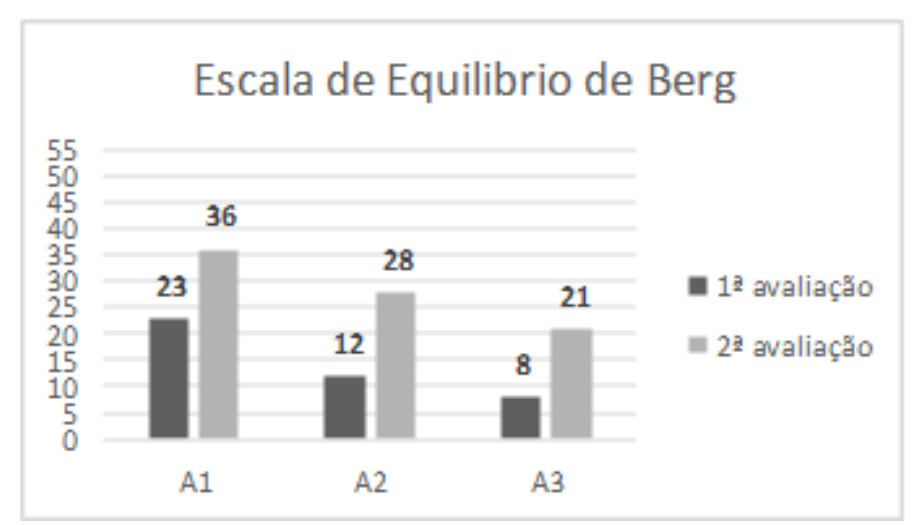

Gráfico 2 - Equilíbrio dos participantes antes e após intervenção de enfermagem de reabilitação

Quanto aos resultados obtidos na EEB, a avaliação diagnóstica classificou duas participantes com elevado 
risco e uma com médio risco de queda. Duas participantes passaram de risco elevado para médio, sendo que apenas num dos casos não houve diminuição do risco. Nas utentes A1 e A2, os maiores ganhos foram essencialmente ao nível passagem da posição de sentando para a posição de pé, passando de uma ajuda mínima para conseguir permanecer de pé autonomamente com auxílio das mãos. Relativamente à passagem de pé para sentado, as utentes conseguiam sentar-se com o uso das mãos para controlo da descida, sendo que no final da avaliação conseguiram fazê-lo com o uso mínimo das mãos. Relativamente à utente $\mathrm{A} 3$, os principais ganhos obtidos foram no equilíbrio estático, tanto na posição sentada como na posição de pé. Sentada sem suporte para o tronco, a utente aumentou o tempo de execução de 10 segundos para 2 minutos com supervisão. Na posição de pé sem suporte com os olhos fechados a utente necessitava de ajuda para evitar a queda e passou a conseguir fazê-lo autonomamente durante 3 segundos.

Também no estudo realizado por Hess e Woollacott, $M$ (22), aplicado em idosos durante 10 semanas através de exercício de alta intensidade, foi possível observar uma evolução na pontuação da EEB de 48,8 no início do programa para 51,2 pontos no final do período.

Os resultados obtidos através da avaliação pelo IB e pela EEB, demonstram a necessidade dos utentes com alterações neurológicas terem intervenções direcionadas para a promoção da autonomia nos autocuidados, de forma a diminuir o risco de queda associado durante a sua execução, nomeadamente no andar e transferir-se. Emerge nestes resultados a reflexão sobre o facto da melhor resposta se ter verificado na utente $\mathrm{A} 3$ que teve o AVC há menos tempo.

\section{CONCLUSÃO}

As competências específicas do EEER são cuidar de pessoas com necessidades especiais ao longo do ciclo de vida, em todos os contextos da prática de cuidados, capacitar a pessoa com deficiência, limitação da atividade e/ou restrição da participação para a reinserção e exercício da cidadania e maximizar a funcionalidade, desenvolvendo as capacidades da pessoa.

Com base nas necessidades identificadas foram concebidos planos de intervenção especializados e individualizados de forma a maximizar as suas capacidades e a diminuir as suas limitações, permitindo assim um melhor desempenho motor. Nos planos de intervenção foram incluídos programas de treino de fortalecimento muscular e equilíbrio de forma a promover a adaptação às limitações decorrentes da patologia, diminuir o risco de queda e a maximizar a autonomia, prevendo assim repercussões na sua reinserção social e na qualidade de vida no domicílio. Estes programas de treino foram traçados em função dos objetivos dos utentes e tendo em conta a patologia e as necessidades individuais de cada um de forma a promover a sua reabilitação.
A implementação do programa de intervenção pelo EEER indicia ter benefícios na obtenção de ganhos no equilíbrio e na capacidade de execução dos autocuidados, o que consequentemente diminui o risco de queda em idosos no domicílio.

Como limitações do trabalho, podem ser apontadas o número reduzido de participantes do estudo, sendo que um número maior teria uma maior representatividade da população. De futuro sugere-se mais estudos de investigação nesta área que possam corroborar os dados apresentados e que possam valorizar o trabalho e o impacto que as intervenções do EEER têm na qualidade de vida dos utentes.

\section{REFERÊNCIAS BIBLIOGRÁFICAS}

1. Ordem dos Enfermeiros. Regulamento das Competências Especificas do Enfermeiro Especialista em Enfermagem de $\begin{array}{ll}\text { Reabilitação. } & \text { [Online] }\end{array}$ https://www.ordemenfermeiros.pt/arquivo -de-p\%C3\%A1ginasantigas/regulamento-das-compet\%C3\%AAncias-comuns-doenfermeiroespecialista-e-regulamentos-dascompet\%C3\%AAncias-espec\%C3\%ADficas-das-especialidades-emenfermagem/.

2. Marques-Vieira, C, Amaral, T e Pontifice-Sousa, P. Contributos para um Envelhecimento Ativo. [autor do livro] C Marques-Vieira e L Sousa. Cuidados de Enfermagem de Reabilitação à Pessoa ao longo da Vida. Loures : Lusodidacta, 2017: 525-34.

3. Instituto Nacional de Estatistica. Indicadores de envelhecimento. [Online] 2018. https://www.pordata.pt/Portugal/Indicadores+de+envelhecime nto -526.

4. Esquenazi, D; Silva, S e Guimarães, M. Aspectos fisiopatológicos do envelhecimento humano e quedas em idosos. Revista HUPE. 2014; 13 (2): 11-20.

5. Lopes, M. A avaliação da funcionalidade dos idosos: uma forma de diagnosticar o estado de saúde e avaliar a eficácia dos cuidados. Conferência Internacional sobre Enfermagem Geriátrica. Livro de Atas. Lisboa. 2012

6. Petridoou, ET; Dikalioti , SK; Dessypris, N; Skalkidis, I; Basbone, F; Fitzpatrick, $\mathrm{P}$ et al. The evolution of unintencional injury mortality among elderly in Europe. s.l. : J Aging Health. 2008; 20: $159-82$.

7. Verbrugge, IM e Jette, AM. The disablement process. s.l. : Soc. Sci. Med. 1994; 38 (1): 1-14.

8. Direção-Geral da Saúde e Fundação MAPFRE. Prograna Nacional de Prevenção de Acidentes. Projeto: Com Mais Cuidado Prevenção de acidentes domésticos com pessoas idosas. Manual de Apoio e Formulário. Lisboa : s.n., 2012.

9. Freiberger, E; Menz, H; Abu-Omar, K; Rütten, A. Preventing Falls in Physically Active. Gerontology. 2007; 53: 298-305.

10. Daly, R; Duckham, R; Tait, J; Rantalainen, T; Nowson, C; Taaffe, $D$ et al. Effectiveness of dual-task functional power training for preventing falls in older people: study protocol for a cluster randomised controlled trial. Daly et al. Trials. 2015; $16: 120$.

11. Yin, Robert K. Estudo de Caso: Planejamento e Métodos. $4^{\mathrm{a} e d}$ Porto Alegre : Bookman. 2010.

12. Araujo, F; Ribeiro , J; Oliveira, A; Pinto, C. Validação do Índice de Barthel numa amostra de Idosos não Institucionalizados. Qualidade de Vida. 2007; 25 (2): 59-66.

13. Ordem dos Enfermeiros. Instrumentos de colheita de dados para a documentação dos Cuidados Especializados em Enfermagem de Reabilitação. [Online] 2016. https://www.ordemenfermeiros.pt/arquivo/colegios/Document s/2017/InstRecolhaDadosDocumentacaoCuidEnfReabilitacao_Fin al_2017.pdf.

14. Victorian Quality Council. Minimising the Risk of Fall \& Fall related injuries. Sub-acute and Residential Care. [Online] 2004. http: / / www.networkofcare.org/library/Guidelines\%20for\%20Fall \%20Prevention\%20in\%20Acute,\%20Sub 
acute\%20and\%20Residential\%20Care\%20Settings.pdf.

15. Lopes, M. A relação entre enfermeiro-doente como intervenção terapêutica: proposta de uma teria de médio alcance. Coimbra : Formasau. 2006.

16. Norma 015/2013. Consentimento Informado, Esclarecido e Livre Dado por Escrito. DGS. 2013.

17. Assembleia Geral da WMA. Declaração de Helsinque da Associação Médica Mundial. Princípio éticos para pesquisa médica envolvendo seres humanos. outubro de 2013.

18. Ordem dos Enfermeiros. Padrão Documental dos Cuidados de Enfermagem da Especialidade de Enfermagem de Reabilitação. [Online]

2015.

https://www.ordemenfermeiros.pt/arquivo/colegios/Document s/2015/MCEER_Assembleia/PadraoDocumental_EER.pdf.

19. Hager, A; Mathieu, N; Lenoble-Hoskovec, C; Swanenburg, J; Bie, R; Hilfiker, R. Effects of three home-based exercise programmes regardings falls, quality of life and exercise adherence in older adults at risk of falling: protocol for a randomized controlled trial. BMC Geriatrics. 2019; 19(13): 1-11.

20. Martinez-Velilla, N; Casas-Herrero, A; Zambom-Ferraresi, F; Lopez, M; Lucia, A; Galbete, A, et al. Effect of Exercise Intervention on Functional Decline in Very Elderly Patients During Acute Hospitalization: A Randomized Clinical Trial. JAMA Intern Med. 2018.

21. Kato, Y; Islam, M; Koizumi, D; Rogers, M; Takeshima, N. Effects of a 12-week marching in place and chair rise daily exercise intervention on $A D L$ and functional mobility in frail older adults. J. Phys. Ther. Sci. 2018; 30(4): 549-554.

22. Hess, J e Woollacott, M. Effect og high-intensity strenghttraining on functional measures of ballance ability in balanceimpaired older adults. J Manipulative Psysiol Ther. 2005; 28(8): 582-90. 


\title{
EXERCíCIO FÍSICO EM PESSOAS COM DIABETES: REVISÃO SISTEMÁTICA DE LITERATURA
}

\author{
EJERCICIO FÍSICO EN PERSONAS CON DIABETES: REVISIÓN SISTEMÁTICA DE LITERATURA
}

\author{
PhySiCAL EXERCISE IN PEOPLE WITH DIABETES: SYSTEMATIC REVIEW OF LITERATURE
}

DOI 10.33194/rper.2019.v2.n1.03.4564 | Submetido 05.03.2019 | Aprovado 27.06.2019

\begin{abstract}
Lénia Alexandra Ramos Loureiro1; (i) Maria Isabel Vaz Afonso²; (i) Patrícia da Silva Ribeiro3; (1) Ana Cristina Nunes Mesquita4; ;i] Helena Castelão Figueira Carlos Pestana ${ }^{4}$; (i) Luís Manuel Mota de Sousa ${ }^{5}$

1 - Unidade de Cuidados Continuados na ASFE Saúde, Portugal; 2- Centro hospitalar Lisboa Ocidental, Hospital Egas Moniz, Portugal; 3 - Centro Hospitalar Lisboa Norte, Hospital Santa Maria, Lisboa, Portugal; 4- . Escola Superior de saúde Atlântica, Barcarena, Portugal; 5 - Universidade de Évora, Escola Superior de Enfermagem S. João de Deus, Évora, Portugal
\end{abstract}

\section{RESUMO}

Introdução: A Diabetes mellitus é caraterizada como um conjunto de alterações metabólicas, manifestada por hiperglicemia crónica. A atividade física surge neste contexto como uma estratégia positiva no processo terapêutico da diabetes.

Objetivo: Avaliar os efeitos do exercício físico em pessoas com diabetes.

Método: Revisão Sistemática da Literatura através do método PICO com a seguinte questão de pesquisa: Quais os benefícios do exercício físico na pessoa com diabetes? A pesquisa foi realizada com recurso a plataformas de bases de dados eletrónicas EBSCOhost, Medline e BVS tendo identificado, selecionado e avaliado a qualidade metodológica, incluindo artigos em acordo com as recomendações do PRISMA.

Resultados: Foram incluídos 9 estudos que cumpriam os critérios de elegibilidade e qualidade metodológica definidos para esta revisão. 0 exercício físico traz benefícios para a pessoa com diabetes nomeadamente a nível da redução da glicose plasmática em jejum e dos valores da hemoglobina glicada, assim como, melhoria da qualidade de vida.

Conclusões: A prescrição de exercícios físico em pessoas com diabetes pode ser um adjuvante no tratamento desta condição com benefícios no controlo metabólico e qualidade de vida.

Descritores: Diabetes; Exercício Físico; Glicémia; Enfermagem em Reabilitação.

\section{RESUMEN}

Introducción: La diabetes mellitus es caracterizada como un conjunto de alteraciones metabólicas, manifestada por hiperglucemia crónica. La actividad física surge en este contexto como una estrategia positiva en el proceso terapéutico de la diabetes.

Objetivo: Evaluar los efectos del ejercicio físico en las personas con diabetes.

Método: Revisión Sistemática de la Literatura. Se utilizó el método PICO con la siguiente pregunta de investigación: ¿Cuáles son los beneficios del ejercicio físico en la persona con diabetes? La pesquisa se realizó utilizando plataformas de bases de datos electrónicas EBSCOhost, Medline y BVS, identificando, seleccionando y evaluando la calidad metodológica, incluyendo artículos de acuerdo con las recomendaciones del PRISMA.

Resultados: Se incluyeron 9 estudios que cumplían los criterios de elegibilidad y calidad metodológica definidos para esta revisión. El ejercicio físico trae beneficios para la persona con diabetes, especialmente en la reducción de la glucosa plasmática en ayuno y de los valores de la hemoglobina glucosa, así como la mejora de la calidad de vida.

Conclusiones: La prescripción de ejercicios físicos en personas con diabetes puede ser un adyuvante en el tratamiento de esta condición con beneficios en el control metabólico y calidad de vida.

Descriptores: Diabetes; Ejercicio físico; Glucemia; Enfermería en Rehabilitación.

\section{ABSTRACT}

Background: Diabetes mellitus is characterized as group of metabolic alterations manifested by chronic hyperglycemia. Physical exercise emerges in this context as a positive strategy in the diabetes therapeutic process.

Objective: Access physical exercise effects on people with diabetes.

Methods: Systematic Review of Literature through the PICO method with the following research question: Which are the benefits of physical exercise in a diabetic person? The research was carried out using the electronic 
database platforms: EBSCOhost, Medline and BVS, having identified, selected, evaluated the methodological quality and included the articles that take into account the PRISMA recommendations.

Results: 9 studies were included that fulfilled the eligibility and methodological quality criteria.

Conclusion: The physical exercise prescription in people with diabetes can be an adjuvant in the treatment of that condition with metabolic control benefits and increase of life quality.

Keywords: Diabetes; Physical Exercise; Glycemia; Rehabilitation Nursing.

\section{INTRODUÇÃO}

A diabetes mellitus é definida como um conjunto de alterações metabólicas caracterizadas por hiperglicemia crónica, que ocorrem devido à destruição das células beta do pâncreas, resistência à ação e/ou distúrbios da secreção da insulina ${ }^{(1)}$.

A diabetes mellitus pode ser classificada nas seguintes categorias: diabetes tipo 1, diabetes tipo 2, diabetes mellitus gestacional e diabetes com origem noutras causas especificas ${ }^{(2-3)}$. Contudo, o estudo vai centrarse na diabetes mellitus tipo 1 e tipo 2 .

A diabetes mellitus tipo 1 surge quando há destruição das células beta, levando a uma produção deficiente de insulina no organismo. A causa para este tipo de diabetes ainda não é conhecida. Os sintomas incluem: sede excessiva, micções frequentes, fome, perda de peso, alterações na visão e fadiga ${ }^{(2-3)}$.

A diabetes mellitus tipo 2 ocorre devido a uma alteração na secreção de insulina levando a uma resistência à insulina pelo organismo. Este tipo de diabetes é um dos mais frequentes e os sintomas são muito semelhantes à diabetes mellitus tipo I mas geralmente menos evidentes ou até mesmo ausentes ${ }^{(2-}$ 3).

O diabetes mellitus tem-se tornado num dos mais importantes desafios de saúde pública do século XXI. Até a última década, foi subestimada, atualmente é vista como uma ameaça à saúde publica global ${ }^{(4)}$.

Em 2014, a nível mundial, estimou-se que 422 milhões de pessoas adultas tinham diabetes, verificando-se um aumento relativamente a 1980 que apresentava uma prevalência de 108 milhões de pessoas. A prevalência global (padronizada por idade) de diabetes aumentou para quase o dobro desde 1980 , passando de $4,7 \%$ para $8,5 \%$ nas pessoas adultas. Este aumento está associado a fatores de risco, como excesso de peso ou obesidade ${ }^{(3)}$.

Em Portugal, existe uma diferença estatisticamente significativa na prevalência da Diabetes entre os homens $(15,9 \%)$ e as mulheres $(10,9 \%)$, assim como a existência de um forte aumento da prevalência da diabetes com a idade (mais de um quarto das pessoas entre os 60-79 anos tem Diabetes) ${ }^{(5)}$.

De entre os vários tipos diabetes, a diabete mellitus tipo 2 é a mais comum representando cerca de $90-95 \%$ dos $\operatorname{casos}^{(6)}$. Alguns fatores de risco para este tipo de diabetes são: a genética, etnia, idade (fatores não modificáveis), o excesso de peso ou obesidade, dieta não saudável, atividade física insuficiente e tabagismo (fatores modificáveis por meio de alterações comportamentais e ambientais) $)^{(3)}$.
A atividade física regular é importante para todos, mas é especialmente relevante para pessoas com diabetes sendo considerado como adjuvante na prevenção e no tratamento ${ }^{(7)}$.

A atividade física inclui todos os movimentos que resultam num gasto de energia acima do nível de repouso. Já o exercício físico é um tipo de atividade que consiste em movimentos corporais programados, estruturados e sistematicamente repetitivos que têm como objetivo melhorar a preparação física ${ }^{(6)}$.

0 exercício físico, para além de hábitos alimentares saudáveis, é uma das primeiras estratégias aconselhadas para pessoas recém-diagnosticadas com diabetes mellitus tipo 2 , trazendo benefícios no que diz respeito à redução do risco de diabetes e do aumento da glicose no sangue ${ }^{(3)}$ sendo essencial para a redução do risco cardiovascular, a perda ou controle de peso e bem-estar geral. O exercício físico, seja aeróbico ou de resistência ou uma combinação, facilita a regulação da glicose. 0 exercício intervalado de alta intensidade é eficaz e tem como vantagem de ser muito eficiente em termos de tempo ${ }^{(7)}$.

O exercício físico regular traz ainda consideráveis benefícios para a saúde das pessoas com diabetes mellitus tipo 1 especificamente, a nível cardiovascular, força muscular e sensibilidade á insulina. ${ }^{(6)}$.

O exercício aeróbio consiste num tipo de exercício que engloba movimentos contínuos e rítmicos de grandes grupos musculares, como caminhar, correr e andar de bicicleta. (8) Este tem impacto a nível do aumento da densidade mitocondrial, sensibilidade à insulina, enzimas oxidativas, reatividade dos vasos sanguíneos, função pulmonar, função imunitária e débito cardíaco. $\mathrm{Na}$ diabetes mellitus tipo 1 , o exercício aeróbio aumenta a aptidão cardiorrespiratória, diminui a resistência à insulina e melhora os níveis lipídicos e a função endotelial ${ }^{(6)}$, já em pessoas com diabetes mellitus tipo 2, melhora o controlo da glicémia, sensibilidade à insulina, capacidade oxidativa e importantes parâmetros metabólicos relacionados ${ }^{(8)}$.

O exercício de resistência é sinónimo de treino de força e engloba movimentos com recurso a pesos livres, aparelhos de musculação, exercícios de peso corporal ou bandas de resistência elástica ${ }^{(8)}$. A nível da diebetes mellitus tipo 1 o exercício de resistência no controle da glicémia capilar não está bem definido, no entanto pode ajudar a minimizar o risco de hipoglicémia induzida pelo exercício físico ${ }^{(6)}$. Nas pessoas com diabetes mellitus tipo 2 o exercício de resistência traz ganhos nomeadamente a nível da força, densidade mineral óssea, pressão arterial, perfil 
lipídico, saúde cardiovascular, sensibilidade à insulina e massa muscular ${ }^{(8)}$.

Em relação aos exercícios de mobilidade e equilíbrio estes têm maior relevância em idosos com diabetes. A mobilidade articular limitada que frequentemente se observa nesta população, resulta em parte da formação de produtos finais de glicosilação avançada, que se acumulam durante o envelhecimento normal e são acelerados pela hiperglicemia( ${ }^{(6)}$

Os exercícios de alongamento contribuem para o aumento da mobilidade, mas não afetam o controle glicémico, enquanto que exercícios de equilíbrio podem reduzir o risco de quedas ${ }^{(6)}$.

0 enfermeiro especialista em enfermagem de reabilitação possui conhecimentos e competências especializadas, intervindo de forma individual e singular, tendo em conta as necessidades, características, capacidades e tolerância de cada pessoa $^{(9)}$.

Tem também como competência monitorizar e implementar programas de reabilitação, avaliando e efetuando os ajustes necessários no processo de prestação de cuidados. Desta forma possibilita melhorar a qualidade de vida, através da melhoria da funcionalidade e da autonomia, envolvendo dimensão física social e emocional(9). Com esta revisão sistemática da literatura pretende-se identificar: "Quais os benefícios do Exercício Físico na Pessoa com Diabetes?". Foi escolhido pela sua prevalência atual que the confere especial importância na área de atuação do Enfermeiro Especialista em Enfermagem de Reabilitação.

Assim, a presente revisão sistemática da literatura (RSL) tem como objetivo avaliar os efeitos do exercício físico em pessoas com diabetes.

\section{MATERIAL E MÉTODOS}

A Investigação em Enfermagem é um método sistemático, científico e rigoroso que busca o desenvolvimento e aprofundamento do conhecimento nesta área, procurando responder a questões ou soluções para problemas em prol do benefício da pessoa, família e comunidade ${ }^{(10)}$.

As investigações científicas na área da enfermagem têm vindo a aumentar, especialmente as pesquisas clínicas, com métodos bem delineados e forte grau de evidência, a fim de sustentar a prática baseada na evidência $(P B E)^{(11)}$.

A RSL é uma metodologia científica que possibilita identificar, avaliar e abreviar os estudos realizados por investigadores, académicos e profissionais de saúde. 0 ponto de partida é uma questão bem delineada e formulada recorrendo a métodos sistemáticos e claros, permitindo também recolher e analisar os dados dos estudos que se incluíram na revisão ${ }^{(12-13)}$. Para uma análise de toda a evidencia disponível é fundamental seguir as seguintes etapas: definir de forma clara os objetivos tendo em conta os critérios de elegibilidade; metodologia explícita e reprodutível, pesquisa sistemática que evidencie que todos os estudos cumpram os critérios de elegibilidade; avaliação da autenticidade dos resultados dos estudos incluídos (1213).

A questão de investigação deste estudo foi conduzida através do método PICO - Participant (Tipo de Participantes); Intervention (Tipo de Intervenção); Comparasion (comparação); Outcomes (Tipo de Resultados), como se pode verificar na tabela $\mathrm{n}^{\circ} 1$.

\begin{tabular}{|c|l|}
\hline Participantes (P) & Pessoa com Diabetes \\
\hline Intervenção (I) & Exercício físico \\
\hline Comparação (C) & $\begin{array}{l}\text { Pessoas com diabetes que não } \\
\text { praticam exercício físico }\end{array}$ \\
\hline Resultados (O) & $\begin{array}{l}\text { Benefícios para a saúde (ex. } \\
\text { bem-estar, qualidade de vida...) }\end{array}$ \\
\hline
\end{tabular}

Tabela 1 - Método PICO

Posto isto, definiu-se para a presente Revisão Sistemática da Literatura, a seguinte questão de investigação: “Quais os benefícios do Exercício Físico na Pessoa com Diabetes?”.

A pesquisa para a revisão sistemática da literatura definiu-se em função da questão de investigação, dos descritores relacionados com cada uma das componentes da estratégia PICO e palavras chave conforme tabela $n^{\circ} 2$. Os descritores foram validados previamente na plataforma Descritores em Ciências da Saúde e Medical Subject Headings.

\begin{tabular}{|c|c|c|c|}
\hline Critérios & $\begin{array}{c}\text { Questões de } \\
\text { Partida }\end{array}$ & Descritores & Palavras Chave \\
\hline $\begin{array}{l}\text { Participantes } \\
\text { (P) }\end{array}$ & $\begin{array}{l}\text { Pessoa com } \\
\text { diabetes }\end{array}$ & Diabetes & \\
\hline $\begin{array}{l}\text { Intervenção } \\
\text { (I) }\end{array}$ & $\begin{array}{l}\text { Exercício } \\
\text { Físico }\end{array}$ & \begin{tabular}{|c|} 
Exercício \\
Físico \\
Enfermagem \\
Reabilitação
\end{tabular} & $\begin{array}{l}\text { Frequência do } \\
\text { exercício, } \\
\text { Intensidade, } \\
\text { Duração, } \\
\text { Modalidade, } \\
\text { Tipo Exercício }\end{array}$ \\
\hline $\begin{array}{l}\text { Comparação } \\
\text { (C) }\end{array}$ & $\begin{array}{l}\text { Diabéticos } \\
\text { que não } \\
\text { praticam } \\
\text { exercício }\end{array}$ & & \\
\hline $\begin{array}{l}\text { Resultados } \\
\text { (0) }\end{array}$ & $\begin{array}{l}\text { Benefícios } \\
\text { para a saúde }\end{array}$ & $\begin{array}{l}\text { Glicemia } \\
\text { Qualidade } \\
\text { de vida }\end{array}$ & \\
\hline
\end{tabular}

Tabela 2 - Método PICO, Descritores e Palavras Chave

A investigação decorreu no mês de novembro 2018 através de duas pesquisas independentes. Tendo como base os descritores já referidos realizou-se a pesquisa nas plataformas de bases de dados eletrónicas: EBESCO host, Medline e Biblioteca Virtual em Saúde.

Atendendo à especificidade do tema e ao grande número de estudos/artigos encontrados foi necessário 
definir critérios de inclusão e exclusão (tabela $n^{\circ} 3$ ) de forma a ajudar na seleção dos estudos/artigos relevantes para o desenvolvimento da temática em questão.

\begin{tabular}{|c|c|c|}
\hline $\begin{array}{c}\text { Critérios } \\
\text { Elegibilidade }\end{array}$ & Critérios Inclusão & Critérios Exclusão \\
\hline $\begin{array}{c}\text { Participantes } \\
\text { (P) }\end{array}$ & $\begin{array}{c}\text { Pessoa com } \\
\text { diabetes }\end{array}$ & $\begin{array}{c}\text { Pessoa com outra } \\
\text { patologia }\end{array}$ \\
\hline $\begin{array}{c}\text { Intervenção } \\
\text { (I) }\end{array}$ & Exercício Físico & \\
\hline $\begin{array}{c}\text { Desenho do(s) } \\
\text { Estudo(s) }\end{array}$ & $\begin{array}{c}\text { Estudo } \\
\text { experimental } \\
\text { aleatório } \\
\text { controlado }\end{array}$ & $\begin{array}{c}\text { Revisão Sistemática } \\
\text { Literatura, Outros } \\
\text { estudos quantitativos } \\
\text { e estudos Qualitativos }\end{array}$ \\
\hline $\begin{array}{c}\text { Período de } \\
\text { Publicação }\end{array}$ & $\begin{array}{c}\text { Artigo publicado } \\
\text { entre 2014 e 2018 }\end{array}$ & \\
\hline $\begin{array}{c}\text { Língua em que } \\
\text { está publicado }\end{array}$ & $\begin{array}{c}\text { Artigo publicado } \\
\text { em Português, } \\
\text { Inglês e Espanhol }\end{array}$ & \\
\hline $\begin{array}{c}\text { Disponibilidade } \\
\text { do Artigo }\end{array}$ & $\begin{array}{c}\text { Artigo Completo e } \\
\text { de acesso livre }\end{array}$ & $\begin{array}{c}\text { Artigo Incompleto ou } \\
\text { que implique custos }\end{array}$ \\
\hline
\end{tabular}

Tabela 3 - Critérios de Elegibilidade

Do processo de pesquisa bibliográfica realizada, com esta metodologia, obtivemos 1039 artigos para a seleção inicial. Destes, 910 foram rejeitados pelo título ou pelo assunto e 30 pelo resumo. Dos 18 resultantes, 7 foram excluídos após análise do texto integral, dado não cumprirem os critérios de inclusão definidos, tendo sido o resultado final de 10 artigos incluídos que preencheram os critérios de inclusão.

A Tabela 4 descreve o processo de conjugação dos descritores e palavras-chave para a pesquisa nas bases de dados. A Figura 1 ilustra o fluxograma PRISMA ${ }^{(14)}$ correspondente à identificação, análise, seleção e inclusão dos artigos.

\begin{tabular}{|l|c|c|c|}
\hline Conjugação booleana & Medline & BVS & EBSCOhost \\
\hline $\begin{array}{l}\text { ((exercise)OR(physical } \\
\text { activity))AND(diabetes) }\end{array}$ & 605 & 67 & \\
\hline $\begin{array}{l}(\text { (Physical activity) OR (Exercise)) } \\
\text { AND (Diabetes) }\end{array}$ & & & 369 \\
\hline Total de artigos & 1039 & & \\
\hline
\end{tabular}

Tabela 4 - Conjugação booleana

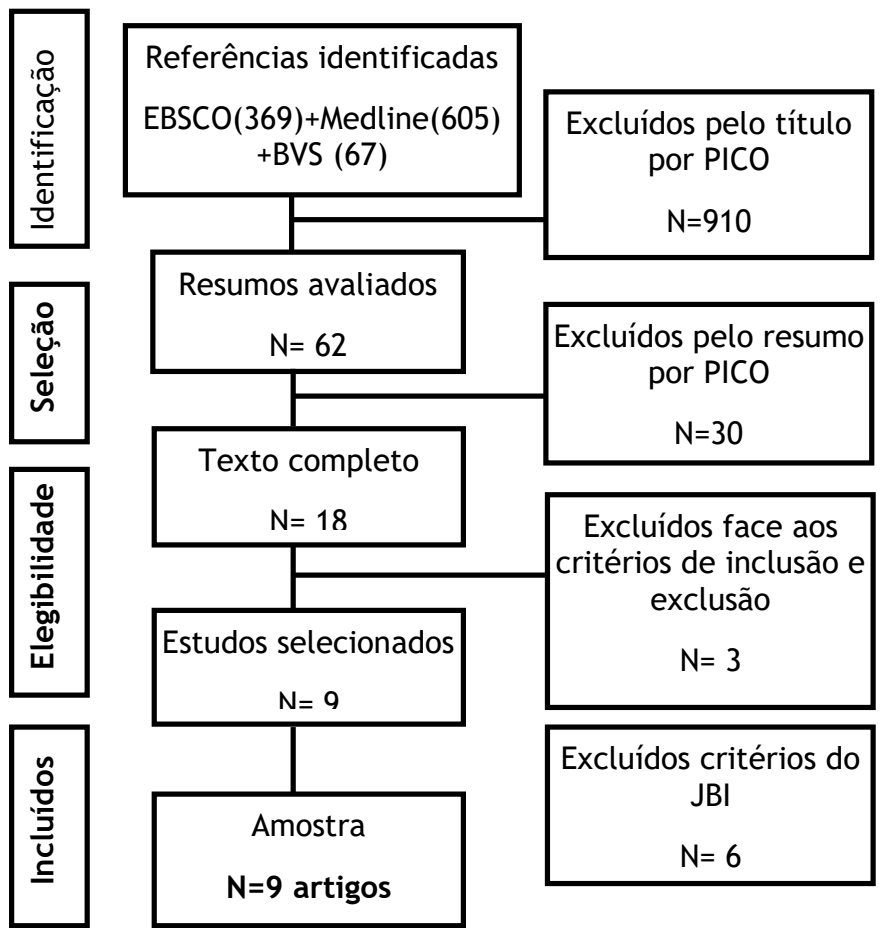

Figura 1 - Identificação, análise e seleção dos artigos. (14)

Os artigos selecionados para leitura completa foram avaliados por dois investigadores de forma independente, tendo em consideração os critérios de qualidade metodológica, propostos pelo JBI, Assessment and Review of Information, (15) tendo sido selecionados os artigos com mais de $75 \%$ dos critérios.

Foi extraida informação dos artigos sobre autores, ano, país, amostra, dados sobre o exercício físico (modalidade, frequência, intensidade, volume $e$ duração), conclusões e nível de evidência. Os níveis de evidência dos estudos incluídos foram classificados de acordo com os critérios da Registered Nurses Association of Ontario como se pode ver seguidamente: Ib-Evidência determinada a partir de pelo menos um estudo aleatório controlado ${ }^{(16-17)}$.

\section{RESULTADOS}

Nesta RSL foram publicados 9 artigos nos seguintes anos: $2014^{(20-21,23)}, 2015^{(19)}, 2016^{(24)}$ e $2017^{(18,22,25-26)}$. A amostra de pessoas com diabetes que foi sujeita a intervenção variou entre $12^{(18)}$ e $536^{(26)}$. O grupo de controlo variou entre $5^{(18)}$ e $149^{(26)}$. Todos os estudos incluídos (Tabela 5) são estudos experimentais, com nível de evidência lb isto é, evidência obtida a partir de um estudo bem desenhado e através de pelo menos um estudo aleatório controlado ${ }^{(15)}$ sendo portanto uma mais valia para esta RSL. 


\begin{tabular}{|c|c|c|c|c|c|}
\hline $\begin{array}{l}\text { Autor, } \\
\text { ano, país }\end{array}$ & Participantes & Objetivo & Intervenção & Resultados & $\begin{array}{c}\text { Nível de } \\
\text { evidência }\end{array}$ \\
\hline $\begin{array}{l}\text { Asuako,Benjami } \\
\text { m; et al (18) } \\
2017 \\
\text { Gana }\end{array}$ & \begin{tabular}{|l}
12 pessoas com \\
diabetes atendidos \\
na unidade diabética \\
do KATH com \\
diagnóstico de \\
diabetes há menos \\
de cinquenta anos, \\
estado ambulatorial \\
/ idade de 20 a 68 \\
anos, sedentários e \\
livres de \\
complicações. \\
7 pessoas no grupo \\
de intervenção (GI) \\
5 pessoas no grupo \\
controle (GC)
\end{tabular} & $\begin{array}{l}\text { Avaliar os efeitos do } \\
\text { exercício físico } \\
\text { aeróbico sobre a } \\
\text { glicose plasmática } \\
\text { em jejum e perfis } \\
\text { lipídicos (FPG / LP) } \\
\text { de pessoas com } \\
\text { diabetes }\end{array}$ & $\begin{array}{l}\text { Oito semanas de treinamento aeróbico entre } \\
\text { agosto de } 2015 \text { e março de } 2016 \\
\text { Durante } 8 \text { semanas: entre agosto de } 2015 \text { e março } \\
\text { de } 2016 \\
\text { Modalidade: Caminhada sem recurso a passadeira } \\
\text { Tipo Exercício: aeróbico } \\
\text { Frequência do exercício: } 3 \text { vezes/ semana } \\
\text { Intensidade: moderada } \\
\text { Volume exercício: Não definido } \\
\text { Duração: } 45 \text { min } \\
\text { Grupo Controlo: não desenvolveram nenhuma } \\
\text { atividade física }\end{array}$ & $\begin{array}{l}\text { - Perda de peso corporal de } 4,85 \mathrm{~kg}(7,0 \%) \\
\text { - Redução de } 4,08 \mathrm{~kg} / \mathrm{m}^{2}(7,3 \%) \text { no IMC A } \\
\text { FPG reduziu em } 43,5 \%(5,28 \mathrm{mmol} / \mathrm{l}) \text { após } \\
\text { oito semanas de treino com exercícios } \\
\text { aeróbicos comparativamente com o grupo } \\
\text { controle } \\
\text { - Descida de valores nos perfis de LDL-C } \\
(0,33 \mathrm{mmol} / \mathrm{l}, 11,9 \%) \text {, CT }(0,47 \mathrm{mmol} / \mathrm{l} \text {, } \\
5,3 \%) \text { e T }(0,48 \mathrm{mmol} / \mathrm{l}, 29,4 \%) \text { dos } \\
\text { pacientes do IG e aumento do HDL-CC } \\
(0,16 \mathrm{mmol} / \mathrm{l}, 7,1 \%)\end{array}$ & \begin{tabular}{|l|} 
Nivel lb \\
Estudo \\
aleatório e \\
controlado
\end{tabular} \\
\hline $\begin{array}{l}\text { Parra-Sánchez, } \\
\text { J; et al (19) } \\
\text { (2015) } \\
\text { Espanha }\end{array}$ & \begin{tabular}{|l|}
100 participantes \\
com diabetes tipo 2 \\
Idade entre os 65 e \\
80 anos, sedentários \\
$50 \%$ grupo controle \\
(Gl) e $50 \%$ grupo \\
intervenção (GC).
\end{tabular} & \begin{tabular}{|l|} 
Analisar se um \\
programa de \\
exercícios pode \\
modificar a \\
hemoglobina glicada \\
(HbA1c), pressão \\
arterial (PA), índice \\
de massa corporal \\
(IMC), lipídios, perfil \\
de risco \\
cardiovascular (RVC), \\
autopercepção do \\
estado de saúde \\
(SHS) e gasto \\
farmacêutico (EP).
\end{tabular} & $\begin{array}{l}\text { Durante 3mesesAtenção Primária: } 2 \text { áreas rurais de } \\
\text { saúde. Área de Saúde de Navalmoral. Cáceres. } \\
\text { Extremadura. Espanha } \\
\text { Modalidade: Não definido } \\
\text { Tipo exercício: aeróbico controlado } \\
\text { Frequência do exercício: } 2 \text { vezes / semana } \\
\text { Intensidade: Não definido } \\
\text { Volume exercício: Não definido } \\
\text { Duração: } 50 \text { min } \\
\text { Grupo Controlo: não desenvolveram nenhuma } \\
\text { atividade física }\end{array}$ & $\begin{array}{l}\text { Diminuição significativa em; } \\
\text { HbA1c: } 0,2 \pm 0,4 \% \text { (IC 95\%: 0,1 a 0,3); } \\
\text { PA sistólica: } 11,8 \pm 8,5 \mathrm{mmHg} \text { (IC } 95 \%: 5,1 \\
\text { a 11,9), IMC: } 0,5 \pm 1 \text { (IC } 95 \%: 0,2 \text { a } 0,8) ; \\
\text { Colesterol total : } 14 \pm 28,2 \mathrm{mg} / \mathrm{dl} \text { (IC } 95 \% \text { : } \\
5,9 \text { a } 22,2) ; \\
\text { LDL: } 18,3 \pm 28,2 \mathrm{mg} / \text { dl IC } 95 \%: 10,2 \text { a } \\
\text { 26,3), } \\
\text { RVC: } 6,7 \pm 7,7 \% \text { (IC } 95 \%: 4,5 \text { a 8,9), } \\
\text { EP: } 3,9 \pm 10,2 € \text { (IC } 95 \%: 0,9 \text { a 6,8) e } \\
\text { Aumento de SHS: } 4,7 \pm 5,7 \text { (IC 95\%: } 3 \text { a } \\
\text { 6,3). }\end{array}$ & \begin{tabular}{|l} 
Nível lb \\
Estudo \\
aleatório e \\
controlado, \\
cego.
\end{tabular} \\
\hline $\begin{array}{l}\text { Dixit, Shenil ;et } \\
\mathrm{al}^{(20)} \\
2014 \\
\text { India }\end{array}$ & $\begin{array}{l}87 \text { Pessoas com } \\
\text { diabetes tipo } 2 \text { com } \\
\text { neuropatia diabética } \\
\\
47 \text { pessoas no grupo } \\
\text { controle com idade } \\
\text { média de } 59.45 \text { anos } \\
40 \text { pessoas no grupo } \\
\text { intervenção com } \\
\text { idade média de } 54,4 \\
\text { anos }\end{array}$ & $\begin{array}{l}\text { Avaliar o efeito do } \\
\text { exercí́cio aeróbio de } \\
\text { intensidade } \\
\text { moderada de } 8 \\
\text { semanas }(40-60 \% \text { da } \\
\text { frequência cardíaca) } \\
\text { sobre a qualidade de } \\
\text { vida da neuropatia } \\
\text { no diabetes tipo } 2 \text {. }\end{array}$ & $\begin{array}{l}\text { O estudo foi realizado em um ambiente terciário } \\
\text { em Karnataka, Índia, de outubro de } 2009 \text { a } \\
\text { dezembro de } 201 \\
\text { Durante } 8 \text { semanas: entre outubro de } 2009 \text { e } \\
\text { dezembro de } 2012 \\
\text { Modalidade: passadeira } \\
\text { Tipo de exercício: aeróbio } \\
\text { Intensidade: moderada } \\
\text { Frequência do exercício: } 5 \text { a } 6 \text { dias /semana } \\
\text { Volume: Não definido } \\
\text { Duração: mínimo } 150 \text { min/semana e máximo } 360 \\
\text { min/semana } \\
\text { Grupo Controlo: não desenvolveram nenhuma } \\
\text { atividade física }\end{array}$ & $\begin{array}{l}\text { Na comparação dos resultados do controle } \\
\text { e do grupo de estudo de RANOV : } \\
\text { Sem alterações significativas: } \\
\text { - nos valores médios das medidas } \\
\text { antropométricas utilizando RANOVA ( } p \\
<0,05) \\
-(p<0,05) \text { nos valores médios do controle } \\
\text { glicémico } \\
\text { Com alterações significativas:Diferença } \\
\text { significativa: } \\
-(p<0,05) \text { nos valores médios de MDNS } \\
-(p<0,05) \text { nas medidas de qualidade de } \\
\text { vida } \\
-(p<0,05) \text { nos valores médios da velocidade } \\
\text { de condução do segmento distal do nervo } \\
\text { fibular (df }=1,62, F=5,14 \text { ep }=0,03) \text { e do } \\
\text { nervo sensorial sural (df }=1,60, F=10,16 \text { e } \\
p \backslash 0,001) \text { - para as velocidades de condução } \\
\text { nervosa em dois grupos, houve diferença } \\
\text { significativa entre ambos os grupos }(p \\
<0,05)\end{array}$ & $\begin{array}{l}\text { Nível Ib } \\
\text { Estudo } \\
\text { aleatório e } \\
\text { controlado }\end{array}$ \\
\hline \begin{tabular}{|l} 
Taylor, J.; et al \\
2014 (21) \\
Arkansas
\end{tabular} & \begin{tabular}{|l|}
21 pessoas com \\
diabetes tipo 2 com \\
idades entre os 18 e \\
69 anos \\
10 pessoas no grupo \\
de treino de \\
exercício de \\
intensidade \\
moderada (grupo \\
MOD) \\
11 pessoas no grupo \\
de treino de \\
exercício de alta \\
intensidade (grupo \\
HIGH).
\end{tabular} & $\begin{array}{l}\text { Investigar os efeitos } \\
\text { do exercício físico } \\
\text { moderado versus de } \\
\text { alta intensidade } \\
\text { sobre aptidão e } \\
\text { condição física em } \\
\text { pessaas com diabetes } \\
\text { tipo } 2 \text {. }\end{array}$ & $\begin{array}{l}\text { De setembro de } 2011 \text { a agosto de } 2012 . \\
\text { Grupo MOD: } \\
\text { Treino aeróbio } \\
\text { Modalidade: passadeira } \\
\text { Tipo de exercício: aeróbio } \\
\text { Intensidade: } 30 \% \text { a } 45 \% \text { de reserva da FC } \\
\text { Frequência do exercício: } 3 \text { vezes/semana } \\
\text { Volume: Não definido } \\
\text { Duração: } 20 \text { min } \\
\text { Treino Resistência } \\
\text { Modalidade: máquinas resistência e pesos } \\
\text { Tipo exercício: resistência } \\
\text { Intensidade: } 75 \% \text { das } 8 \text {-RM } \\
\text { Frequência do exercício: } 2 \text { vezes/semana } \\
\text { Volume: } 4 \text { series de } 8 \text { repetições } \\
\text { Duração: Não definido } \\
\text { Grupo HIGH } \\
\text { Treino aeróbio } \\
\text { Modalidade: passadeira } \\
\text { Tipo de exercício: aeróbio } \\
\text { Intensidade: } 50 \% \text { a } 65 \% \text { de reserva da FC } \\
\text { Frequência do exercício: } 3 \text { vezes/semana } \\
\text { Volume: Não definido } \\
\text { Duração: } 20 \text { min } \\
\text { Treino Resistência } \\
\text { Modalidade: máquinas resistência e pesos }\end{array}$ & 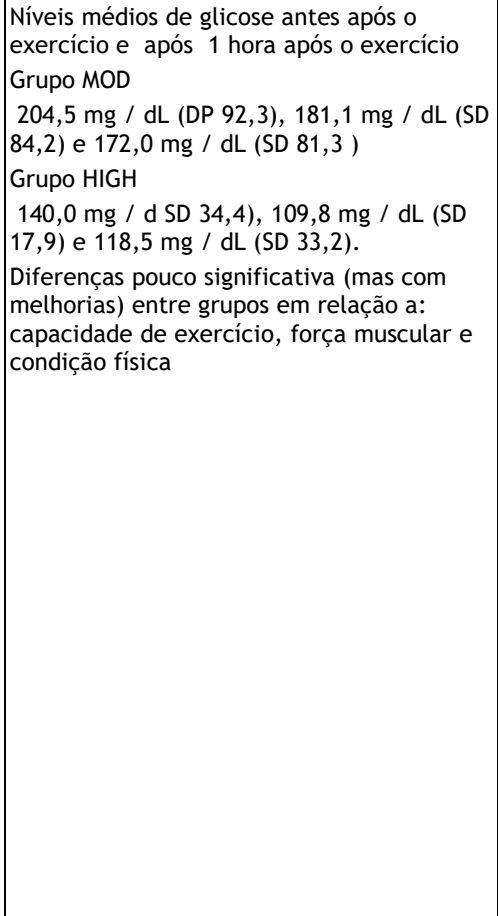 & $\begin{array}{l}\text { Nível lb } \\
\text { Estudo } \\
\text { aleatório e } \\
\text { controlado }\end{array}$ \\
\hline
\end{tabular}




\begin{tabular}{|c|c|c|c|c|c|}
\hline & & & $\begin{array}{l}\text { Tipo exercício: resistência } \\
\text { Intensidade: } 100 \% \text { das } 8 \text {-RM } \\
\text { Frequência do exercício: } 2 \text { vezes/semana } \\
\text { Volume: } 4 \text { series de } 8 \text { repetições } \\
\text { Duração: - Não definido }\end{array}$ & & \\
\hline $\begin{array}{l}\text { Karimi, Hossein, } \\
\text { et al (22) } \\
2017 \\
\text { Paquistão }\end{array}$ & \begin{tabular}{|l|}
102 participantes \\
Grupo experimental \\
$(\mathrm{n}=51)$ com média \\
de idade de $53,74 \pm$ \\
8,75 anos \\
Grupo controle $(\mathrm{n}=$ \\
$51)$ com média de \\
idade de $55,08 \pm 7,67$ \\
anos
\end{tabular} & $\begin{array}{l}\text { Determinar os efeitos } \\
\text { do programa de } \\
\text { treinamento físico } \\
\text { aeróbico estruturado } \\
\text { supervisionado } \\
\text { (SSAET) sobre a } \\
\text { interleucina-6 (IL-6), } \\
\text { óxido nitrico sintase } \\
1 \text { (NOS-1) e } \\
\text { ciclooxigenase-2 } \\
\text { (COX-2) no diabetes } \\
\text { tipo 2. }\end{array}$ & $\begin{array}{l}\text { Durante } 25 \text { semanas } \\
\text { De janeiro de } 2015 \text { a junho de } 2016 \text {. } \\
\text { SSAET combinado com medicação de rotina e plano } \\
\text { de dieta foi aplicado no grupo experimental } \\
\text { Grupo controle tratado com medicação de rotina } \\
\text { e plano de dieta } \\
\text { Modalidade: passadeira } \\
\text { Tipo de exercício: aeróbio } \\
\text { Intensidade: Não definido } \\
\text { Frequência do exercício: Não definido } \\
\text { Volume: Não definido } \\
\text { Duração: } 30 \text { min na primeira semana aumentando } \\
30 \text { min a cada semana num total } 4 \text { semanas }\end{array}$ & $\begin{array}{l}\text { O programa SSAET, medicação de rotina e } \\
\text { plano alimentar melhoram os valores de IL- } \\
6 \text { no grupo experimental, em comparação } \\
\text { com grupo controle controlado por } \\
\text { medicação de rotina e plano alimentar, } \\
\text { onde foi observada deterioração na IL-6 }\end{array}$ & $\begin{array}{l}\text { Nível lb } \\
\text { Estudo } \\
\text { aleatório e } \\
\text { controlado }\end{array}$ \\
\hline $\begin{array}{l}\text { Leehey, DJ; et } \\
\text { al } \\
2016 \text { (24) } \\
\text { USA }\end{array}$ & \begin{tabular}{|l}
36 pacientes do sexo \\
masculino \\
Idade entre os $49-81$ \\
Grupos: \\
- Exercício + gestão \\
da dieta $(\mathrm{n}=18)$ \\
- Dieta sozinho $(\mathrm{n}=$ \\
18).
\end{tabular} & $\begin{array}{l}\text { Determinar os efeitos } \\
\text { do exercício } \\
\text { estruturado } \\
\text { aptidão física, } \\
\text { função renal, função } \\
\text { endotelial, } \\
\text { inflamação, } \\
\text { e composição } \\
\text { corporal nesses } \\
\text { pacientes. }\end{array}$ & $\begin{array}{l}\text { Durante } 12 \text { semanas } \\
\text { Grupo Exercício + gestão dieta } \\
\text { Modalidade: passadeira } \\
\text { Tipo Exercício: Aeróbico e Resistência } \\
\text { Frequência: } 3 \text { vezes por semana } \\
\text { Intensidade: Não definido } \\
\text { Volume: Não definido } \\
\text { Duração: Não definido } \\
\text { Grupo Controlo: apenas a dieta, sem exercício } \\
\text { físico }\end{array}$ & $\begin{array}{l}\text { Sem alterações significativas na: } \\
\text { - taxa de albumina na urina para } \\
\text { creatinina, } \\
\text { - taxa de filtração glomerular estimada, } \\
\text { - função endotelial, inflamação ou } \\
\text { composição corporal entre os grupos. } \\
\text { O exercício controlado melhorou a } \\
\text { capacidade de exercício na pessoa } \\
\text { diabética obesa com DRC mas não a } \\
\text { composição corporal ou a função renal. }\end{array}$ & $\begin{array}{l}\text { Nível lb } \\
\text { Estudo } \\
\text { aleatório e } \\
\text { controlado }\end{array}$ \\
\hline $\begin{array}{l}\text { Vlaar MA, } \\
\text { et al (26) } \\
(2017) \\
\text { Holanda }\end{array}$ & \begin{tabular}{|l|}
536 sul-asiáticos de \\
18 a 60 anos com \\
risco para diabetes \\
Grupo intervenção (n \\
$=283)$ : entrevista \\
motivacional, sessão \\
familiar, aulas \\
culinária, programa \\
de atividade física \\
supervisionada \\
Grupo controle $(\mathrm{n}=$ \\
253)- receberam \\
concelhos genéricos \\
de estilo vida
\end{tabular} & $\begin{array}{l}\text { Investigar a eficácia } \\
\text { de uma intervenção } \\
\text { intensiva } \\
\text { culturalmente } \\
\text { direcionada ao estilo } \\
\text { de vida para prevenir } \\
\text { DM2 e fatores de } \\
\text { risco cardiovascular } \\
\text { entre Surinameses do } \\
\text { Sul da Ásia na } \\
\text { atenção primária. }\end{array}$ & $\begin{array}{l}\text { De } 18 \text { de maio de } 2009 \text { e } 11 \text { de outubro de } 2010 \\
\text { Grupo Intervenção: } \\
\text { Modalidade: Qualquer atividade física; } \\
\text { Tipo Exercício: Não definido } \\
\text { Intensidade: Moderada a Intensa } \\
\text { Frequência: - Não definido } \\
\text { Intensidade: Não definido } \\
\text { Volume: - Não definido } \\
\text { Duração: Não definido } \\
\text { Grupo Controlo: receberam diretrizes atuais para } \\
\text { dieta e atividade física }\end{array}$ & $\begin{array}{l}\text { Uma intervenção de estilo de vida } \\
\text { culturalmente direcionada na atenção } \\
\text { primária não alterou o comportamento } \\
\text { alimentar e a atividade física de um grupo } \\
\text { de pessoas do sul da Ásia sob risco de } \\
\text { diabetes tipo } 2\end{array}$ & $\begin{array}{l}\text { lb } \\
\text { Estudo } \\
\text { aleatório e } \\
\text { controlado }\end{array}$ \\
\hline
\end{tabular}




\section{DISCUSSÃO}

As modalidades de exercício físico mais aplicadas nos estudos abordados foram: a caminhada (18,20-21,23-24) máquinas de resistência e peso livre ${ }^{(22,25)}$ e bicicleta(24). O tipo de exercício físico recomendado para a pessoa diabética vai depender de alguns fatores nomeadamente a sua condição física basal, preferências, meios disponíveis ou presença de limitações físicas ${ }^{(19)}$.

Os estudos analisados recorreram essencialmente a exercícios aeróbios com a exceção de (22-25) que combinaram exercícios aeróbios e de resistência. Alguns estudos realizados referem que a combinação de exercício físico aeróbico em complemento com treino de resistência pode ser melhor que qualquer um deles separadamente ${ }^{(20)}$.

A frequência do exercício evidenciada nos estudos variou entre 2 vezes por semana(19) e 5 a 6 vezes por semana ${ }^{(20)}$ e teve uma duração entre os 30 minutos $^{(22)}$ e os 60 minutos $^{(24-25)}$ por cada sessão de exercício. A frequência mínima de exercício recomendada pela American Diabetes Association é de 150 minutos por semana de exercício físico aeróbio moderado ao longo de pelo menos três dias para a semana; já a Sociedade Espanhola de Diabetes recomenda sessões de exercício com a duração de pelo menos 45 minutos, três vezes por semana, divididas em pré-aquecimento, fase principal e por fim o relaxamento ${ }^{(20)}$.

A intensidade do exercício não foi avaliada de igual forma nos artigos analisados e nem todos faziam referência a este parâmetro. Asuako e colaboradores $\left({ }^{18)}\right.$ avaliaram a intensidade recorrendo à frequência cardíaca máxima, valor este obtido através de um oxímetro de pulso versão 803, China, colocado aquando do exercício e através da aplicação online Pace Calculator.

Nos estudos realizados por Dixit e colaboradores ${ }^{(20)}$ e Taylor e colaboradores ${ }^{(21)}$, a intensidade do exercício foi avaliada com recurso a fórmula de Karvonen (Frequência cardíaca treino = Frequência cardíaca Repouso +(Intensidade) x (Frequência cardíaca máxima - Frequência Cardíaca em repouso). Dixit e colaboradores ${ }^{(20)}$ recorreram a monitor de frequência cardíaca (Polar Electro Oy, Kempele, Finlândia) e usaram-no para monitorizar a frequência cardíaca continuamente durante o exercício aeróbico.

De salientar que nos estudos analisados nem sempre a caracterização do exercício estava completa (modalidade, tipo exercício, frequência, intensidade, volume e duração) o que limitou a análise limitando de alguma forma a generalização dos resultados.

$\mathrm{Na}$ análise realizada, apenas dois artigos combinaram o estudo do exercício com um tipo de dieta específica $^{(25-26)}$.

Otten e colaboraores ${ }^{(25)}$ combinaram o exercício físico com dieta paleolítica, dieta esta baseada no consumo de carne magra, peixe, frutos do mar, ovos, legumes, frutas, frutas vermelhas e nozes e excluindo cereais, produtos lácteos, leguminosas, gorduras refinadas, açúcares refinados e sal. Em estudos já realizados anteriormente a dieta Paleolítica teve efeitos metabólicos benéficos sobre a obesidade e no tipo de diabetes $^{(25)}$.

Vlaar e colaboradores ${ }^{(26)}$ combinaram o exercício físico com a dieta saudável baseadas nas diretrizes alimentares nacionais do sul da Asia e que inclui 2 pedaços de fruta/dia, vegetais $(200 \mathrm{~g} / \mathrm{dia})$, trigo integral (exclusivamente produtos de trigo integral), arroz (unicamente arroz integral) e 3 refeições por dia/horário regular.

$\mathrm{Na}$ análise dos artigos, verificamos que existem ganhos importantes na saúde da pessoa com diabetes associada à prática de exercício físico. As variáveis mais utilizados na maioria dos estudos e que evidenciam esses ganhos foram a glicose ${ }^{(20)}$, a HbA1c $^{(19-25)}$, o peso corporal(18-25) e o colesterol ${ }^{(18-19)} .0$ exercício físico controlado está associado a valores da hemoglobina glicosada mais controlados e menor risco cardiovascular, melhorando também o estado de saúde psicossocial e diminuindo os gastos farmacêuticos ${ }^{(19)}$.

\section{Implicações Práticas}

O exercício físico tem um efeito positivo na saúde da pessoa diabética, contudo, o tipo de exercícios, duração, frequência e intensidade para utilizar na redução da glicemia devem ser clarificados em futuros estudos experimentais.

O sedentarismo e a obesidade na pessoa com diabetes, são fatores, que marcam a aptidão física. Neste sentido, enfermeiros, médicos e outros cuidadores devem promover um maior incentivo e acompanhamento (inter e extra-hospitalar) de modo a melhorar a adesão destas pessoas à atividade física em geral e ao exercício físico em particular. Salientandose que a atividade física é definida como qualquer movimento corporal produzido pela contração muscular que resulte num gasto energético acima do nível de repouso e o exercício físico é caraterizado por movimentos corporais planeados, organizados e repetidos, tendo como objetivo, manter ou melhorar uma ou mais componentes da aptidão física ${ }^{(27)}$.

A Enfermagem de Reabilitação pode ter um papel determinante no aumento da prática de exercício físico em pessoa com diabetes. $\mathrm{E}$ os enfermeiros especialistas em enfermagem de reabilitação devem participar na produção de evidências neste âmbito, participar nas tomadas de decisões relacionadas com a saúde, assim como na construção de políticas de saúde que visem a adoção de estilos de vida saudáveis relacionados com a prática de exercício físico em pessoas com diabetes.

\section{Limitações do estudo}

Os estudos que integraram esta RSL apresentaram algumas limitações, nomeadamente: o tamanho reduzido da amostra, limitando a generalização dos resultados, nem todos os artigos analisados caracterizavam o exercício físico e os que o faziam, não abordavam todos os critérios, especificamente, frequência, volume, duração e intensidade. 
Relativamente à intensidade, poucos estudos recorreram a escalas para descrever a intensidade como baixa, moderada ou vigorosa, o que torna esta avaliação pouco objetiva. Além disso, existe uma parca produção científica sobre este tema, o que foi um obstáculo à realização desta RSL. Por fim, referese o número reduzido de bases de dados acedidas assim como à língua e horizonte temporal utilizado, que pode contribuir para o reduzido número de estudos identificados e incluídos na última etapa.

\section{CONCLUSÃO}

Com esta RSL e após a análise dos 9 estudos, podemos concluir que o exercício físico traz benefícios na pessoa com diabetes nomeadamente a nível da redução da glicose plasmática em jejum, valores da hemoglobina glicosada, redução do peso corporal e colesterol, assim como melhorar a qualidade de vida da pessoa.

Este estudo permitiu aumentar o conhecimento em enfermagem de reabilitação, bem como, contribuir para avaliar os benefícios do exercício físico estruturado na pessoa com diabetes. No entanto, verificaram-se lacunas na descrição dos exercícios ao nível da modalidade, frequência, intensidade, volume, duração e progressão. Recomendam-se mais estudos, com amostra mais robustas, onde sejam descritas de forma mais objetiva as intervenções no âmbito do exercício físico, assim como, os instrumentos de avaliação que permitam não só definir a intensidade do exercício, como demonstrar os ganhos sensíveis à prescrição de exercício realizada por enfermeiros especialistas em enfermagem de reabilitação.

\section{REFERÊNCIAS BIBLIOGRÁFICAS}

1. Kerner W, Brückel J. Definition, Classification and Diagnosis of Diabetes Mellitus. Exp Clin Endocrinol Diabetes. 2014 Jul;122(07):384-6. Acessível em https://doi.org/10.1055/s0034-1366278

2. American Diabetes Association. 2. Classification and diagnosis of diabetes. Diabetes care. 2015 Jan 1;38(Supplement 1):S8-16. Acessível em https://doi.org/10.2337/dc15-S005

3. World Health Organization. Global report on diabetes. Geneva: World Health Organization; 2016. Acessível em: http: / /apps.who.int/iris/bitstream/handle/10665/204871/9?se quence $=1$

4. Zimmet P, Alberti KG, Magliano DJ, Bennett PH. Diabetes mellitus statistics on prevalence and mortality: facts and fallacies. Nat Rev Endocrinol. 2016 Oct;12(10):616-22. https: / / www.nature.com/articles/nrendo.2016.105

5. Observatório Nacional da Diabetes. Diabetes Factos e Números o ano de 2015-Relatório Anual do Observatório Nacional da Diabetes. Sociedade Portuguesa de Diabetologia. 2016.

6. Colberg SR, Sigal RJ, Yardley JE, Riddell MC, Dunstan DW, Dempsey PC, Horton ES, Castorino K, Tate DF. Physical activity/exercise and diabetes: a position statement of the American Diabetes Association. Diabetes Care. 2016 Nov 1;39(11):2065-79. Acessível em https://doi.org/10.2337/dc161728

7. Biazzon AC. Influência da atividade física no tratamento da diabetes mellitus tipo 1 e tipo 2. Rev Saúde Biol. 2018 Mar 14;12(2):68-73.

http://revista2.grupointegrado.br/revista/index.php/sabios2/a rticle/view/1744/983

8. Kirwan JP, Sacks J, Nieuwoudt S. The essential role of exercise in the management of type 2 diabetes. Cleve Clin J Med. 2017 Jul;84(7 Suppl 1):S15. Acessível em https://dx.doi.org/10.3949\%2Fccjm.84.s1.03

9. Petronilho F, Machado M. Teorias de Enfermagem e Autocuidado: Contributos para a Construção do Cuidado de Reabilitação. in Marques-Vieira CM, Sousa LM (Eds). Cuidados de Enfermagem de Reabilitação à pessoa ao longo da vida. Loures: Lusoditacta; 2017:3-14.

10. Ordem dos Enfermeiros. Investigação em enfermagem: Tomada de posição. Lisboa: Ordem dos Enfermeiros; 2006.

11. Danski MT, de Oliveira GL, Pedrolo E, Lind J, Johann DA. Importância da prática baseada em evidências nos processos de trabalho do enfermeiro/Importance of evidence-based practice in nurse's work processes. Ciênc Cuid Saúde. 2017 Apr;16(2). DOI: 10.4025

12. Sousa LMM, Firmino CF, Marques-Vieira CMA, Severino $S$, Pestana HCFC. Revisões da literatura científica: tipos, métodos e aplicações em enfermagem. Rev Port Enferm Reabil. 2018; 1(1): 46-55.

13. Galvão TF, Pereira MG. Systematic reviews of the literature: steps for preparation. Epidemiol Serv Saúde. 2014 Mar;23(1):183-4. Acessível em http://dx.doi.org/10.5123/S1679-49742014000100018

14. Moher D, Shamseer L, Clarke M, Ghersi D, Liberati A, Petticrew $M$, Shekelle P, Stewart LA. Preferred reporting items for systematic review and meta-analysis protocols (PRISMA-P) 2015 statement. Syst Rev. 2015 Dec;4(1):1. Acessivel em https: / / doi.org/10.1186/2046-4053-4-1

15. . Joanna Briggs Institute's. User Manual: Version 5.0 System for the Unified Management. Assessment and Review of Information. Joanna Briggs Institute's. 2011. Acessível em: http://joannabriggs. org/assets/docs/sumari/SUMARI-V5-Userguide

16. Sousa LM, Marques-Vieira CM, Severino SS, Antunes AV. Metodologia de Revisão Integrativa da Literatura em Enfermagem. Rev Inv Enferm. 2017; S2(21):17-26 Disponível em: http://hdl.handle.net/20.500.12253/1311

17. Registered Nurses Association of Ontario (RNAO). Falls Prevention: Building the Foundations for Patient Safety. A Self Learning Package. Toronto: Registered Nurses Association of Ontario; 2007.

18. Asuako B, Moses MO, Eghan BA, Sarpong PA. Fasting plasma glucose and lipid profiles of diabetic patients improve with aerobic exercise training. Ghana Med J. 2017;51(3):120-7. Acessível em http://dx.doi.org/10.4314/gmj.v51i3.5

19. Parra-Sánchez J, Moreno-Jiménez $M$, Nicola $C M$, NocuaRodríguez II, Amegló-Parejo MR, del Carmen-Peña M, CorderoPrieto C, Gajardo-Barrena MJ. Evaluación de un programa de ejercicio físico supervisado en pacientes sedentarios mayores de 65 años con diabetes mellitus tipo 2. Aten Primaria. 2015 Nov 1;47(9):555-62. Acessível em https://doi.org/10.1016/j.aprim.2015.01.006

20. Dixit S, Maiya A, Shastry B. Effect of aerobic exercise on quality of life in population with diabetic peripheral neuropathy in type 2 diabetes: a single blind, randomized controlled trial. Res Qual Life. 2014 Jun 1;23(5):1629-40. Acessível em DOI 10.1007/s11136-013-0602-7

21. Taylor JD, Fletcher JP, Mathis RA, Cade WT. Effects of moderate-versus high-intensity exercise training on physical fitness and physical function in people with type 2 diabetes: a randomized clinical trial. Phys Ther. 2014 Dec 1;94(12):172030. Acessivel em https://doi.org/10.2522/ptj.20140097

22. Karimi H, Rehman SS, Gillani SA. Effects of Supervised Structured Aerobic Exercise Training Program on Interleukin-6, Nitric Oxide Synthase-1, and Cyclooxygenase-2 in Type 2 Diabetes Mellitus. J Coll Physicians Surg Pak. 2017 Jun 1;27(6):352-5. Acessível em: https: / / inis.iaea.org/search/search.aspx?orig_q=RN:48076473

23. Schreuder TH, Duncker DJ, Hopman MT, Thijssen DH. Randomized controlled trial using bosentan to enhance the impact of exercise training in subjects with type 2 diabetes mellitus. Exp Physiol. 2014 Nov 1;99(11):1538-47. Acessível em https://doi.org/10.1113/expphysiol.2014.081182

24. Leehey DJ, Collins E, Kramer HJ, Cooper C, Butler J, McBurney C, Jelinek C, Reda D, Edwards L, Garabedian A, O'Connell S. Structured exercise in obese diabetic patients with chronic 
kidney disease: a randomized controlled trial. Am J Nephrol. 2016;44(1):54-62. Acessível

em https://doi.org/10.1159/000447703

25. Otten J, Stomby A, Waling $M$, Isaksson A, Tellström A, Lundin-Olsson L, Brage $S$, Ryberg $M$, Svensson $M$, Olsson $T$. Benefits of a Paleolithic diet with and without supervised exercise on fat mass, insulin sensitivity, and glycemic control: a randomized controlled trial in individuals with type 2 diabetes. Diabetes Metab Res Rev. 2017 Jan;33(1):e2828. Acessível em https://doi.org/10.1002/dmrr.2828

26. Vlaar EM, Nierkens V, Nicolaou M, Middelkoop BJ, Busschers
WB, Stronks K, van Valkengoed IG. Effectiveness of a targeted lifestyle intervention in primary care on diet and physical activity among South Asians at risk for diabetes: 2-year results of a randomised controlled trial in the Netherlands. BMJ open. 2017 Jun 1;7(6):e012221. Acessível em https://doi:10.1136/ bmjopen-2016-012221

27. Santa-Clara H, Pinto I, Santos V, Pinto R, Melo X, Almeida JP, Pimenta N, Abreu A, Mendes M. Atividade física e exercício físico: especificidades no doente cardíaco. Rev Factores de Risco. 2015, 35:28-35. Acessível em. http://hdl.handle.net/10400.17/2154 


\title{
EXERCíCIO FísICO NA PESSOA COM DEMÊNCIA: REVISÃo SISTEMÁTICA DE LITERATURA.
}

\author{
EJERCICIO FísICO EN LA PERSONA CON DEMENCIA: REVISIÓN SISTEMÁTICA DE LA LITERATURA.
}

\section{PHYSICAL EXERCISE IN A PERSON WITH DEMENTIA: SYSTEMATIC REVIEW OF LITERATURE}

DOI 10.33194/rper.2019.v2.n1.04.4562 | Submetido 5.3.2019 | Aprovado 24.06.2019

\begin{abstract}
(D) Diana Vanessa Ferreira Maia1; (iD Rui Miguel de Andrade Gaspar2; (iD António Manuel Gradíssimo Costa²; (iD) Filipe Manuel Gonçalves Dias ${ }^{3}$; (i) Helena Castelão Figueira Carlos Pestana ${ }^{4}$; (iD Luís Manuel Mota de Sousa

1 - Centro hospitalar Lisboa Ocidental, Hospital Egas Moniz, Lisboa, Portugal; 2- Centro hospitalar Lisboa Ocidental, Hospital S. Francisco Xavier, Lisboa, Portugal; 3 - Centro Hospitalar Universitário Lisboa Central, Hospital Curry Cabral, Lisboa, Portugal;

4 - Escola Superior de saúde Atlântica, Barcarena, Portugal; 5 - Universidade de Évora, Escola Superior de Enfermagem S. João de Deus, Évora, Portugal
\end{abstract}

\section{RESUMO}

Introdução: A demência é caraterizada por um conjunto de transtornos que englobam uma perda progressiva das funções cognitivas e afeta a destreza que é necessária ao desenvolvimento normal das atividades de vida diária.

Objetivo: Identificar os benefícios do exercício físico a nível cognitivo, sensorial e motor na pessoa com demência.

Método: revisão sistemática da literatura com a questão de pesquisa "Quais os benefícios do exercício físico em pessoas com demência?". A pesquisa foi realizada com recurso a plataformas de bases de dados eletrónicas EBSCOHost e Biblioteca Virtual em Saúde, tendo sido identificados, selecionados, avaliados na qualidade metodológica e incluídos artigos de acordo com as recomendações do PRISMA.

Resultados: Foram incluídos 7 estudos que cumpriam os critérios de inclusão, ou seja, estudos primários experimentais, que abordam a prática de exercício físico em pessoas com demência, publicados nos últimos 5 anos (2014-2018), em português, inglês e espanhol, com texto integral de livre acesso.

Conclusões: Esta revisão sistemática de literatura revela evidência dos efeitos benéficos do exercício sobre cognição, agitação, depressão e capacidade motora em pessoas com demência.

Descritores: Atividade Física; Exercício Físico; Demência; Doença Alzheimer; Enfermagem em Reabilitação.

\section{RESUMEN}

Introducción: La demencia es caracterizada por un conjunto de trastornos que engloban una pérdida progresiva de las funciones cognitivas y afecta la destreza que es necesaria para el desarrollo normal de las actividades de vida diaria.

Objectivo: Identificar los beneficios de ejercicio físico a nivel cognitivo, sensorial y motor en la persona con demencia.

Método: Revisión Sistemática de la Literatura con la cuestión de la investigación "¿Cuáles son los beneficios del ejercicio físico en las personas con demencia?". La investigación fue realizada con recurso a plataformas de bases de datos electrónicas EBSCOHost y Biblioteca Virtual en Salud, habiendo sido identificados, seleccionados, evaluados en la calidad metodológica e incluidos artículos de acuerdo con las recomendaciones del PRISMA.

Resultados: Se incluyeron siete estudios que cumplieron los criterios de inclusión, es decir, estudios primarios experimentales que aborden el ejercicio físico en personas con demencia, publicado en los últimos cinco años (2014-2018), en portugués, Inglés y Español, con texto integral de libre acceso.

Conclusiones: Esta revisión sistemática de la literatura revela evidencia de los efectos del ejercicio sobre cognición, agitación, depresión y capacidad motora en personas con demencia.

Descriptores: Actividad Física; Ejercicio físico; Demencia; Enfermedad Alzheimer; Enfermería en Rehabilitación.

\section{ABSTRACT}

Background: Dementia is characterized by a set of disorders that involving a progressive loss of cognitive functions as well as affecting the skill necessary for the normal development of activities of daily living.

Objective: Identify the benefits of physical exercise at the cognitive, sensory and motor level in the person with dementia.

Method: Systematic Review of literature, started with the question: "What are the benefits of physical exercise in people with dementia?". The research was carried out using the electronic database platforms: EBSCOHost and BVS, 
having been identified, selected, evaluated in a methodological quality and included articles that take into account the PRISMA recommendations.

Results: There were included seven studies meeting the inclusion criteria, that is, primary experimental studies, addressing the practice of physical exercise in people with dementia and Alzheimer Disease, published in the last 5 years (2014-2018), in Portuguese, English and Spanish, were included, with full text of free access.

Conclusions: This Systematic Review reveals evidence of the beneficial effects of physical exercise on cognition and motor ability in people with dementia.

Keywords: Physical Activity; Physical exercise; Dementia; Alzheimer Disease; Rehabilitation Nursing

\section{INTRODUÇÃO}

A Health at a Glance 2017, da Organização para a Cooperação e Desenvolvimento Económico (OCDE), refere que a demência é umas das principais causas de morte. Em 2015, representava 4.5\% nas mulheres e $2.1 \%$ nos homens. 0 mesmo estudo coloca Portugal em $4^{\circ}$ lugar com 19.9 casos por mil habitantes, sendo apenas ultrapassado pela Alemanha, Itália e Japão, ocupando este último o topo da tabela com 23,3 casos por mil habitantes, enquanto que a média da OCDE se situa nos 14.8. À medida que a esperança média de vida aumenta em Portugal, o número de casos de demência aumenta, estimando-se que este número aumentará para 31,3 por mil habitantes até $2037^{(1)}$.

Embora afete principalmente os idosos, a demência não é uma consequência normal do envelhecimento. A demência é um grupo de transtornos que englobam uma perda progressiva das funções cognitivas e afeta a destreza que é necessária ao desenvolvimento normal das atividades de vida diária (AVD) ${ }^{(2-3)}$ entre elas, a atenção, memória a curto e longo prazo, planeamento de atividades e movimentos ${ }^{(4)}$, o que leva à perda do desenvolvimento da pessoa provocando alterações no seu ambiente familiar e social, devido ao seu estado de dependência ${ }^{(5)}$.

A Doença de Alzheimer é a forma mais comum, representando cerca de $60-70 \%$ dos casos de demência. Entre as formas menos frequentes de demência podemos destacar as demências vasculares, mista, dos corpos de Lewy e Doença de Parkinson entre outras ${ }^{(5)}$.

Assim sendo, a Doença de Alzheimer, de causa ainda desconhecida, provoca a neurodegeneração e o consequente agravamento (progressivo e irreversível) das funções cerebrais, culminando na total perda de autonomia ${ }^{(6)}$.

Os sintomas iniciais incluem perda de memória, a desorientação espacial e temporal, confusão e problemas de raciocínio e pensamento, provocando alterações no comportamento, na personalidade e na capacidade funcional da pessoa, e dificultando a realização das suas $\operatorname{AVD}^{(6)}$.

De momento, não existe nenhum tratamento para travar a progressão da doença e o tratamento farmacológico limita-se ao alívio dos sintomas causados pela demência ${ }^{(7)}$.
Os estudos realizados indicam que a alteração nos estilos de vida e o exercício físico podem prevenir ou retardar o aparecimento da demência ${ }^{(8,9)}$. Esses dados sugerem que 0 exercício físico melhora 0 funcionamento neuropsicológico, embora atividades de lazer também possam trazer melhorias. Deste modo, um programa de exercício físico aeróbico pode ser uma alternativa adjuvante para manter e melhorar essas funções ${ }^{(9)}$.

O Enfermeiro Especialista em Enfermagem de Reabilitação (EEER), de acordo com o Regulamento das Competências Específicas tem como competência conceber, implementar, avaliar e reformular programas de treino motor e cardiorrespiratório, em função dos resultados esperados ${ }^{(10)}$ onde a prescrição do exercício físico está inserida.

Esta revisão sistemática da literatura (RSL) tem como questão de partida, quais os benefícios do exercício físico em pessoas com demência?

O objetivo da RSL é identificar os benefícios do exercício físico a nível cognitivo, sensorial e motor na pessoa com demência.

\section{MATERIAL E MÉTODOS}

De entre os vários tipos de revisões, a RSL é a mais usada, e define-se "como um método sistemático, explícito e reproduzivel que permite identificar, avaliar $e$ sintetizar os estudos realizados por investigadores, académicos e profissionais de saúde"(11:47) com a finalidade de reduzir enviesamentos. É um método que permite fazer uma síntese rigorosa de todas as pesquisas relacionadas a uma pergunta específica, possibilitando assim obter a melhor evidência, sendo por isso considerada um dos pilares para a prática baseada em evidência ${ }^{(11)}$.

Para realizar uma RSL devem ser tidas em conta sete etapas: 1) construção do protocolo de pesquisa; 2) formulação da pergunta; 3) pesquisa de estudos; 4) seleção e revisão dos estudos; 5) avaliação crítica de cada um dos artigos; 6) colheita de dados; 7) síntese de resultados/dados ${ }^{(11)}$.

Para a formulação da questão de investigação utilizamos as recomendações da Joanna Briggs Institute $(\mathrm{JBI})^{(12)}$ a partir da estratégia PICO. Cada dimensão do PICO contribuiu para definir os critérios de inclusão: População (P) - Pessoas com demência incluindo a Doença de Alzheimer por ser uma tipologia de demência mais frequente; Intervenção (I) 
- Exercício físico; Comparação (C) e Resultados (O) Benefícios do exercício físico.

Deste modo resultou uma questão de Investigação: "Quais os benefícios do exercício físico em pessoas com demência?".

Os descritores relacionados com cada uma das componentes da estratégia PICO foram: Dementia; Alzheimer Disease; Physical Exercise; Physical Activity, validados previamente na plataforma Descritores em Ciências da Saúde e Medical Subject Headings.

Definiram-se como critérios de inclusão: estudos primários experimentais e quase experimentais, que abordam a prática de exercício físico em pessoas com demência e Doença de Alzheimer, publicados ao longo dos últimos 5 anos (2014-2018), em português, inglês e espanhol, com texto integral de livre acesso.

A pesquisa foi realizada durante os meses de outubro e novembro de 2018 através das plataformas de bases de dados eletrónicas EBSCOHost (CINAHL Complete; Cochrane Collection Plus; Nursing \& Allied Health Collection: Expanded; MEDLINE $®$ Complete; Library, Information Science \& Technology Abstracts; Medic Latina), Biblioteca Virtual de Saúde (BVS).

A pesquisa foi efetuada por duas pessoas em simultâneo, de 20 de outubro a 24 de novembro de 2018, tendo em conta a seguinte conjugação booleana com os descritores em inglês:

((Physical Exercise) OR (Physical Activity)) AND ((Alzheimer Disease) OR Dementia))

A Tabela 1 descreve o processo de conjugação dos descritores e palavras-chave para a pesquisa nas bases de dados. A Figura 1 ilustra o fluxograma PRISMA correspondente à identificação, análise, seleção e inclusão dos artigos.

\begin{tabular}{|c|c|c|}
\hline Conjugação Booleana & EBSCO & BVS \\
\hline $\begin{array}{l}\text { ((Physical Exercise) OR (Physical } \\
\text { Activity)) AND ((Alzheimer Disease) } \\
\text { OR (Dementia)) }\end{array}$ & 3430 & 1019 \\
\hline
\end{tabular}

Tabela 1 - Conjugação Booleana

Os artigos selecionados para leitura completa foram avaliados por dois investigadores de forma independente, de acordo com critérios de qualidade metodológica, propostos pelo $\mathrm{JBI}^{(12)}$, tendo sido selecionados apenas os artigos com mais de $75 \%$ dos critérios.

Foi extraída informação dos artigos sobre autores, ano, país, amostra, dados sobre modalidade, intensidade, volume, frequência e duração do exercício físico. A classificação dos níveis de evidência dos estudos incluídos foi feita com base nos critérios da Registered Nurses Association of Ontario(13).

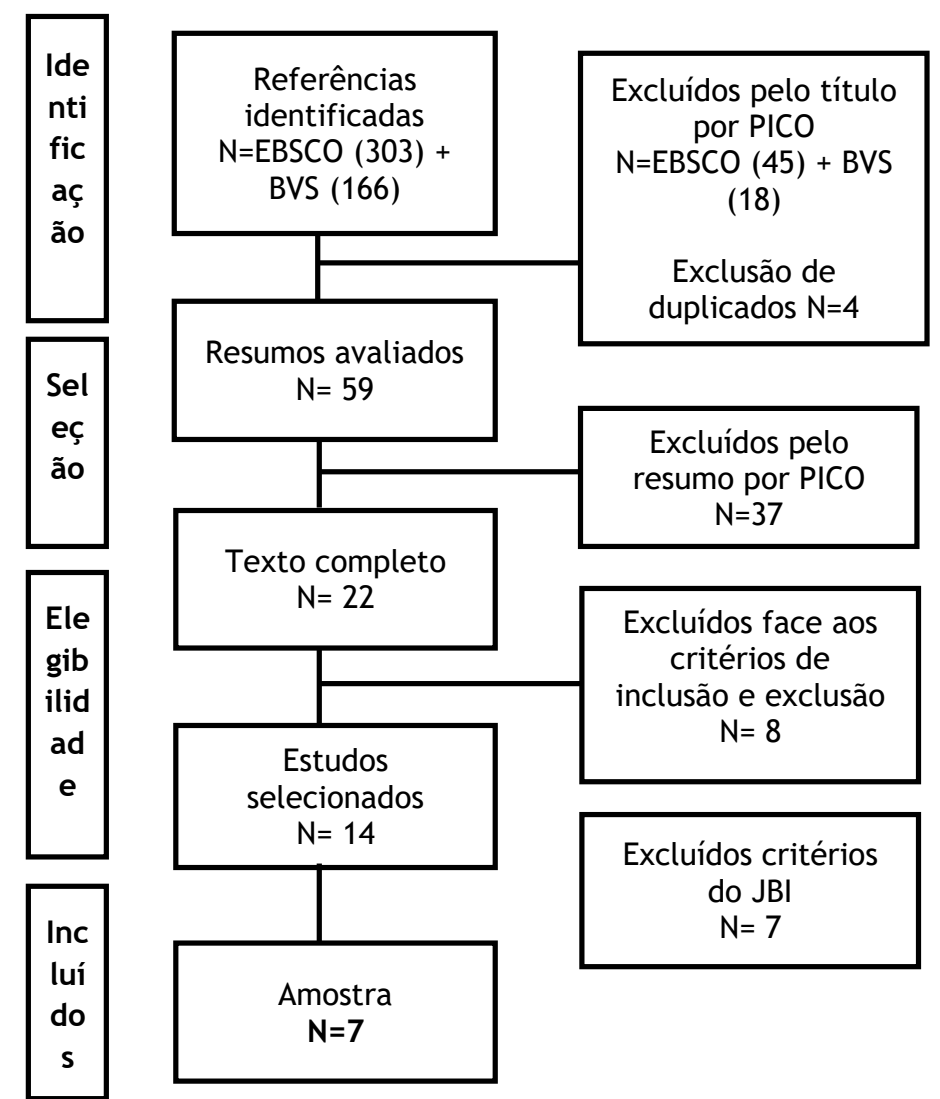

Figura 1 - Identificação, análise e seleção dos artigos (14).

\section{RESULTADOS}

Foram incluídos 7 artigos nesta RSL, publicados nos seguintes anos $2015^{(15,16,17,19)}, 2016^{(18,21)}$ e $2017^{(20)}$, a amostra de pessoas variou entre $30^{(21)}$ e $170^{(15)}$. Relativamente ao grupo de controlo variou entre $15^{(16,21)}$ e $116^{(19)}$. A duração dos estudos entre 8 semanas $^{(18)}$ e 15 meses $^{(19)}$. Todos os estudos incluídos (Tabela 2) são estudos primários experimentais de acordo com a Nurses Association of Ontario com níveis de evidência $\mathrm{lb}$, isto é, evidência obtida $\mathrm{a}$ partir de pelo menos um estudo controlado ${ }^{(13)}$. 


\begin{tabular}{|c|c|c|c|c|c|}
\hline $\begin{array}{c}\text { Autor, ano, } \\
\text { país }\end{array}$ & Participantes & Objetivo & Intervenção & Resultados & $\begin{array}{c}\text { Nível } \\
\text { Evidência }\end{array}$ \\
\hline $\begin{array}{l}\text { Telenius E., et al. } \\
2015, \\
\text { Noruega(15) }\end{array}$ & $\begin{array}{l}\text { Total }(n=170) \\
\text { Grupo experimental }(n= \\
87) \\
\text { Grupo controlo }(n=83)\end{array}$ & \begin{tabular}{|l|} 
Investigar o efeito de um \\
programa de exercícios \\
funcionais de alta intensidade \\
sobre o equilíbrio, mobilidade, e \\
atividades de vida diária e \\
sintomas neuropsiquiátricos em \\
residentes de um lar de idosos.
\end{tabular} & $\begin{array}{l}\text { Duração do estudo: } 12 \text { semanas } \\
\text { Grupo experimental: } \\
\text { Modalidade - Exercícios de fortalecimento } \\
\text { muscular (cinco minutos de aquecimento, } \\
\text { pelo menos dois exercícios de força para o } \\
\text { músculo do membro inferior e dois exercícios } \\
\text { de equilíbrio) } \\
\text { Intensidade - Alta } \\
\text { Frequência - duas vezes por semana } \\
\text { Volume - duas séries e } 12 \text { repetições } \\
\text { Duração - } 50 \text { a } 60 \text { minutos } \\
\text { Grupo de controlo: Atividades recreativas } \\
\text { (leitura, jogos, ouvir música e convívio) }\end{array}$ & $\begin{array}{l}\text { Os resultados demonstram que o } \\
\text { programa de exercícios de } \\
\text { fortalecimento muscular de alta } \\
\text { intensidade, têm efeitos } \\
\text { estatisticamente positivos no } \\
\text { equilíbrio, mobilidade e } \\
\text { atividades de vida diária e } \\
\text { reduziu a apatia e agitação. No } \\
\text { grupo de controlo houve um } \\
\text { declínio na função das } \\
\text { atividades de vida diária. }\end{array}$ & Ib \\
\hline $\begin{array}{l}\text { Holthoff VA., et } \\
\text { al. 2015, } \\
\text { Alemanha(16) }\end{array}$ & $\begin{array}{l}\text { Total }(n=30) \\
\text { Grupo experimental }(n \\
=15) \\
\text { Grupo de controlo }(n= \\
15)\end{array}$ & \begin{tabular}{|l|} 
Investigar os efeitos da \\
atividade física em pessoas com \\
Doença de Alzheimer e os seus \\
benefícios nas atividades de vida \\
diária em ambiente domiciliário.
\end{tabular} & $\begin{array}{l}\text { Duração do estudo: } 12 \text { semanas } \\
\text { Grupo experimental: } \\
\text { Modalidade - Uso da pedaleira } \\
\text { Intensidade-duas a quatro, grau dificuldade } \\
0-20 \\
\text { Frequência - três vezes por semana } \\
\text { Volume- não definido } \\
\text { Duração - } 30 \text { a } 60 \text { minutos } \\
\text { Grupo de controlo: } \\
\text { Visita mensal de um médico para } \\
\text { aconselhamento e alteração de hábitos de } \\
\text { sedentarismo e suas implicações. }\end{array}$ & $\begin{array}{l}\text { Os resultados demonstraram } \\
\text { benefícios consideráveis na } \\
\text { atividade física e função } \\
\text { cognitiva dos participantes. } \\
\text { Sugerem que o exercício físico } \\
\text { na Doença de Alzheimer } \\
\text { concorre para diminuir a } \\
\text { sobrecarga do cuidador nas AVD } \\
\text { no domicílio. }\end{array}$ & $\mathrm{Ib}$ \\
\hline $\begin{array}{l}\text { Morris JK., et al. } \\
2015 \\
\operatorname{EUA}(17)\end{array}$ & $\begin{array}{l}\text { Total }(n=76) \\
\text { Grupo experimental }(n \\
=39) \\
\text { Grupo de controlo }(n= \\
37)\end{array}$ & $\begin{array}{l}\text { Investigar os benefícios de } \\
\text { exercícios aeróbicos na } \\
\text { capacidade funcional e pessoas } \\
\text { com Doença de Alzheimer. }\end{array}$ & $\begin{array}{l}\text { Duração do estudo: } 26 \text { semanas } \\
\text { Grupo experimental: } \\
\text { Modalidade - exercício aeróbico } \\
\text { Intensidade - frequência cardíaca (FC) } \\
\text { gradualmente aumentando de } 40-55 \% \text { para } 60- \\
75 \% \text { da } F C \text { em reserva. } \\
\text { Borg (6-20) } \\
\text { Frequência - três a cinco sessões por semana } \\
\text { Volume - não definido } \\
\text { Duração - } 150 \text { minutos } \\
\text { Grupo de controlo: } \\
\text { Modalidade - exercício não-aeróbico } \\
\text { Intensidade - FC<100bpm } \\
\text { Frequência - três a cinco sessões por semana } \\
\text { Volume - não definido } \\
\text { Duração - } 150 \text { minutos }\end{array}$ & $\begin{array}{l}\text { Os resultados demonstram } \\
\text { benefícios na capacidade } \\
\text { funcional (Cuidar das Atividades } \\
\text { de Vida Diária) em pessoas com } \\
\text { Doença de Alzheimer }\end{array}$ & Ib \\
\hline $\begin{array}{l}\text { Lee HJ, Kim KD. } \\
2016 \\
\text { República da } \\
\text { Coreia(18) }\end{array}$ & $\begin{array}{l}\text { Total } n=60 \\
\text { Grupo experimental ( } \mathrm{n} \\
=30) \\
\begin{array}{l}\text { Grupo de controlo }(\mathrm{n} \\
=30)\end{array}\end{array}$ & \begin{tabular}{|l|} 
Determinar o efeito de um \\
programa de Exercício físico e \\
cognitivo nas funções cognitivas \\
e atividades de vida diária em \\
ambiente de idosos com \\
demência admitidos num centro \\
de dia.
\end{tabular} & $\begin{array}{l}\text { Duração do estudo: oito semanas } \\
\text { Grupo experimental: } \\
\text { Modalidade - exercícios Otago, (Exercícios de } \\
\text { Coordenação motora e Equilíbrio) } \\
\text { Intensidade - } \\
\text { Frequência - Três vezes por semana } \\
\text { Volume - não definido } \\
\text { Duração - } 30 \text { minutos } \\
\text { Grupo de controlo: } \\
\text { Realizou as mesmas atividades que o Grupo } \\
\text { experimental exceto o exercício físico }\end{array}$ & \begin{tabular}{|l|} 
Os resultados demonstram que o \\
programa de exercício físico \\
melhora a função cognitiva e \\
atividades de vida diária em \\
ambiente em pessoas com \\
demência leve.
\end{tabular} & Ib \\
\hline $\begin{array}{l}\text { Cancela JM., et al. } \\
\text { 2015. } \\
\text { Espanha(19) }\end{array}$ & $\begin{array}{l}\text { Total } n=189 \\
\text { Grupo experimental } n= \\
73 \\
\text { Grupo de controlo }(n= \\
116)\end{array}$ & \begin{tabular}{|l|} 
Identificar os efeitos de um \\
programa de exercício físico \\
sobre o declínio cognitivo, \\
memória, depressão, \\
dependência funcional e \\
distúrbios neuropsiquiátricos em \\
pessoas institucionalizadas com \\
demência.
\end{tabular} & $\begin{array}{l}\text { Duração do estudo: } 15 \text { meses } \\
\text { Grupo experimental: } \\
\text { Modalidade - atividade física aeróbica em } \\
\text { bicicleta estática } \\
\text { Intensidade - Baixa } \\
\text { Frequência - Diária } \\
\text { Volume - não definido } \\
\text { Duração - Mínimo de } 15 \text { minutos } \\
\text { Grupo de controlo: } \\
\text { Atividades recreativas sedentária (jogos de } \\
\text { cartas, leitura, artesanato). }\end{array}$ & $\begin{array}{l}\text { Os resultados demonstram que } \\
\text { ocorreu uma diminuiçãa } \\
\text { significativa na função cognitiva } \\
\text { no grupo de controlo, enquanto } \\
\text { que no grupo do exercício físico } \\
\text { houve uma ligeira melhoria dos } \\
\text { sintomas neuropsiquiátricos, } \\
\text { função de memória e } \\
\text { mobilidade funcional. }\end{array}$ & Ib \\
\hline $\begin{array}{l}\text { Souto Barreto P., } \\
\text { et al. 2017 } \\
\text { França(20) }\end{array}$ & $\begin{array}{l}\text { Total }(\mathrm{n}=98) \\
\text { Grupo experimental }(\mathrm{r} \\
48) \\
\text { Grupo de controlo }(\mathrm{n}\end{array}$ & \begin{tabular}{|l|} 
Comparar os efeitos do exercício \\
físico sobre a capacidade de \\
realizar atividades de vida diária \\
em ambiente, atividades físicas \\
e função cognitiva \\
relativamente a uma \\
intervenção não-física
\end{tabular} & $\begin{array}{l}\text { Duração do estudo: } 24 \text { semanas } \\
\text { Grupo experimental: } \\
\text { Modalidade - Exercícios combinados de } \\
\text { coordenação, equilíbrio, fortalecimento } \\
\text { muscular, exercícios aeróbicos e } \\
\text { arrefecimento }\end{array}$ & \begin{tabular}{|l} 
O estudo não demonstrou \\
diferenças estatísticas \\
significativas entre a realização \\
de exercício físico e atividades \\
recreativas. No entanto, \\
demonstrou que as pessoas que \\
praticaram exercício físico \\
\end{tabular} & Ib \\
\hline
\end{tabular}




\begin{tabular}{|c|c|c|c|c|c|}
\hline & $=50)$ & $\begin{array}{l}\text { (intervenção social) em pessoas } \\
\text { com demência a viver em lares } \\
\text { de idosos. }\end{array}$ & \begin{tabular}{|l|} 
Intensidade - moderada \\
Frequência - duas vezes por semana \\
Volume - não definido \\
Duração - 60 minutos \\
Grupo de controlo: \\
Atividades de grupo duas vezes por semana, \\
durante 60 minutos. As atividades eram novas \\
para os participantes e incluáam \\
musicoterapia e atividades de arte e ofícios.
\end{tabular} & $\begin{array}{l}\text { tiveram menos quedas que no } \\
\text { grupo de intervenção social. }\end{array}$ & \\
\hline $\begin{array}{l}\text { Menezes AV., et } \\
\text { al. 2016, } \\
\text { Brasil(21) }\end{array}$ & $\begin{array}{l}\text { Total }(n=30) \\
\text { Grupo experimental }(n= \\
15) \\
\text { Grupo de controlo }(n \\
=15)\end{array}$ & $\begin{array}{l}\text { Identificar o efeito do exercício } \\
\text { físico na cognição, mobilidade e } \\
\text { independência funcional de } \\
\text { idosos com comprometimento } \\
\text { cognitivo e demência leve } \\
\text { residentes num lar de idosos. }\end{array}$ & \begin{tabular}{|l|} 
Duração do estudo: quarto meses \\
Grupo experimental: \\
Modalidade - Alongamentos seguidos de \\
exercícios de fortalecimento muscular, \\
coordenação motora, equilíbrio e treino de \\
marcha com estimulação cognitiva \\
(musicoterapia) \\
Intensidade - pressão arterial e a frequência \\
respiratória foram aferidas no início e no fim \\
de cada sessão \\
Frequência - uma vez por semana \\
Volume - não definido \\
Duração - 60 minutos \\
Grupo de controlo: Não realizou atividade \\
física
\end{tabular} & \begin{tabular}{|l|l} 
Os resultados demonstraram & I \\
efeito positivo no equilíbrio e \\
mobilidade, no entanto não \\
demonstraram efeitos \\
significativos na cognição e na \\
independência funcional., \\
embora no grupo controlo tenha \\
havido declínio das capacidades \\
funcionais que não se refletiu no \\
grupo experimental.
\end{tabular} & Ib \\
\hline
\end{tabular}

Tabela 2: Sistematização da informação fornecida pelos artigos

\section{DISCUSSÃO}

Os estudos analisados apresentam uma variedade de resultados apurados nomeadamente: função cognitiva e memória(16,18-19); equilíbrio e risco de queda ${ }^{(15,20-21)}$; mobilidade (15-16,19,21); $\quad \operatorname{AVD}^{(15-18,21)}$ e papel do cuidador $^{(15-16,19,21)}$; apatia, agitação e depressão(19). Relativamente às modalidades, foram realizados estudos através de programas de exercícios de fortalecimento muscular ${ }^{(15,20-21)}$, exercícios aeróbicos ${ }^{(17,19-20)}$, exercícios combinados de coordenação motora e equilíbrio(20-21) ${ }^{(E x e r c i ́ c i o s ~ d e ~}$ Otago $)^{(18)}$, marcha ${ }^{(21)}$, uso de pedaleira $^{(16)}$ e bicicleta $^{(19)}$, que englobam diferentes características a nível de frequência, intensidade, volume e duração. 0 programa de Exercícios de Otago é constituído por um conjunto de exercícios de fortalecimento muscular dos membros inferiores, exercícios de equilíbrio e um plano de caminhada, são prescritos individualmente, demoram cerca de 30 minutos e são realizados três vezes por semana, contudo, a caminhada é realizada, pelo menos, duas vezes por semana, sendo que a progressão vai aumentando ao longo das sessões. ${ }^{(22)}$

A intensidade varia entre leve $\mathrm{e}^{(16,19)}$, moderada ${ }^{(20)} \mathrm{e}$ alta ${ }^{(15)}$ apesar de ser pouco explorada nos presentes artigos. Observa-se que as formas de prescrever intensidade variaram bastante, tendo sete preditores: Frequência Cardíaca Máxima (FCmáx); Consumo Máximo de Oxigénio (VO2máx); Frequência Cardíaca de Repouso (FCR); Consumo de Oxigénio de Pico (VO2pico); Limiares: L1: Limiar anaeróbio e L2: Ponto de compensação respiratória (PCR); frequência Cardíaca Pico (FCpico) e Capacidade Funcional Útil. ${ }^{(23)}$ $\mathrm{E}$ ainda, de acordo com as diretrizes do Colégio Americano de Medicina Desportiva para os testes de Esforço e sua prescrição(24) a intensidade deve ser categorizada por exercícios cardiorrespiratórios, exercícios de resistência, exercícios de flexibilidade e exercícios neuro-motores, sendo recomendado para estes últimos, dois ou três dias por semana, 20-30 minutos por dia e devem envolver as habilidades motoras nomeadamente equilíbrio, agilidade, coordenação, treino com exercícios propriocetivos e atividades multifacetadas, para melhorar as capacidades coordenativas e diminuir o risco de quedas em idosos. Preconiza atividade aeróbica de intensidade de 40 a $60 \%$ da frequência cardíaca de reserva, ou 11 a 13 na escala de Borg ${ }^{(25)}$. Refere ainda que a duração está relacionada com a intensidade do exercício, dessa forma, uma intensidade mais baixa deve ser mantida por um período maior de tempo e devido aos riscos potenciais associados a exercícios de alta intensidade, recomenda-se intensidade leve a moderada com maior duração para o adulto não atleta.

\section{Função cognitiva e memória}

Os benefícios cognitivos e de memória foram documentados noutros estudos ${ }^{(26-27)}$. Através desta revisão, a realização de exercícios com recurso a pedaleira, 3 vezes por semana durante 30 a 60 minutos $^{(16)}$, exercícios de Otago ${ }^{(18)} 3$ vezes por semana e de bicicleta estática durante 15 minutos diariamente $^{(19)}$ traduzem-se em resultados positivos nas funções cognitivas e memória. É de salientar que ao fim de 15 meses de estudo houve um declínio das capacidades cognitivas e memória no grupo onde apenas se praticou atividades recreativas ${ }^{(19)}$.

\section{Apatia, depressão e agitação}

Um dos benefícios do exercício apurado nos estudos analisados foi uma ligeira melhoria a nível da depressão(19), tendo sido conseguido este resultado através da implementação de um treino de exercícios aeróbicos em bicicleta estática durante 15 minutos diários num período de 15 meses. Por sua vez, as melhorias na apatia e agitação( ${ }^{(15)}$ foram conseguidas através de exercícios de fortalecimento muscular 
(cinco minutos de aquecimento, pelo menos dois exercícios de força para o músculo do membro inferior e dois exercícios de equilíbrio), durante 50 minutos duas vezes por semana, num período de 12 semanas.

Conforme outros estudos(28) a prática de exercício físico representa uma via no tratamento de depressão e melhoria da agitação e apatia, além de proporcionar melhorias significativas em outros parâmetros fisiológicos. Além disso, estes resultados não vão de encontro ao estudo realizado por DeVreede ${ }^{(29)}$, onde refere que parece haver uma evidência fraca ou inexistente na melhoria da apatia.

\section{Mobilidade}

A mobilidade é um fator importante no que respeita à capacidade de realizar atividades básicas de vida diária e tarefas como deambular, transferências, subir e descer escadas e vestir a parte inferior do corpo ${ }^{(30)}$.

No que respeita à mobilidade, esta foi referida como um dos benefícios do exercício físico nos estudos $^{(15,16,19,21)}$, onde houve várias modalidades utilizadas, exercícios de fortalecimento muscular ${ }^{(15,21)}$, exercício aeróbico ${ }^{(16,19)}$, coordenação motora ${ }^{(21)}$, equilíbrio ${ }^{(15,21)}$ e treino de marcha ${ }^{(21)}$. No entanto, a intensidade, frequência e duração dos exercícios foi diferente em todos os estudos pelo que não é possível estabelecer uma comparação com as diferentes modalidades de modo a perceber qual a que apresenta mais benefícios ao nível do exercício físico.

Estes resultados vão de encontro a outros estudos(31) que referem que o exercício físico é uma intervenção viável para pessoas com demência e que os benefícios superam em muito os riscos, além de evidenciar o uso de exercício físico na melhoria da mobilidade.

\section{Equilíbrio e Quedas}

De acordo com artigos analisados, as pessoas com demência têm um duplo aumento do risco de quedas em comparação com pessoas não dementes ${ }^{(32)}$. As consequências das quedas são em muitos casos prejudiciais. O medo de cair em si é um fator de risco para inatividade e pode criar um círculo vicioso ${ }^{(33)}$. Portanto, aumentar a mobilidade através de exercícios de fortalecimento muscular provoca melhorias no equilíbrio podendo potencialmente reduzir o risco de quedas $^{(34)}$.

Relativamente ao que foi verificado nos estudos que incluem esta pesquisa verifica-se que há melhoria no equilíbrio quando se implementa um programa de exercícios de fortalecimento muscular de alta intensidade e um programa combinado de coordenação motora, equilíbrio e marcha ${ }^{(15,18,20)}$. Em relação à intensidade é variável entre moderada a elevada numa frequência que varia entre 2 a 5 vezes por semana ${ }^{(15,18,20)}$ com 2 séries de 12 repetições $^{(15)}$.

É de salientar que a utilização de musicoterapia aquando da realização dos exercícios pode produzir benefícios na concretização da atividade ${ }^{(21)}$.
Num estudo de 24 semanas não houve evidência estatística de benefícios a nível motor ou cognitivo, no entanto houve uma redução significativa no número de quedas $^{(20)}$.

\section{Atividade de vida diária e Papel do cuidador}

Pessoas com demência têm níveis mais altos de dependência do que outros e têm maior probabilidade de precisar de assistência nas atividades de vida diária $(35,36)$.

O exercício leva à melhoria da capacidade de realizar atividades de vida diária em e por sua vez a melhoria da capacidade funcional. Os estudos que demonstram estes resultados recorreram à implementação de exercícios aeróbicos três a cinco vezes por semana com uma intensidade progressiva, através de uma frequência cardíaca gradualmente aumentada de 40 $55 \%$ para $60-75 \%$ da frequência cardíaca de reserva até uma duração de 150 minutos na totalidade ${ }^{(17)}$ e ao uso de pedaleira três vezes por semana ${ }^{(16)}$. Nestes estudos há uma diminuição da sobrecarga do cuidador enquanto que no grupo de controlo houve um efeito consideravelmente aumentado ${ }^{(16)}$. Alguns estudos têm demonstrado que os sintomas comportamentais na demência são uma fonte de angústia e um fardo para cuidadores familiares e profissionais e estão associados ao rápido aumento da institucionalização das pessoas com demência( ${ }^{(37)}$.

O exercício físico é de fundamental importância, pois melhora as capacidades físicas funcionais e integra novamente a pessoa nas tarefas quotidianas, o que possibilita a sua reintegração social ${ }^{(38)}$.

\section{Implicações Práticas}

O Regulamento das Competências Específicas do EEER reconhece competências para conceber, implementar, avaliar e reformular programas de treino motor e cardiorrespiratório(10). Neste sentido o EEER tem conhecimentos teóricos e práticos que lhes permitem desenvolver competências na área da prescrição do exercício físico em populações com necessidades especiais (como por exemplo pessoas com demência) e objetivos específicos.

O EEER deverá usar o exercício físico de modo a conseguir extrair os seus benefícios. Assim sendo, recomendamos a implementação de exercício aeróbico e exercícios de fortalecimento muscular em pessoas com demência, demonstrando que a melhoria da aptidão cardiorrespiratória através deste tipo de exercícios pode ser importante para a menor progressão da doença e trazer claros benefícios na melhoria da sua capacidade funcional, além de que, este tipo de exercícios oferecem uma intervenção de baixo custo, baixo risco e amplamente disponível ${ }^{(17)}$. Para tal é fundamental que o exercício físico seja incluído como recurso terapêutico e/ou profilático em planos de Enfermagem de Reabilitação em pessoas com demência. 


\section{Limitações do estudo}

Este estudo tem algumas limitações, em primeiro lugar, o acesso às bases de dados, sendo que o número limitado de estudos impediu-nos de investigar outros potenciais estudos a incluir.

Outra limitação que consideramos importante é o facto de apenas um estudo ter sido realizado no domicílio, bem como a severidade da incapacidade funcional e a sobrecarga dos cuidadores ser pouco explorada, o que não nos permite concluir de forma sustentada o benefício do exercício físico para as pessoas com demência que permanecem no domicílio e para os seus cuidadores.

Outra das limitações do refere-se ao pequeno número de estudos incluídos, à sua heterogeneidade e a ampla gama de intervenções de exercício impediram a análise do melhor exercício. Parâmetros como a modalidade e intensidade são abordados de forma superficial na maior parte dos estudos realizados, em relação ao volume apenas foi referenciado num estudo, tornando por isso difícil fazer uma interligação entre a modalidade praticada e os resultados esperados para poder orientar a prática de exercício físico com vista a alcançar determinados benefícios. Uma vez abordada esta questão, no futuro, os EEER serão capazes de estabelecer diretrizes específicas para a prescrição de exercício físico na pessoa com demência.

\section{CONCLUSÃO}

O objetivo inicial desta RSL foi atingido pois é revelada evidência dos efeitos benéficos do exercício físico sobre cognição e capacidade motora em pessoas com demência.

Assim conseguimos dar resposta à pergunta de investigação e perceber que intervenções que combinam exercícios aeróbicos, força, resistência, equilíbrio e coordenação motora são intervenções indispensáveis para produzir melhorias na saúde e bem-estar das pessoas com demência, não somente ao longo do tempo, mas também quando comparadas a outras intervenções, como atividades sociais e recreativas sedentárias.

Os estudos demonstraram melhorias significativas em áreas como cognição, agitação, humor, mobilidade e capacidade funcional. Apesar de frequência, intensidade e volume dos exercícios estudados variarem e mesmo que os parâmetros ótimos ainda não tenham sido determinados, com a análise desta revisão conclui-se que um programa de atividade física baseada em exercícios aeróbicos, como uso da pedaleira numa frequência de 3 a 5 vezes por semana, numa intensidade que vai até 60 a $75 \%$ da frequência cardíaca de reserva e com uma duração de 30 a 50 minutos pode trazer benefícios a nível do aumento da capacidade para realização das AVD. Conclui-se também que um programa de exercícios de fortalecimento muscular de intensidade alta com ênfase nos membros inferiores, com 2 séries de 12 repetições numa frequência de 2 a 5 vezes por semana pode trazer efeitos a nível do equilíbrio e coordenação motora.

Em próximos estudos deve ser instituído um plano de atividades que incluam exercícios específicos com características bem determinadas, bem como a possibilidade de serem realizados nos domicílios com a capacitação e intervenção dos cuidadores a serem tidas em consideração.

Para finalizar resta reconhecer que apesar dos inúmeros conhecimentos que já se possui, ainda permanecem dúvidas sobre o exercício físico a ser prescrito, nomeadamente qual a duração, volume e intensidade necessários, e assim extrair dele o máximo dos benefícios para as pessoas com demência. Responder a estas questões é fundamental para prescrição de exercício físico pelo EEER.

\section{REFERÊNCIAS BIBLIOGRÁFICAS}

1. Organisation for Economic Co-operation and Development [OECD]. Health at a Glance 2017: OECD Indicators, OECD Publishing, Paris; 2017. [cited 2018 Oct 26]. Available from: https://doi.org/10.1787/health_glance-2017-en.

2.Organización Mundial de la Salud. Demencia. [Web page] 2017. $\begin{array}{llll}\text { [cited } & 2018 & \text { Oct } & \text { 26]. }\end{array}$ from:http: //www.who.int/es/news-room/factsheets/detail/dementia

3. Davis DH, Creavin ST, Yip JL, Noel-Storr AH, Brayne C, Cullum S. Montreal Cognitive Assessment for the diagnosis of Alzheimer's disease and other dementias. Cochrane Database. Syst Rev [Internet]. 2015 Oct 29 [cited 2018 Oct 26];(10). Available from: http://doi.wiley.com/10.1002/14651858.CD010775.pub2

4. Beydoun MA, Beydoun HA, Gamaldo AA, Teel A, Zonderman AB, Wang Y. Epidemiologic studies of modifiable factors associated with cognition and dementia: systematic review and metaanalysis. BMC Public Health [Internet]. 2014 Jun;14(1):643. Available from: https://doi.org/10.1186/1471-2458-14-643

5. Bahar-Fuchs A, Clare L, Woods B. Cognitive training and cognitive rehabilitation for persons with mild to moderate dementia of the Alzheimer's or vascular type: a review. Alzheimers Res Ther [Internet]. 2013;5(4):35. Available from: https://doi.org/10.1186/alzrt189

6. Direção Geral da Saúde. Dia Mundial da Doença de Alzheimer. Lisboa: Direção Geral da Saúde. 2015. [Web page] 2018. [cited 2018 Oct 26] Available fromhttps://www.dgs.pt/emdestaque/dia-mundial-da-doenca-de-alzheimer-21-desetembro.aspx

7. Groot C, Hooghiemstra AM, Raijmakers PGHM, van Berckel BNM, Scheltens P, Scherder EJA, et al. The effect of physical activity on cognitive function in patients with dementia: A meta-analysis of randomized control trials. Ageing Res Rev [Internet]. 2016;25:13-23. Available from: https://doi.org/10.1016/j.arr.2015.11.005

8. Farina N, Rusted J, Tabet N. The effect of exercise interventions on cognitive outcome in Alzheimer's disease: a systematic review. International Psychogeriatrics. Cambridge University Press; 2014;26(1):9-18. Available from: https://doi.org/10.1017/S1041610213001385

9. Antunes HKM, Santos-Galduroz RF, De Aquino Lemos V, Bueno OFA, Rzezak P, de Santana MG, et al. The influence of physical exercise and leisure activity on neuropsychological functioning in older adults. Age (Omaha) [Internet]. 2015 Jul;37(4):71. Available from: https://doi.org/10.1007/s11357-015-9815-8

10. Regulamento das Competências Comuns do Enfermeiro Especialista Lisboa: Ordem dos Enfermeiros, Diário da República, 2. ${ }^{a}$ série-N. ${ }^{\circ}$ 35-18 de Fevereiro.

11.Sousa LMM, Firmino CF, Marques-Vieira CMA, Severino S, Pestana HCFC. Revisões da literatura científica: tipos, métodos e aplicações em enfermagem. Rev Port Enferm Reabil. 2018; 1(1): 46-55. 
http: //www.aper.pt/ficheiros/revista/rpern0.pdf

12. Joanna Briggs Institute. User manual: Version 5.0 system for the unified management, assessment and review of information. Recuperado de http: / /joannabriggs. org/assets/docs/sumari/SUMARI-V5-User-guide. pdf[Links]. 2012

13. Registered Nurses'Association of Ontario. Falls prevention: building the foundations for the patient safety. A self-learning package. Toronto: Registered Nurses' Association of Ontario. 2007 Available in: http://rnao.ca/sites/rnaoca/files/Falls_Prevention_-

_Building_the_Foundations_for_Patient_Safety._A_Self_Learning _Package.pdf

14. Preferred Reporting Items for Systematic Review and MetaAnalyses (PRISMA). Welcome to the Preferred Reporting Items for Systematic Reviews and Meta-Analyses (PRISMA). 2015. Available from: http: / /www.prisma-statement.org/

15.Telenius EW, Engedal K, Bergland A. Long-term effects of a 12 weeks high-intensity functional exercise program on physical function and mental health in nursing home residents with dementia: a single blinded randomized controlled trial. BMC Geriatr [Internet]. 2015[cited 2018 Nov 24];15(1):158. Available from: https: //doi.org/10.1186/s12877-015-0151-8

16. Holthoff VA, Marschner K, Scharf M, Steding J, Meyer S, Koch R, et al. Effects of physical activity training in patients with Alzheimer's dementia: results of a pilot RCT study. Plos One [Internet]. 2015 Apr 17 [cited 2018 Nov 24];10(4):e0121478.

17. Morris JK, Vidoni ED, Johnson DK, Van Sciver A, Mahnken JD, Honea RA, et al. Aerobic exercise for Alzheimer's disease: A randomized controlled pilot trial. Scholey A, editor. PLoS One [Internet]. 2017 Feb 10 [cited 2018 Nov 24];12(2):e0170547. Available

https://dx.plos.org/10.1371/journal.pone.0170547

18. Lee HJ, Don Kim K. Effect of physical activity on cognition and daily living activities of the elderly with mild dementia. J Phys Ther Sci [Internet]. 2018;30(3):428-33. Available from: https://www.jstage.jst.go.jp/article/jpts/30/3/30_jpts-2017$551 /$ article

19. Cancela JM, Ayán C, Varela S, Seijo M. Effects of a long-term aerobic exercise intervention on institutionalized patients with dementia. J Sci Med Sport [Internet]. 2016 Apr 1 [cited 2018 Nov 24];19(4):293-8. Available from: https://doi.org/10.1016/j.jsams.2015.05.007

20. de Souto Barreto P, Cesari M, Denormandie P, Armaingaud D, Vellas B, Rolland $Y$. Exercise or social intervention for nursing home residents with dementia: a pilot randomized, controlled trial. J Am Geriatr Soc. 2017 Sep [cited 2018 Nov 24];65(9):E123-9. Available from: https://doi.org/10.1111/jgs.14947

21. Menezes AV, Aguiar A da S de, Alves EF, et al. Efetividade de uma intervenção fisioterapêutica cognitivo-motora em idosos institucionalizados com comprometimento cognitivo leve e demência leve. Cien Saude Colet [Internet]. 2016 Nov [cited 2018 Nov 24];21(11):3459-67. Available from: http: / / www.scielo.br/scielo.php?script=sci_arttext\&pid=S14138 1232016001103459\&lng=pt\&tlng=pt

22. Thomas S, Mackintosh S, Halbert J. Does the "Otago exercise programme" reduce mortality and falls in older adults? A systematic review and meta-analysis. Age Ageing. 2010;39(6):168-7.

23. Araújo PA, Guimarães SN, de Sousa Guidarini FC. Exercício físico com tratamento não farmacológico das doenças cardiovasculares: Qual a intensidade ideal?. Revista Brasileira de Prescrição e Fisiologia do Exercício (RBPFEX). 2014;8(44):11

24. American College of Sports Medicine. Diretrizes de ACSM para os testes de esforço e sua prescrição. Rio de Janeiro: Guanabara Koogan; 2018

25. Williams N. The Borg Rating of Perceived Exertion (RPE) scale. Occup Med [Internet]. 2017 Jul 1;67(5):404-5. Available from: http://dx.doi.org/10.1093/occmed/kqx063

26. Phillips VL, Diwan S. The incremental effect of dementia-related problem behaviors on the time to nursing home placement in poor, frail, demented older people. J. am. geriatr. soc. 2003 Feb;51(2):188-93.

27. Selbæk G, Engedal K. Stability of the factor structure of the Neuropsychiatric Inventory in a 31-month follow-up study of a large sample of nursing-home patients with dementia. Int Psychogeriatrics [Internet]. 2012 Jan 20 [cited 2018 Nov 24];24(01):62-73. Available from: http://www.journals.cambridge.org/abstract_S10416102110008 6X

28. Batista JI, de Oliveira A. Efeitos psicofisiológicos do exercício físico em pacientes com transtornos de ansiedade e depressão. Rev Corpoconsciência. 2016 Oct 6;19(3):1-0

29. de Vreede PL, Samson MM, van Meeteren NLU, Duursma SA, Verhaar HJJ. Functional-task exercise versus resistance strength exercise to improve daily function in older women: a randomized, controlled trial. J Am Geriatr Soc.[Internet]. 2005;53(1):2-10. Available from: https: / /doi.org/10.1111/j.1532-5415.2005.53003.x

30. Stubbs B, Patchay S, Soundy A, Schofield P. The Avoidance of Activities due to Fear of Falling Contributes to Sedentary Behavior among Community-Dwelling Older Adults with Chronic Musculoskeletal Pain: A Multisite Observational Study. Pain Med [Internet]. 2014 Nov 1;15(11):1861-71. Available from: http://dx.doi.org/10.1111/pme.12570

31. Lam FM, Huang M-Z, Liao L-R, Chung RC, Kwok TC, Pang MY. Physical exercise improves strength, balance, mobility, and endurance in people with cognitive impairment and dementia: a systematic review. J Physiother [Internet]. 2018 Jan 1 [cited 2018 Nov 28];64(1):4-15. Available from: https: / /doi.org/10.1016/j.jphys.2017.12.001

32. Blankevoort CG, Van Heuvelen MJ, Boersma F, Luning H, De Jong $J$, Scherder EJ. Review of effects of physical activity on strength, balance, mobility and ADL performance in elderly subjects with dementia. Dement. geriatr. cogn. disord. [Internet]. 2010;30(5):392-402.Available from: https://doi.org/10.1159/000321357

33. Jensen J, Nyberg L, Gustafson Y, Lundin-Olsson L. Fall and injury prevention in residential care-effects in residents with higher and lower levels of cognition. J. am. geriatr. soc. [Internet]. 2003 May;51(5):627-35. Available from: https: / /doi.org/10.1034/j.1600-0579.2003.00206.x

34. Selbaek G, Engedal K, Bergh S. The prevalence and course of neuropsychiatric symptoms in nursing home patients with dementia: a systematic review. J Am Med Dir Assoc. [Internet]. 2013 Mar 1;14(3):161-9. Available from: https://doi.org/10.1016/j.jamda.2012.09.027

35. Helvik AS, Engedal K, Benth JŠ, Selbæk G. A 52 month follow-up of functional decline in nursing home residents-degree of dementia contributes. BMC Geriatr [Internet]. 2014;14(1):45. Available from: https://doi.org/10.1186/1471-2318-14-45

36. Bennett HP, Corbett AJ, Gaden S, Grayson DA, Kril JJ, Broe GA. Subcortical vascular disease and functional decline: A 6-year predictor study. J Am Geriatr Soc. 2002 Dec;50(12):1969-77.

37. Brodaty H, McGilchrist C, Harris L, KE P. Time until institutionalization and death in patients with dementia: Role of caregiver training and risk factors. Arch Neurol [Internet]. 1993 Jun 1;50(6):643-50. Available from: http://dx.doi.org/10.1001/archneur.1993.00540060073021

38. Paulo TR, Castellano SM, Santos WL, Campos DR, Campos LA. O exercício físico funcional para idosos institucionalizados: um novo olhar para as atividades da vida diária. Estud. interdiscip. envelhec. 2012:413-27. 


\title{
EXERCíCIO FÍSICO NA PESSOA COM DEPRESSÃO: REVISÃO SISTEMÁTICA DA LITERATURA
}

\section{EJERCICIO FÍ́IICO EN LA PERSONA CON TRASTORNO DEPRESIVO: REVISIÓN SISTEMÁTICA DE LA LITERATURA}

\section{PHYSICAL EXERCISE IN THE PERSON WITH DEPRESSIVE DISORDER: A SYSTEMATIC REVIEW OF THE LITERATURE}

\author{
DOI 10.33194/rper.2019.v2.n1.05.4565 | Submetido 07.03.2019 | Aprovado 24.06.2019
}

Inês de Jesus Rocha ${ }^{1}$; (i) Carla Alexandra Fundevila de Barros ${ }^{2}$; (i⿱ Ana Maria Pinto Mateus ${ }^{1}$; Rosa Cristina Rodrigues Correia ${ }^{2}$; (1) Helena Castelão Figueira Carlos Pestana ${ }^{3}$; (i) Luís Manuel Mota de Sousa

1 - Centro Hospitalar Universitário Lisboa Central Hospital Curry Cabral, Portugal; 2 - Centro Hospitalar Lisboa Norte, Hospital Santa Maria, Lisboa, Portugal; 3- . Escola Superior de saúde Atlântica, Barcarena, Portugal; 4 - Universidade de Évora, Escola Superior de Enfermagem S. João de Deus, Évora, Portugal

\section{RESUMO}

Introdução: A depressão é das formas mais comuns de distúrbio mental e uma das maiores causas de problemas de saúde da atualidade. Tem surgido a necessidade de aliar ao tratamento farmacológico, tratamentos adjuvantes tais como a psicoterapia e a prática de exercício físico, no tratamento deste transtorno.

Objetivo: identificar quais os benefícios do exercício físico na pessoa com depressão.

Método: Revisão Sistemática da Literatura, que utiliza as recomendações do Joanna Briggs Institute na estratégia PICO e as recomendações PRISMA, foi formulada a questão de pesquisa "quais os benefícios do exercício físico na pessoa com transtorno depressivo?" A pesquisa foi realizada com recurso a plataformas de bases de dados eletrónicas EBSCOhost e B-on.

Resultados: Foram incluídos nove estudos que cumpriam os critérios de inclusão, e onde se descreveram e analisaram o tipo, frequência, volume e duração de cada modalidade de exercício físico praticado em cada um dos estudos.

Conclusões: Os resultados obtidos permitem concluir que independentemente da frequência, duração e intensidade da prática de exercício físico no transtorno depressivo, esta diminui os sintomas depressivos, melhorando também a forma física, função cognitiva e bem-estar da pessoa com transtorno depressivo.

Descritores: Transtorno depressivo; treino de exercício; atividade física; Enfermagem em Reabilitação.

\section{RESUMEN}

Introducción: El trastorno depresivo es una de las formas más comunes de trastorno mental y una de las mayores causas de problemas de salud en la actualidad. Ha surgido la necesidad de aliar al tratamiento farmacológico, tratamientos adyuvantes tales como la psicoterapia y la práctica de ejercicio físico en este trastorno.

Objetivo: Identificar cuales son los beneficios del ejercicio físico en una persona con un trastorno depresivo.

Método: Revisión sistemática de la literatura, que utiliza las recomendaciones de Joanna Briggs Institute con la estrategia PICO y las recomendaciones PRISMA, se formuló la cuestión de investigación "¿cuáles son los beneficios del ejercicio físico en una persona con trastorno depresivo?" La búsqueda se realizó con recursos a plataformas de bases de datos electrónicas EBSCOhost y B-on.

Resultados: Se incluyeron nueve estudios que cumplían los criterios de inclusión, y donde se describieron y analizaron el tipo, frecuencia y duración del ejercicio físico practicado en cada uno de los estudios.

Conclusiones: Los resultados obtenidos permiten concluir que independientemente de la frecuencia, duración, volumen e intensidad de la práctica de ejercicio físico en el tratamiento depresivo, ésta disminuye los síntomas depresivos, mejorando también la forma física, función cognitiva y el bienestar de la persona con trastorno depresivo.

Palabras clave: Trastorno depresivo; entrenamiento de ejercicio; actividad física; Enfermería en Rehabilitación.

\section{ABSTRACT}

Background: Depressive disorder is one of the most common forms of mental disorder and one of the greatest causes of health problems nowadays. There has been a need to combine the pharmacological approach with adjuvant treatment such as psychoterapy and physical exercise in the treatment of this disorder.

Objective: To identify the benefits of physical exercise in the person with depressive disorder. 
Method: Systematic Review of Literature that was based on the recommendations of the Joanna Briggs Institute on PICO strategy and based on PRISMA, the research question raised was "What are the benefits of physical exercise in people with Depressive Disorder?". The research was carried out using the electronic database platforms: EBSCOHost and B-on.

Results: A sample of nine studies were included that fulfilled the eligibility and methodological quality criteria, where the type, volume, frequency and duration of the physical exercise practiced in each of the studies were described and analyzed.

Conclusions: The results obtained allow us to conclude that regardless of the frequency, duration and intensity of physical exercise in depressive disorder, this decreases the depressive symptoms, improving also the physical fitness, the cognitive function and the well-being of the person with this disorder.

Key words: exercise training, physical activity, depressive disorder. rehabilitation nursing

\section{INTRODUÇÃO}

A depressão é considerada um transtorno mental que se caracteriza pela manifestação de uma a duas vezes por semana de episódios depressivos. Estes episódios expressam-se pela perda de interesse e prazer nas atividades de vida diárias (AVD). A alteração do humor persistente associada a sintomas emocionais, cognitivos e comportamentais traduz-se em perda de autoestima, sentimentos de culpa e de incapacidade ${ }^{(1)}$.

A depressão é uma doença prevalente ao longo da vida que atinge 10 a $20 \%$ da população em diferentes países, sendo a maior responsável pela incapacidade causada por transtornos mentais e por uso de substâncias (cerca de 40,5\% do total de anos de vida ajustados por incapacidade) ${ }^{(2)}$.

As pessoas com depressão, em muitos casos, apresentam co-morbilidades associadas, fazendo aumentar o impacto negativo na qualidade de vida das mesmas, não só nas atividades sociais e nas AVD, mas também no aumento de hospitalizações e na mortalidade ${ }^{(3)}$.

De forma a contrariar os sintomas depressivos existe uma crescente necessidade de encontrar estratégias e terapias que possibilitam a diminuição destes sintomas. Neste sentido, a utilização de terapias não medicamentosas, como o exercício físico pode ter um efeito positivo na diminuição dos sintomas depressivos. Este é bem tolerado por pessoas com transtorno depressivo, com boa adesão, mas tem de ser administrado, prescrito, gerido, efetuado e/ou realizado por profissionais de saúde com formação específica em prescrição de exercícios ${ }^{(4)}$. Entende-se por exercício físico os movimentos corporais planeados, organizados e repetidos de forma a manter ou melhorar uma ou mais componentes da aptidão física. ${ }^{(5)}$ Existem evidências de que o exercício físico é coadjuvante do tratamento do transtorno depressivo major, apresentando efeitos benéficos nas pessoas ${ }^{(6)}$. Assim, com a revisão sistemática da literatura (RSL), pretende-se encontrar resposta para a seguinte questão: quais os benefícios do exercício físico na pessoa com depressão?

Deste modo, pretende-se identificar quais os benefícios do exercício físico na pessoa com depressão.

\section{MATERIAL E MÉTODOS}

Uma revisão da literatura tem como intuito a sistematização dos estudos da prática clínica dos cuidados de saúde, podendo ser expressa de várias formas. A RSL é definida como um método de investigação focado numa questão claramente formulada, que através de métodos sistemáticos, explícitos e reproduzíveis permite identificar, avaliar e sintetizar os estudos com evidências relevantes. Esta é realizada por investigadores, académicos e profissionais de saúde e permite ainda colher e analisar os dados dos estudos que são incluídos na revisão. $^{(7)}$

Para o presente estudo, foi realizada uma RSL a publicações a nível mundial entre janeiro de 2014 e novembro de 2018.

Consideraram-se as recomendações do Joanna Briggs Institute $(\mathrm{JBI})$, das quais resultou a questão de investigação a partir da estratégia $\mathrm{PICO},{ }^{(8-10)}$ formulouse a questão de pesquisa “ Quais os benefícios $(0)$ do exercício físico (I) na pessoa com transtorno depressivo $(\mathrm{P})$ em comparação com o grupo controlo (C)?" onde cada dimensão do PICO contribuiu para definir os critérios de inclusão: População $(P)$ - Pessoas com transtorno depressivo; Intervenção (I) - exercício físico, e Comparação $(C)$ - pessoas com depressão que não realizem exercício físico em comparação com um grupo de pessoas com transtorno depressivo que são sujeitas a terapia complementar, exercício físico, e Resultados (0) - benefícios do exercício físico nas pessoas com transtorno depressivo.

Os descritores relacionados com cada uma das componentes da estratégia PICO foram validados previamente na plataforma Descritores em Ciências da Saúde e Medical Subject Headings. Foram utilizadas ainda as seguintes Palavras-chave: exercise training, physical activity, depressive disorder.

Definiram-se como critérios de inclusão dos artigos:(Tabela1) estudos quantitativos, publicados nos últimos 4 anos (2014-2018), em português inglês e espanhol, com texto integral acessível. 


\begin{tabular}{|l|l|}
\hline \multicolumn{1}{|c|}{ Critérios de inclusão } & Critérios de exclusão \\
\hline $\begin{array}{l}\text { Pessoa com síndroma } \\
\text { Depressivo } \\
\text { simplesmente) } \\
\text { depressão. }\end{array} \quad \begin{array}{r}\text { com } \\
\text { Estudos experimentais }\end{array}$ & $\begin{array}{l}\text { Outros } \\
\text { quantitativos, estudos } \\
\text { qualitativos estudos } \\
\text { sistemática da literatura. }\end{array}$ \\
\hline $\begin{array}{l}\text { Estudos publicados entre } \\
\text { 2014 e 2018, inclusive. }\end{array}$ & $\begin{array}{l}\text { Estudos publicados } \\
\text { anteriores a 2014 }\end{array}$ \\
\hline $\begin{array}{l}\text { Estudos publicados em } \\
\text { português, inglês e } \\
\text { espanhol. }\end{array}$ & \\
\hline
\end{tabular}

Tabela 1- Critérios de inclusão e de exclusão.

A pesquisa foi efetuada por quatro pessoas em simultâneo, no período compreendido entre Outubro e Novembro de 2018, sendo que para a mesma foram utilizadas as seguintes bases de dados: EBSCOHost e biblioteca on-line B-on.

Os artigos selecionados para leitura completa foram avaliados por dois investigadores de forma independente, de acordo com critérios de qualidade metodológica, propostos pelo JBI, (8) tendo sido selecionados apenas os artigos com mais de $75 \%$ dos critérios.

Foi extraída informação dos artigos sobre autores, ano, país, amostra, dados sobre a intervenção (frequência, intensidade, volume, duração $e$ modalidade), conclusões e nível de evidência. A classificação dos níveis de evidência dos estudos incluídos foi feita com base nos critérios da Registered Nurses Association of Ontario ${ }^{(9,11)}$

\section{RESULTADOS}

Do processo de pesquisa bibliográfica realizada com esta metodologia, na plataforma EBSCOhost obtivemos 1138 artigos para a seleção inicial. Após inserção dos critérios de inclusão foram encontrados 156 artigos. Destes, 117 foram rejeitados pelo título ou pelo assunto e 33 pelo resumo. Dos 6 artigos resultantes foram todos excluídos após análise do texto integral, por não cumprirem os critérios de inclusão definidos.

Replicando-se a mesma metodologia na plataforma Bon foram encontrados 1967 artigos dos quais, 702 artigos foram selecionados após a inserção dos critérios de inclusão. Destes, 658 foram rejeitados pelo título ou pelo assunto e 31 pelo resumo. Dos 13 resultantes, 4 foram excluídos após a leitura integral do texto, dado não cumprirem os critérios de inclusão definidos. Como resultado final obtiveram-se 9 artigos que preenchem os critérios de inclusão.

A Tabela 2 descreve o processo de conjugação dos descritores e palavras-chave para a pesquisa nas bases de dados. A Figura 1 ilustra o fluxograma PRISMA ${ }^{(12)}$ correspondente à identificação, análise, seleção e inclusão dos artigos.

\begin{tabular}{|l|l|l|}
\hline Conjugação Boleana & EBSCO & B-on \\
\hline $\begin{array}{l}\text { ((exercise training) } \\
\text { activity)) OR (physical } \\
\text { disorder) }\end{array}$ (depressive & & \\
\hline Total de Artigos & 1138 & 1967 \\
\hline
\end{tabular}

Tabela 2 - Conjugação Boleana

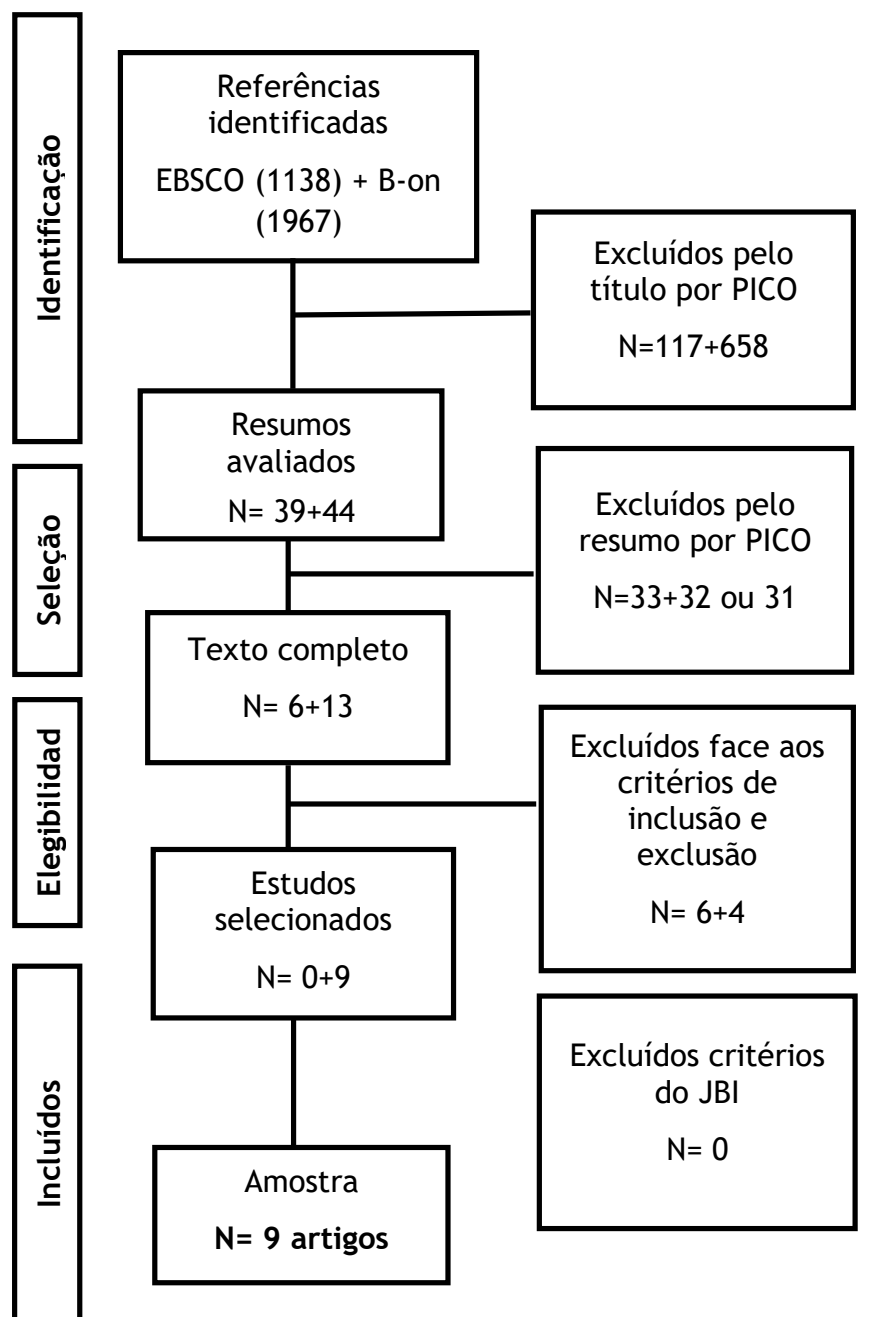

Figura 1 - Identificação, análise e seleção dos artigos.(12)

Resumindo, foram incluídos 9 artigos nesta RSL que foram publicados nos anos de 2015 a 2018.

A amostra de pessoas/participantes, no diferentes estudos, variou entre $14{ }^{(17)}$ e $310 . .^{(21)}$ e relativamente ao grupo de controlo o número de participantes variou entre seis ${ }^{(17)}$ e $310^{(21)}$. Todos os estudos incluídos (Tabela 2) são estudos descritivos, com nível de evidência IB, ou seja, evidência obtida a partir de um estudo bem desenhado, e de pelo menos um estudo aleatório controlado ${ }^{(10-11)}$ (Tabela 3). 


\begin{tabular}{|c|c|c|c|c|c|}
\hline $\begin{array}{c}\text { Autor, ano, } \\
\text { país }\end{array}$ & Participantes & Objetivo & Intervenção & Resultados & $\begin{array}{l}\text { Nível de } \\
\text { Evidência }\end{array}$ \\
\hline $\begin{array}{l}\text { Minghetti, A. et al., } \\
\text { 2018, Suíça } \\
\text { (13) }\end{array}$ & $\begin{array}{l}\text { Total }(n=59) \\
\text { Grupo intervenção }(n= \\
29) \\
(n=21 \text { mulheres } \\
n=8 \text { homens }) \\
\text { Grupo controlo ( } n \\
=30) \\
(n=25 \text { mulheres; } \\
n=6 \text { homens })\end{array}$ & \begin{tabular}{|l|} 
Avaliar o benefício do sprint \\
interval training em \\
pessoas com depressão em \\
comparando com a prática \\
contínua de exercício físico \\
aeróbico
\end{tabular} & $\begin{array}{l}\text { Duração do estudo: } 4 \text { semanas } \\
\text { Grupo de Intervenção: } \\
\text { Modalidade - Treino intervalado de Sprints em } \\
\text { bicicleta } \\
\text { Frequência - } 3 \text { sessões/ semana } \\
\text { Intensidade - Alta } \\
\text { Duração - sprint } 25 \text { ataques de } 30 \text { segundos } \\
\text { Volume - } 2 \text { séries e } 4-6 \text { repetições } \\
\text { Grupo de controlo: } \\
\text { Modalidade -Exercício aeróbico } \\
\text { Frequência - } 3 \text { sessões/ semana } \\
\text { Intensidade - Moderada } \\
\text { Duração - } 20 \text { min }\end{array}$ & 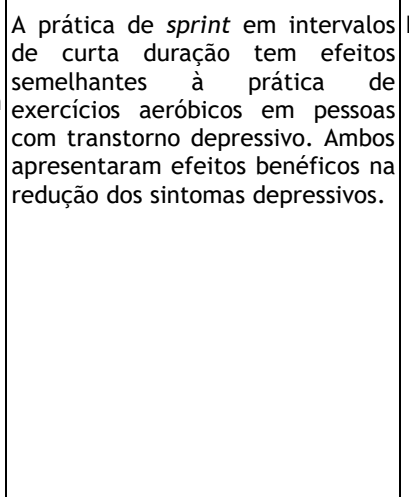 & IB \\
\hline $\begin{array}{l}\text { Kerling et al., 2017, } \\
\text { Alemanha }^{(14)}\end{array}$ & $\begin{array}{l}\text { Total }(\mathrm{n}=30) \\
\text { Grupo intervenção }(\mathrm{n}= \\
20) \\
(\mathrm{n}=8 \text { mulheres; } \\
\mathrm{n}=12 \text { homens }) \\
\\
\text { Grupo controlo }(\mathrm{n} \\
=10) \\
(\mathrm{n}=4 \text { mulheres; } \\
\mathrm{n}=6 \text { homens })\end{array}$ & $\begin{array}{l}\text { Avaliar os efeitos da prática } \\
\text { de exercício físico aeróbico } \\
\text { na massa muscular em } \\
\text { pessoas com depressão. }\end{array}$ & $\begin{array}{l}\text { Duração do estudo: } 6 \text { semanas } \\
\text { Grupo Intervenção: } \\
\text { Modalidade - Exercícios aeróbicos e de } \\
\text { resistência } \\
\text { Frequência - } 3 \text { sessões/ semana } \\
\text { Intensidade - Moderada } \\
\text { Duração - } 45 \text { minutos (25 minutos de Bicicleta } \\
\text { e } 20 \text { minutos de máquina de resistência) } \\
\text { Grupo de controlo: } \\
\text { Modalidade - Caminhadas, jogos com bolas e } \\
\text { exercícios de alongamentos } \\
\text { Frequência - } 3 \text { sessões/ semana } \\
\text { Intensidade - Baixa } \\
\text { Duração - } 20 \text { minutos }\end{array}$ & $\begin{array}{l}\text { Verificou-se um ligeiro aumento } \\
\text { de massa muscular no grupo de } \\
\text { intervenção enquanto que no } \\
\text { grupo de controlo se verificou um } \\
\text { ligeiro decréscimo da massa } \\
\text { muscular. }\end{array}$ & IB \\
\hline $\begin{array}{l}\text { Kerling et al., 2015, } \\
\text { Alemanha }^{(15)}\end{array}$ & $\begin{array}{l}\text { Total }(\mathrm{n}=42) \\
\text { Grupo intervenção } \\
(\mathrm{n}=22) \\
(\mathrm{n}=10 \text { mulheres; } \\
\mathrm{n}=12 \text { homens }) \\
\text { Grupo de controlo } \\
(\mathrm{n}=20) \\
(\mathrm{n}=6 \text { mulheres; } \\
\mathrm{n}=14 \text { homens })\end{array}$ & 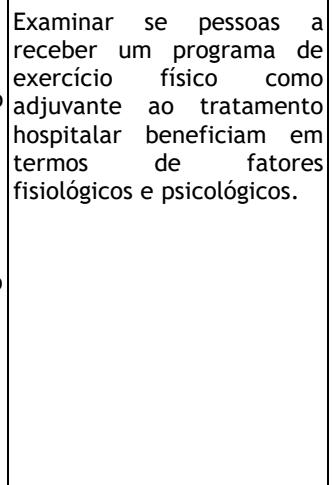 & $\begin{array}{l}\text { Duração do estudo: } 6 \text { semanas } \\
\text { Grupo intervenção: } \\
\text { Modalidade - Bicicleta estática } \\
\text { Frequência - } 3 \text { sessões/ semana } \\
\text { Intensidade - Moderada } \\
\text { Duração - } 45 \text { minutos } \\
\text { Grupo de controlo: } \\
\text { Modalidade - Caminhadas, jogos de bola e } \\
\text { alongamentos } \\
\text { Frequência - } 3 \text { sessões/ semana } \\
\text { Intensidade - de atividade física de moderada } \\
\text { intensidade } \\
\text { Duração_20 minutos }\end{array}$ & $\mid \begin{array}{l}\text { Em pessoas com transtorno } \\
\text { depressivo, a prática de exercício } \\
\text { físico como tratamento adjuvante, } \\
\text { melhora a aptidão físical } \\
\text { funcional e psicológica. } \\
\text { Quando o transtorno depressivo e } \\
\text { as desordens cardiometabólicas } \\
\text { estão presentes, a prática de } \\
\text { exercício físico e recomendada } \\
\text { como terapia adjuvante. }\end{array}$ & IB \\
\hline $\begin{array}{l}\text { Olson R.L., et al., } \\
\text { 2015, EUA(16) }\end{array}$ & $\begin{array}{l}\text { Total }(\mathrm{n}=30) \\
\text { Grupo } \\
\text { intervenção( } \mathrm{n}=15) \\
(\mathrm{n}=11 \text { mulheres; } \\
\mathrm{n}=4 \text { homens) } \\
\\
\text { Grupo controlo }(\mathrm{n}=15) \\
(\mathrm{n}=13 \text { mulheres; } \\
\mathrm{n}=2 \text { homens })\end{array}$ & $\begin{array}{l}\text { Avaliar o efeito do exercício } \\
\text { aeróbico de } \\
\text { intensidade moderada } \\
\text { controlo cognitivo, sintomas } \\
\text { depressivos e } \\
\text { ruminativos. }\end{array}$ & $\begin{array}{l}\text { Duração do Estudo: } 8 \text { semanas } \\
\text { Grupo de Intervenção: } \\
\text { Modalidades - Exercícios aeróbicos } \\
\text { (passadeira ou bicicleta estática) } \\
\text { Volume - Ausente, exercício contínuo } \\
\text { Frequência - } 3 \text { sessões/ semana } \\
\text { Intensidade - Moderada } \\
\text { Duração: - } 45 \text { minutos de exercício contínuos } \\
\text { Grupo de controlo: } \\
\text { Modalidades - Exercícios de alongamentos } \\
\text { Volume - } 3 \text { séries (alongamentos de } 20 \\
\text { segundos, com um período de descanso de } 40 \\
\text { segundos entre os alongamentos) } \\
\text { Frequência - } 3 \text { sessões/ semana } \\
\text { Intensidade - Leve } \\
\text { Duração - } 30-40 \text { minutos/ semana }\end{array}$ & 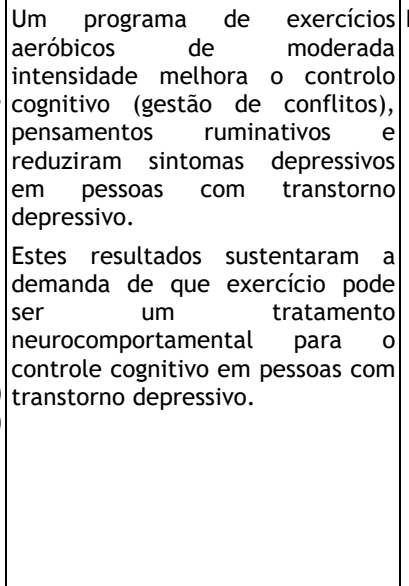 & IB \\
\hline $\begin{array}{l}\text { Haller et al., 2018, } \\
\text { Alemanha(17) }\end{array}$ & $\begin{array}{l}\text { Total }(\mathrm{n}=20) \\
\text { Grupo intervenção } \\
(\mathrm{n}=14) \\
(\mathrm{n}=10 \text { mulheres } \\
\mathrm{n}=4 \text { homens }) \\
\\
\text { Grupo controlo }(\mathrm{n}=6) \\
(\mathrm{n}=3 \text { homens } \\
\mathrm{n}=3 \text { mulheres })\end{array}$ & 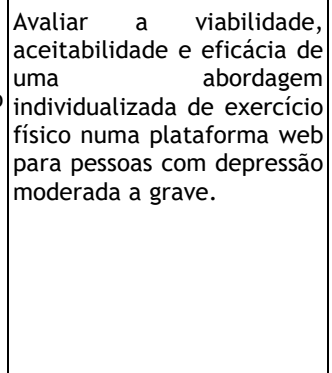 & $\begin{array}{l}\text { Duração do estudo: } 8 \text { semanas } \\
\text { Grupo de Intervenção } \\
\text { Modalidade - Resistência (através de bandas) } \\
\text { e força (corrida em passadeira) } \\
\text { Volume - } 3 \text { séries (12 repetições) } \\
\text { Frequência - } 1 \text { a } 2 \text { x por semana } \\
\text { Intensidade - Moderado Borg }<4 \text { (reduzir se } \\
\text { Borg > 7) } \\
\text { Duração - 0-60 minutos } \\
\text { Grupo de controlo }\end{array}$ & 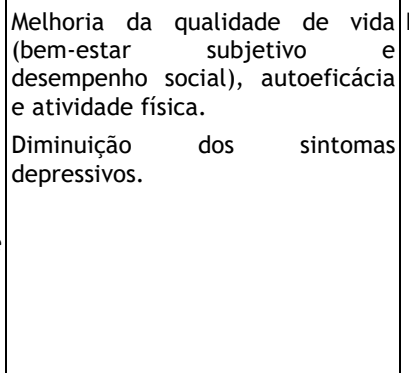 & IB \\
\hline
\end{tabular}




\begin{tabular}{|c|c|c|c|c|c|}
\hline & & & $\begin{array}{l}\text { Modalidade - resistência (através de bandas) } \\
\text { e força (corrida em passadeira) } \\
\text { Volume - } 3 \text { séries (12 repetições) } \\
\text { Frequência - } 1 \text { a } 2 \text { sessões / semana } \\
\text { Intensidade - Moderado Borg < } 4 \text { (reduzir se } \\
\text { Borg > 7) } \\
\text { Duração - 10-20 minutos }\end{array}$ & & \\
\hline $\begin{array}{l}\text { Carneiro LS, et al., } \\
2015, \text { Portugal }(18)\end{array}$ & 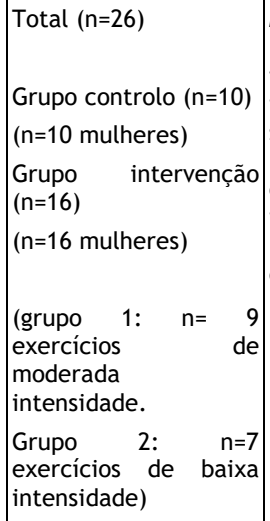 & $\begin{array}{l}\text { Medir o efeito de um } \\
\text { programa de exercícios } \\
\text { físicos estruturados es e } \\
\text { individualizado, } \\
\text { supervisionado por um } \\
\text { professor de educação física } \\
\text { como complemento à } \\
\text { terapêutica antidepressiva } \\
\text { no tratamento de mulheres } \\
\text { com transtorno depressivo. }\end{array}$ & $\begin{array}{l}\text { Duração do Estudo: } 16 \text { semanas } \\
\text { Grupo de Intervenção: } \\
\text { Modalidade - o exercício aeróbico (jogos } \\
\text { tradicionais, exercícios de circuito natural } \\
\text { indoor /outdoor com bandas de resistência, } \\
\text { cordas para saltar, bolas de fitness, dança e } \\
\text { Teste de caminhada rápida - } 6 \text { minutos). } \\
\text { Frequência - } 3 \text { sessões/ semana } \\
\text { Intensidade - Grupo 1: moderada } \\
\text { Grupo 2: baixa (Escala de Borg) } \\
\text { Duração - } 45-50 \text { minutos/ semana (10 minutos } \\
\text { de aquecimento, } 30 \text { minutos de exercício } \\
\text { aeróbico e } 5 \text { minutos de alongamentos) } \\
\text { Grupo de Controlo: Grupo a realizar apenas } \\
\text { terapêutica farmacológica antidepressiva. }\end{array}$ & 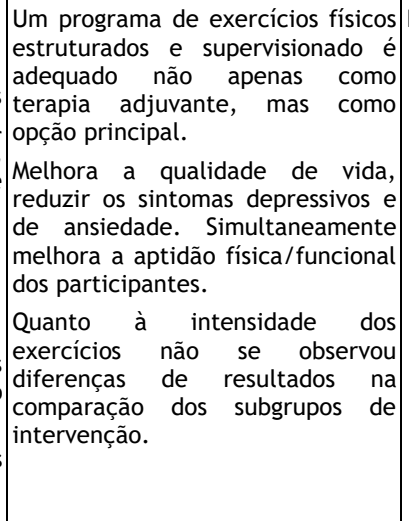 & \\
\hline $\begin{array}{l}\text { Pentecost, C., et } \\
\text { al., } \\
\text { Inglaterra(19) }\end{array}$ & $\begin{array}{l}\text { Total }(\mathrm{n}=60) \\
\begin{array}{l}\text { Grupo } \\
(\mathrm{n}=30) \\
(\mathrm{n}=12 \text { mulheres; } \mathrm{n}=18 \\
\text { homens) }\end{array} \\
\begin{array}{l}\text { Grupo controlo } \quad(\mathrm{n} \\
=30) \\
(\mathrm{n}=17 \text { mulheres; } \mathrm{n}=13 \\
\text { homens) }\end{array}\end{array}$ & \begin{tabular}{|lrrr} 
Comparar & um & grupo & de \\
pessoas & submetido a & um \\
programa & de & auto-ajuda \\
baseado & na & ativação \\
comportamental & sob \\
supervisão & de & um \\
Profissional & de & Bem-Estar \\
Psicológico & com & um & grupo \\
de pessoas & submetido & ao \\
mesmo programa & de auto- \\
ajuda & combinada & com & a \\
atividade física. & &
\end{tabular} & $\begin{array}{l}\text { Duração do Estudo: } 12 \text { semanas } \\
\text { Grupo de Intervenção: } \\
\text { Modalidade - Programa de auto-ajuda } \\
\text { (manual, sessões de avaliação com os } \\
\text { profissionais de Bem-Estar Psicológico e } \\
\text { ensinos de capacitação de auto- } \\
\text { determinação) associado com atividades } \\
\text { monitorizadas por podómetro, } \\
\text { Frequência - } 1 \text { sessão/ semana } \\
\text { Intensidade - Leve } \\
\text { Duração - Sessões de avaliação e } \\
\text { acompanhamento de } 25 \text { a } 35 \text { minutos } \\
\text { Grupo de Controlo: } \\
\text { Modalidade - manual de autoajuda } \\
\text { associado a um conjunto de intervenções de } \\
\text { terapia comportamental de baixa intensidade } \\
\text { cognitiva. } \\
\text { Frequência - } 1 \text { sessão/ semana } \\
\text { Intensidade - Baixa intensidade } \\
\text { cognitiva. } \\
\text { Duração - sessões de avaliação e } \\
\text { acompanhamento de } 25 \text { a } 35 \text { minutos }\end{array}$ & 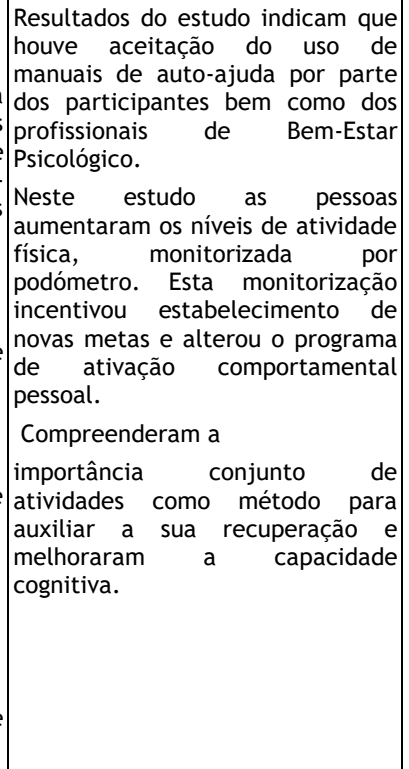 & AB \\
\hline $\begin{array}{l}\text { Ólafsdóttir, } \\
\text { et } \quad \text { K. B., } \\
\text { Islândia (20) }\end{array}$ & $\mid \begin{array}{l}\text { Total }(\mathrm{n}=15) \\
(\mathrm{n}=12 \text { mulheres; } \mathrm{n}=3 \\
\text { homens }) \\
\text { Grupo intervenção; } \\
\text { (n=15) } \\
\text { Grupo } \quad \text { controlo: } \\
(\mathrm{n}=15) \quad \\
\\
0 \text { estudo foi realizado } \\
\text { em dois períodos com } \\
0 \quad \text { mesmo grupo de } \\
\text { participantes }\end{array}$ & $\begin{array}{l}\text { Conhecer os efeitos do } \\
\text { exercício físico num grupo } \\
\text { de pessoas com transtorno } \\
\text { depressivo e ansiedade, em } \\
\text { comparação com o mesmo } \\
\text { grupo de pessoas } \\
\text { submetidos apenas a } \\
\text { Terapia de Grupo } \\
\text { Comportamental Cognitivo } \\
\text { Transdiagnóstico. }\end{array}$ & $\begin{array}{l}\text { Duração do Estudo: De } 5 \text { a } 8 \text { semanas } \\
\text { Grupo de Intervenção: } \\
\text { Modalidade - Exercícios aeróbicos } \\
\text { Frequência - } 3 \text { sessões/ semana } \\
\text { Intensidade - Moderada } \\
\text { Duração - } 60 \text { minutos } \\
\text { Grupo de Controlo: Terapia de Grupo } \\
\text { Modalidade - To To } \\
\text { Comportamental Cognitivo Transdiagnóstico } \\
\text { Frequência - } 1 \text { sessão/semana } \\
\text { Duração - } 120 \text { minutos (grupo da terapia } \\
\text { comportamental) }\end{array}$ & $\begin{array}{l}0 \text { exercício físico apresenta } \\
\text { efeitos benéficos na redução dos } \\
\text { sintomas depressivos em pessoas } \\
\text { com transtorno depressivo e } \\
\text { ansiedade. } \\
0 \text { grupo quando submetido a } \\
\text { exercício físico apresentou } \\
\text { resultados um pouco melhor que } \\
\text { quando submetido a Terapia de } \\
\text { Grupo Comportamental Cognitivo } \\
\text { Transdiagnóstico. }\end{array}$ & S \\
\hline $\begin{array}{l}\text { Helgadóttir B., } \\
\text { et al.,(21) } \\
2016, \\
\text { Suécia. }\end{array}$ & 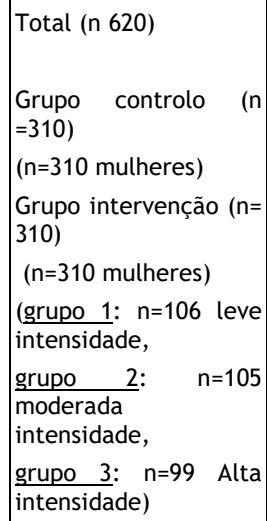 & 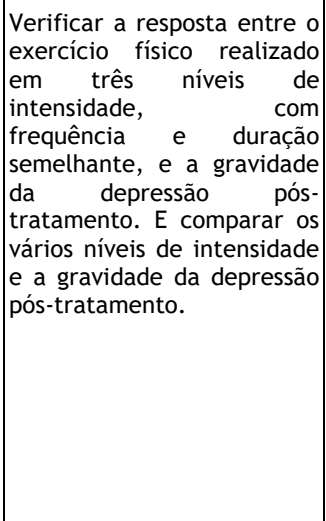 & $\begin{array}{l}\text { Duração do Estudo: } 12 \text { Semanas } \\
\text { Grupo de Intervenção: } \\
\text { Modalidade - Yoga, Mindfulness (grupo 1), } \\
\text { aulas de aeróbica (grupo 2), exercícios } \\
\text { vigorosos (grupo 3) } \\
\text { Frequência - 3 sessões/ semana } \\
\text { Intensidade - Grupo } 1 \text { - Leve, Grupo } 2 \\
\text { Moderada, Grupo 3- Alta } \\
\text { Duração - } 55 \text { minutos } \\
\text { Grupo controlo: } \\
\text { Modalidade - Grupo a realizar apenas } \\
\text { tratamento Usual dos distúrbios depressivos } \\
\text { (TAU) }\end{array}$ & 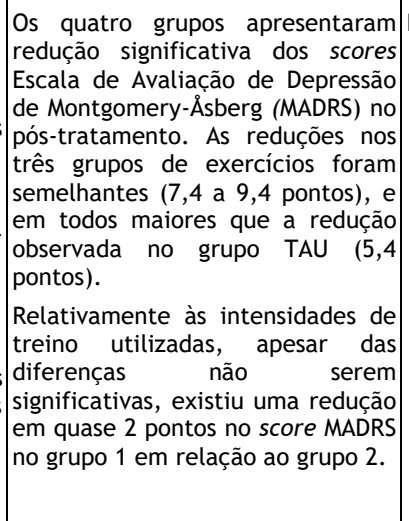 & 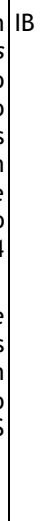 \\
\hline
\end{tabular}




\section{DISCUSSÃO}

De forma a compreender os benefícios do exercício físico na pessoa com transtorno depressivo, analisámos diferentes estudos onde se encontraram uma variedade de estratégias como a utilização do exercício físico e/ou as terapias cognitivocomportamentais para a diminuição dos sintomas depressivos $^{(13-21)}$.

Através das pesquisas dos diferentes estudos conseguiu-se verificar algumas semelhanças nas intervenções utilizadas pelos vários autores, estes utilizaram parâmetros como a modalidade, intensidade, frequência, volume e duração dos diversos tipos de exercícios.

Perante a diversidade de exercícios apresentados pelos autores, agrupou-se os mesmos de acordo com a intensidade associada. Conseguimos verificar que o estudo de Minghetti e colaboradores ${ }^{(13)}$, comparando dois grupos de pessoas, em que um deles praticava treino de sprint intervalado (exercício de alta intensidade) e o outro exercício físico aeróbico contínuo (exercício de moderada intensidade), constatou benefícios semelhantes de ambas as práticas de exercício físico no tratamento dos transtornos depressivos. Deste modo, não ficou claro se o exercício físico de alta intensidade trouxe mais valias em relação ao exercício de moderada intensidade.

Esta mesma linha de pensamento foi encontrada por Helgadóttir e colaboradores ${ }^{(21)}$ que ao compararem os diferentes tipos de intensidades da prática de exercício físico não encontraram diferenças significativas entre os mesmos. No entanto, verificouse que no grupo de exercício físico intensidade leve (yoga) houve uma redução em quase 2 pontos no score MADRS (Escala de Avaliação de Depressão de Montgomery-Åsberg) em comparação com o grupo de exercício físico moderado/aeróbico.

Olson e colaboradores (16), vão de encontro ao já descrito, uma vez que também estes autores concluíram, que a prática de exercício de intensidade leve permite a obtenção de melhorias ao nível cognitivo e na diminuição dos sintomas depressivos.

Já Shuch e colaboradores ${ }^{(2)}$ referem no seu estudo que os exercícios de intensidade moderada a intensa apresentaram melhores resultados, contudo realçam o facto da amostra do estudo ser pequena, sendo de difícil extrapolação.

Mas perante o exposto, nenhum dos artigos conseguiu apresentar vantagens quando a duração dos exercícios. As intensidades dos exercícios variaram entre leve e moderada, verificando-se uma variação na duração entre os 20-60 minutos ${ }^{(16-18,20)}$, à exceção do exercício de alta intensidade ${ }^{(13)}$ que foi realizado em sessões de 25 repetições de com a duração de 30 segundos (seguidos de 30 segundos de descanso total).

Relativamente à frequência dos exercícios variou entre uma a três vezes por semana durante um período compreendido entre quatro a dezasseis semanas. ${ }^{(13-21)}$

Constatou-se que o exercício físico realizado com maior frequência ${ }^{(16,18,21)}$ permitiu obter melhorias mais evidentes do que aqueles que apenas realizaram uma a duas vezes ${ }^{(17,19)}$.

Quando se fala sobre o impacto do exercício físico em pessoas com transtorno depressivo a realizar terapêutica farmacológica comparado com pessoas com transtorno depressivo que fizeram terapia ao nível comportamental,(21) verificou-se que de acordo com a escala de MADRS (Escala de Avaliação de Depressão de Montgomery-Åsberg) as reduções dos scores nos três grupos de exercícios físicos foram semelhantes, e em todos os três foram maiores do que a redução observada na terapêutica farmacológica. $\mathrm{Na}$ mesma perspetiva, Carneiro e colaboradores $^{(18)}$, verificaram que 0 grupo de pessoas a realizar terapêutica farmacológica aliada ao exercício físico teve uma melhoria na qualidade de vida e uma redução dos sintomas depressivos e de ansiedade, melhorando ainda a aptidão física.

Pentecost e colaboradores ${ }^{(19)}$, referem que a utilização de manuais de autoajuda na terapia de ativação comportamental com incentivo ao exercício físico facilitou a adesão ao tratamento do mesmo e mostrouse uma opção a considerar no tratamento dos sintomas depressivos.

Por sua vez Ólafsdóttir e colaboradores ${ }^{(20)}$, concluíram que o exercício físico pode ser uma alternativa altamente recomendada, em detrimento do grupo comportamental cognitivo transdiagnóstico. Já Minghetti e colaboradores ${ }^{(13)}$, verificaram que a associação destes, trazia melhorias significativas para a diminuição dos sintomas da depressão. Ou seja, aliar um programa de exercício físico à terapêutica antidepressiva e terapia cognitiva comportamental (15), resultava numa melhoria da capacidade cardiovascular e na redução dos fatores de risco metabólicos.

$\mathrm{Na}$ mesma linha de raciocínio Helgadóttir e colaboradores ${ }^{(21)}$, também verificaram que o exercício físico, ajudava a prevenir desordens somáticas, tal como doenças cardio e cerebrovasculares e doenças metabólicas. Knapen e colaboradores ${ }^{(1)}$ sugerem que ocorre uma melhoria ao nível metabólico. Para além da melhoria da saúde física, ocorreu uma melhoria ao nível da imagem corporal, das estratégias de coping em lidar com o stress, consequentemente melhoria na qualidade de vida e a independência nas atividades da vida diária em idosos com depressão.

Sendo a perda de massa muscular uma consequência do transtorno depressivo, o Kerling e colaboradores ${ }^{(14)}$, concluíram que prática de exercício físico aeróbico regular (treino de resistência) é eficaz na preservação da massa nas pessoas com depressão. No entanto, os autores referiram serem necessários mais estudos para comprovar uma melhoria concreta neste campo.

Knapen e colaboradores ${ }^{(1)}$ revelam ainda que a implementação de estratégias motivacionais nos 
planos de exercícios parecem melhorar a motivação das pessoas com depressão, bem como a sua adesão a longo prazo ao exercício.

Shuch e colaboradores(2), afirmam ainda que os resultados na melhoria de sintomas de depressão com recurso ao exercício físico são mais evidentes quando não existem outras co-morbilidades associadas e quando os exercícios foram supervisionados por profissionais qualificados.

Noutros estudos ainda foi possível constatar a evidência do exercício físico na redução de sintomas depressivos. Tu e colaboradores (3) concluíram que em pessoas com insuficiência cardíaca estável com depressão, o exercício físico (exercícios aeróbicos e de força) foi benéfico na melhoria dos sintomas depressivos e ainda tem efeitos positivos na autoestima e na interação social.

Kerling e colaboradores (6) revelam que o exercício físico tem impacto positivo ao nível das concentrações séricas do neurotransmissor no cérebro. Uma avaliação dos níveis dos neurotransmissores antes e depois de um treino estruturado e supervisionado em pessoas com depressão major, demonstou resultados benéficos pelo que deve ser considerado o exercício físico como tratamento adjuvante.

Todos estes estudos realçam a importância dos programas de exercício físico a serem supervisionados por profissionais com formação relevante pois parece que as taxas de abandono das intervenções diminuem quando ministradas por estes profissionais (professor de educação física, profissionais de saúde, instrutores).

\section{Implicações Práticas}

De um modo geral todos os estudos incluídos referem que o exercício físico é benéfico e que promove uma melhoria na qualidade de vida das pessoas com depressão e sob terapêutica farmacológica. (13-21)

Mais do que submeter a pessoa com depressão a um plano de exercícios físico rígido, deve-se mantê-la ativa. Os estudos evidenciaram que independentemente da modalidade, frequência e/ou intensidade utilizadas, a pessoa necessita de estar motivada. Para tal, é essencial que a escolha do exercício físico e ou atividade física seja realizada de acordo com os gostos pessoais já que aumenta o interesse e a motivação para a prática do mesmo.

Perante tais resultados, e sabendo que a pessoa com depressão evidencia graus de ansiedade e desmotivação variáveis, é importante que estes planos de exercício físíco sejam realizados por profissionais de saúde qualificados, uma vez que permite um acompanhamento e manutenção do plano de exercícios. Deste modo existe um seguimento mais personalizado da pessoa e sempre que necessário um ajuste no plano de exercício para assim obter melhores resultados.
As limitações encontradas prendem-se pela heterogeneidade dos artigos, nomeadamente a existência de artigos que comparam grupos de pessoas com depressão major e grupo de pessoas com depressão e ansiedade. Outros, por sua vez, fazem comparações entre grupos que apenas realizam terapia farmacológica versus grupos que fazem terapia farmacológica e realizam exercício físico ${ }^{(15)}$. E ainda outros estudos comparam grupos submetidos a terapias comportamentais (terapia de grupo comportamental cognitiva(16,20) e terapia de ativação comportamental) ${ }^{(19)}$ versus grupos a realizar exercício físico.

Deparámo-nos ainda com a heterogeneidade dos grupos relativamente ao género. Existe um predomínio do género feminino(13,16-18,20-21) nos estudos apresentados o que provoca um enviesamento para replicação dos estudos para a população com depressão.

O número reduzido de pessoas na amostra ${ }^{(14,16-18,20)}$ foi também uma limitação apresentada por alguns dos autores. Bem como a dificuldade de monitorização das pessoas na execução e cumprimento das intervenções propostas pelo estudo.

É consensual entre os estudos que o exercício físico é benéfico, no entanto, com base nos pontos referidos anteriormente, a variedade dos exercícios foi de tal modo extensa que não nos permitiu obter conclusões específicas do benefício que cada exercício por si só teve na melhoria dos sintomas depressivos. Não foi possível estabelecer uma comparação direta entre estudos, no que toca aos exercícios físicos específicos usados, uma vez que a seleção das atividades consoante o grau de intensidade era divergente entre os estudos, o que inviabilizou uma conclusão específica para a seleção de determinado tipo de exercício em detrimento de outro.

\section{CONCLUSÃO}

Após a RSL, podemos concluir que existe uma melhoria da qualidade de vida, melhoria cognitiva, e diminuição dos sintomas depressivos aquando da prática de um plano de treino de exercícios de intensidade leve a moderada com supervisão de profissionais de saúde no tratamento do transtorno depressivo.

Os estudos incluídos recomendam que a pessoa com depressão e sob terapêutica farmacológica, deverá manter-se fisicamente ativa independentemente do tipo, frequência ou intensidade do exercício físico praticado. Além disso, a motivação, bem como, a preferência da atividade física a praticar pela pessoa com depressão deverá ser tida em conta em detrimento de um plano estruturado e rígido, obtendo assim melhores resultados.

Por último, o objetivo do tratamento da depressão não se deverá limitar apenas à remissão dos sintomas depressivos, mas focarem-se na recuperação funcional, participação social e melhoria da saúde física da pessoa. 
Considerando os resultados obtidos desta RSL, assim como as suas limitações, parece-nos fundamental continuar com a investigação neste campo de conhecimento, uma vez que o exercício físico é uma estratégia promissora e que deverá ser incluída como opção de tratamento de pessoas com depressão. E por último, definir de forma objetiva as intervenções e selecionar os instrumentos de avaliação que permitam medir o nível de efetividade e ainda, verificar a transferibilidade destas intervenções noutros contextos.

\section{REFERÊNCIAS BIBLIOGRÁFICAS}

1. Knapen J, Vancampfort D, Moriën Y, Marchal Y. Exercise therapy improves both mental and physical health in patients with major depression. Disabil Rehabil.. 2015 Jul $31 ; 37(16): 1490-5$. Acessivel em: https://doi.org/10.3109/09638288.2014.972579

2. Schuch FB, Vancampfort D, Richards J, Rosenbaum S, Ward PB, Stubbs B. Exercise as a treatment for depression: a metaanalysis adjusting for publication bias. J Psychiatr. Res. 2016 Jun 1;77:42-51. Acessível em: https://doi.org/10.1016/j.jpsychires.2016.02.023

3. Tu RH, Zeng ZY, Zhong GQ, Wu WF, Lu YJ, Bo ZD, He Y, Huang WQ, Yao LM. Effects of exercise training on depression in patients with heart failure: a systematic review and meta-analysis of randomized controlled trials. Eur J Heart Fail.. 2014 Jul;16(7):749-57. Acessível em: https: / /doi.org/10.1002/ejhf.101

4. Stubbs B, Vancampfort D, Rosenbaum S, Ward PB, Richards J, Soundy A, Veronese N, Solmi M, Schuch FB. Dropout from exercise randomized controlled trials among people with depression: a meta-analysis and meta regression. J Affect Disord.. 2016 Jan 15;190:457-66. Acessível em: https://doi.org/10.1016/j.jad.2015.10.019

5. Santa-Clara H, Pinto I, Santos V, Pinto R, Melo X, Almeida JP, Pimenta N, Abreu A, Mendes M. Atividade física e exercício físico: especificidades no doente cardíaco. Rev Factores de Risco. 2015, 35:28-35.

6. Kerling A, Kück M, Tegtbur U, Grams L, Weber-Spickschen S, Hanke A, Stubbs B, Kahl KG. Exercise increases serum brainderived neurotrophic factor in patients with major depressive disorder. J Affect Disord.. 2017 Jun 1;215:152-5. Acessível em: https://doi.org/10.1016/j.jad.2017.03.034

7. Sousa LMM, Firmino CF, Marques-Vieira CMA, Severino $S$, Pestana HCFC. Revisões da literatura científica: tipos, métodos e aplicações em enfermagem. Rev Port Enferm Reabil. 2018; 1(1): 46-55. Acessível em: http://www.aper.pt/ficheiros/revista/rpern0.pdf.

8. The Joanna Briggs Institute (AT). Joanna Briggs Institute's user manual: version 5.0 system for the unified management. Assessment and Review of Information. Adelaide: Joanna Briggs Institute; $2011 \quad$ Acessível em: http://joannabriggs.org/assets/docs/sumari/SUMARI-V5-Userguide.pdf

9. Sousa LM, Marques JM, Firmino CF, Frade F, Valentim OS, Antunes AV. Modelos de formulação da questão de investigação na Prática Baseada na Evidência. Rev Inv. Enferm. 2018; S2(23): 31-39. Acessível em: http://hdl.handle.net/20.500.12253/1287

10. Sousa, LMM, Vieira, CMA, Severino, SS, Antunes, AV. A metodologia de Revisão Integrativa da Literatura em Enfermagem. Rev Inv. Enferm. 2017; S2(21): 17-26. Acessível em: http: / /hdl.handle.net/20.500.12253/1311

11. Registered Nurses' Association of Ontario (CA). Falls Prevention: Building the Foundations for Patient Safety. A Self Learning Package. Toronto, Canada: Registered Nurses' Association of Ontario; 2007. Acessivel em: https://rnao.ca/bpg/guidelines/resources/falls-preventionbuilding-foundations-patient-safety-selflearning-package

12. Moher D, Liberati A, Tetzlaff J, Altman DG, The PRISMA Group. Preferred Reporting Items for Systematic Reviews and Meta-
Analyses: The PRISMA Statement.PLoS Med. 2009; 6(7): https: //doi.org/10.1371/journal.pmed1000097.

13. Minghetti A, Faude O, Hanssen H, Zahner L, Gerber M, Donath L. Sprint interval training (SIT) substantially reduces depressive symptoms in major depressive disorder (MDD): A randomized controlled trial. Psychiatry Res. 2018 Jul 1; 265:292-7. Acessível em: https://doi.org/10.1016/j.psychres.2018.04.053

14. Kerling A, Hartung D, Stubbs B, Kück M, Tegtbur U, Grams L, Weber-Spickschen TS, Kahl KG. Impact of aerobic exercise on muscle mass in patients with major depressive disorder: a randomized controlled trial. Neuropsychiatr Dis Treat.. 2018; 14:1969. Acessivel em: https://doi.org/ 10.2147/NDT.S167786

15. Kerling A, Tegtbur U, Gützlaff E, Kück M, Borchert L, Ates Z, Frieling $H$, Hüper K, Hartung D, Schweiger U, Kahl KG. Effects of adjunctive exercise on physiological and psychological parameters in depression: a randomized pilot trial. J Affect Disord. 2015 May; 177:1-6. Acessível em: https://doi.org/10.1016/j.jad.2015.01.006

16. Olson RL, Brush CJ, Ehmann PJ, Alderman BL. A randomized trial of aerobic exercise on cognitive control in major depression. Clin Neurophysiol. 2017 Jun;128(6):903. Acessível em: https: //doi.org/ 10.1016/j.clinph.2017.01.023

17. Haller N, Lorenz S, Pfirrmann D, Koch C, Lieb K, Dettweiler U, Simon $P$, Jung $P$. Individualized Web-Based Exercise for the Treatment of Depression: Randomized Controlled Trial. JMIR mental health. 2018;5(4):e10698. Acessivel em: https: / /doi.org/ 10.2196/10698

18. Carneiro LS, Fonseca AM, Vieira-Coelho MA, Mota MP, Vasconcelos-Raposo J. Effects of structured exercise and pharmacotherapy vs. pharmacotherapy for adults with depressive symptoms: a randomized clinical trial. J Psychiatr Res. 2015 Dec 1;71:48-55. Acessivel em: https://doi.org/ 10.1016/j.jpsychires.2015.09.007

19. Pentecost C, Farrand P, Greaves CJ, Taylor RS, Warren FC, Hillsdon M, Green C, Welsman JR, Rayson K, Evans PH, Taylor AH. Combining behavioural activation with physical activity promotion for adults with depression: findings of a parallelgroup pilot randomised controlled trial (BAcPAc). Trials. 2015 Dec 1;16(1):367. Acessível em: https://doi.org/ 10.1186/s13063-015-0881-0

20. Ólafsdóttir KB, Kristjánsdóttir $H$, Saavedra JM. Effects of exercise on depression and anxiety. A comparison to transdiagnostic cognitive behavioral therapy. Community Ment Health J. 2018 Aug 1;54(6):855-9. Acessível em: https://doi.org/ 10.1007/s10597-017-0213-9

21. Helgadóttir B, Hallgren M, Ekblom Ö, Forsell Y. Training fast or slow? Exercise for depression: a randomized controlled trial. Prev Med. 2016 Oct 1; 91:123-31. Acessível em: https://doi.org/10.1016/j.ypmed.2016.08.011 
FUNCIONALIDADE DE PESSOAS SUBMETIDAS A ARTOPLASTIA TOTAL DO OMBRO POR FRATURAS DO ÚMERO PROXIMAL: ESTUDO RETROSPETIVO

FUNCIONALIDAD DE PERSONAS SOMETIDAS A ARTROPLASTIA TOTAL DEL HOMBRO POR FRACTURAS DEL HÚMERO PROXIMAL: ESTUDIO RETROSPETIVO

FUNCTIONALITY OF PERSONS SUBMITTED TO TOTAL SHOULDER ARTHROPLASTY BY PROXIMAL HUMERUS FRACTURES: RETROSPECTIVE STUDY

DOI 10.33194/rper.2019.v2.n1.06.4558 | Submetido 21.02.2019 | Aprovado 27.06.2019

\author{
Carolina Tiago Afonso우 \\ (i) André $\mathrm{Novo}^{2} ;$ Afonso Salgado Ruano ${ }^{1}$ \\ 1 - Unidade Local de Saúde do Nordeste; 2 - Escola Superior de Saúde do Instituto Politécnico de Bragança; NurseID - CINTESIS
}

\title{
RESUMO
}

Objetivo: Identificar retrospetivamente, em pessoas submetidas a artroplastia total do ombro por fraturas do úmero proximal, o tipo de artroplastia utilizado, os scores funcionais do ombro, as complicações registadas, a influência do tempo decorrido desde a fratura e a colocação do implante no resultado funcional final.

Método: Estudo retrospetivo entre os anos 2014 e 2017. Foram identificadas as seguintes variáveis: idade, sexo, tempo entre a fratura e a cirurgia, tipo de artroplastia, cimentação, modularidade, reabilitação, complicações, tempo de seguimento e funcionalidade. Foram recolhidos dados dos instrumentos Constant Shoulder Score e American Shoulder and Elbow Surgeons Standardized Shoulder Assessment Form.

Resultados: Amostra constituída por 12 mulheres e 3 homens com idade média de 78 anos e um tempo médio entre a fratura e a cirurgia de 29,4 dias. A nível de funcionalidade observou-se que as pessoas com próteses inversas apresentaram melhores resultados em comparação com as submetidas a hemiartroplastia $(53,2$ vs. 41,1 e 68,5 vs. 44,6). 0 seguimento foi feito durante foi de 29,4 meses.

Conclusão: A escolha de prótese inversa parece ser a melhor opção de tratamento e que permite melhor funcionalidade. A modularidade protésica é importante.

Descritores: Fraturas do úmero; Intervenção Cirúrgica; Procedimentos Ortopédicos; Artroplastia do ombro; Reabilitação

\section{RESUMEN}

Objetivo: Identificar retrospectivamente, en personas sometidas a artroplastia total del hombro por fracturas del húmero proximal, el tipo de artroplastia utilizado, la puntuación funcional del hombro, las complicaciones registradas, la influencia del tiempo transcurrido desde la fractura y la colocación del implante en el resultado funcional final.

Método: estudio retrospectivo entre 2014 y 2017. Se identificaron las siguientes variables: edad, sexo, tiempo entre fractura y cirugía, tipo de artroplastia, cementación, modularidad, rehabilitación, complicaciones, tiempo de seguimiento y funcionalidad. Fueron recogidos datos de los instrumentos Constant Shoulder Score y American Shoulder and Elbow Surgeons Standardized Shoulder Assessment Form.

Resultados: Muestra compuesta por 12 mujeres y 3 hombres con una edad media de 78 años y un tiempo medio entre la fractura y la cirugía de 29,4 días. En términos de funcionalidad, se observó que las personas con próstesis inversa presentaran mejores resultados en comparación con las sometidas a hemiartroplastia $(53,2$ vs. 41,1 y 68,5 vs. 44,6). El seguimiento se realizó durante 29,4 meses.

Conclusión: La prótesis inversa parece ser la mejor opción de tratamiento y que permite una mejor funcionalidad. La modularidad protésica es importante.

Descriptores: Fracturas humerales; Procedimientos quirúrgicos; Procedimientos ortopédicos; Artroplastia total del hombro; Rehabilitación

\section{ABSTRACT}

Objective: To retrospectively identify, in people submitted to total shoulder arthroplasty for proximal humeral fractures, the type of arthroplasty used, the functional shoulder scores, the recorded complications, the influence of the elapsed time from the fracture and the placement of the implant in the final functional outcome. 
Method: Retrospective study between 2014 and 2017. The following variables were identified: age, sex, time between fracture and surgery, type of arthroplasty, cementation, modularity, rehabilitation, complications, followup time and functionality. Data from the scales Constant Shoulder Score and American Shoulder and Elbow Surgeons Standardized Shoulder Assessment Form were obtained.

Results: Sample comprised of 12 women and 3 men with mean age of 78 years and a mean time between fracture and surgery of 29.4 days. In terms of functionality, it was observed that persons with inverse prosthesis presented better results compared to the ones submitted to hemiarthroplasty (53.2 vs. 41.1 and 68.5 vs. 44.6$)$. The follow-up was done during 29.4 months.

Conclusion: The reverse prosthesis seems to be the best treatment option and allows better functionality. Prosthetic modularity is important.

Keywords: Humeral fractures; Surgical Procedures; Orthopedic Procedures; Total shoulder replacement; Rehabilitation

\section{INTRODUÇÃO}

As fraturas do úmero proximal (FUP) são as terceiras fraturas mais frequentes, apenas suplantadas pelas fraturas da anca e rádio distal ${ }^{(1)}$. Têm uma incidência de 4-6\%, afetando mais as mulheres. Ocorrem maioritariamente por traumatismos de baixa energia e em idosos ${ }^{(2)}$.

O tipo de tratamento a instituir depende de fatores como a idade do doente, da sua demanda funcional, dominância, comorbilidades, do tipo de fratura e da sua classificação(3)

Apesar de na sua maioria as FUP serem tratadas conservadoramente, estima-se que até $20 \%$ destas necessitem de tratamento cirúrgico. Pelo envelhecimento da população, o número de FUP pode aumentar e consequentemente a percentagem que necessitem de uma intervenção cirúrgica também ${ }^{(4)}$.

O tratamento das FUP do tipo 3 ou 4 partes de Neer, é um desafio. Inicialmente, a hemiartroplastia $(\mathrm{HA})$ era recomendada como 0 tratamento ideal, pela dificuldade da redução fechada e risco de necrose avascular da cabeça umeral( ${ }^{(5)}$. Também foi recomendada para fraturas com componente "headsplit"(6).

No entanto, as FUP complexas com atingimento das tuberosidades são tecnicamente exigentes de tratar e o seu mau posicionamento correlaciona-se com piores resultados funcionais, se a opção for a $\mathrm{HA}^{(7)}$.

Atualmente, a artroplastia total inversa do ombro (ATIO) tem vindo a mostrar-se efetiva no tratamento de fraturas 3 ou 4 partes de Neer, em doentes idosos e com artropatia da coifa dos rotadores ${ }^{(8-11)}$, com bons resultados funcionais ${ }^{(12-14)}$, sendo que estes últimos dependem menos do posicionamento das tuberosidades do que na $\mathrm{HA}^{(15)}$.

O aumento progressivo no número destes casos tratados com artroplastias pode acarretar a longo prazo complicações que necessitam de um cirurgião com habilidades técnicas para as resolver. A cirurgia de revisão de uma HA ou ATIO também acarreta resultados funcionais menos previsíveis e com maiores taxas de complicações ${ }^{(16-18)}$.

Entre as complicações descritas salienta-se a descelagem asséptica ou séptica, a instabilidade, o desgaste do componente glenoideu e a incompetência/rotura da coifa dos rotadores ${ }^{(19-21)}$.

O desenvolvimento de implantes modulares permite uma maior facilidade em cirurgias de revisão, com possibilidade de preservação do componente umeral e conversão de uma HA para uma $\mathrm{ATIO}^{(22)}$. O tempo decorrido entre a fratura e a cirurgia é considerado um fator que afeta o resultado final nas HA.

Este estudo tem como objetivo identificar retrospetivamente, em pessoas submetidas a artroplastia total do ombro por fraturas do úmero proximal, o tipo de artroplastia utilizado, os scores funcionais do ombro, as complicações registadas, a influência do tempo decorrido desde a fratura e a colocação do implante no resultado funcional final.

\section{MÉTODO}

Estudo retrospetivo de consulta dos processos clínicos em que foram incluídos os doentes submetidos a HA e ATIO por FUP, no período de 1 de janeiro de 2014 e 31 de março de 2017, num Serviço de Ortopedia e Traumatologia.

Foram consultados os processos clínicos eletrónicos, tendo sido registadas as características demográficas (idade e sexo), tipo de FUP (classificação de Neer), tempo decorrido entre o diagnóstico da fratura e a cirurgia inicial para HA ou ATIO, necessidade de cimentação e modularidade protésica, necessidade de revisão, complicações, tempo de seguimento e participação em programa de reabilitação habitual.

Os resultados funcionais de cada doente foram recolhidos de dois instrumentos aplicados previamente:

- Constant Shoulder Score (CSS)(23), adaptado para Portugal(24), é uma escala de 100 pontos que se encontra dividido em quatro subescalas - dor, atividades de vida diária, força e amplitude articular.

- American Shoulder and Elbow Surgeons Standardized Shoulder Assessment Form (ASES) ${ }^{(25)}$, versão Portuguesa ${ }^{(25)}$, encontra-se dividida em duas secções, uma clínica e outra autoadministrada. Esta segunda secção apresenta uma escala de 100 pontos que consiste em duas dimensões, uma subescala de dor 
que vale 50 pontos e dez itens de atividades de vida diária que valem os restantes 50 pontos.

Foram cumpridos os procedimentos éticos e deontológicos e salvaguardados os superiores interesses dos doentes, nomeadamente 0 seu anonimato.

A análise estatística descritiva e inferencial dos dados foi feita através do software IBM SPSS statistics, versão 23. Os resultados são apresentados em valor absoluto e em percentagem quando se justifica facilitar a sua interpretação. Os valores de média são apresentados seguidos do desvio padrão (média \pm desvio padrão). Para a análise inferencial foi utilizado o teste não paramétrico Mann-Whitney U para comparar os grupos operados precocemente e tardiamente e os grupos submetidos a HA vs. ATIO. $O$ valor de $p$ assumido para este estudo foi de $p \leq 0,05$.

\section{RESULTADOS}

No tempo abrangido pelo nosso estudo foram realizadas 15 artroplastias do ombro por FUP em 12 mulheres e 3 homens. A idade média da amostra foi de 78 anos (Tabela 1).
Registámos 6 casos de FUP 2 partes de Neer, 2 casos de FUP de 3 partes de Neer e 7 casos de FUP 4 partes de Neer (Tabela 1).

O tempo médio decorrido entre o diagnóstico da fratura e a cirurgia foi de 29,4 dias (Tabela 2), sendo que 9 dos doentes foram operados precocemente (até às 3 semanas após o diagnóstico). Registamos 6 casos operados tardiamente ( 3 semanas após o diagnóstico).

Foram realizadas 10 ATIO, com a particularidade de 3 delas como tratamento de resgate de falência de tratamento conservador (dois casos de FUP 2 partes de Neer e uma FUP 3-partes de Neer) e 2 delas como tratamento de resgate de falência do tratamento inicial com osteossíntese (ambas as FUP 2 partes de Neer). Foram registadas 5 HA (Tabela 2).

Todos os procedimentos foram realizados pelo mesmo cirurgião.

Com exceção de 2 casos de ATIO, todos os implantes foram cimentados (Tabela 2) e todas as próteses colocadas foram modulares (Tabela 3 ).

\begin{tabular}{|c|c|c|c|c|c|c|c|c|}
\hline \multicolumn{2}{|c|}{ Sexo } & \multicolumn{3}{|c|}{ Idade (anos) } & Tempo de seguimento (dias) & \multicolumn{3}{c|}{ Tipo fratura (Neer) } \\
\hline F & M & Min & Max & Média \pm DP & Média \pm DP & 2-partes & 3-partes & 4-partes \\
\hline 12 & 3 & 89 & 63 & $77,60 \pm 7,76$ & $29,40 \pm 48,04$ & $6(40 \%)$ & $2(13,3 \%)$ & $7(46,7 \%)$ \\
\hline
\end{tabular}

Tabela 1: Dados demográficos da amostra : sexo (F-feminino; $M$ - masculino) e idade; tempo de seguimento; classificação da fratura (classificação de Neer).

\begin{tabular}{|c|c|c|c|c|}
\hline \multicolumn{2}{|c|}{ Tipo de artroplastia } & \multicolumn{2}{c|}{ Cimentação } & Modularidade \\
\hline ATIO & HA & Não Cimentada & Cimentada & \\
\hline $\begin{array}{c}10 \text { (5 resgate; } 3 \text { falências tratamento } \\
\text { conservador; } 2 \text { falências osteossíntese) }\end{array}$ & 5 & 2 (ATIO) & 13 & 15 \\
\hline
\end{tabular}

Tabela 2: Tipo de artroplastia utilizado (ATIO- artroplastia total inversa do ombro; HA- hemiartroplastia); Cimentação das artroplastias; Modularidade.

\begin{tabular}{|c|c|c|c|c|c|c|}
\hline \multicolumn{4}{|c|}{ Scores funcionais } & \multicolumn{3}{c|}{ Complicações } \\
\hline CSS(\%) & \multicolumn{2}{c|}{ ASES } & Infeção & Migração haste & “Impingement” subacromial \\
\hline 53 & ATRO & HA & ATRO & \multirow{2}{*}{1 (ATRO) } & 1 1 (HA) & 1 (HA) \\
\hline
\end{tabular}

Tabela 3: Scores funcionais (CSS - Constant Shoulder Scores; ASES - Americam Shoulder and Elbow Score) para o tipo de artroplastia utilizado (ATIO - artroplastia total inversa do ombro; HA - hemiartroplastia); Complicações registadas.

No que respeita à funcionalidade dos grupos, para o grupo dos doentes submetidos a $\mathrm{HA}$, a pontuação média foi de $53.2 \%$ e 44,6 , respetivamente para CSS e ASES; no grupo de doentes submetido a ATIO, a pontuação média foi de $41,1 \%$ e 68,5 , respetivamente para CSS e ASES (Tabela 3).

Não foram obtidos resultados com significado estatístico no estudo comparativo dos valores médios do CSS e ASES entre os grupos operados precocemente e tardiamente (Gráficos 1 e 2).
No estudo comparativo dos scores funcionais entre os doentes submetidos a HA e ATIO, registou-se um valor estatisticamente significativo $(p<0,05)$ para ASES dos doentes com ATIO (Gráfico 2).

As complicações que foram registadas dividiram-se por um caso de infeção aguda de uma ATIO, um caso de migração proximal da haste de uma HA com necessidade de revisão (com conversão para ATIO), um caso de impingement sub-acromial de uma HA (Tabela 3), com necessidade de revisão com conversão para 
ATRO. Nas cirurgias de revisão não foram registadas complicações.

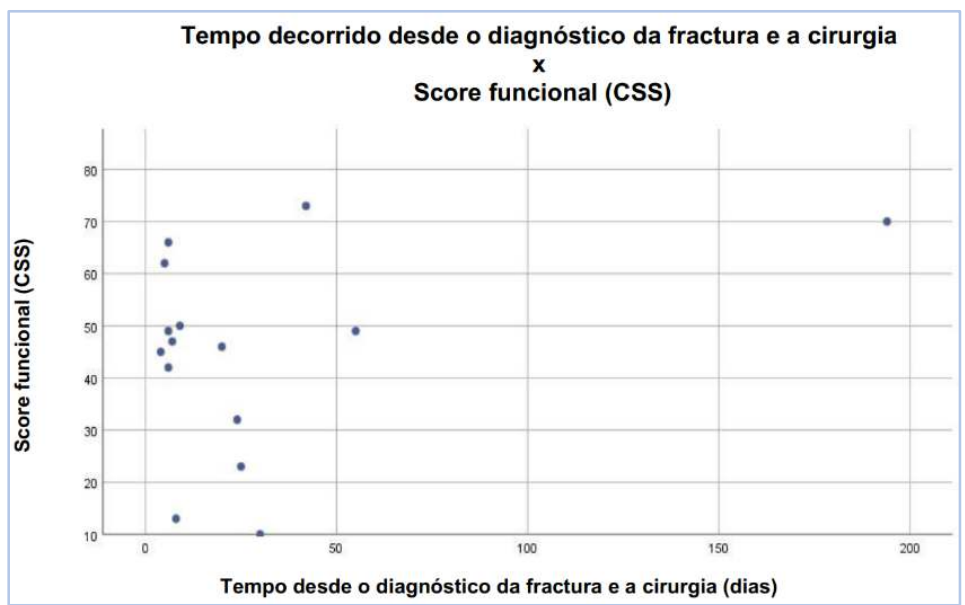

Gráfico 1 - Relação entre o tempo decorrido desde o diagnóstico da fratura e a cirurgia e o score funcional CSS (Constant Shoulder Score)

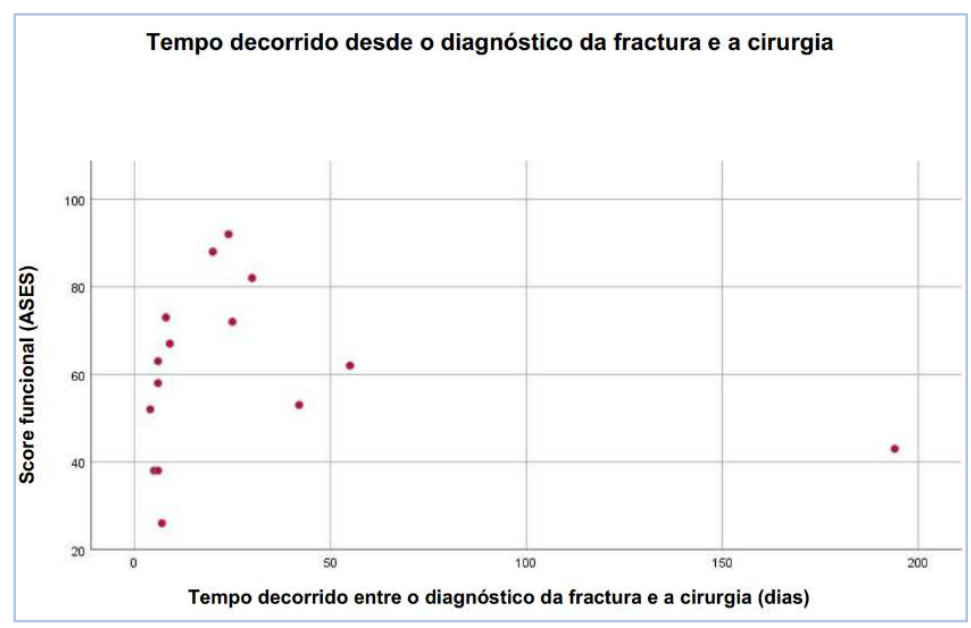

Gráfico 2 - Relação entre o tempo decorrido desde o diagnóstico da fratura e a cirurgia e oscor funcional AESE (American and Elbow Score)

O tempo médio de seguimento foi de 29,4 meses (Tabela 2). Todos os doentes foram incluídos num programa de reabilitação.

\section{DISCUSSÃO}

De um modo geral, a maioria das FUP pode ser tratada conservadoramente. Já as FUP com indicação cirúrgica são típicas dos idosos, que pela osteoporose inerente à idade aumenta a complexidade destas fraturas ${ }^{(16,26,27)}$. Aliás, um estudo recentemente publicado por Jung et al. ${ }^{(28)}$ referem que encontraram um taxa de refraturas de mais de 18 por cento em idosos com osteoporose. A idade média dos doentes intervencionados no presente estudo foi de 78 anos, o que reflete a população envelhecida da área geográfica de abrangência e que é corroborado por vários artigos de revisão publicados desde $2015^{(29-32)}$.

A literatura atual cada vez mais recomenda a ATIO como tratamento de primeira linha nas FUP complexas em idosos, com critérios cirúrgicos, quando a osteossíntese não está indicada( ${ }^{(8-11)}$. A ATIO também é cada vez mais recomendada enquanto tratamento de regaste, quando os tratamentos primários falharam ${ }^{(19-}$ 21), reconhecendo-se também a importância da modularidade protésica para cirurgias de revisão(22).

As complicações registadas foram as complicações previstas em qualquer artroplastia do ombro, no entanto não foram registadas complicações de envolvimento vasculo-nervoso(16).

No estudo comparativo dos resultados funcionais em doentes submetidos a HA versus ATIO, a melhor pontuação registou-se para a ATIO, mas apenas com significado estatístico para o score ASES $(p<0,05)$. Estes dados vão ao encontro aos da literatura, que refere que a ATIO permite melhores resultados funcionais quando comparada com $\mathrm{HA}^{(8-11)}$. Os resultados obtidos pela avaliação ASES vão ao encontro dos resultados encontrados por outros estudos, nomeadamente 64,14 pontos descritos no trabalho publicado por Horneff et al. ${ }^{(33)}, 66$ pontos no trabalho desenvolvido por Wagner et al. ${ }^{(34)}, 59$ pontos no artigo publicado em 2017 Holschen et al. e 65,3 pontos noutro artigo publicado pela mesma equipa ${ }^{(35,36)}$. Relativamente à avaliação CSS, os resultados encontrados vão desde 57 e $45 \%$ no estudo desenvolvido por Lignel et al. ${ }^{(37)}, 63 \%$ no artigo publicado por Holschen et al., 52,9\% na publicação de Giardella et al. ${ }^{(38)}$ a $73 \%$ no estudo efetuado por ${ }^{(39)}$. 0 presente estudo não conseguiu aferir sobre a influência do intervalo de tempo desde o diagnóstico da FUP até à cirurgia, nos resultados funcionais. 0 estudo comparativo das pontuações dos scores funcionais entre doentes operados precocemente e tardiamente não foi estatisticamente significativo $(p>0,05)$. O facto da amostra deste estudo ser relativamente pequena e 5 dos casos terem sido implantes realizados como tratamento de resgate podem ter influenciado negativamente este estudo comparativo.

\section{CONCLUSÃO}

O presente estudo conclui que as FUP com critérios cirúrgicos são típicas da população envelhecida e com mau stock ósseo.

Para FUP complexas e em idosos, sem critérios para osteossíntese, este estudo conclui que a ATIO parece ser a melhor opção enquanto tratamento de primeira linha em FUP com critérios cirúrgicos e que esta permite ao doente melhor funcionalidade pósoperatória, no que respeita ao score ASES.

Também se pode concluir que a modularidade protésica é uma mais-valia nas cirurgias de revisão, tornando este procedimento intrinsecamente mais exigente, mais seguro e mais simples.

Assim sendo, apesar curta experiência e de se apresentar uma pequena amostra de casos, podemos deduzir que se apresentam boas práticas no que respeita ao tratamento oferecido e que são seguidas as recomendações internacionais mais atuais. 
Em termos de limitações do presente estudo pode-se indicar o reduzido tamanho da amostra, o tempo de follow-up relativamente curto, os contextos e experiências diferentes da equipa de reabilitação e a tipologia das próteses utilizadas, que não era homogénea.

Para o futuro sugere-se que se alargue o tempo de follow up, a criação de uma equipa de intervenção e reabilitação específicas e a melhoria do modelo do implante.

\section{REFERÊNCIAS}

1. Baron JA, Barrett JA, Karagas MR. The epidemiology of peripheral fractures. Bone. 1996 Mar;18(3 Suppl):209S-213S.

2. Court-Brown CM, Garg A, McQueen MM. The translated two-part fracture of the proximal humerus. Epidemiology and outcome in the older patient. J Bone Joint Surg Br. 2001 Aug;83(6):799-804. Available from: https://doi.org/10.1016/j.otsr.2008.09.002

3. Neer CS. Displaced proximal humeral fractures. I. Classification and evaluation. J Bone Joint Surg Am. 1970 Sep;52(6):1077-89.

4. Hanson B, Neidenbach $P$, de Boer $P$, Stengel D. Functional outcomes after nonoperative management of fractures of the proximal humerus. J Shoulder Elb Surg. 2009 Jul;18(4):612-21. Available from: https://doi.org/10.1016/j.jse.2009.03.024

5. Neer CS. Displaced proximal humeral fractures. II. Treatment of three-part and four-part displacement. J Bone Joint Surg Am. 1970 Sep;52(6):1090-103.

6. Greiwe RM, Vargas-Ariza R, Bigliani LU, Levine WN, Ahmad CS. Hemiarthroplasty for head-split fractures of the proximal humerus. Orthopedics. 2013 Jul;36(7):e905-11. Available from: https://doi.org/10.3928/01477447-20130624-21

7. Kralinger $F$, Schwaiger $R$, Wambacher $M$, Farrell E, Menth-Chiari $W$, Lajtai G, et al. Outcome after primary hemiarthroplasty for fracture of the head of the humerus. A retrospective multicentre study of 167 patients. J Bone Joint Surg Br. 2004 Mar;86(2):217-9.

8. Chambers L, Dines JS, Lorich DG, Dines DM. Hemiarthroplasty for proximal humerus fractures. Curr Rev Musculoskelet Med. 2013 Mar;6(1):57-62. Available from: https://doi.org/10.1007/s12178-012-9152-9

9. Gallinet D, Clappaz P, Garbuio P, Tropet $Y$, Obert L. Three or four parts complex proximal humerus fractures: hemiarthroplasty versus reverse prosthesis: a comparative study of 40 cases. Orthop Traumatol Surg Res. 2009 Feb;95(1):48-55. Available from:https://doi.org/10.1016/j.otsr.2008.09.002

10.Cuff D, Clark R, Pupello D, Frankle M. Reverse shoulder arthroplasty for the treatment of rotator cuff deficiency: a concise follow-up, at a minimum of five years, of a previous report. J Bone Joint Surg Am. 2012 Nov 7;94(21):1996-2000. Available from:https://doi.org/10.2106/JBJS.K.01206

11.Guery J, Favard L, Sirveaux F, Oudet D, Mole D, Walch G. Reverse total shoulder arthroplasty. Survivorship analysis of eighty replacements followed for five to ten years. J Bone Joint Surg Am. $2006 \quad$ Aug;88(8):1742-7. Available from: https://doi.org/10.2106/JBJS.E.00851

12.Singhal K, Rammohan R. Going forward with reverse shoulder arthroplasty. J Clin Orthop Trauma. 2018 Jan;9(1):87-93. Available from: https://doi.org/10.1016/j.jcot.2017.10.002

13.van der Merwe M, Boyle MJ, Frampton CMA, Ball CM. Reverse shoulder arthroplasty compared with hemiarthroplasty in the treatment of acute proximal humeral fractures. J shoulder Elb Surg. $2017 \quad$ Sep;26(9):1539-45. Available from: https: / /doi.org/10.1016/j.jse.2017.02.005

14.Frombach AA, Brett K, Lapner P. Humeral Head Replacement and Reverse Shoulder Arthroplasty for the Treatment of Proximal Humerus Fracturesm. Open Orthop J. 2017;11:1108-14. Available from: https://doi.org/10.2174/1874325001711011108

15. Reuther F, Petermann M, Stangl R. Reverse Shoulder Arthroplasty in Acute Fractures of the Proximal Humerus: Does Tuberosity Healing Improve Clinical Outcomes? J Orthop Trauma. 2019 Feb;33(2):e46-51. from: https://doi.org/10.1097/BOT.0000000000001338

16.Stone MA, Namdari S. Surgical Considerations in the Treatment of Osteoporotic Proximal Humerus Fractures. Orthop Clin North Am. $2019 \quad$ Apr;50(2):223-31. Available from: https://doi.org/10.1016/j.ocl.2018.10.005

17. Chalmers PN, Boileau P, Romeo AA, Tashjian RZ. Revision Reverse Shoulder Arthroplasty. J Am Acad Orthop Surg. 2019 Jun 15;27(12):426-36. from: https://doi.org/10.5435/JAAOS-D-17-00535

18. Boileau P. Complications and revision of reverse total shoulder arthroplasty. Orthop Traumatol Surg Res. 2016 Feb;102(1 Suppl):S33-43. Available from: https://doi.org/10.1016/j.otsr.2015.06.031

19. Besch L, Daniels-Wredenhagen M, Mueller M, Varoga D, Hilgert RE, Seekamp A. Hemiarthroplasty of the shoulder after four-part fracture of the humeral head: a long-term analysis of 34 cases. $J$ Trauma. $2009 \quad$ Jan;66(1):211-4. Available from: https://doi.org/10.1097/TA.0b013e31815d9649

20.Cadet ER, Ahmad CS. Hemiarthroplasty for three- and four-part proximal humerus fractures. J Am Acad Orthop Surg. 2012 Jan;20(1):17-27. from: https://doi.org/10.5435/JAAOS-20-01-017

21.Robinson CM, Page RS, Hill RMF, Sanders DL, Court-Brown CM, Wakefield AE. Primary hemiarthroplasty for treatment of proximal humeral fractures. J Bone Joint Surg Am. 2003 Jul;85(7):1215-23.

from: https://doi.org/10.2106/00004623-200307000-00006

22. Flury MP, Frey P, Goldhahn J, Schwyzer H-K, Simmen BR. Reverse shoulder arthroplasty as a salvage procedure for failed conventional shoulder replacement due to cuff failure--midterm results. Int Orthop. 2011 Jan;35(1):53-60. Available from:https://doi.org/10.1007/s00264-010-0990-z

23.Constant CR, Murley AH. A clinical method of functional assessment of the shoulder. Clin Orthop Relat Res. 1987 Jan;(214):160-4.

24.Leal SM, Cavalheiro L. Constant Score e Shoulder Pain and Disability Index (SPADI)-Adaptação cultural e linguística. Monogr Coimbra Esc Super Tecnol da Saúde Coimbra. 2001;

25.Ruivo RM, Pezarat-Correia P, Carita Al. Versão Portuguesa do American Shoulder and Elbow Surgeons Standardized Shoulder Assessment Form (ASES). Rev Port Ortop e Traumatol. 2015;23(4):288-97.

26. Ratajczak K, Szczęsny G, Małdyk P. Comminuted fractures of the proximal humerus - principles of the diagnosis, treatment and rehabilitation. Ortop Traumatol Rehabil. 2019 Apr 30;21(2):7186. Available from: https://doi.org/10.5604/01.3001.0013.1544

27. Misra S, Vaishya R, Trikha V, Maheshwari J. Practice guidelines for proximal humeral fractures. J Clin Orthop Trauma. 2019 May;10(3):631-3. from: https://doi.org/10.1016/j.jcot.2019.04.005

28.Jung $\mathrm{H}-\mathrm{S}$, Nho J-H, Ha Y-C, Jang S, Kim H-Y, Yoo J-I, et al. Incidence of Osteoporotic Refractures Following Proximal Humerus Fractures in Adults Aged 50 Years and Older in Korea. J bone Metab. 2019 May;26(2):105-11. Available from:https: / /doi.org/10.11005/jbm.2019.26.2.105

29.Schumaier A, Grawe B. Proximal Humerus Fractures: Evaluation and Management in the Elderly Patient. Geriatr Orthop Surg Rehabil. 2018 Jan 25;9:215145851775051. Available from: https://doi.org/10.1177/2151458517750516

30.Longo UG, Petrillo S, Berton A, Denaro V. Reverse total shoulder arthroplasty for the management of fractures of the proximal humerus: a systematic review. Musculoskelet Surg. 2016 Aug;100(2):83-91. from: https://doi.org/10.1007/s12306-016-0409-0

31.Xie L, Ding $F$, Zhao $Z$, Chen $Y$, Xing D. Operative versus nonoperative treatment in complex proximal humeral fractures: a meta-analysis of randomized controlled trials. Springerplus. 2015;4:728. Available from: https://doi.org/10.1186/s40064015-1522-5

32.Slobogean GP, Johal H, Lefaivre KA, Maclntyre NJ, Sprague S, Scott $T$, et al. A scoping review of the proximal humerus fracture literature. BMC Musculoskelet Disord. 2015 May 10;16:112. Available from: https://doi.org/10.1186/s12891-0150564-8

33. Horneff JG, Nicholson TA, Namdari S, Williams GR, Abboud JA. 
The Midterm Results of the Delta Xtend Reverse Shoulder System: A Five-Year Outcome Study. Arch bone Jt Surg. 2018 Nov;6(6):532-8.

34. Wagner ER, Hevesi M, Houdek MT, Cofield RH, Sperling JW, Sanchez-Sotelo J. Can a reverse shoulder arthroplasty be used to revise a failed primary reverse shoulder arthroplasty? Bone Joint J. $2018 \quad$ Nov;100-B(11):1493-8. Available from:https://doi.org/10.1302/0301-620X.100B11.BJJ-2018-

\section{$\underline{0226 . R 2}$}

35. Holschen M, Franetzki B, Witt K-A, Liem D, Steinbeck J. Is reverse total shoulder arthroplasty a feasible treatment option for failed shoulder arthroplasty? A retrospective study of 44 cases with special regards to stemless and stemmed primary implants. Musculoskelet Surg. 2017 Aug;101(2):173-80. Available from: https://doi.org/10.1007/s12306-017-0467-y

36. Holschen $M$, Siemes $M-K$, Witt K-A, Steinbeck J. Five-year outcome after conversion of a hemiarthroplasty when used for the treatment of a proximal humeral fracture to a reverse total shoulder arthroplasty. Bone Joint J. 2018 Aug 1;100-B(6):761-6. Available from:https://doi.org/10.1302/0301-620X.100B6.BJJ2017-1280.R1

37.Lignel A, Berhouet J, Loirat M-A, Collin P, Thomazeau H, Gallinet $D$, et al. Reverse shoulder arthroplasty for proximal humerus fractures: Is the glenoid implant problematic? Orthop Traumatol Surg Res. 2018 Oct;104(6):773-7.

38.Giardella A, Ascione F, Mocchi M, Berlusconi M, Romano AM, Oliva F, et al. Reverse total shoulder versus angular stable plate treatment for proximal humeral fractures in over 65 years old patients. Muscles Ligaments Tendons J. 7(2):271-8.

39.Schliemann B, Theisen C, Kösters C, Raschke MJ, Weimann A. Reverse total shoulder arthroplasty for type I fracture sequelae after internal fixation of proximal humerus fractures. Arch Orthop Trauma Surg. 2017 Dec;137(12):1677-83. 


\title{
MOBiLIZAÇÃo PRECOCE EM PESSOAS SUbMETIDAS A VENTILAÇÃo MeCÂNICA INVASIVA: REVISÃo INTEGRATIVA DA LITERATURA
}

\author{
MOVILIZACIÓN PRECOZ EN PERSONAS SOMETIDAS A VENTILACIÓN MECÁNICA INVASIVA: REVISIÓN INTEGRATIVA DE LA \\ LITERATURA.
}

\author{
EARLY MOBILIZATION IN PEOPLE UNDERGOING MECHANICAL INVASIVE VENTILATION: INTEGRATIVE REVIEW OF \\ LITERATURE
}

DOI 10.33194/rper.2019.v2.n1.07.4563 | Submetido 05.03.2019 | Aprovado 27.06.2019

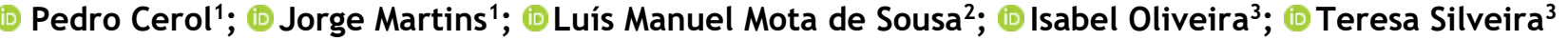 \\ 1 - Centro Hospitalar Universitário do Algarve, Unidade de Portimão, Portugal; 2 - Universidade de Évora, Escola Superior de \\ Enfermagem S. João de Deus, Évora, Portugal; 3- Escola Superior de Saúde da Cruz Vermelha Portuguesa, Lisboa, Portugal
}

\section{RESUMO}

Introdução: A mobilização precoce na unidade de cuidados intensivos é considerada uma intervenção importante na prevenção de complicações relacionadas com a imobilidade e a ventilação mecânica, principalmente no desenvolvimento de fraqueza muscular generalizada.

Objetivo: Identificar os benefícios das várias modalidades terapêuticas utilizadas na mobilização precoce das pessoas em situação crítica, submetidas a ventilação mecânica invasiva.

Método: Realizou-se uma revisão integrativa da literatura. Formulou-se a seguinte questão através da estratégia PICo - o qual o estado do conhecimento sobre a mobilização precoce em pessoas em situação critica submetidas a ventilação invasiva? A pesquisa foi realizada na plataforma EBSCOhost em setembro de 2018 , nas bases de dados eletrónicas CINAHL e MEDLINE e foi definido o período compreendido entre janeiro de 2010 e setembro de 2018.

Resultados: Dos 397 artigos identificados, foram incluídos 9 artigos. A mobilização precoce em pessoa submetida a ventilação mecânica invasiva é considerada uma prática segura, uma vez que a ocorrência de eventos adversos é reduzida. Os principais benefícios são melhoria da capacidade funcional, diminuição das complicações associadas à imobilidade e ventilação mecânica invasiva, redução do número de dias sob ventilação mecânica invasiva e, consequentemente, à diminuição dos dias de permanência na unidade de cuidados intensivos e de internamento hospitalar. Esta intervenção diminui a morbilidade e mortalidade hospitalar.

Conclusão: A mobilização precoce em pessoas submetidas a ventilação mecânica invasiva é segura e contribui para os ganhos em saúde quer a nível da pessoa/família, quer organizacional.

Descritores: Enfermagem em Reabilitação, Mobilização Precoce, Técnicas de Exercício e de Movimento, Ventilação Mecânica

\section{RESUMEN}

Introducción: La movilización precoz en la unidad de cuidados intensivos se considera una intervención importante en la prevención de complicaciones relacionadas con la inmovilidad y la ventilación mecánica, principalmente en el desarrollo de debilidad muscular generalizada.

Objetivo: Identificar los beneficios de las diversas modalidades terapéuticas utilizadas en la movilización precoz de las personas en situación crítica, sometidas a ventilación mecánica invasiva.

Identificar los beneficios de las diversas modalidades terapéuticas utilizadas en la movilización precoz de las personas en situación crítica, sometidas a ventilación mecánica invasiva.

Método: Se realizó una revisión integrativa de la literatura. Se formuló la siguiente cuestión: a través de la estrategia PICo: ¿cual el estado del conocimiento sobre la movilización precoz en personas en situación crítica sometidas a ventilación invasiva? La investigación se realizó en la plataforma EBSCOhost en septiembre de 2018, en las bases de datos electrónicas CINAHL y MEDLINE y se definió el período comprendido entre enero de 2010 y septiembre de 2018.

Resultados: De los 397 artículos identificados, se incluyeron 9 artículos. La movilización precoz en persona sometida a ventilación mecánica invasiva se considera una práctica segura, ya que la aparición de eventos adversos es reducida. Los principales beneficios son la mejora de la capacidad funcional, disminución de las complicaciones asociadas a la inmovilidad y ventilación mecánica invasiva, reducción del número de días bajo ventilación mecánica invasiva y, consecuentemente, a la disminución de los días de permanencia en la UCl y de internamiento hospitalario. Esta intervención disminuye la morbilidad y mortalidad hospitalaria. 
Conclusión: La movilización precoz en personas sometidas a ventilación mecánica invasiva es segura y contribuye a las ganancias en salud tanto a nivel de la persona/familia, bien organizacional.

Descriptores: Enfermería en Rehabilitación, Movilización Precoz, Técnicas de Ejercicio y de Movimiento, Ventilación Mecánica

\section{ABSTRACT}

Introduction: Early mobilization in the intensive care unit is considered an important intervention in the prevention of complications related to immobility and mechanical ventilation, mainly in the development of generalized muscular weakness.

Objective: To identify the benefits of the various therapeutic modalities used in the early mobilization of critically ill people submitted to invasive mechanical ventilation.

Method: It was performed an integrative review. The following question was formulated through the PICo strategy what is the state of knowledge about early mobilization in critically placed people submitted to invasive ventilation? The research was carried out on the EBSCOhost platform in September 2018, in the electronic databases CINAHL and MEDLINE and the period between January 2010 and September 2018 was defined.

Results: Of the 397 articles identified, 9 articles were included. Early mobilization in person submitted to invasive mechanical ventilation is considered a safe practice, since the occurrence of adverse events is reduced. The main benefits are improvement of functional capacity, reduction of complications associated with immobility and invasive mechanical ventilation, reduction of the number of days under invasive mechanical ventilation and, consequently, the reduction of the days of ICU stay and hospitalization. This intervention reduces hospital morbidity and mortality.

Conclusion: Early mobilization in people undergoing invasive mechanical ventilation is safe and contributes to health gains at both the person / family and organizational levels.

Keywords: Rehabilitation Nursing; Early Mobilization; Exercise and Movement Techniques; Mechanical Ventilation

\section{INTRODUÇÃO}

Atualmente na Europa, por doença crítica, são submetidas a ventilação mecânica invasiva (VMI) cerca de 990000 e 1500000 pessoas/ano. Nos países mais desenvolvidos, as unidades de cuidados intensivos (UCl) são responsáveis por cerca de $13,4 \%$ do total de custos hospitalares, cerca de $4,1 \%$ dos gastos nacionais em saúde e cerca de $0,56 \%$ do produto nacional bruto. 0 envelhecimento da população e a expansão das chamadas doenças da civilização levarão a um crescimento das necessidades de cuidados intensivos nos próximos 10 anos, que algumas estimativas preveem de $160 \%$ (1).

Em consequência da necessidade de tratamento intensivo, as pessoas em situação crítica permanecem restritas ao leito por longos períodos. A sua grave condição e a administração de terapêutica vasopressora, sedativa e curarizante condicionam a mobilidade destas pessoas, expondo-as a complicações inerentes à imobilidade como a atrofia, disfunção e fraqueza muscular, diminuição da capacidade funcional, hipotensão ortostática, taquicardia, entre outras ${ }^{(2)}$. 0 desenvolvimento de fraqueza generalizada associada às pessoas em situação crítica, especialmente aquelas que necessitam de ventilação mecânica, é uma complicação significativa e comum (3). Portanto, é apontada uma incidência aproximada entre $30 \%$ a $60 \%$ nas pessoas internadas em $\mathrm{UCl}$, com perda de $4 \%$ a $5 \%$ da força muscular periférica por semana durante o período de imobilidade ${ }^{(4)}$. Hogdson e colaboradores ${ }^{(5)}$ concluíram que $52 \%$ dos pacientes em estudo apresentaram fraqueza muscular associada aos cuidados intensivos.
A imobilidade compromete os sistemas respiratório, cardiovascular, gastrintestinal músculo-esquelético, génito-urinário, metabólico, cutâneo e neurológico. 0 desuso, repouso ou inatividade de membros ou corpo e a perda de enervação promovem o declínio na massa muscular, força e endurance ${ }^{(6)}$, podendo-se desenvolver várias complicações neuromusculares, pulmonares, cognitivas e na qualidade de vida, podendo perdurar até 5 anos após a alta ${ }^{(7)}$. Todos estes fatores contribuem para o prolongar do tempo de internamento nas $\mathrm{UCl}$, resultando num risco acrescido de complicações, num incremento do índice de morbilidade e mortalidade e, consequentemente, custos mais elevados (6). Ågård e colaboradores (8) referem que, durante 0 primeiro ano de convalescença, as pessoas em situação crítica lutam pela independência, tentando recuperar a força física e capacidade funcional e retomarem os seus papéis familiares. Este declínio funcional acentua-se nas $\mathrm{UCI}$ onde a pessoa encontra-se na maior parte do tempo restrita ao leito ${ }^{(7)}$.

A reabilitação da pessoa em situação crítica iniciada na UCl é referida como parte importante do plano de cuidados, sendo sugerida como uma terapêutica relevante na modificação do risco de desenvolvimento de sequelas ao nível da morbilidade física e funcional. A mobilização precoce, também designada de mobilidade progressiva, refere-se a um padrão de aumento de atividade com início na mobilização passiva até à deambulação, iniciando-se imediatamente após a estabilização hemodinâmica e respiratória, habitualmente entre as 24 a 48 horas após a admissão em UCl ${ }^{(9)}$. 0 início da mobilização 
precoce tem como intuito a prevenção de complicações inerentes à imobilidade no leito, minimizar a perda de mobilidade, otimizar a autonomia e facilitar o desmame do ventilador. Desta forma, a sua importância passa pelos ganhos na capacidade funcional, mas repercute-se num patamar mais elevado, na independência da pessoa e na melhoria da sua qualidade de vida ${ }^{(2)}$.

Pesquisas anteriores identificaram barreiras para a implementação de programas de reabilitação precoce que incluíam sedação profunda, inadequado staff e cooperação multidisciplinar, preocupações com a segurança e desconhecimento sobre os benefícios da reabilitação precoce. Algumas UCI ultrapassaram essas barreiras implementando com sucesso a reabilitação precoce na sua rotina mas, mesmo assim, a implementação generalizada contínua reduzida e apenas $8 \%$ a $12 \%$ de pessoas sob ventilação mecânica eram mobilizadas fora do leito ${ }^{(10)}$.

A reabilitação precoce é segura e bem tolerada, mas não é isenta de riscos. Dever-se-á estar alerta para potenciais problemas de segurança como a resposta fisiológica ao esforço, necessidade de alteração de planos de tratamento, sedação, administração de vasopressores, extubação acidental e exteriorização de outros dispositivos. A ocorrência dos eventos mencionados é residual e surgiram em menos de $4 \%$ de todas as interações com as pessoas, nenhuma delas consideradas graves ${ }^{(11)}$.

A intervenção do enfermeiro de reabilitação à pessoa submetida a VMI tem como objetivo melhorar a qualidade de vida através da melhoria da funcionalidade (atividades de vida diárias e instrumentais), tolerância ao esforço, redução das complicações da VMI e do sucesso do desmame do ventilador. A reabilitação precoce, no que concerne à pessoa submetida a VMI, torna-se cada vez mais fundamental, devendo esta ser iniciada nas primeiras 24 horas (12). Nesta perspetiva, identificamos a intervenção do enfermeiro especialista em enfermagem de reabilitação, no contexto da pessoa submetida a VMI, como uma necessidade premente.

A questão de investigação por nós formulada para o presente trabalho foi a seguinte: "Quais os benefícios da mobilização precoce em pessoas submetidas a ventilação invasiva?" Para respondermos a esta problemática identificada, definimos como objetivo geral: analisar a intervenção de enfermagem na mobilização precoce; e como objetivos específicos: descrever as intervenções de reabilitação que poderão ser implementadas à pessoa submetida a VMI e identificar os benefícios dessa mesma intervenção.

\section{MATERIAIS E MÉTODOS}

\section{Aspetos éticos}

Por tratar-se de uma revisão integrativa e não envolver

seres humanos, não precisou passar por apreciação de uma colisão de ética. Foram atendidos os procedimentos éticos a ter em consideração num trabalho deste tipo, nomeadamente, o rigor na referenciação e o respeito pela perspetiva dos autores dos artigos incluídos

\section{Tipo de estudo}

Uma revisão integrativa da literatura é um dos métodos de pesquisa utilizados na Prática Baseada na Evidência que permite a incorporação de evidências na situação clínica. É fundamentada em conhecimento científico, com resultados de qualidade e custo efetividade $(13,14)$.

\section{Procedimentos metodológicos}

De acordo com as etapas constituintes de uma revisão integrativa da literatura, foi definido, na primeira etapa, a seguinte questão que motivou o interesse e a pesquisa que é "Quais os benefícios da mobilização precoce em pessoas submetidas a ventilação invasiva?", tendo por base o acrómio PICo, derivado do PICO em que P (População) I (fenómeno de interesse) e Co (contexto), foram definidos os critérios de inclusão e exclusão expressos no seguinte tabela tendo em conta o acrónimo:

\begin{tabular}{|c|c|c|}
\hline & $\begin{array}{l}\text { Critérios de } \\
\text { inclusão }\end{array}$ & Critérios de Exclusão \\
\hline $\begin{array}{c}\text { População } \\
\text { (P) }\end{array}$ & $\begin{array}{l}\text { Pessoa adulta } \\
\text { em situação } \\
\text { crítica; }\end{array}$ & $\begin{array}{c}\text { Pessoas com idade } \\
\text { pediátrica e adultos } \\
\text { que não estão } \\
\text { internados em } \\
\text { unidades de cuidados } \\
\text { intensivos; }\end{array}$ \\
\hline $\begin{array}{c}\text { Fenómeno } \\
\text { de } \\
\text { Interesse } \\
\text { (I) }\end{array}$ & $\begin{array}{l}\text { Benefícios da } \\
\text { mobilização } \\
\text { precoce; }\end{array}$ & $\begin{array}{c}\text { Intervenções não } \\
\text { relacionadas com a } \\
\text { mobilização precoce; }\end{array}$ \\
\hline $\begin{array}{l}\text { Contexto } \\
\text { (Co) }\end{array}$ & $\begin{array}{l}\text { ventilação } \\
\text { invasiva; }\end{array}$ & $\begin{array}{l}\text { Pessoas não } \\
\text { submetidos a } \\
\text { ventilação não } \\
\text { invasiva; }\end{array}$ \\
\hline
\end{tabular}

Tabela 1 - Critérios de inclusão e exclusão

Foram incluídos neste estudo artigos com referência a pessoas adultas com idade superior a 19 anos, texto completo de janeiro de 2010 e setembro de 2018, sem limitações geográficas e artigos em Inglês, Português e Espanhol. Após a leitura do resumo e análise dos artigos foram excluídos aqueles que não se referiam à temática em estudo. Foram encontrados os seguintes descritores, previamente validados como descritores usados em ciências da saúde nas plataformas DeCs e MESH: "rehabilitation", "rehabilitation nursing", "early ambulation", "exercise movement techniques", "respiratory therapy" e "mechanical ventilation", "Respiration, Artificial" 
Fonte de dados, identificação e seleção dos estudos

A pesquisa foi realizada na plataforma EBSCOhost em setembro de 2018, em todas as bases de dados eletrónicas nela incluídas, e foi definido o período compreendido entre janeiro de 2010 e setembro de 2018 para as datas de publicação dos artigos pesquisados. As palavras selecionadas para a pesquisa foram combinadas através das expressões booleanas AND e OR obtendo-se a seguinte equação de pesquisa:

1. [(Ventilator weaning) OR (mechanical ventilation) OR (respiration, artificial)] $n=100812$

2. [(rehabilitation nursing) OR (rehabilitation) OR (early ambulation) OR (exercise movement techniques)] $n=621380$

3. ((Ventilator weaning) OR (mechanical ventilation) OR (respiration, artificial)) AND ((rehabilitation nursing) OR (Rehabilitation) OR (early ambulation) OR (exercise movement techniques)) $n=2537$

Os artigos selecionados para leitura completa foram avaliados por dois investigadores de forma independente, de acordo com critérios de qualidade metodológica, propostos pelo JBI (14) tendo sido selecionados apenas os artigos com mais de 75\% dos critérios e a qualidade da revisão sistemática foi avaliada com a grelha de Carneiro e Bogalho ${ }^{(15)}$.

\section{Extração e análise dos dados}

Foi extraída informação dos artigos sobre autores, ano, país, amostra, dados sobre as propriedades métricas, conclusões e nível de evidência. A classificação dos níveis de evidência dos estudos incluídos foi realizada com base nos critérios da Registered Nurses Association of Ontario: 1A - revisões sistemáticas (meta análises); Nível 1B - estudos prospetivos ou estudos experimentais com grupos selecionados aleatoriamente; Nível II - estudos quase experimentais; Nível III - estudos descritivos e estudos de coorte; Nível IV - artigos de opinião de peritos ${ }^{(17)}$.

A informação colhida dos artigos foi efetuada com base nos seguintes critérios: autor, ano, país, participantes, objetivos, intervenções, resultados e o nível de evidência. A informação sobre a intervenção foi organizada de acordo com a frequência, intensidade, volume, duração e modalidade da atividade terapêutica /exercício físico.

\section{RESULTADOS}

Foram identificadas 2537 referencias e incluídos 8 artigos (figura 1). Após a aplicação do método de avaliação da qualidade dos artigos através das grelhas Johanne Briggs Insitute optou-se pela inclusão de um artigo com algumas limitações quanto à metodologia utilizada e à seleção dos grupos, no entanto foi incluído por se enquadrar na temática ${ }^{(17)}$. Também se decidiu incluir uma revisão sistemática da literatura com o intuito de enriquecer este trabalho ${ }^{(18)}$.
As amostras dos artigos são heterogéneas com grande variabilidade na seleção dos grupos de controlo e de intervenção (tabela 2).

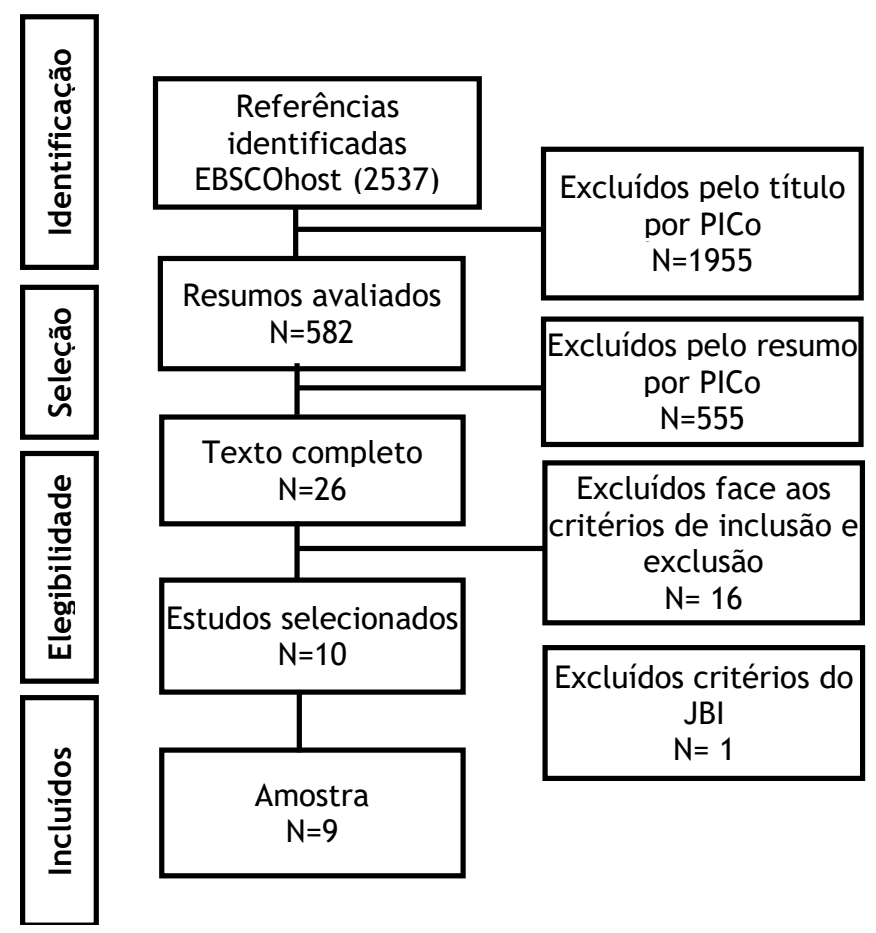

Fluxograma 1 - identificação, análise e seleção dos artigos.

\begin{tabular}{|c|c|c|c|c|c|}
\hline Referência & País & Autores & Ano & $\begin{array}{l}\text { Tipo de } \\
\text { estudo }\end{array}$ & NE \\
\hline $\begin{array}{c}\text { Estudo } 1 \\
(19)\end{array}$ & Austrália & $\begin{array}{l}\text { Hodgson C. et } \\
\text { al. }\end{array}$ & 2015 & $\begin{array}{c}\text { Coorte } \\
\text { prospetivo }\end{array}$ & III \\
\hline $\begin{array}{c}\text { Estudo } 2 \\
(20)\end{array}$ & EUA & Castro E. et al. & 2015 & Descritivo & III \\
\hline $\begin{array}{c}\text { Estudo } 3 \\
(21)\end{array}$ & Israel & $\begin{array}{l}\text { Yousef-Brauner } \\
\text { O. et al. }\end{array}$ & 2013 & $\begin{array}{c}\text { Experimental } \\
\text { (ensaios } \\
\text { clínicos) }\end{array}$ & $1 \mathrm{~B}$ \\
\hline $\begin{array}{c}\text { Estudo } 4 \\
(22)\end{array}$ & EUA & Clark D. et al. & 2013 & Coorte & III \\
\hline $\begin{array}{c}\text { Estudo } 5 \\
\text { (23) }\end{array}$ & Inglaterra & $\begin{array}{l}\text { McWilliams D. et } \\
\text { al. }\end{array}$ & 2014 & Coorte & III \\
\hline $\begin{array}{c}\text { Estudo } 6 \\
(24)\end{array}$ & Itália & Enrico M. et al. & 2011 & Coorte & III \\
\hline $\begin{array}{c}\text { Estudo } 7 \\
(25)\end{array}$ & Brasil & $\begin{array}{l}\text { Toccolini BF. et } \\
\text { al. }\end{array}$ & 2014 & Coorte & III \\
\hline $\begin{array}{c}\text { Estudo } 8 \\
(26)\end{array}$ & EUA & Amidei C. et al. & 2013 & $\begin{array}{c}\text { Quasi- } \\
\text { experimental }\end{array}$ & II \\
\hline $\begin{array}{c}\text { Estudo } 9 \\
(27)\end{array}$ & Brasil & $\begin{array}{c}\text { Azevedo PM. et } \\
\text { al. }\end{array}$ & 2015 & $\begin{array}{c}\text { Revisão } \\
\text { sistemática }\end{array}$ & $1 \mathrm{~A}$ \\
\hline
\end{tabular}

Tabela 2 - Identificação dos estudos (NE - Nível de Evidência)

Seguidamente, será apresentado uma síntese individualizada dos principais dados dos artigos incluídos: identificação do estudo, participantes, objetivos, intervenções, resultados. 


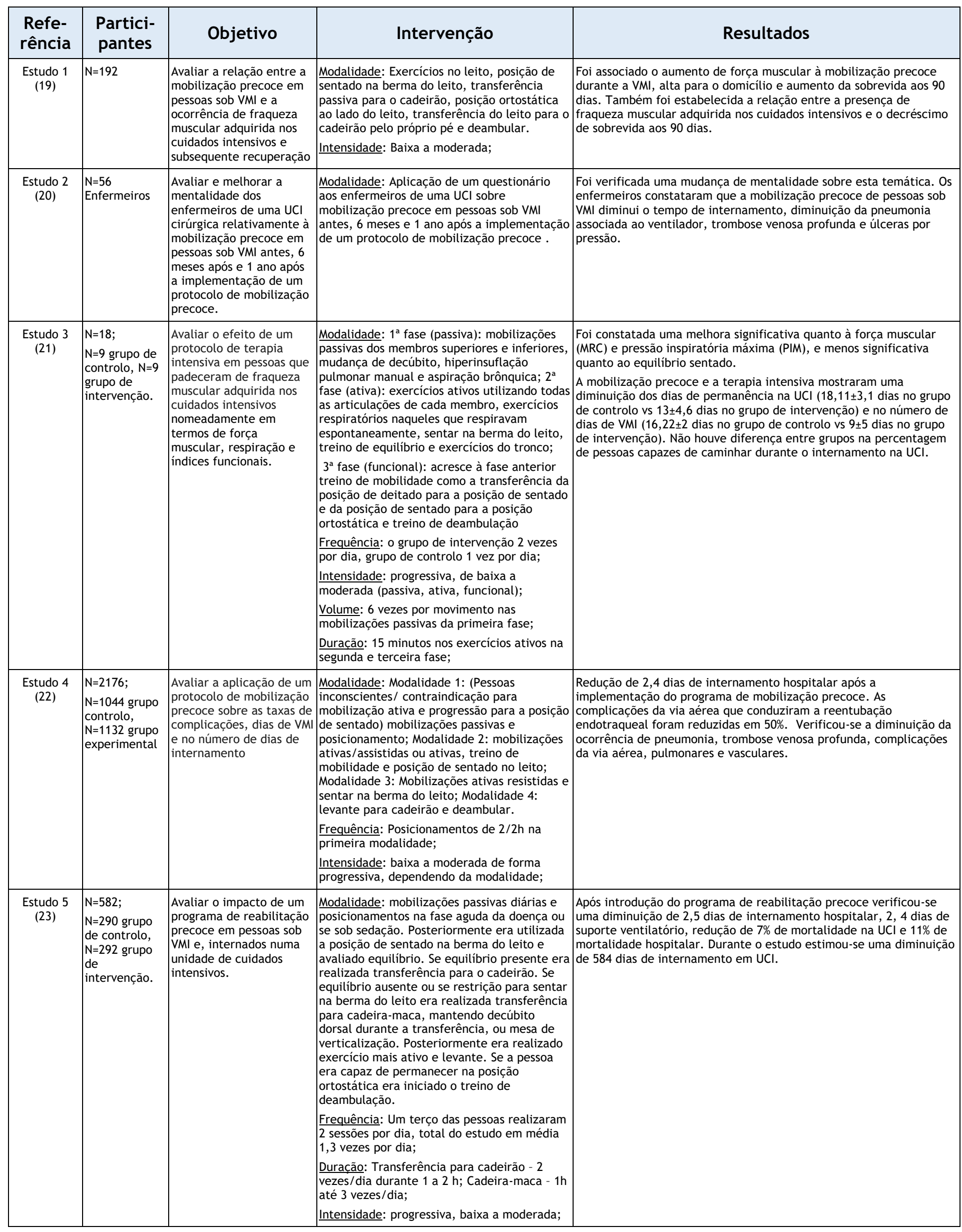




\begin{tabular}{|c|c|c|c|c|}
\hline $\begin{array}{c}\text { Estudo } 6 \\
\text { (24) }\end{array}$ & $N=77$ & $\begin{array}{l}\text { Avaliar o grau de } \\
\text { recuperação funcional } \\
\text { após um programa de } \\
\text { reabilitação e a } \\
\text { influência no outcome } \\
\text { hospitalar em pessoas } \\
\text { traqueostomizadas e } \\
\text { cronicamente ventiladas, } \\
\text { admitidas para desmame } \\
\text { ventilatório. }\end{array}$ & $\begin{array}{l}\text { Modalidade: mobilizações ativas dos } \\
\text { membros, fortalecimento muscular para } \\
\text { controlo do tronco e manutenção da postura } \\
\text { corporal, atividades dos membros superiores } \\
\text { e inferiores para facilitar a transferência do } \\
\text { leito para o cadeirão e permanecer em } \\
\text { posição ortostática. Efetuado treino de } \\
\text { deambulação, mobilizações ativas-resistidas } \\
\text { com uso de pesos e pedaleira (utilizadas nos } \\
\text { membros superiores e inferiores). Pedaleira e } \\
\text { mobilizações ativas-resistidas: } \\
\text { Frequência: } 6 \text { vezes por semana (pelo menos } \\
15 \text { sessões), } 2 \text { vezes por dia; } \\
\text { Intensidade: progressiva, de baixa a } \\
\text { moderada; } \\
\text { Volume: Pedaleira - } 30 \text { rotações por minuto; } \\
\text { Mobilizações ativas-resistidas - } 2 \text { séries de } 10 \\
\text { repetições, carga de } 100 \mathrm{~g} \text { a } 500 \mathrm{~g} ; \\
\text { Duração: Pedaleira - máximo de } 30 \text { minutos; } \\
\text { Em simultâneo foi aplicado um protocolo de } \\
\text { desmame ventilatório com períodos de } \\
\text { respiração espontânea progressivamente mais } \\
\text { alargados, independente do treino físico. }\end{array}$ & $\begin{array}{l}\text { O sucesso do desmame ventilatório e o índice de sobrevivência } \\
\text { hospitalar foi de } 74 \% \text { e } 87 \% \text { respetivamente. Uma larga percentagem } \\
\text { de pessoas recuperou em todos os domínios de atividades de vida } \\
\text { diárias no momento da alta da UCI. Também foi associado o maior } \\
\text { grau de dependência nas AVD a pior resultado clínico. }\end{array}$ \\
\hline $\begin{array}{c}\text { Estudo } 7 \\
\text { (25) }\end{array}$ & $N=23$ & $\begin{array}{l}\text { Avaliar os efeitos do } \\
\text { ortostatismo passivo em } \\
\text { vários parâmetros clínicos } \\
\text { e fisiológicos na pessoa } \\
\text { em situação crítica, } \\
\text { através da utilização da } \\
\text { mesa de verticalização }\end{array}$ & $\begin{array}{l}\text { Modalidade: mesa de verticalização } \\
\text { Frequência: } 1 \text { vez por dia; } \\
\text { Intensidade: baixa, sem repercussão } \\
\text { hemodinâmica; } \\
\text { Duração: } 1^{\circ} \text { dia - } 30^{\circ}(5 \mathrm{~min} .), 45^{\circ}(5 \mathrm{~min} .) \text { e } \\
60^{\circ}(15 \mathrm{~min} .) ; 2^{\circ} \text { dia e restantes - } 30^{\circ}(5 \mathrm{~min} .), \\
45^{\circ}(5 \mathrm{~min} .) \text { e } 60^{\circ}(5 \mathrm{~min} .), 75^{\circ}(5 \mathrm{~min} .) \text { e } 90^{\circ} \\
(15 \text { min.); } \\
\text { Em média realizaram-se } 5,2 \text { dias deste } \\
\text { protocolo. }\end{array}$ & $\begin{array}{l}\text { Os maiores benefícios foram o aumento da força muscular } \\
\text { inspiratória e o aumento do nível de consciência. O aumento do nível } \\
\text { de consciência poderá ser explicado pela estimulação sensorial } \\
\text { devido à posição ortostática. Neste estudo, } 5 \text { pessoas foram } \\
\text { extubadas precocemente devido ao aumento do nível de consciência } \\
\text { na posição de } 90^{\circ} \text {. A colocação de pessoas em posição ortostática } \\
\text { não revelou alterações fisiológicas que pudessem impedir o } \\
\text { procedimento. }\end{array}$ \\
\hline $\begin{array}{c}\text { Estudo } 8 \\
\text { (26) }\end{array}$ & $N=30$ & $\begin{array}{l}\text { Avaliar as respostas } \\
\text { fisiológicas à } \\
\text { implementação de um } \\
\text { protocolo de exercício } \\
\text { passivo precoce para } \\
\text { prevenir a fraqueza } \\
\text { muscular em pessoas sob } \\
\text { VMI. }\end{array}$ & $\begin{array}{l}\text { Modalidade: mobilização passiva de cada } \\
\text { membro inferior através de dispositivo que } \\
\text { efetuava flexão/extensão do joelho (flexão } \\
\left.\text { de } 5^{\circ} \text { a } 70^{\circ}\right) \text {. Os dois membros inferiores eram } \\
\text { mobilizados em simultâneo e de forma } \\
\text { alternada, simulando a deambulação; } \\
\text { Frequência: uma única sessão; } \\
\text { Intensidade: baixa, sem repercussão } \\
\text { hemodinâmica; } \\
\text { Volume: } 20 \text { extensões/flexões por minuto; } \\
\text { Duração: } 20 \text { minutos; }\end{array}$ & $\begin{array}{l}\text { Sem alterações nos parâmetros vitais avaliados nos vários momentos } \\
\text { da intervenção. Verificou-se diminuição do nível de dor (BPS) } \\
\text { durante e } 60 \text { minutos após a intervenção. }\end{array}$ \\
\hline $\begin{array}{l}\text { Estudo } 9 \\
\quad(27)\end{array}$ & $\begin{array}{l}\mathrm{N}=6 \text { estudos } \\
\text { Total }=806 \\
\text { participantes }\end{array}$ & $\begin{array}{l}\text { Determinar os efeitos da } \\
\text { mobilização precoce na } \\
\text { reabilitação funcional de } \\
\text { pessoas internadas em } \\
\text { UCl. }\end{array}$ & $\begin{array}{l}\text { Análise de } 6 \text { estudos: } 2 \text { estudos de Coorte e } 4 \\
\text { estudos Controlados Randomizados. }\end{array}$ & $\begin{array}{l}\text { Menos tempo de internamento em UCl e hospitalar. } \\
\text { Menor tempo sob VMI. } \\
\text { Aumento do } \mathrm{n}^{\circ} \text { de pessoas capazes de deambularem. } \\
\text { Menor tempo até ao } 1^{\circ} \text { levante, capacidade de realizar transferência } \\
\text { ativa para cadeirão, maior capacidade funcional, mais independência } \\
\text { na realização das atividades de vida diária e maior score no Índice de } \\
\text { Barthel. } \\
\text { Maior capacidade de realização de exercícios resistidos, aumento } \\
\text { significativo da força muscular e da pressão inspiratória máxima. }\end{array}$ \\
\hline
\end{tabular}

Tabela 3 - Informação extraída dos estudos

\section{DISCUSSÃO DE RESULTADOS}

De acordo com os estudos selecionados, através desta revisão integrativa da literatura, os resultados obtidos serão descritos segundo diferentes tópicos, nomeadamente as principais intervenções efetuadas, que benefícios advêm da mobilização precoce, segurança, principais barreiras para se proceder à mobilização precoce da pessoa submetida a ventilação mecânica invasiva, fragilidades dos estudos e, por último, as recomendações para a prática.

\section{Intervenções de reabilitação, Contexto}

A colheita de dados foi realizada tendo em conta a
frequência, intensidade, duração, volume e
modalidade com o objetivo de facilitar a

prescrição/aplicação de atividade terapêutica por parte dos enfermeiros especialistas em reabilitação.

Vários estudos utilizaram protocolos que tinham por base 0 modelo de mobilização progressiva contemplando vários níveis de intervenção, de acordo com a condição clínica e a capacidade das pessoas, com início nas mobilizações passivas e culminando no levante e deambulação (20-24). Apesar de mencionarem as modalidades realizadas, estes não referiram pormenorizadamente a frequência, intensidade, duração e volume das mesmas, pelo que descreveremos apenas a informação disponível.

O Estudo 3 utilizou um protocolo de mobilização precoce que contemplava 3 fases de modalidades (passiva, ativa e funcional). As mobilizações passivas da primeira fase eram realizadas 6 vezes por 
movimento e os exercícios ativos da segunda e terceira fase tinham a duração de 15 minutos. As pessoas que pertenciam ao grupo de intervenção foram submetidas a 2 sessões diárias deste protocolo (21).

O protocolo de mobilidade precoce descrito por Morris e colaboradores foi utilizado pelo Estudo 4, que consiste na utilização de 4 modalidades de intervenções. Neste estudo não houve referência a frequência, volume, intensidade ou duração das modalidades efetuadas, apenas houve referência a critérios necessários para a progressão da modalidade de intervenções. A administração de terapêutica vasopressora era condicionante para a realização das intervenções referentes às modalidades 3 e $4{ }^{(22)}$. Este protocolo foi também utilizado no Estudo 2, descrevendo apenas que, na primeira modalidade, as mobilizações passivas eram realizadas três vezes por dia nos membros superiores e inferiores. Nas restantes três modalidades apenas descrevem as intervenções realizadas, mas sem referirem a frequência, volume, intensidade ou duração das mesmas. A administração de vasopressores não foi contraindicação para a realização de mobilização precoce, desde que fosse em doses reduzidas e houvesse ausência de hipotensão ortostática ${ }^{(20)}$.

O protocolo utilizado no Estudo 5 consistia na realização de posicionamentos e mobilizações passivas diárias, mobilizações ativas e sentar na berma do leito e efetuada transferência para cadeirão 2 vezes por dia durante 1 a 2 horas. Uma das restrições para o sentar na berma do leito abrangia dosagens reduzidas de vasopressores (noradrenalina entre 0,1-0,2 $\mathrm{mcg} / \mathrm{Kg} / \mathrm{min}$ ). Se a pessoa não tivesse equilíbrio ou havia restrições para sentar na berma do leito eram transferidas para uma cadeira-maca, mantendo o decúbito dorsal durante a transferência, durante 1 hora até 3 vezes por dia ou, se tivesse hipotensão ortostática, era transferida para a mesa de verticalização com aumento progressivo da inclinação até atingir a posição ortostática À medida que as pessoas melhoravam era realizado um exercício mais ativo e, progressivamente, iniciado levante e deambulação. Aproximadamente um terço das pessoas realizou 2 sessões por dia e $0 \mathrm{n}^{\circ}$ de sessões por dia foi de $1,3^{(23)}$.

Quanto ao Estudo 6, este utilizou um programa de cuidados que atuava em 3 diferentes níveis. No primeiro nível constava a aplicação de um protocolo de desmame ventilatório em que se realizava períodos de respiração espontânea progressivamente mais prolongados. 0 segundo nível de intervenção refere-se ao treino físico, em que a realização da pedaleira e o treino resistido foram realizados 6 vezes por semana, de pelo menos 15 sessões. A intensidade e duração da realização da pedaleira eram de aumento progressivo (máximo de 30 minutos 2 vezes por dia), assim como das mobilizações ativas-resistidas (máximo de 2 séries de 10 repetições e com carga de $100 \mathrm{~g}$ até $500 \mathrm{~g}$ ). 0 terceiro nível de atuação consistia na avaliação do suporte nutricional tendo em conta duração da sessão de fisioterapia ${ }^{(24)}$.
No que concerne ao Estudo 1, foi descrito a realização de diversas intervenções, mas não houve qualquer referência à frequência, volume, intensidade ou duração das modalidades efetuadas ${ }^{(19)}$.

No que concerne à utilização da mesa de verticalização (Estudo 7), esta foi utilizada no primeiro dia até $60^{\circ}$ e nos segundo e restantes dias até $90^{\circ}$, conforme descrito na tabela 3 . Foram avaliados parâmetros vitais, escala de comas de Glasgow, a Richmond Agitation Sedation Scale e a avaliação do volume/minuto expiratório, volume corrente, índice de respiração rápido e superficial e pressão inspiratória e expiratória máxima nos diversos graus de inclinação. Em média realizaram-se 5,2 dias deste protocolo. De referir ainda que a administração de terapêutica vasopressora foi critério de exclusão na seleção dos participantes ${ }^{(25)}$.

O Estudo 8 tinha por objetivo demonstrar os benefícios das mobilizações passivas com a utilização do artromotor. Esta intervenção foi realizada uma única vez durante 20 minutos na intensidade de 20 flexões/extensões por minuto (flexão de $5^{\circ}$ a $70^{\circ}$ ). Antes do início desta intervenção a pessoa permanecia 30 minutos em repouso. No final do período repouso eram avaliados diversos parâmetros como a frequência cardíaca, pressão arterial média, saturação de oxigénio, pressão intracraniana, pressão de perfusão cerebral e a Behavioral Pain Scale. Esses parâmetros vitais eram avaliados 5 e 10 minutos após o início da intervenção e, após o fim da mesma, havia um período de repouso de 60 minutos e eram novamente avaliados os parâmetros vitais (26).

\section{Benefícios}

O ganho na capacidade funcional das pessoas foi descrito por vários estudos através da aplicação de diversos instrumentos, nomeadamente a escala de força muscular Medical Research Council e escala de Kendall, Manchester Mobility Score, teste de equilíbrio sentado de acordo com os critérios de Stolov, Índice de Barthel, Medida de Independência Funcional e também na capacidade de realização das atividades de vida diárias, demonstrando melhoria nestes parâmetros no grupo de intervenção(21, 23, 24, 27). Por outro lado, foi associado um maior grau de dependência nas atividades de vida diária a um pior resultado clínico ${ }^{(24)}$. Os estudos demonstraram que a mobilização precoce conduziu à diminuição do número de dias de internamento nas $\mathrm{UCl}$ e internamentos hospitalar e à redução da morbilidade e mortalidade $(19,21-24,27)$. Estes indicadores de melhoria da capacidade funcional bem como o abreviar dos dias de internamento hospitalar traduzem-se em ganhos em saúde, para as pessoas e para as instituições, representando uma importante poupança de recursos.

Relativamente à função respiratória, os estudos demonstraram que houve redução do número de dias sob VMI, aumento da pressão inspiratória máxima, redução em $50 \%$ das reentubações endotraqueais devido a complicações da via aérea e, um outro estudo, referiu que após a intervenção efetuada as pessoas foram extubadas no imediato devido à 
melhoria do nível de consciência que esta aportou (21. $23,24,25,27)$.

A implementação da mobilização precoce em pessoas submetidas a VMI reduziu a ocorrência de pneumonia associada ao ventilador, complicações pulmonares e vasculares, trombose venosa profunda e úlceras por pressão $(20,22)$. Estes resultados obtidos contribuíram para que houvesse uma mudança significativa na mentalidade dos enfermeiros envolvidos num estudo, constatando a importância da mobilização precoce e que esta é passível de ser efetuada em segurança ${ }^{(22)}$.

Outros benefícios importantes reportados nos estudos em análise foi a melhoria do nível de consciência através da colocação das pessoas em posição ortostática utilizando a mesa de verticalização, explicada pelo aumento da estimulação sensorial, e a melhoria do conforto durante a realização de mobilizações passivas, sendo que este conforto poderá prolongar-se por 60 minutos após a intervenção $(25,26)$.

Todos os estudos em análise demonstraram inúmeros benefícios da aplicação da mobilização precoce na pessoa em situação crítica. Estes dados obtidos demonstraram ganhos em saúde, tanto para a pessoa como a nível institucional. Uma vez que a política atual tem por base a otimização de custos no nosso Sistema Nacional de Saúde, a aplicação da mobilização precoce nas unidades de cuidados intensivos poderá ter um impacto significativo.

\section{Segurança}

$\mathrm{Na}$ prática clínica atual a segurança do doente tem surgido como um elemento primordial em cuidados de saúde. A pessoa internada na $\mathrm{UCl}$ está sujeita diversos condicionantes que poderão acrescer risco na execução da mobilização precoce, uma vez que poderá advir instabilidade hemodinâmica e ventilatória, extubação acidental ou exteriorização de outros dispositivos médicos. De acordo com os estudos, a implementação de intervenções de mobilização precoce é segura, não havendo referência à ocorrência de eventos adversos (19, 20, 22, 24, 25).

A estabilidade hemodinâmica e ventilatória foi considerada um critério essencial para a implementação da mobilização precoce. A utilização da mesa de verticalização e as mobilizações passivas não revelaram alterações fisiológicas que pudessem interromper a sua execução $(25,26)$. A administração de terapêutica vasopressora nem sempre era impeditiva para a realização de mobilização precoce $(21,26)$. Num dos estudos a terapêutica vasopressora era considerada um critério de exclusão (25) e noutros estudos era considerada contraindicação absoluta ou relativa, dependendo da dosagem administrada, adequando assim o tipo de intervenção a que estas pessoas eram sujeitas $(20,22,23)$.

A mobilização precoce se for devidamente implementada através da utilização de protocolos, assegurada uma monitorização contínua dos parâmetros hemodinâmicos e ventilatórios e identificadas as intervenções adequadas para superar as barreiras que poderão existir, a realização da mobilização precoce é segura para as pessoas e o risco da sua aplicação na prática diária é mínimo, corroborado pela opinião dos referidos autores. Por outro lado, a formação da equipa multidisciplinar acerca da mobilização precoce da pessoa submetida a ventilação mecânica invasiva é essencial para que esteja devidamente esclarecida e preparada para a sua realização. Todos estes fatores são fundamentais para garantir a segurança das pessoas.

\section{Barreiras à mobilização precoce}

As principais barreiras identificadas que impossibilitaram a mobilização precoce foram a sedação e a entubação endotraqueal (19). A utilização de protocolos que permitam uma adequada gestão do nível de sedação, bem como a necessidade de uma apropriada analgesia e controlo do delírio são componentes essenciais para a capacidade da pessoa se mobilizar precocemente e de cooperar com as intervenções a realizar ${ }^{(28)}$. Níveis de sedação elevados impossibilitam a capacidade da pessoa se mobilizar de forma ativa ou fora do leito, mas não são impeditivos de se efetuar mobilizações passivas, de acordo com protocolos de mobilização precoce utilizados em vários estudos $(22,23,25,26)$. Alguns estudos alteraram as práticas de sedação de forma a diminuir o impacto desta barreira na realização da mobilização precoce $(20,22)$. No que concerne à entubação endotraqueal, esta é reportada como barreira à mobilização precoce devido ao risco acrescido de extubação. Um dos estudos superou esta barreira através da aquisição de dispositivos de reforço da fixação dos tubos endotraqueais ${ }^{(20)}$. Para além do risco de extubação, a exteriorização de outros dispositivos médicos como cateteres arteriais e venosos centrais também foram descritos como fatores restritivos da mobilização precoce $^{(19,20,22)}$.

A estabilidade hemodinâmica e ventilatória é uma componente fundamental para a realização de mobilização precoce. Se a pessoa não tiver reserva cardiovascular e respiratória adequada poderá influenciar a evolução do processo de mobilização precoce ${ }^{(28)}$. Devido a este facto, fatores como necessidade de elevadas frações inspiratórias de oxigénio, frequências respiratórias elevadas e valores instáveis de tensão arterial ou frequência cardíaca foram considerados critérios de exclusão para se proceder à mobilização precoce (19, 21-26). A administração de vasopressores (19), por vezes era considerada critério de exclusão ${ }^{(25)}$ ou contraindicação absoluta ou relativa, dependendo da dosagem administrada, sendo assim necessário adequar o tipo de intervenção a efetuar $(20,22,23)$.

Mobilizar a pessoa em situação crítica, conectada a diversos dispositivos médicos e com necessidade de monitorização hemodinâmica e ventilatória contínua, requer inúmeros recursos materiais e humanos, essencialmente quando é necessária a mobilização fora do leito. A necessidade de reforço de recursos humanos e materiais para a implementação de protocolos de mobilização precoce foi constatada por diversos estudos, não sendo estes barreiras adicionais 
na sua implementação $(20,22,23)$. A envolvência da equipa multidisciplinar (médico, enfermeiro especialista em enfermagem de reabilitação, enfermeiro, fisioterapeuta) é essencial para a esta prática seja efetivamente implementada.

\section{Fragilidades dos estudos}

Gostaríamos de salientar que alguns estudos apresentaram um número reduzido de participantes $(20,21,24-26)$, bem como o tempo reduzido de duração de alguns estudos, o que poderá pôr em causa os benefícios obtidos através das intervenções realizadas $(25,26)$.

Alguns estudos apesar de descreverem as modalidades efetuadas não especificam a frequência, intensidade, volume e duração das mesmas. Esta informação é essencial para determinar 0 seu impacto nos resultados obtidos (19, 22, 23). Apenas 2 estudos abordaram a componente ventilatória através de realização de exercícios respiratórios ou na utilização de um protocolo de desmame ventilatório ${ }^{(21,24)}$. De salientar ainda que apenas um estudo teve em conta a avaliação das necessidades calóricas das pessoas, sendo este um importante fator a ter em conta na capacidade da pessoa para a execução das intervenções ${ }^{(24)}$.

Na maioria dos estudos analisados não há referência a presença de enfermeiros especialistas em reabilitação. Os exercícios efetuados foram realizados essencialmente pelos fisioterapeutas pelo que consideramos uma limitação deste estudo, pois o objetivo do mesmo era analisar as intervenções de enfermagem de reabilitação, para além de descrever os benefícios da mobilização, sendo que este último facto foi alcançado.

\section{Implicações práticas e para futuras investigações}

A utilização de protocolos de mobilização precoce é uma das estratégias usadas pela equipa multidisciplinar para facilitar a progressão nos ganhos de mobilidade durante a hospitalização das pessoas, assim como garantir maior segurança no cuidado providenciado às pessoas ${ }^{(28)}$. Constatámos que é de extrema importância a utilização de um protocolo estruturado, de forma a providenciar mobilização precoce uniformizada à pessoa em situação crítica, com o intuito de combater a imobilidade e as suas sequentes sequelas ${ }^{(20-23)}$.

A identificação de barreiras que impossibilitem a mobilização precoce é essencial para que esta seja uma prática consolidada nas unidades de cuidados intensivos. Alguns estudos utilizaram um modelo de melhoria de qualidade para implementar protocolos de mobilização precoce, identificaram barreiras à sua implementação, efetuaram formação da equipa multidisciplinar e identificaram intervenções adequadas para superar as barreiras identificadas, para que estas não fossem impeditivas da sua implementação ${ }^{(20,22)}$.
Alguns estudos não foram exaustivos no que diz respeito à referência da frequência, intensidade, volume e duração das intervenções efetuadas, referindo apenas quais as diferentes intervenções realizadas. Para melhor determinar o impacto das intervenções de mobilização precoce nos resultados obtidos torna-se essencial uma maior pormenorização destes parâmetros $(19,22,23)$.

A utilização de protocolos, a promoção de uma cultura de mobilização precoce, a formação da equipa multidisciplinar e a identificação de barreiras, bem como as intervenções adequadas para as superar, são questões fundamentais para que os profissionais estejam mais capacitados e consciencializados, conduzindo a uma disseminação efetiva da mobilização precoce nas UCI.

\section{Limitações do estudo}

No que concerne à presente revisão esta apresenta condicionantes que podem ser consideradas como limitações, uma vez que apenas foram incluídos na pesquisa estudos em Português, Inglês e Espanhol, artigos com texto completo, de livre acesso e num horizonte temporal de janeiro de 2010 e setembro de 2018. Ainda como limitação gostaríamos de referir a utilização de um número reduzido de bases de dados.

\section{CONCLUSÃO}

A mobilização precoce tem sido reportada como intervenção essencial e imprescindível na prática diária do cuidar da pessoa em situação crítica, sendo um fator determinante da sua recuperação. Através da análise dos 9 estudos incluídos, verificámos que a mobilização precoce conduz a uma melhoria da capacidade funcional, diminui o tempo de VMI e reduz a ocorrência de diversas complicações. Consequentemente levará a uma diminuição dos dias de permanência em $\mathrm{UCl}$ e de internamento hospitalar, reduz a morbilidade, a mortalidade e o número de reinternamentos. Tudo isto indica que as intervenções de mobilização precoce das pessoas em situação crítica têm influência direta na recuperação a curto e longo prazo, ou seja, intra-hospitalar e após a alta hospitalar, aportando inúmeros ganhos em saúde.

Consideramos que a mobilização precoce em pessoas submetidas a VMI, e também na pessoa em situação crítica em geral, é dotada de benefícios que podem ser realizados em segurança, com um relato mínimo de eventos adversos. A falta de formação e de protocolos de atuação foram identificados como a maior lacuna à aderência a esta prática, pelo que consideramos essencial a criação de protocolos para a implementação destas medidas terapêuticas.

O Enfermeiro Especialista em Reabilitação assume um papel determinante no que concerne à mobilização precoce realizada nas $\mathrm{UCl}$. Este deverá ser considerado um elemento disseminador e promotor de uma cultura de mobilização precoce. No que diz respeito a este tema, existe uma carência de estudos realizados pelos enfermeiros detentores desta 
especialidade, podendo estar associado ao facto dos mesmos não exercerem as suas competências específicas nas unidades de cuidados intensivos, o que consideramos uma limitação desta revisão integrativa.

\section{REFERÊNCIAS BIBLIOGRÁFICAS}

1.Ministério da Saúde. RNEHR de Medicina Intensiva.2017;3,4. Available from: https://www.sns.gov.pt/wpcontent/uploads/2017/08/RNEHR-Medicina-Intensiva-Aprovada$\underline{10-a}$

2.Santos A, Oliveira I, Silveira T. Mobilização precoce em UCI. Salutis Scientia, 2010; 2, 20-24 Available from: http://www.salutisscientia.esscvp.eu/Site/Artigo.aspx?artigoid= $\underline{30463}$

3.Albuquerque IM, Machado AD. Impacto da mobilização precoce em (de la movilidad temprana en) pacientes de terapia intensiva. Salud(i)Ciencia (Impresa). 2015;21:403-8. Available from: https://www.researchgate.net/profile/Isabella_Albuquerque/pu blication/282848751_Impacto_da_mobilizacao_precoce_em_de_l a_movilidad_temprana_en_pacientes_de_terapia_intensiva_Impa ct_of_early_mobilization_in_intensive_care_patients/links/561e 3f6c08ae50795afd933c/Impacto-da-mobilizacao-precoce-em-dela-movilidad-temprana-en-pacientes-de-terapia-intensivaImpact-of-early-mobilization-in-intensive-care-patients.pdf

4.Santos F, Mandelli PG, Ostrowski VR, Tezza R, da Silva Dias J. Relação entre mobilização precoce e tempo de internação em uma unidade de terapia intensiva. Revista Eletronica Gestão \& Saúde. 2015 Jan 12;6(2):1394-407. Available from: http://periodicos.unb.br/index.php/rgs/article/view/22475/160 72

5. Hodgson C, Bellomo R, Berney S, Bailey M, Buhr H, Denehy L, Harrold M, Higgins A, Presneill J, Saxena M, Skinner E. Early mobilization and recovery in mechanically ventilated patients in the ICU: a bi-national, multi-centre, prospective cohort study. Crit Care. 2015 Dec 1;19(1):81. P 1-10 Available from: https://link.springer.com/article/10.1186/s13054-015-0765-4

6.Severino, S. Enfermagem de Reabilitação à Pessoa Submetida a Ventilação Mecânica. In: Marques-Vieira, C. Santos, LL. Cuidados de Enfermagem de Reabilitação à Pessoa ao Longo da Vida. Primeira E. Loures: Lusodidacta - Soc. Port. de Material Didáctico, Lda.; 2017. P 365-378

7. Martinez BP, Bispo AO, Duarte AC, Neto MG. Declínio funcional em uma unidade de terapia intensiva (UTI). movimento. 2013;5(1). P 1-5. Available from: https://www.researchgate.net/profile/Mansueto_Neto/publicati on/257169739_Functional_decline_in_intensive_care_unit_ICU/li nks/0a85e53b2eee6ec14d000000/Functional-decline-inintensive-care-unit-ICU.pdf

8.Ågård AS, Egerod I, Tønnesen E, Lomborg K. Struggling for independence: A grounded theory study on convalescence of ICU survivors 12 months post ICU discharge. Intensive Crit Care Nurs. 2012 Apr 1;28(2):105-13. https://pure.au.dk/portal/files/51944995/Struggling_for_indep endence.pdf20

9.Azevedo PM, Gomes BP. Efeitos da mobilização precoce na reabilitação funcional em doentes críticos: uma revisão sistemática. Referência. 2015 Jun. IV(5) 129-38. Available from: http: / / www. scielo.mec.pt/scielo.php?pid=S0874$02832015000200015 \&$ script $=$ sci_arttext\&tlng=em

10.Eakin $M N$ intensive care unit: a qualitative analysis. J Crit Care. 2015 Aug 1;30(4):698-704. Available from: https://scihub.tw/10.1016/j.jcrc.2015.03.019, Ugbah L, Arnautovic T, Parker AM, Needham DM. Implementing and sustaining an early rehabilitation program in a medical

11.Jong, N. Rehabilitation in the Intensive Care Unit. In: He, K. Yap, S. Joo, L. Handbook of Rehabilitation Medicine. Singapore. World Scientific Publishing. 2017. P133-139. Available from: https://sci-hub.tw/10.1142/9789813148727_0012

12.Duque, H. Ferreira, A. Sousa, L. Reabilitação Respiratória na Pessoa Submetida a Ventilação Invasiva. In: Cordeiro, M; Menoita, E. Manual de boas práticas na reabilitação respiratória: conceitos, Princípios e Técnicas. 1 ed. Loures. Lusociência; 2012. P194-211

13. Vilelas J. Investigação: 0 processo de construção do conhecimento. 2 ed. Lisboa: Edições Sílabo; 2017.

14. JBI User Manual: System for the Unified Management. Assessment and Review of Information. Joanna Briggs Institute's. Version 2.5. 2011.

15. Bugalho A, Carneiro AV. Intervenções para aumentar a adesão terapêutica em patologias crónicas. Lisboa: Centro de Estudos de Medicina Baseada na Evidência. 2004 Jun.

16. Registered Nurses Association of Ontario (RNAO). Falls Prevention: Building the Foundations for Patient Safety. A Self Learning Package. Toronto: Registered Nurses Association of Ontario; 2007.

17. Amidei C, Sole ML. Physiological responses to passive exercise in adults receiving mechanical ventilation. American J Crit Care. 2013 Jul 1;22(4):337-48. Available from: http://ajcc.aacnjournals.org/content/22/4/337.full.pdf+html

18. Azevedo PM, Gomes BP. Efeitos da mobilização precoce na reabilitação funcional em doentes críticos: uma revisão sistemática. Referência. 2015 Jun. IV(5) 129-38. Available from: http://www.scielo.mec.pt/scielo.php?pid=S0874$02832015000200015 \&$ script $=$ sci_arttext\&tlng=em

19. TEAM Study Investigators. Early mobilization and recovery in mechanically ventilated patients in the ICU: a bi-national, multicentre, prospective cohort study. Crit Care. 2015 Dec 1;19(1):81.Available from: https://link.springer.com/article/10.1186/s13054-015-0765-4.

20. Castro E, Turcinovic M, Platz J, Law I. Early mobilization: changing the mindset. Crit care nurs. 2015 Aug 1;35(4):e1-6. Available http://ccn.aacnjournals.org/content/35/4/e1.full.pdf+html.

21. Yosef-Brauner O, Adi N, Ben Shahar T, Yehezkel E, Carmeli E. Effect of physical therapy on muscle strength, respiratory muscles and functional parameters in patients with intensive care unit-acquired weakness. The Clinical Respiratory Journal [serial on the Internet]. (2015, Jan), [cited September 18, 2018]; 9(1): $\quad 1-6 . \quad$ Available https://onlinelibrary.wiley.com/doi/pdf/10.1111/crj.12091

22. Clark DE, Lowman JD, Griffin RL, Matthews HM, Reiff DA. Effectiveness of an early mobilization protocol in a trauma and burns intensive care unit: a retrospective cohort study. Physical therapy. 2013 Feb 1;93(2):186-96. Available from: https://academic.oup.com/ptj/article/93/2/186/2735509

23. McWilliams D, Weblin J, Atkins $G$, Bion J, Williams J, Elliott C, Whitehouse T, Snelson C. Enhancing rehabilitation of mechanically ventilated patients in the intensive care unit: a quality improvement project. J Crit Care. 2015 Feb 1;30(1):13-8. Available

from: https://www.sciencedirect.com/science/article/pii/S088394411 4004018

24. Clini EM, Crisafulli E, Degli Antoni F, Beneventi C, Trianni L, Costi S, Fabbri LM, Nava S. Functional recovery following physical training in tracheotomized and chronically ventilated patients. Respiratory care. 2011 Mar 1;56(3):306-13. Available from:

http://rc.rcjournal.com/content/respcare/56/3/306.full.pdf

25. Toccolini BF, Osaku EF, de Macedo Costa CR, Teixeira SN, Costa NL, Cândia MF, Leite MA, de Albuquerque CE, Jorge AC, Duarte PA. Passive orthostatism (tilt table) in critical patients: Clinicophysiologic evaluation. J Crit Care. 2015 Jun 1;30(3):655e1. Available from: https://www.sciencedirect.com/science/article/pii/S088394411 $\underline{4005085}$

26. Amidei C, Sole ML. Physiological responses to passive exercise in adults receiving mechanical ventilation. American J Crit Care. 2013 Jul 1;22(4):337-48. Available from: http://ajcc. aacnjournals.org/content/22/4/337.full.pdf+html

27. Azevedo PM, Gomes BP. Efeitos da mobilização precoce na reabilitação funcional em doentes críticos: uma revisão sistemática. Referência. 2015 Jun. IV(5) 129-38. Available from: http://www.scielo.mec.pt/scielo.php?pid=S0874$02832015000200015 \&$ script $=$ sci_arttext\&tlng $=e m$

28. Rocha AM, Martinez BP, da Silva VM, Junior LF. Early mobilization: Why, what for and how?. Med intensiva. 2017 Oct 1;41(7):429-36. Available from: http://ipametodista.edu.br/posgraduacao/stricto-sensu/processo-seletivo/early-mobilization2017.pdf 
O TREINO DE EXERCÍCIO EM PESSOAS COM DOENÇA RESPIRATÓRIA CRÓNICA ESTABILIZADA : UMA SCOPING REVIEW

\title{
ENTRENAMIENTO MUSCULAR EN PERSONAS CON ENFERMEDAD RESPIRATORIA CRÓNICA ESTABILIZADA: UNA SCOPING REVIEW
}

\section{EXERCISE TRAINING IN PEOPLE WITH A STABILIZED CHRONIC RESPIRATORY DISEASE: A SCOPING REVIEW}

DOI 10.33194/rper.2019.v2.n1.08.4567 | Submetido 14.03.2019 | Aprovado 22.06.2019

\author{
Luis Gaspar'; Dulce Ferreira²; Francisco Vieira³; Paulo Machado³; ;iguel Padilha ${ }^{3}$ \\ 1 - Centro Hospitalar e Universitário São João; 2 - ECCI Torres Vedras; 3 - Escola Superior de Enfermagem do Porto
}

\section{RESUMO}

Introdução: A Reabilitação Respiratória (RR) integra a componente não farmacológica das principais guidelines clínicas para o controlo e tratamento das doenças respiratórias crónicas.

O Enfermeiro de Reabilitação (ER), integrado numa equipa multidisciplinar, concebe, implementa e monitoriza programas de RR onde se inclui o treino do exercício.

Sendo o conhecimento disciplinar de enfermagem um dos pilares da decisão clínica e a garantia da qualidade e segurança dos cuidados de enfermagem torna-se relevante conhecer o impacte destes programas, conduzidos por ER, de forma a melhorar a prática clinica.

Objetivo: Conhecer o impacte dos programas de RR, conduzidos por enfermeiros, nas pessoas com doença respiratória crónica.

Metodologia: Scoping review com metodologia do Joanna Briggs Institute ${ }^{\circ}$ com recurso a dois revisores independentes.

Resultados: incluímos 10 estudos que revelaram que programas de RR conduzidos por enfermeiros de reabilitação aumentam a tolerância ao exercício, a qualidade de vida, a independência funcional e reduzem a dispneia e a ansiedade.

Conclusão: A RR realizada por ER em pessoas com doença respiratória crónica é sobreponível à mais recente evidência.

Palavras-chave: Treino de exercício, Enfermagem de Reabilitação, Reabilitação Respiratória, Doença respiratória crónica

\section{RESUMEN}

Introducción: La Rehabilitación Pulmonar (RP) es el tratamiento no farmacológico que consta en los principales guías clínicos para el control y la realización de las tareas respiratorias crónicas.

El Enfermero de Rehabilitación (ER), constituido en una disciplina multidisciplinaria, concibe, implementa y monitorea programas de RP en que se incluye el entrenamiento del ejercicio.

Siendo el conocimiento disciplinario de enfermería uno de los pilares de la decisión clínica y el garante de la calidad y seguridad de los cuidados de enfermería, resulta relevante conocer el impacto de estos programas, conducidos por ER, para mejorar la práctica clínica.

Objetivo: conocer el impacto de los programas de RR, conducidos por enfermeros, en las personas con la enfermedad respiratoria crónica.

Metodología: Revisión de alcance con metodología del Instituto Joanna Briggs ${ }^{\circledR}$ con dos revisores independientes.

Resultados: incluimos 10 estudios que revelaron que los RR conducidos por enfermeros aumentaron la tolerancia al ejercicio, una calidad de vida, una autonomía funcional y una disnea y la ansiedad.

Conclusión: La RR realizada por ER en personas con enfermedad respiratoria es crónica es sobreponible a la más reciente evidencia.

Palabras clave: Ejercicio, Enfermería de Rehabilitación, Rehabilitación Respiratoria, Enfermedad respiratoria crónica 
Introduction: Pulmonary Rehabilitation is (PR) integrates the non-pharmacological component of the clinical guidelines for the control and treatment of chronic respiratory diseases.

The Rehabilitation Nurse (RN), integrated into a multidisciplinary team, designs, implements and monitors PR programs that include exercise training.

Being the nursing disciplinary knowledge one of the pillars of clinical decision and the guarantor of the quality and safety of nursing care becomes relevant to know the impact of these programs, conducted by RN, in order to improve clinical practice.

Objective: To know the impact of RR programs, conducted by nurses, on people with chronic respiratory disease.

Methodology: Scoping review with Joanna Briggs Institute ${ }^{\circ}$ methodology using two independent reviewers.

Results: We included 10 studies that showed that nurse-led PR programs increase exercise tolerance, quality of life, functional independence, and reduce dyspnea and anxiety.

Conclusion: The PR performed by RN in patients with chronic respiratory disease is overlapping with the latest evidence.

Key words: Exercise training, Rehabilitation Nursing, Respiratory Rehabilitation, Chronic Respiratory Disease

\section{INTRODUÇÃO}

A dispneia, a intolerância à atividade e a redução da qualidade de vida são manifestações frequentes em pessoas com doença respiratória crónica (DRC) (1-4). Estas manifestações não são apenas resultantes da perda da função pulmonar, mas resultam da disfunção muscular periférica. Se assim fosse a medicação, isoladamente, seria efetiva no aumento da tolerância à atividade, facto que não se verifica (1-2, 5-6). A disfunção muscular periférica é caraterizada pela perda de força e massa muscular que conduz a alterações da distribuição de fibras musculares, que conjuntamente com alterações nas trocas gasosas resultam em redução da capacidade para o exercício nas pessoas com DRC.

Esta intolerância à atividade limita a independência funcional com consequente impacte negativo na capacidade para o autocuidado (9), e no aumento da mortalidade $(1,10)$.

Clinicamente, traduz-se por incapacidade da pessoa em realizar as suas atividades de vida diária, na intensidade ou na duração normalmente tolerável para pessoas saudáveis e sedentárias (1). Esta adoção de um estilo de vida sedentário (de forma a evitar a dispneia funcional) origina descondicionamento muscular, potenciando a perda de função $(1,7,10$ 11).

A performance muscular (força e endurance) resulta da estrutura fisiológica dos músculos, sendo que a disfunção muscular periférica manifestada pelas pessoas com DRC resulta de uma alteração da distribuição das fibras musculares, do seu tamanho, da densidade capilar e da capacidade metabólica $(2,4-$ $5,11)$.

Neste contexto emerge a importância incontornável do treino de exercício, que

num programa de reabilitação respiratória (PRR) contribui para o aumento da tolerância ao exercício, diminuindo o consumo de oxigénio face à mesma quantidade de exercício e reduzindo as manifestações de dispneia $(1,5,8)$.

0 treino de exercício neste contexto inclui o treino aeróbio, ou treino de endurance e treino anaeróbio ou de força muscular.

O treino aeróbio, ou treino de endurance, utiliza grandes grupos musculares com duração moderada a longa e com intensidade moderada a elevada $(2,4,9,12)$. Requer atividade física repetida ao longo de um período específico de tempo e tem como objetivo aumentar e modular a capacidade de resistência e aumentar o numero de fibras do tipo I.

Por seu lado o treino de força muscular (componente anaeróbica do treino) destinado a aumentar a força e massa musculares, fundamental para a realização de atividades de vida diária, utiliza pequenos grupos musculares em intensidade elevada e em curta duração reduzindo desta forma as limitações cardiorrespiratórias características das pessoas com doença respiratória crónica em estadios mais avançados da doença.

A melhor resposta fisiológica, obtém-se, pela junção das duas modalidades de treino sendo tendencialmente, realizada em alta intensidade.

Esta é a razão porque a Reabilitação Respiratória, que inclui obrigatoriamente o treino de exercício, é o tratamento não farmacológico recomendado para pessoas com doença respiratória crónica em contexto ambulatório.

Neste sentido o papel do Enfermeiro de Reabilitação não deve estar unicamente relacionado com a cinesiterapia respiratória nem com a componente educacional devendo acompanhar a evidencia científica e passar também pelo treino de exercício, como se encontra de resto plasmado no Regulamento de Competências Especificas do Enfermeiro Especialista em Enfermagem de Reabilitação, que descreve como competência do Enfermeiro de Reabilitação - conceber, implementar, avaliar e reformular programas de treino motor e cardiorespiratório. 
Face ao exposto torna-se fundamental conhecer os programas de treino de exercício englobados nos PRR realizados por enfermeiros de reabilitação.

Uma pesquisa prévia realizada na MEDLINE e CINAHL não revelou nenhuma revisão da literatura sobre esta temática, pelo que se optou por realizar uma Scoping Review com o objetivo de mapear o uso do treino de exercício nos programas de reabilitação respiratória realizados por enfermeiros a pessoas com doença respiratória crónica em contexto ambulatório.

A opção por uma scoping review prendeu-se não só pelo objetivo de mapear a evidência científica de forma a suportar a decisão clínica dos enfermeiros de reabilitação, mas também, para identificar eventuais áreas de interesse para a investigação disciplinar.

\section{MÉTODO}

A metodologia usada na realização desta scoping review seguiu os passos propostos pelo Joanna Briggs Institute ${ }^{\circledR}$, e pretendeu responder à seguinte questão: "Qual o impacte dos programas de treino de exercício, conduzidos por enfermeiros de reabilitação, nas pessoas com doença respiratória crónica?”

\section{Critérios de inclusão}

\section{Tipo de participantes}

Pessoas com doença respiratória crónica, sem limite de idade $\mathrm{e}$ independentemente da gravidade da doença.

\section{Conceito}

No que respeita aos conceitos foram incluídos artigos focados em programas de reabilitação respiratória definidos como "intervenção abrangente, baseada numa avaliação extensiva dos doentes, seguida por tratamentos individualizados que incluem - mas não limitados a - exercício físico. Educação e alteração comportamental, desenhados para melhorar a condição física e emocional de pessoas com doença respiratória crónica e para promover a adesão prolongada a comportamentos de saúde.” (1-3)

A definição de treino de exercício inclui a combinação de treino aeróbio e anaeróbio (com fortalecimento muscular dos membros superiores e inferiores) com a duração mínima de 8 semanas.(1-3)

\section{Contexto}

Foram integrados todos os artigos independentemente do local de implementação (hospital de dia, instituiçõos de cuidados de saúde primários ou domicílio).

\section{Tipo de estudos}

Esta revisão incluiu todos os tipos de estudos, incluindo estudos primários, revisões da literatura (em língua portuguesa, inglesa e espanhola) e literatura cinzenta (em língua Portuguesa) independente do ano de publicação.

\section{Critérios de exclusão}

Foram excluídos da revisão estudos aplicados a outras áreas da saúde que não enfermagem e aqueles em que a metodologia apresenta omissões no desenho da investigação.

\section{Estratégia de Pesquisa}

A pesquisa, realizada em junho de 2018 , foi desenhada considerando três principais etapas:

Na primeira etapa consideraram-se termos controlados de primeiro e segundo nível para a definição do termo de pesquisa, nomeadamente pela recolha dos descritores e qualificadores principais e adicionais presentes nos Medical Subject Headings (MeSH) e nos Headings do Cumulative Index of Nursing and Allied Health Literature (CINAHL). Foram acrescentadas, na segunda etapa, palavras-chave e termos utilizados pelos autores para a definição das categorias em análise, construindo-se o seguinte termo de pesquisa:

("Exercise training" OR "Pulmonary rehab*") AND ("Lung Disease*" OR "Pulmonary disease*" OR COPD OR Bronchiectasis OR "Cystic fibrosis" OR Asthma OR "Interstitial lung disease*") AND ("nurse led intervent*" OR "nurse-led clinic*" OR "Nurses practice pattern*") AND ("self-care" OR "functional independence" OR "exercise tolerance" OR "activity of daily living" OR "quality of life" OR "motor activity") NOT ("physical therapy*")

Assim sendo, foram rastreadas bases de dados referenciais, designadamente a Scopus e Web of Science, e o agregador de conteúdos EBSCO, permitindo a cobertura das seguintes bases de dados e índices MEDLINE, Science Citation Index, Social Sciences Citation Index, Emerging Sources Citation Index, Book Citation Index, Conference Proceedings Citation Index, Korean Citation Index, Russian Science Citation Index, SciELO Citation Index, Directory of Open Access Journals, Directory of Open Access Scholarly Resources, Academic Search Complete, Business Source Complete, CINAHL Complete, ERIC, MedicLatina, Psychology and Behavioral Sciences Collection e SPORTDiscus database. Acesce, ainda, a pesquisa em literature cinzenta no Repositório Científico de Acesso Aberto de Portugal.

$\mathrm{Na}$ terceira etapa foram analisadas as listas referenciais dos estudos incluídos por forma a construir o mapa de citações e referências potenciais para inclusão.

A seleção dos estudos foi feita de acordo com os critérios de inclusão e exclusão previamente definidos por dois revisores independentes, tendo por base as informações referidas no título e no resumo. 0 desacordo entre os dois revisores implicou a intervenção de um terceiro revisor. 
Para a etapa de separação, sumarização e relatório dos elementos essenciais encontrados em cada estudo, foi construído um instrumento estruturado próprio que permitiu a síntese, interpretação e análise dos dados, da natureza e da distribuição dos estudos incorporados na revisão. Itens como o ano de publicação, metodologia utilizada, duração dos programas de treino de exercício, as intervenções e os resultados obtidos foram agrupados.

$\mathrm{Na}$ fase final, foi construído um quadro de forma a obter uma visão global dos estudos incluídos na revisão. (figura 2 )

\section{EXTRAÇÃO DE RESULTADOS}

Tendo por base a estratégia de pesquisa aplicada foram identificados 34 artigos potencialmente relevantes.

Um foi excluído por ser duplicado, quatro foram excluídos após a análise do título e dezassete foram excluídos após a análise do resumo.

A análise do texto integral dos doze artigos restantes levou à exclusão de dois. Finalmente foram incluídos dez artigos na revisão (figura 1).

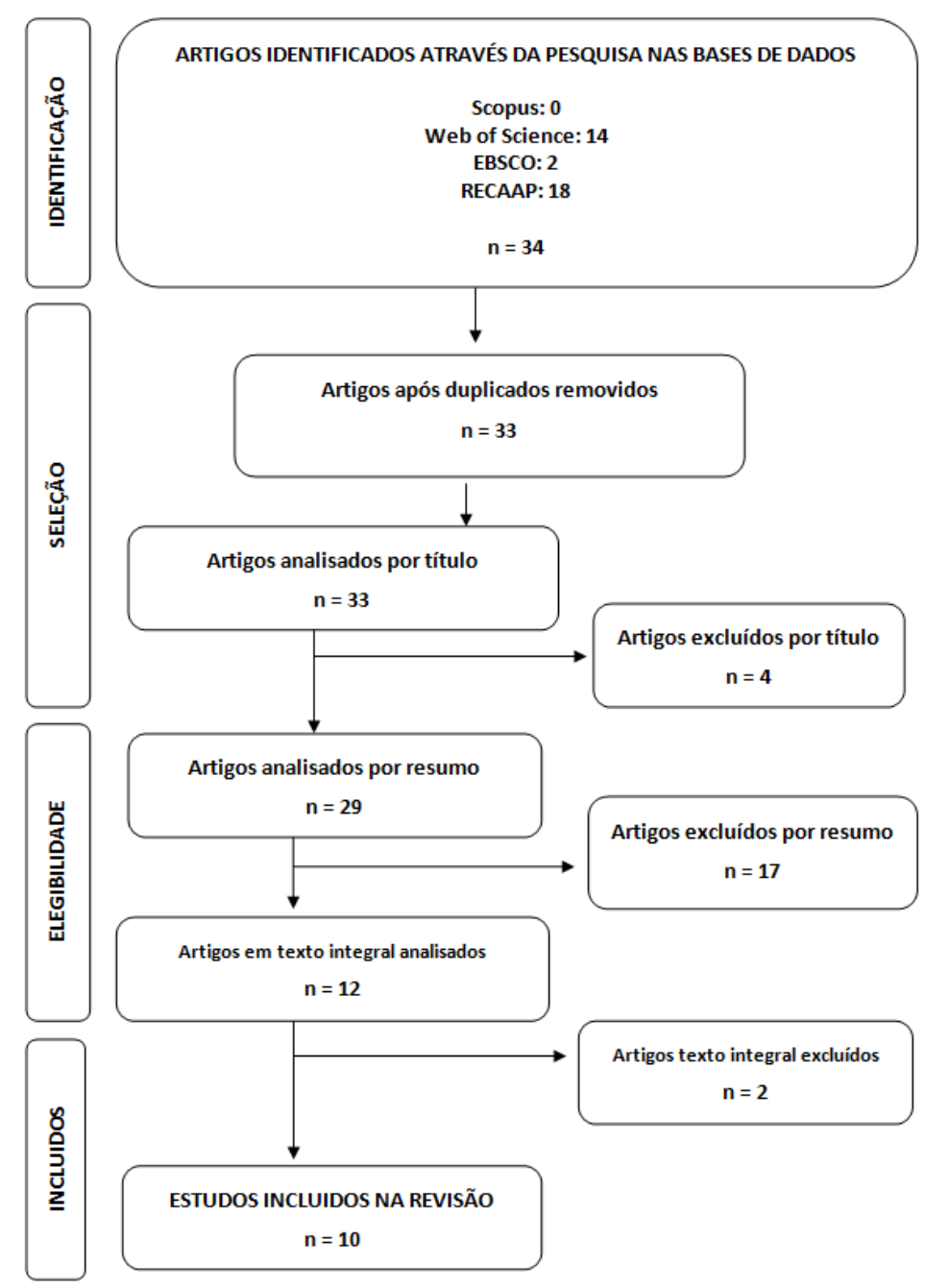

Figura 1 - Fluxograma PRISMA do processo de seleção dos artigos
A totalidade dos estudos é portuguesa sendo que oito resultam de dissertações de mestrado e dois de artigos científicos publicados em revista.

Do ponto de vista metodológico todos os estudos são quantitativos sendo que sete são Quasi-experimentais, dois descritivos exploratórios e uma revisão sistemática da literatura.

Constatou-se escassa produção científica acerca deste tema considerando os diversos contextos.

Seis estudos têm como intervenção cinesiterapia respiratória que não está recomendada neste contexto.

Da análise dos artigos emergiram as seguintes categorias de informação: duração / frequência do programa de treino de exercício, tipologia do treino de exercício e resultados obtidos.

\section{Duração dos programas de treino de exercício}

A duração dos programas de treino de exercício encontrada nos artigos em análise foi bastante diversa variando entre 7 e 39 semanas, sendo que na maioria dos artigos encontrados a duração dos programas se encontra entre 25 e 39 semanas.

\section{Tipologia do treino de Exercício}

A categoria tipologia do treino de exercício compreende o tipo e as características do treino.

$\mathrm{Na}$ totalidade dos artigos selecionados os programas de treino de exercício incluíram treino aeróbio de 30 minutos e treino anaeróbio, sendo este último dos membros superiores e inferiores.

Cinco artigos incluem como intervenção cinesiterapia respiratória que não está recomendada neste contexto.

\section{Resultados obtidos.}

Relativamente aos resultados obtidos três artigos referem diminuição da dispneia, cinco aumento da qualidade de vida e da tolerância nas atividades de vida diária, dois artigos revelam promoção do autocuidado, diminuição da ansiedade e aumento da tolerância ao esforço e um artigo refere melhoria da gestão do regime terapêutico

\section{DISCUSSÃO}

Os resultados desta revisão permitem-nos identificar que os programas de treino de exercício concebidos, implementados e realizados por enfermeiros de reabilitação concorrem para a diminuição da dispneia, da ansiedade, aumentando a tolerância ao esforço e às atividades de vida contribuindo desta forma para a melhoria da qualidade de vida.

Estes resultados são sobreponíveis à evidência cientifica claramente identificada nas ultimas Guidelines da European Respiratory Society publicadas 
em 2013(3) e confirmados em 2017 por Shioya et al (13).

Mais recentemente estudos como o de Robinson et al (8) e de McNamara et al (12) ambos em 2018 confirmaram o papel do treino do exercício na melhoria da dispneia.

Gordon et al em 2019 (14) publicaram uma metaanálise evidenciando o impacte do treino do exercício

\begin{tabular}{|c|c|c|c|c|c|c|c|c|}
\hline Âmbito & Autor & Data & $\mathbf{N}$ & Metodologia & Avaliação & Duração / frequência & Intervenção & Resultados \\
\hline Mestrado & Ferreira, A. & 2013 & 8 & Quasi experimental & $\begin{array}{l}\text { Dispneia } \\
\text { Atividades de vida diária } \\
\text { Qualidade de vida }\end{array}$ & 6 Semanas $3 x$ semana & \begin{tabular}{|l|} 
Treino de Força \\
Treino de Endurance \\
Cinesiterapia Respiratória \\
\end{tabular} & $\begin{array}{l}\downarrow \text { Dispneia } \\
\uparrow \text { Atividades de vida diária } \\
=\text { Qualidade de vida }\end{array}$ \\
\hline Mestrado & Gaspar, L. & 2013 & 23 & Quasi experimental & $\begin{array}{l}\text { Qualidade de vida } \\
\text { Ansiedade } \\
\text { Função Respiratória }\end{array}$ & $\begin{array}{l}13 \text { Semanas } \\
\text { 3xsemana }\end{array}$ & \begin{tabular}{|l} 
Treino de Força \\
Treino de Endurance \\
Cinesiterapia Respiratória (SOS)
\end{tabular} & $\begin{array}{l}\text { } \text { Qualidade de vida } \\
\downarrow \text { Ansiedade } \\
=\text { Função Respiratória }\end{array}$ \\
\hline Mestrado & Mendes, M. & 2014 & 11 & $\begin{array}{l}\text { Revisão sistemática } \\
\text { da literatura }\end{array}$ & $\begin{array}{l}\text { Gestão regime terapêutico } \\
\text { Promoção do Autocuidado }\end{array}$ & até 28 sessões & \begin{tabular}{|l|} 
Treino de Força \\
Treino de Endurance \\
Cinesiterapia Respiratória \\
\end{tabular} & 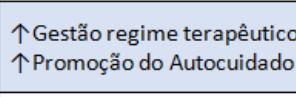 \\
\hline Mestrado & Casado, S. & 2012 & 14 & Quasi experimental & $\begin{array}{l}\text { Dispneia, } \\
\text { Atividades de vida diária } \\
\text { Qualidade de vida } \\
\text { Função Respiratória }\end{array}$ & $\begin{array}{l}15 \text { Sessões } \\
2 \text { Xsemana }\end{array}$ & $\begin{array}{l}\text { Treino de Força } \\
\text { Treino de Endurance } \\
\text { Cinesiterapia Respiratória }\end{array}$ & $\begin{array}{l}\downarrow \text { Dispneia, } \\
\uparrow \text { Atividades de vida diária } \\
\uparrow \text { Qualidade de vida } \\
\uparrow \text { Função Respiratória }\end{array}$ \\
\hline Mestrado & Ferreira, D. & 2014 & 7 & $\begin{array}{l}\text { Estudo de } \\
\text { multicasos }\end{array}$ & $\begin{array}{l}\text { Atividades de vida diária } \\
\text { Qualidade de vida } \\
\text { Tolerância ao esforço } \\
\text { Força muscular }\end{array}$ & 7 Sessões & $\begin{array}{l}\text { Treino de força e treino de } \\
\text { endurance, dos membros superiores }\end{array}$ & $\begin{array}{l}\text { 个 Atividades de vida diária } \\
=\text { Qualidade de vida } \\
\text { 个Tolerância ao esforço } \\
\text { 个Força muscular }\end{array}$ \\
\hline Mestrado & Santos, C. & 2017 & 30 & Quasi experimental & $\begin{array}{l}\text { Dispneia } \\
\text { Atividades de vida diária } \\
\text { Qualidade de vida }\end{array}$ & Max 30 sessões & $\begin{array}{l}\text { Treino de Força } \\
\text { Treino de Endurance }\end{array}$ & $\begin{array}{l}\downarrow \text { Dispneia } \\
\uparrow \text { Atividades de vida diária } \\
\uparrow \text { Qualidade de vida }\end{array}$ \\
\hline Mestrado & Rocha, S. & 2017 & 60 & Quasi experimental & $\begin{array}{l}\text { Atividades de vida diária } \\
\text { Qualidade de vida }\end{array}$ & 20 Sessões & \begin{tabular}{|l|} 
Treino de Força \\
Treino de Endurance \\
Cinesiterapia Respiratória \\
\end{tabular} & $\begin{array}{l}\text { 个Atividades de vida diária } \\
\text { = Qualidade de vida }\end{array}$ \\
\hline Mestrado & Cardoso, V. & 2013 & 4 & Quasi experimental & Qualidade de vida & 8 semanas $3 x$ semana & $\begin{array}{l}\text { Treino de Força } \\
\text { Treino de Endurance }\end{array}$ & $\uparrow$ Qualidade de vida \\
\hline $\begin{array}{l}\text { Artigo } \\
\text { Cientifico }\end{array}$ & Gaspar, L. & 2018 & 30 & $\begin{array}{l}\text { Prospectivo } \\
\text { Exploratório }\end{array}$ & $\begin{array}{l}\text { Qualidade de vida } \\
\text { Ansiedade } \\
\text { Função Respiratória }\end{array}$ & $\begin{array}{l}13 \text { Semanas } \\
\text { 3xsemana }\end{array}$ & $\begin{array}{l}\text { Treino de Força } \\
\text { Treino de Endurance }\end{array}$ & $\begin{array}{l}\text { TQualidade de vida } \\
\downarrow \text { Ansiedade } \\
=\text { Função Respiratória }\end{array}$ \\
\hline $\begin{array}{l}\text { Artigo } \\
\text { Cientifico }\end{array}$ & Gaspar, L. & 2018 & 38 & Quasi experimental & $\begin{array}{l}\text { Autocuidados: } \\
\text { Higiene } \\
\text { Vestir/Despir-se } \\
\text { Andar }\end{array}$ & $\begin{array}{l}13 \text { Semanas } \\
\text { 3xsemana }\end{array}$ & $\begin{array}{l}\text { Treino de Força } \\
\text { Treino de Endurance }\end{array}$ & $\begin{array}{l}\uparrow \text { Higiene } \\
\uparrow \text { Vestir/Despir-se } \\
\uparrow \text { Andar }\end{array}$ \\
\hline
\end{tabular}

Figura 2: Síntese dos artigos incluídos na revisão

O caracter multissistémico das doenças respiratórias crónicas (especialmente a DPOC) origina um declínio funcional progressivo, decorrente da sarcopenia secundária à imobilidade com consequências importantes, nomeadamente ao nível da autonomia na realização das atividades de vida diária e do autocuidado $(9-10,13)$.

Neste contexto surge a Reabilitação Respiratória como o tratamento não farmacológico indicado para pessoas com doença respiratória crónica centrada fundamentalmente numa abordagem em que o treino de exercício é, a par com a educação, a componente principal $(1,4,6)$.

Os programas de reabilitação respiratória aumentam a tolerância à atividade e reduzem a dispneia, aspetos que se traduzem em ganhos funcionais e na capacidade para o autocuidado $(2,9,15)$.

Para além destes efeitos, a reabilitação respiratória reduz também as hospitalizações e a mortalidade (16).

Não existe consenso acerca da sua duração sendo que a mais recente recomendação define como duração mínima de 8 semanas com 3 sessões por semana $(1,3,16)$. Sendo a maioria dos sintomas decorrentes da na depressão e na ansiedade. Relativamente ao aumento da tolerância ao esforço e suas consequências sobre a capacidade para executar as atividades de vida diária a evidência é vasta como comprovam os estudos de Bisca et al (2014) (15), Spruit et al em 2015 (5) e mais recentemente em 2019 o estudo de Vaes (15) evidenciando o impacte positivo nestas variáveis. 
Esta é a razão pela qual se conclui que a junção de treino aeróbio e anaeróbio é mais eficaz $(1,3,5)$.

A evidência relacionada com os resultados dos programas de treino de exercício é bastante vasta. Os estudos revelam existirem ganhos em saúde praticamente em todos os indicadores estudados, nomeadamente na dispneia e na intolerância à atividade com impacto importante na promoção do autocuidado e na qualidade de vida.

\section{CONCLUSÃO}

Este estudo permitiu identificar dois aspetos centrais: o primeiro, é que os programas de treino de exercício conduzidos por enfermeiros aderem aos guidelines internacionais; o segundo é que os resultados obtidos (melhoria na perceção de dispneia; diminuição da ansiedade; aumento à tolerância ao esforço e atividades de vida diária bem como na melhoria na qualidade de vida) são sobreponíveis à melhor evidência científica disponível.

Este estudo demonstra o impacte positivo da ação dos enfermeiros de reabilitação na condição de saúde das pessoas com doença respiratória crónica que participam em programas de treino de exercício.

Dada a importância amplamente descrita sobre os benefícios do treino de exercício neste contexto, mais estudos deverão ser realizados e publicados sobre esta temática.

\section{REFERÊNCIAS BIBLIOGRÁFICAS}

1. Ferreira D, Teodoro A, Gaspar Lea. Guia Orientador de Boa Prática - Reabilitação Respiratória Lisboa: Ordem dos Enfermeiros; 2018.

2. Gaspar L. Treino aeróbico e de fortalecimento muscular no doente com patologia respiratória. Enfermeiro: Anuário 2017. 2017 Maio;. (Reabilitação Respiratória).

3. Spruit MA, Singh SJ, Garvey C, ZuWallack R, Nici L, Rochester C, Hill K, Holland AE, Lareau SC, Man WD, Pitta F. An official American Thoracic Society/European Respiratory Society statement: key concepts and advances in pulmonary rehabilitation. Am J Respir Crit Care Med. 2013 Oct 15;188(8):e1364.

4. Andrianopoulos V, Klijn P, Franssen FM, Spruit MA. Exercise training in pulmonary rehabilitationClin Chest Med. 2014 Jun $1 ; 35(2): 313-22$.

5. Spruit MA, Pitta F, McAuley E, ZuWallack RL, Nici L. Pulmonary rehabilitation and physical activity in patients with chronic obstructive pulmonary disease. Am J Respir Crit Care Med. 2015 Oct 15;192(8):924-33..

6. Pitta F, Troosters T, Spruit MA, Probst VS, Decramer M, Gosselink R. Characteristics of physical activities in daily life in chronic obstructive pulmonary disease. Am J Respir Crit Care Med. 2005 May 1;171(9):972-7.

7. Braido F, Baiardini I, Menoni S, Bagnasco AM, Balbi F, Bocchibianchi S, Balestracci S, Piroddi MG, Canonica GW. Disability in COPD and its relationship to clinical and patientreported outcomes. Curr Med Res Opin. 2011 May 1;27(5):981-6.

8. Robinson H, Williams V, Curtis F, Bridle C, Jones AW. Facilitators and barriers to physical activity following pulmonary rehabilitation in COPD: a systematic review of qualitative studies. NPJ Prim Care Respir Med. 2018 Jun 4;28(1):19.

9. Gaspar L, Martins P. Impacto de um programa de reabilitação respiratória nos autocuidados higiene, vestir-se/despir-se e andar avaliados pela escala London Chest Of Daily Living em pessoas com doença respiratória crónica. Rev Port Enferm Reabil. 2018; 1(1):13-17.

10.Lahaije AJ, Van Helvoort HA, Dekhuijzen PN, Heijdra YF. Physiologic limitations during daily life activities in COPD patients. Respir Med. 2010 Aug 1;104(8):1152-9.

11. Miravitlles M, Cantoni J, Naberan K. Factors associated with a low level of physical activity in patients with chronic obstructive pulmonary disease. Lung. 2014 Apr 1;192(2):259-65.

12.McNamara RJ, Spencer L, Dale M, Leung RW, McKeough ZJ. Alternative Exercise and Breathing Interventions in Chronic Obstructive Pulmonary Disease: A Critical Review. EMJ Respir. 2018;6(1):117-27.

13. Bisca GW, Proença M, Salomão A, Hernandes NA, Pitta F. Minimal detectable change of the London chest activity of daily living scale in patients with COPD. J Cardiopulm Rehabil Prev. 2014 May $1 ; 34(3): 213-6$.

14.Spruit MA, Pitta F, McAuley E, ZuWallack RL, Nici L. Pulmonary rehabilitation and physical activity in patients with chronic obstructive pulmonary disease. Am J Respir Crit Care Med. 2015 Oct 15;192(8):924-33..

15. Martins T, Araujo MF, Peixoto MJ, Machado PP. A pessoa dependente \& 0 familiar cuidados Porto: Enfermagem.Porto; 2016.

16. McCarthy B, Casey D, Devane D, Murphy K, Murphy E, Lacasse Y. Pulmonary rehabilitation for chronic obstructive pulmonary disease. Cochrane database of systematic reviews. 2015(2). Disponível em: https://doi.org/10.1002/14651858.CD003793.pub3

17. Velloso M, Stella SG, Cendon S, Silva AC, Jardim JR. Metabolic and ventilatory parameters of four activities of daily living accomplished with arms in COPD patients. Chest. 2003 Apr 1;123(4):1047-53.

18. ICN. Classificação Internacinal para a Prática de Enfermagem (CIPE) versão 1.0 Genebra; 2005

19. Pitta F, Probst VS, Kovelis D, Segretti NO, Leoni AM, Garrod R, Brunetto AF. Validação da versão em português da escala London Chest Activity of Daily Living (LCADL) em doentes com doença pulmonar obstrutiva crónica. Rev Port Pneumol. 2008 Feb;14(1):27-47.

20.Goto Y. Measurement of Activities of daily living in patients with chronic obstructive pulmonary disease. Pulm Res Respir Med Open J. 2017; SE(2): S23-S25. doi: 10.17140/PRRMOJ-SE-2-104

21.Garrod R, Paul EA, Wedzicha JA. An evaluation of the reliability and sensitivity of the London Chest Activity of Daily Living Scale (LCADL). Respir Med. 2002 Sep 1;96(9):725-30..

22.Jehn M, Schmidt-Trucksäss A, Meyer A, Schindler C, Tamm M, Stolz D. Association of daily physical activity volume and intensity with COPD severity. Respir Med. 2011 Dec 1;105(12):1846-52.

23. Carpes MF, Mayer AF, Simon KM, Jardim JR, Garrod R. Versão brasileira da escala London Chest Activity of Daily Living para uso em pacientes com doença pulmonar obstrutiva crônica. J Bras Pneumol. 2008 Mar;34(3):143-51.

24. Muller JP, Goncalves PA, da Fontoura FF, Mattiello R, Florian J. Aplicabilidade da escala London Chest Activity of Daily Living em pacientes em lista de espera para transplante de pulmão. J Bras Pneumol. 2013;39(1):92-7.

25.ATS Committee on Proficiency Standards for Clinical Pulmonary Function Laboratories. ATS statement: guidelines for the sixminute walk test. Am J Respir Crit Care Med. 2002;166:111-7.

26. Agusti A, Decramer M, Celli BR. Pocket guide to COPD diagnosis, management and prevention. Global Initiative for Chronic Obstructive Lung Disease. 2017; 14:37-44.

27. Sciriha A, Moore K, Montefort S. Combining inspiratory muscle training and upper limb exercises. Does it improve outcomes in COPD patients?. J ACPRC. 2009; 41.

28.Zeng $\mathrm{Y}$, Jiang $\mathrm{F}$, Chen $\mathrm{Y}$, Chen $\mathrm{P}$, Cai $\mathrm{S}$. Exercise assessments and trainings of pulmonary rehabilitation in COPD: a literature review. Int J Chron Obstruct Pulmon Dis. 2018;13:2013-23. 
29. Shioya T, Iwakura M, Kawagoshi A. Recent advances in pulmonary rehabilitation for patients with COPD. Pulm Res Respir Med Open J. 2017:S7-19.

30.Braido F, Baiardini I, Menoni S, Bagnasco AM, Balbi F, Bocchibianchi S, Balestracci S, Piroddi MG, Canonica GW. Disability in COPD and its relationship to clinical and patientreported outcomes. Curr Med Res Opin. 2011 May 1;27(5):981-6.

31. Carpes MF, Mayer AF, Simon KM, Jardim JR, Garrod R. Versão brasileira da escala London Chest Activity of Daily Living para uso em pacientes com doença pulmonar obstrutiva crônica. J Bras Pneumol. 2008 Mar;34(3):143-51..

32. Jehn M, Schmidt-Trucksäss A, Meyer A, Schindler C, Tamm M, Stolz D. Association of daily physical activity volume and intensity with COPD severity. Respir Med. 2011 Dec 1;105(12):1846-52. 
O TREINO PROPRIOCETIVO E DE EQUILÍBRIO POSTURAL NO IDOSO PARA A PREVENÇÃO DE QUEDAS: SCOPING REVIEW

\title{
EL ENTRENAMIENTO PROPICIO Y DE EQUILIBRIO POSTURAL EN EL ANCIANO PARA LA PREVENCIÓN DE CAÍDAS: SCOPING REVIEW
}

\section{THE PROPRIOCEPTIVE AND POSTURAL BALANCE TRAINING IN THE ELDERLY FOR THE PREVENTION OF FALLS: SCOPING REVIEW}

DOI 10.33194/rper.2019.v2.n1.09.4573 | Submetido 10.05.2019 | Aprovado 26.06.2019

\author{
Catarina Correia ${ }^{1}$; Liliana Barbosa ${ }^{2}$; Luís Rebelo ${ }^{3}$; Marco Alves ${ }^{4}$; Nuno Pinho5; Bruno Magalhães ${ }^{6}$ \\ 1 - EEER HFARP, Polo Porto; 2 - EEER CHU São João; 3 - EEER CHTS E.P.E.; 4 - EEER CHTS E.P.E.; \\ 5 - EEER CHTS E.P.E.; 6 - Professor Adjunto ESSSM
}

\section{RESUMO}

A população mundial está cada vez mais envelhecida e o risco de queda está diretamente relacionado.

O objetivo do estudo é perceber qual o efeito do treino propriocetivo e do equilíbrio postural no idoso para a prevenção de quedas.

Estudo baseado no modelo JBI. Os artigos foram extraídos das bases de dados CINAHL, MEDLINE e PEDro, redigidos em português e inglês, de janeiro de 2012 a julho de 2018, com população de 65 anos ou mais, sem condição patológica subjacente.

Incluíram-se 13 artigos que consideravam programas de treino e exercícios propriocetivos e de equilíbrio postural, força muscular, resistência, treino de marcha e a implicação sobre o medo de cair.

Concluiu-se que, a implementação destes programas, têm um impacto positivo e significativo na prevenção de quedas. Considera-se fundamental a realização de mais estudos sem recurso a tecnologia que beneficiem o treino propriocetivo e de equilíbrio postural preventivos de queda.

Palavras-Chave: Idoso, Proprioceção e Equilíbrio Postural.

\section{RESUMEN}

La población mundial está cada vez más envejecida y el riesgo de caída está directamente relacionado.

El objetivo del estudio es percibir cuál es el efecto del entrenamiento propicio y del equilibrio postural en el anciano para la prevención de caídas.

Estudio basado en el modelo JBI. Los artículos fueron extraídos de las bases de datos MEDLINE, CINAHL y Pedro, escritos en portugués y en Inglés, a partir de enero 2012-julio 2018, con una población de 65 años o más, sin condición patológica subyacente.

Se incluyeron 13 artículos que consideraban programas de entrenamiento y ejercicios propios y de equilibrio postural, fuerza muscular, resistencia, entrenamiento de marcha y la implicación sobre el miedo a caer.

Se concluyó que, la aplicación de estos programas, tienen un impacto positivo y significativo en la prevención de caídas. Se considera fundamental la realización de más estudios sin recurso a la tecnología que beneficien el entrenamiento propicio y de equilibrio postural preventivo de caída.

Palabras Clave: Anciano, Propriocepción y Equilíbrio Postural.

\section{ABSTRACT}

The world population is increasingly aging and the risk of falling is directly related.

The objective of this study is to understand the effect of proprioceptive training and postural balance on the elderly for the prevention of falls.

Study based on the JBI model. The articles were extracted from the CINAHL, MEDLINE and PEDro databases, written in Portuguese and English, from January 2012 to July 2018, with a population of 65 years and over, with no underlying pathological condition.

We included 13 articles that considered training programs and proprioceptive exercises and postural balance, muscular strength, resistance, gait training and the implication about the fear of falling. 
It was concluded that the implementation of these programs have a positive and significant impact on the prevention of falls. It is considered fundamental to carry out more studies without using technology that benefit the preventive training and preventive postural balance.

Keywords: Aged, Proprioception and Postural Balance.

\section{INTRODUÇÃO}

O envelhecimento da população mundial é uma realidade que impõe novos desafios e exigências na promoção da saúde e prevenção de doenças (1). 0 aumento da idade, a inatividade física, juntamente com processos degenerativos nos sistemas nervoso central e musculares, resulta num declínio da proprioceção, do equilíbrio e da força muscular, que por consequência leva ao aumento do risco de queda na população idosa.

Da literatura emerge que o risco de queda está presente em cerca de $30 \%$ das pessoas com 65 ou mais anos de idade e que sofrem pelo menos uma queda por ano, resultando cerca de 10 a $15 \%$ de lesões graves (2).

Entende-se por proprioceção como sendo a capacidade que o corpo tem de se adaptar a diferentes posturas, consequência inconsciente de sentir, interpretar e interagir com o movimento e a posição no espaço (3). Caracteriza-se por aferências neurais, cumulativas que têm origem em mecanorreceptores.

O equilíbrio corporal é descrito como a habilidade de manter o centro de massa corporal dentro da base de sustentação. O corpo deve ser capaz de adquirir e controlar determinadas posturas para atingir um objetivo, com capacidade de se deslocar com rapidez e precisão, de forma multidirecional, com coordenação, segurança e ajustado frente às perturbações externas (4).

Estudos relatam que os treinos de equilíbrio e de proprioceção melhoraram a condição física da pessoa, no aumento da massa e força muscular, aumento da resistência física e melhoria do equilíbrio corporal, que por sua vez potenciam as capacidades funcionais obtendo ganhos na mobilidade bem como na autoconfiança. Ao intervirmos na população idosa com programas de treinos adequados que possam melhorar o desempenho nas atividades de vida diária que demandam a proprioceção e o equilíbrio, estes tornam-se fundamentais para reduzir o risco de queda (5).

Um défice na proprioceção e no equilíbrio corporal da pessoa idosa associados à restrição de mobilidade e ao medo de cair, são fatores condicionadores para a menor capacidade de realização das atividades de vida diárias e do exercício físico, aumentando assim o risco de queda. Nesta geração mais frágil, lesões graves como fraturas ou traumatismos cranianos levam a internamentos hospitalares prolongados, com um aumento dos encargos económicos não só para o idoso e para a família, mas também para toda uma sociedade (6).

Esta associação de fatores pode então culminar num importante compromisso da qualidade de vida dos idosos, em que a ocorrência da queda poderá ser o fator precipitante para uma transição saúde/doença, passando da autonomia para a situação de dependência.

Assim, a reabilitação, enquanto especialidade multidisciplinar, compreende um corpo de conhecimentos e procedimentos específicos que permite ajudar as pessoas com doenças agudas, crónicas ou com as suas sequelas a maximizar o seu potencial funcional e independência. Os seus objetivos gerais são melhorar a função, promover a independência e a máxima satisfação da pessoa e, deste modo, preservar a autoestima (7).

0 Enfermeiro Especialista em Enfermagem de Reabilitação (EEER) concebe, implementa e monitoriza planos de enfermagem de reabilitação diferenciados, baseados nos problemas reais e potenciais das pessoas. 0 nível elevado de conhecimentos e experiência acrescida permitem-lhe tomar decisões relativas à promoção da saúde, prevenção de complicações secundárias, tratamento e reabilitação maximizando o potencial da pessoa. A sua intervenção visa promover o diagnóstico precoce e ações preventivas de Enfermagem de Reabilitação, de forma a assegurar a manutenção das capacidades funcionais dos clientes, prevenir complicações e evitar incapacidades, assim como proporcionar intervenções terapêuticas que visam melhorar as funções residuais, manter ou recuperar a independência (7).

Desta forma, o EEER tem uma ação interventiva e preponderante na prevenção de quedas no idoso, através da implementação de exercícios e programas de treino que podem ser replicáveis em ambiente domiciliar.

Nesta linha de pensamento, a elaboração desta scoping review advém da identificação da necessidade da prevenção de quedas na população idosa, o que poderá ser feito para minimizar este risco cujo impacto na pessoa, família e sociedade é tão relevante?

Os programas de treino de equilíbrio e de proprioceção são úteis e eficazes na prevenção de lesões, mas que impacto detém na prevenção de quedas nesta na população? Somos assim encaminhados para a questão de qual o efeito do treino propriocetivo e do equilíbrio postural no idoso para a prevenção de queda.

\section{METODOLOGIA}

$\mathrm{Na}$ investigação científica, diferentes objetivos e questões podem ser identificados recorrendo a novas abordagens. As scoping reviews são um tipo de abordagem projetadas para sintetizar de uma forma mais efetiva e rigorosa a evidência, o mapear de 
conhecimento sobre uma determinada área de investigação (8).

A opção pela realização de uma scoping review fundamenta-se por ser um tipo de revisão que assume como principais objetivos: mapear as evidências existentes subjacentes a uma área de pesquisa, identificar lacunas na evidência existente, constituir um exercício preliminar que justifique e informe a realização de uma revisão sistemática da literatura. Deste modo, o recurso a esta metodologia segundo os objetivos descritos anteriormente, não é encontrar a melhor evidência, mas sim, mapear a evidência científica já existente (8) .

Procuraram-se artigos que incluíssem programas de treino de exercícios de equilíbrio e proprioceção sem recurso a tecnologias e/ou equipamentos com o objetivo de poderem ser realizados no domicílio por idosos sem condições patológicas especificas subjacentes.

A pesquisa foi realizada através das bases de dados, MEDLINE, CINAHL e PEDro. Incluíram-se estudos primários, estudos controlados randomizados e revisões sistemáticas da literatura. Utilizando a estratégia participants, concept e context (PCC), foram abrangidos na scoping review estudos que: a) quanto ao tipo de participantes, idosos com idade superior ou igual a 65 anos; b) quanto ao conceito, o efeito do treino propriocetivo e do equilíbrio postural; c) quanto ao contexto, a prevenção de queda.

\section{Estratégia de pesquisa}

A estratégia de pesquisa incluiu estudos publicados em três diferentes bases de dados CINAHL, MEDLINE e PEDro, sendo os nossos limitadores de pesquisa, artigos compreendidos entre janeiro de 2012 e julho de 2018, idade igual ou superior a 65 anos e estudos em língua portuguesa e inglesa. Para a realização da mesma, utilizamos as seguintes frases booleanas para cada base de dados. $\mathrm{Na}$ base de dados PEDro, recorremos a termos de pesquisa, pelo método de procura disponibilizado na referida base de dados (Tabela 1).

\section{Base de dados: CINAHL (via EBSCO)}

Resultados: 415

(((MM "Geriatrics") OR (MH "Aged+")) AND ((MM "Proprioception") OR (MM "Balance, Postural") OR (MM "Balance Training, Physical")) AND ((MM "Accidental Falls") OR (MM "Safety Behavior: Fall Prevention (lowa NOC)") OR (MM "Fall Risk Assessment Tool") OR (MM "Hendrich Fall Risk Model") OR (MM "Morse Fall Scale") OR (MM "Fall Risk (Saba CCC)") OR (MM "Fall Prevention (lowa NIC)") OR (MM "Safety Status: Falls Occurrence (lowa NOC)")))

Base de dados: MEDLINE (via EBSCO)

Resultados: 539
(((MM “Geriatrics”) OR (MH “Aged+”)) AND ((MM "Proprioception+") OR (MM “Postural, Balance”) OR (MM “Fedback, Sensory")) AND ((MM “Accidental Falls") OR (MM “Accident Prevention") OR (MM "Risk") OR (MM “Risk Assessment") OR (MM “Risk Factors”) OR (MM “Risk Redution BEHAVIOR”)))

Base de dados: PEDro

Resultados: 27

“Balance" AND “Education" AND “Frailty" AND "Gerontology"

clinical trial/practice guideline/systematic review

Tabela 1: Estratégia de pesquisa aplicados por base de dados

\section{Seleção dos artigos}

A relevância dos artigos para a scoping review foi analisada por três investigadores independentes com base nas informações fornecidas no título e no resumo. Em caso de discrepância, foram resolvidas por outros dois investigadores. 0 artigo completo foi recuperado para todos os estudos que cumpriam os critérios de inclusão. Os primeiros três investigadores examinaram, de forma independente, o texto completo dos artigos para verificar se cumpriam os critérios de inclusão. As divergências surgidas entre os investigadores foram resolvidas através de discussão.

\section{Extração de dados}

Os dados foram extraídos por três investigadores independentes, usando um instrumento desenvolvido pelos próprios. Foi elaborada uma tabela que contempla o autor do artigo, ano, local, objetivo do estudo e respetivos resultados obtidos.

\section{RESULTADOS}

Tal como apresentado na Figura 1, a pesquisa inicial identificou um total de 1924 artigos nas três bases de dados. Após a inclusão dos limitadores referidos anteriormente, identificamos um total de 981 artigos potencialmente relevantes. De seguida e após a remoção dos 219 artigos duplicados, a amostra final foi de 762 estudos.

Desta amostra e de acordo com os critérios de inclusão, foram envolvidos 44 estudos. Após a leitura integral dos artigos, foram excluídos cinco por língua ilegível, dois artigos por se encontrarem inacessíveis, três abordavam outros modelos de intervenção para a prevenção de quedas, 16 artigos por recorrerem a tecnologia e equipamentos e cinco por abordarem apenas conteúdos teóricos sobre a queda no idoso.

Foram incluídos para esta scoping review 13 artigos.

Os estudos foram realizados por fisioterapeutas, terapeutas ocupacionais, ortopedistas, professores nas áreas de geriatria, ciências do desporto e medicina desportiva e apenas um estudo realizado por EEER portugueses. Os artigos são originários da Austrália, Japão, Coreia do Sul, Reino Unido, Suécia, Alemanha, Espanha e Portugal. A pesquisa englobou uma revisão sistemática e 12 estudos primários. 
Os programas de treino de proprioceção e de equilíbrio postural no idoso, apresentavam uma variabilidade quanto ao número de semanas de treino, desde quatro a 52 semanas, onde foram analisados pelos autores, a recuperação do equilíbrio, a capacidade funcional, a mobilidade física, a marcha, o sistema vestibular propriocetivo, a força muscular, a resistência física e o medo de cair.

A população geral é referente a idosos com mais de 65 anos, objeto de estudo, inseridos na comunidade e sem condição patológica associada. A média de idades rondava os 70-75 anos, maioritariamente do género feminino. Apenas quatro estudos mencionam que a população selecionada já tinha vivenciado uma ou mais quedas.

A população, de uma forma geral, foi avaliada com recurso a questionários e aplicação de testes de performance. Entre os quais salientamos: MMSE (Mini Mental State Examination, de acordo com a versão de cada país), Escala de Depressão Geriátrica, The Late Life Function and Disability Instrument, PASE (Physical Activity Scale), IMC (Índice de Massa Corporal), FQoPA (Freiburger Questionnary of Physical Activity) e HRQOL (Health Related Quality of Life). No que respeita à marcha foi considerado a velocidade, ciclo de marcha e apoio uni e bipodal. Os autores recorreram a algumas escalas de avaliação, como por exemplo, 10 Metre Walk Test e Step Test. Os testes de força muscular foram determinados através de dinamómetros.

Os testes de equilíbrio primaram pela variedade. Entre eles salientamos: TAF (Teste de Alcance Funcional), Teste de Romberg, TUG (Timed Up and Go Test), BBS (Berg Balance Scale), FAB (Fullerton Advanced Balance Scale), 5XSST (5 Times Site to Stand). Os testes VST (Vestibular Stepping Test), PT (Proprioceptation Test), FRT (Functional Reach Test) foram determinantes para avaliar a proprioceção.
O risco de queda e o medo de cair foram avaliados, por alguns investigadores, recorrendo às escalas - FRI (Fall Risk Index), FRAT (Fall Risk Assessment Tool), FES-I (Falls Efficacy Scale International) e The CONFbal Scale
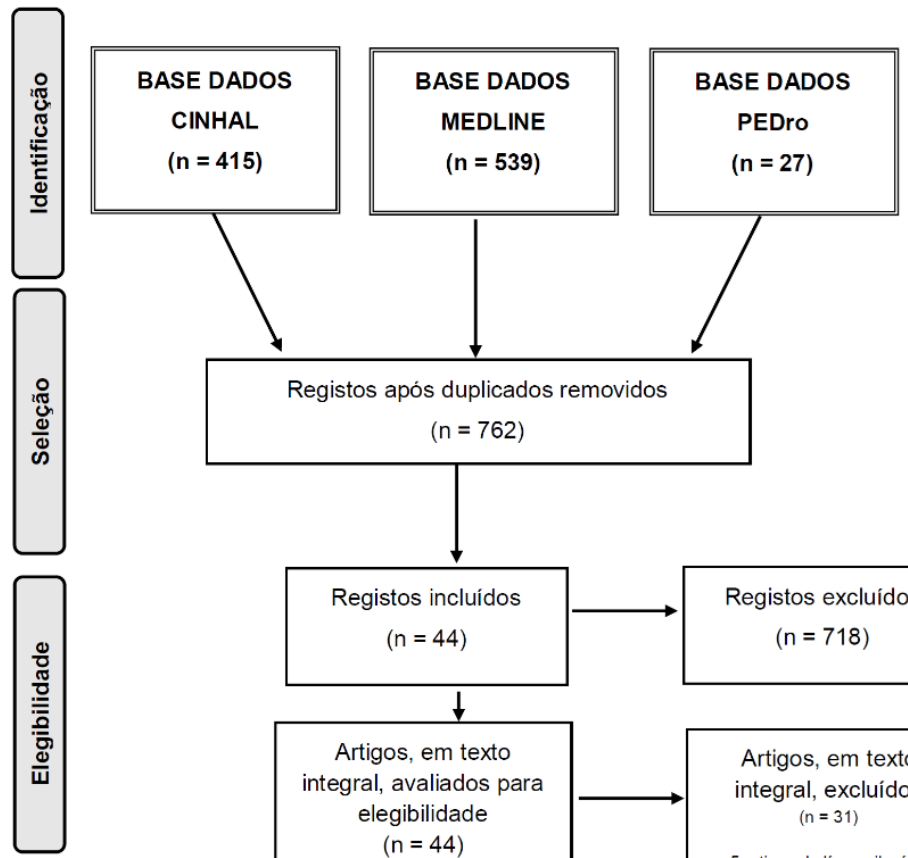



Figura 1. Fluxograma PRISMA (adaptado) do processo de seleção dos

estudos

\begin{tabular}{|c|c|c|c|}
\hline Autor (ano)/Local & $\begin{array}{c}\text { Tipo de } \\
\text { estudo/população }\end{array}$ & Objetivos & Resultados \\
\hline $\begin{array}{l}\text { 1. Sakamoto, K.; } \\
\text { Endo, N.; } \\
\text { Harada, A.; } \\
\text { Sakada, T.; } \\
\text { Tsushita, K.; } \\
\text { Kita, K.; } \\
\text { Hagino, H.; } \\
\text { Sakai, A. et al. } \\
2012 \text { (Japão) (9) }\end{array}$ & $\begin{array}{l}\text { Ensaio clínico controlado } \\
\text { randomizado. } \\
\text { Idosos com idade } \geq 75 \text { anos } \\
\text { residentes na comunidade, } \\
\text { grupo dinâmico de exercícios de } \\
\text { flamingo - DF (410 idosos): } 86 \text { क } \\
\text { e } 324 \text { \& } \\
\text { grupo sem exercício (455 idosos): } \\
78 \text { क् e } 377 \text { \&. }\end{array}$ & $\begin{array}{l}\text { Determinar os efeitos do } \\
\text { exercício de equilíbrio na } \\
\text { queda e prevenção de fraturas } \\
\text { em pessoas idosas e com pouco } \\
\text { equilíbrio. }\end{array}$ & $\begin{array}{l}\text { Grupo DF (6meses): } \uparrow \text { tempo permanência sobre uma perna de olhos } \\
\text { abertos (mais significativo que no grupo sem exercício); melhoria na } \\
\text { independência na vida diária das mulheres, } \downarrow \text { peso corporal, } \uparrow \text { tempo de } \\
\text { permanência sobre uma perna } 3 x \text {. } \\
\text { Grupo sem exercício: } 11 \text { fraturas (10 \& } 1 \text { ఠ). } \\
\text { Grupo DF: } 4 \text { fraturas }(3 \& 1 \text { ஓ). }\end{array}$ \\
\hline $\begin{array}{l}\text { 2. Clemson, L.; } \\
\text { Singh, M.; } \\
\text { Bundy, A.; } \\
\text { Cumming, R.; } \\
\text { Manollaras, K.; } \\
\text { O'Loughlin, P.; } \\
\text { Black, D. } \\
2012 \text { (Austrália) (10) }\end{array}$ & $\begin{array}{l}\text { Ensaio paralelo randomizado. } \\
\text { Participantes com } 70 \text { anos de } \\
\text { idade que sofreram duas ou mais } \\
\text { quedas ou lesões por queda nos } \\
\text { últimos } 12 \text { meses. }\end{array}$ & $\begin{array}{l}\text { Determinar se uma abordagem } \\
\text { integrada do estilo de vida } \\
\text { para o treino de equilíbrio e } \\
\text { força é eficaz na redução da } \\
\text { taxa de quedas em pessoas } \\
\text { idosas residentes r na } \\
\text { comunidade. }\end{array}$ & $\begin{array}{l}\text { Após } 12 \text { meses, a incidência global de quedas no grupo LiFE foram } 172 \\
\text { quedas ( } 1,66 \text { por pessoa/ano), no grupo exercício estruturado (GE) } 193 \\
\text { quedas }(1,90 \text { pessoa/ano) e no grupo de controlo (GC) } 224 \text { quedas (2,28 } \\
\text { pessoa/ano). } \\
\text { Redução significativa de } 31 \% \text { na taxa de quedas do programa LiFE em } \\
\text { comparação com o GC (taxa de incidência } 0,69 \text { (intervalo de confiança de } \\
95 \% 0,48 \text { a } 0,99) \text {; a diferença correspondente entre o GE e GC não foi } \\
\text { significativa }(0,81 \text { ( } 0,56 \text { a } 1,17) \text {. } \\
\text { Grupo LiFE melhor no equilíbrio estático, força e função, o grupo } \\
\text { estruturado teve uma melhoria significativa e moderada no equilíbrio } \\
\text { dinâmico, comparados GC. }\end{array}$ \\
\hline
\end{tabular}


3. Yang, XJ.;

Hill, K.;

Moore, $\mathrm{K}$;

Williams, S.;

Dowson, L.;

Borschmann, K.;

Simpson, JÁ.;

Dharmage, SC.

2012 (Austrália) (11)

4. Halvarsson, $A$;

Franzén, E.;

Farén, E.;

Olsson, E.;

Oddsson, L.;

Ståhle, A.

2013 (Suécia) (12)

5. Cadore, EL.;

Rodríguez-Mañas, L.;

Sinclair, A.;

Izquierdo, $M$.

2013 (Espanha) (13)

3543 idosos num total de 20
especialmente em programas
artigos incluidos (estudos
de exercícios supervisionados

$\begin{array}{lll}\text { artigos incluidos (estudos } & \text { de exercícios supervisionados } \\ \text { controlados randomizados). } & \text { que melhoram a forç }\end{array}$ ee, peso multidirecional em bicos de pés (elevadores), caminhar em queda, o calcanhares/ ponta dos pés/ sobre uma linha, de pé sob uma perna e com equilibrio e a habilidade na transferências de peso e exercícios modificados de Tai Chi; marcha.

$\begin{array}{llll}\text { O objetivo desta revisão foi } & 30 \% \text { e progrida para } 80 \% \text {; } \\ \text { recomendar estratégias de } & \text { 2. Para otimizar a capacidade funcional e a resistência, os programas de }\end{array}$ treino que melhorassem a treino devem incluir exercícios simuladores de atividades diárias como o capacidade funcional em sit-to-stand exercise;

idosos fisicamente frágeis, 3.Treino de resistência deve incluir caminhada com mudanças de direção e baseados na literatura ritmo, andar em passadeiras, declives, escalada de degraus e pedaleira Revisão sistemática

5. Programas de treino com múltiplos componentes devem incluir 个graduais no volume, intensidade e complexidade dos exercícios e com o desempenho simultâneo da resistência e exercícios de equilíbrio.

\section{Freiberger, E.;}

Blank, WA.;

Salb, J.;

Geilhof, B. et al.

2013 (Alemanha) (14)

7. Kim, Jl.;

Park, SD.;

Song, HS.

2014 (Coreia do Sul) (15)

8. Roaldsen, KS.;

Halvarsson, A.;

Sahlström, T.;

Ståhle, A.

2014 (Suécia) (16)
Conjunto de ensaios controlados randomizados

378 programa de exercícios com 378 pessoas com $\geq 65$ anos que componente física últimos 12 sofrido uma

GI - grupo intervenção

GC- grupo controlo

Estudo controlado randomizado

30 idosos saudáveis, $>65$ anos, igualmente divididos
grupo aleatoriamente num grupo de tapados) e um grupo com visão tapados) e um

Estudo prospetivo, controlado e randomizado.

programa de treino de

59 idosos saudáveis residentes nequilibrio de 12 semanas sobre $\mathrm{O} \mathrm{Gl}$ relatou melhoria na função global $(\mathrm{p}=0,016)$, bem como na função

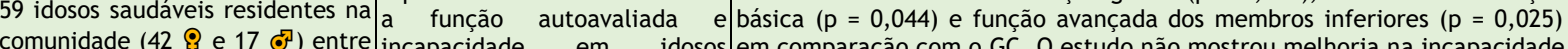
67- 93 idosos em comparação com o GC. 0 estudo não mostrou melhoria na incapacidade 67- 93 anos foram randomizados saudáveis com défices de auto geral ou na função dos membros superiores.

para o grupo de intervenção perceção do equilíbrio e medo

$(\mathrm{Gl}=38)$ ou para o grupo de de cair.

controlo $(\mathrm{GC}=21)$.

Estudo controlado randomizado

Investigar os efeitos dos

INT 1: apresentou melhoria estatisticamente significativa na força muscular de 5 dos 7 grupos musculares (exceto flexores do joelho e exercícios de equilíbrio e dos flexores plantares do tornozelo); INT 2 foi melhor em todos os 7 grupos exercícios de resistência musculares. Comparando às forças musculares médias do CON, após elástica sobre a força muscular exercícios de equilíbrio, INT 1 e INT 2 mostraram melhorias 9. Cho, S.; $\mathrm{Na}, \mathrm{D}$.

55 idosos com mais de 75 anos que viviam na comunidade.

Grupo de intervenção de la elástica sobre a força muscular estatisticamente significativas nos grupos musculares apos a intervenção; INT 1 e INT 2 com melhoria no índice de queda comparados com CON; CON Grupo de intervenção de população de risco, durante não apresentou diferenças nas forças de qualquer grupo muscular nem no exercícios de resistência elástica um programa de oito semanas. índice de queda após as 8 semanas. 


\begin{tabular}{|c|c|c|c|}
\hline $\begin{array}{l}\text { 10. Kim, WJ.; } \\
\text { Duk-Hyun, MC. } \\
2014 \text { (Coreia do Sul) (18) }\end{array}$ & $\begin{array}{l}\text { Estudo controlado randomizado } \\
\text { Dez participantes com mais de } 65 \\
\text { anos de idade, saudáveis e } \\
\text { residentes na comunidade. }\end{array}$ & \begin{tabular}{|lll} 
Identificar os & efeitos de & um \\
programa de exercícios & de \\
prevenção de quedas & na \\
participação na atividade e no & \\
equilíbrio estático de idosos. \\
O programa de exercícios foi \\
baseado na aptidão e e \\
mobilidade física (FaME).
\end{tabular} & $\begin{array}{l}\text { Após o exercício, a participação na atividade e equilíbrio estático } \\
\text { mostraram diferenças significativas }(\mathrm{p}<0,05) \text {. A participação na atividade } \\
\text { aumentou de } 22,90 \pm 5,55 \text { para } 32,35 \pm 11,16 \text { pontos, e o índice de queda } \\
\text { diminuiu de } 64,60 \pm 27,0051,40 \pm 22,84 \text { pontos. No entanto, não houve } \\
\text { diferenças significativas em qualquer categoria para participação em } \\
\text { atividades antes e depois da intervenção. }\end{array}$ \\
\hline $\begin{array}{l}\text { 11.Gouveia, BR.; } \\
\text { Jardim, HG.; } \\
\text { Martins, MM.; } \\
\text { Gouveia, ER.; } \\
\text { Freitas, DL.; } \\
\text { Maia, JÁ.; } \\
\text { Rose, DJ. } \\
2015 \text { (Portugal) (19) }\end{array}$ & $\begin{array}{l}\text { Estudo controlado randomizado. } \\
52 \text { idosos (65-85 anos); grupo } \\
\text { controlo (GC): } 25 \text { idosos; grupo } \\
\text { submetido ao programa de treino } \\
\text { (GT): } 27 \text { idosos. }\end{array}$ & $\begin{array}{l}\text { Avaliar a eficácia do } \\
\text { ProBalance programme no } \\
\text { equilibrio e risco de queda num } \\
\text { grupo de idosos }\end{array}$ & $\begin{array}{l}\text { Doze semanas após o programa os dois grupos foram avaliados, em relação } \\
\text { ao equilibrio e o grupo submetido ao programa obteve significativamente } \\
\text { melhores resultados. }\end{array}$ \\
\hline $\begin{array}{l}\text { 13. Lacroix, A.; } \\
\text { Kressig, RW.; } \\
\text { Muehlbauer, T.; } \\
\text { Gschwind, YJ.; } \\
\text { Pfenninger, B.; } \\
\text { Bruegger, O.; } \\
\text { Granacher, U. } \\
\text { 2016 (Alemanha) (21) }\end{array}$ & $\begin{array}{l}\text { Estudo controlado randomizado. } \\
66 \text { idosos com idade média de } 73 \\
\text { anos }(3 \text { grupos: grupo de } \\
\text { controlo, grupo de treino não } \\
\text { supervisionado e grupo de treino } \\
\text { supervisionado. }\end{array}$ & $\begin{array}{l}\text { Avaliar o impacto de um } \\
\text { programa de treino de força e } \\
\text { de equilíbrio (BST -balance and } \\
\text { strength training) de } \quad 12 \\
\text { semanas, seguido de } 12 \\
\text { semanas de inatividade, com } \\
\text { supervisão e sem supervisão. }\end{array}$ & $\begin{array}{l}\text { No grupo supervisionado, ao fim das } 12 \text { semanas de treino, houve melhoria } \\
\text { nos testes de equilíbrio bem como após o período de inatividade (melhorias } \\
\text { relacionadas ao Teste Romberg, velocidade da passada, Timed Up and Go } \\
\text { Test e Chair Stand Test, a favor do grupo não supervisionado. }\end{array}$ \\
\hline
\end{tabular}

Tabela 2: Estudos constituintes da amostra bibliográfica.

\section{DISCUSSÃO}

O objetivo desta scoping review foi analisar e mapear artigos que abordassem 0 efeito do treino propriocetivo e do equilíbrio postural no idoso para a prevenção de quedas.

Os vários artigos incluídos abordam programas de exercícios e exercícios isolados e contribuem para a minimização do risco de queda e do medo de cair na pessoa idosa.

0 artigo número 2 (10) aborda um programa de exercício denominado $L i F E$, que consiste na prática dos exercícios de equilíbrio e da força muscular a realizar no domicílio, baseados nas atividades de vida diárias.

Idosos que já vivenciaram quedas foram selecionados e acompanhados por 12 meses. Dos três grupos em estudo, o grupo LiFE foi o que apresentou melhores resultados com menor número de quedas/ano (172 quedas), a incidência global de quedas no programa LiFE foi de 1,66 por pessoa/ano, em comparação com 1,90 (193 quedas) no grupo de exercício estruturado (GE) e 2,28 (249 quedas) no grupo de controlo (GC). Ocorreu uma redução significativa de $31 \%$ na taxa de quedas no grupo LiFE em comparação com o GC (taxa de incidência 0,69 (intervalo de confiança de 95\% 0,48 a 0,99). Contudo a diferença da taxa de queda correspondente entre o GE e GC não foi significativa $(0,81(0,56$ a 1,17$)$.

0 equilíbrio estático, a força muscular, a função e participação do tornozelo foram significativamente melhores no grupo LiFE do que no GC. 0 grupo LiFE e GE tiveram um impacto significativo na melhoria do equilíbrio dinâmico, em comparação com os GC.

Os autores deste artigo concluíram que este tipo de programa de exercícios teve um impacto significativo e uma moderada melhoria no equilíbrio dinâmico na população estudada.

O programa LiFE oferece assim uma alternativa ao tradicional exercício a considerar para prevenção de quedas com foco de intervenção no exercício funcional.

0 artigo número 3 (4) refere-se ao programa OTAGO. Este programa de treino foi desenvolvido especificamente para prevenir as quedas. Consiste num conjunto de exercícios de fortalecimento muscular dos membros inferiores e treino de equilíbrio com dificuldade progressiva - programa de exercícios domiciliários. Os exercícios têm duração de 30 minutos, os participantes devem-se exercitar três 
vezes por semanas e caminhar pelo menos duas vezes por semana.

Este estudo avaliou a efetividade de uma intervenção de equilíbrio domiciliar e de exercício de força em idosos, sendo sistematicamente avaliada como tendo disfunção leve do equilíbrio.

Os 83 participantes do grupo de intervenção (GI) receberam um programa de exercícios domiciliares de força e equilíbrio por seis meses (prescritos por um fisioterapeuta, com base no Programa de Exercício de OTAGO e no Equilíbrio de Informação de Saúde Visual e Kit de Exercício Vestibular). Os 82 participantes do GC continuaram com suas atividades habituais.

Após os seis meses de estudo, o $\mathrm{Gl}$ melhorou significativamente em relação ao GC para: o Teste do Alcance Funcional (diferença média 2,95 cm, 95\% intervalo de confiança [IC] 1,75 a 4,15), no Teste do Passo (2,10 passos / 15 segundos, IC 95\% 1,17 a 3,02), força do abdutor do quadril $(0,02$; IC95\% 0,01 a 0,03) e na largura do passo da marcha $(2,17 \mathrm{~cm}, I C 95 \% 1,23$ a $3,11)$.

Os autores concluem que a prescrição de um programa de exercícios domiciliários como o OTAGO, visando o equilíbrio e a força muscular, foi eficaz na melhoria do equilíbrio e na redução de quedas em idosos com equilíbrio corporal já comprometido.

O FaME (Falls Management Exercise) é um programa de treino de exercícios físicos que foi estudado no artigo número 10 (17), baseado na aptidão e mobilidade do exercício físico. Este programa já conhecido desde 2006 no Canadá, tem como objetivo aumentar o equilíbrio e a força muscular dos idosos, uma vez que são a classe mais predisposta para o risco de queda.

Consiste em treino específico, individualizado e direcionado para o equilíbrio dinâmico, força muscular, resistência, flexibilidade, marcha e habilidades funcionais para evitar a queda. 0 exercício foi realizado três vezes por semana durante uma hora, em que uma sessão era realizada em grupo e as restantes em casa, com supervisão de um fisioterapeuta e/ou um terapeuta ocupacional, durante três meses.

0 equilíbrio estático melhorou bem como a participação na atividade $(22,90 \pm 5,55$ para $32,35 \pm$ 11,16 pontos) e o índice de queda diminuiu de 64,60 \pm 27,00 para $51,40 \pm 22,84$ pontos. No entanto, não houve diferenças significativas em qualquer categoria para participação em antes e depois da intervenção. Contudo, estes investigadores fazem referência que outros programas de exercício de prevenção de quedas são tão eficazes quanto o programa FaME.

Refletindo sobre estes três programas de treino de exercício para a prevenção de quedas referidos anteriormente, são descritos pelos investigadores que fornecem evidências para a promoção do equilíbrio, do fortalecimento muscular e aumento da participação da população idosa na prática do exercício físico. Podemos admitir que um programa de exercícios no domicílio para prevenção de quedas pode ter um efeito positivo sobre a participação nas atividades de vida diárias e no equilíbrio em idosos.

O ProAct65+, abordado no artigo número 12 (19), é um ensaio clinico em que foi investigada a eficácia de um programa de exercícios domiciliários (OTAGO) e um programa de exercícios físicos (FaME) em comparação com os cuidados usuais ao aumento da atividade física moderada a vigorosa (AFMV), na redução de quedas e lesões associadas.

O grupo FaME experimentou uma redução significativa em quedas prejudiciais em comparação com a taxa de incidência (IRR) 0,55, IC 95\% 0,31, 0,96; p = 0,04) e isto continuou durante os 12 meses após o final da intervenção (TIR 0,73, IC 95\% 0,54, 0,99; $p=0,05$ ).

Houve também uma redução significativa na incidência de todas as quedas (prejudiciais e não prejudiciais) no grupo FaME em comparação com os cuidados usuais (IRR 0,74, IC 95\% 0,55, 0,99; p = 0,04) no período de 12 meses após a cessação da intervenção. No grupo OTAGO, a redução não foi significativa na incidência de todas as quedas em comparação com os cuidados usuais (IRR 0,76, 95\% Cl $0,53,1,09 ; p=0,14)$ nos 12 meses seguintes à cessação da intervenção.

Após 24 meses, os efeitos dos programas de treino sobre a prevenção de quedas não persistiram em qualquer grupo de exercício. No entanto, uma amostra do grupo FaME que continuou a realizar 150 minutos de AFMV por semana pós-intervenção, apresentou uma redução significativa na incidência de quedas (TIR = 0,49; IC95\% 0,30; 0,79; $p=0,004$ ) comparativamente com aqueles que não mantiveram a sua atividade física regular.

Os investigadores apuram que os idosos submetidos ao programa FaME não apresentaram quedas durante o programa de treino. Após 12 meses caíram menos e tiveram menos lesões associadas a quedas. Contudo, 24 meses após o programa, os benefícios da intervenção findaram, exceto naqueles que mantiveram uma atividade física moderada. 0 programa OTAGO foi menos efetivo na prevenção de quedas.

Ressalta aqui a importância e o benefício da continuidade da prática do exercício físico de forma regular para a prevenção de quedas na população idosa.

O artigo número 13 (20), avalia o impacto de um programa de treino de força e de equilíbrio (BST balance and strength training) durante 12 semanas, seguido do mesmo período de tempo de inatividade, com e sem supervisão profissional.

O programa de exercícios foi realizado três vezes por semana, onde eram incluídos exercícios progressivos, com diferentes estadios de intensidade. 0 protocolo do programa consistia em exercícios de equilíbrio estático, equilíbrio dinâmico (marcha) e exercícios de força/potência para os membros inferiores e músculos do tronco (agachamentos, prancha, entre outros). Utilizaram-se como recursos o peso corporal dos participantes e um pequeno equipamento como toalhas, garrafas e bolas. 
O grupo de idosos supervisionado realizava o treino três vezes por semana, sendo que uma sessão de treino era realizada sem supervisão no domicílio. O grupo não supervisionado concretizava os mesmos exercícios no seu domicílio três vezes por semana.

Os resultados relevaram que houve melhoria nos testes de equilíbrio, melhorias no Teste Romberg, na velocidade de passada, no Timed Up and Go Test e no Chair Stand Test, mesmo após o período de inatividade, a favor do grupo supervisionado.

Os investigadores deste artigo chegam à conclusão de que houve melhorias na força e no equilíbrio dos idosos quando estes exercícios são realizados com supervisão de um profissional.

O ProBalance é um programa de reabilitação, realizado por enfermeiros de reabilitação portugueses que inclui vários tipos de exercício: de equilíbrio, coordenação, treino de tarefas funcionais, treino de marcha, fortalecimento e exercícios de flexibilidade, inspirado pelo programa de equilíbrio e mobilidade FallProof.

O ProBalance programe adota uma abordagem multifatorial do equilíbrio e da mobilidade em idosos independentes com défices de equilíbrio.

No artigo número 11 (18), é realçado a sua eficâcia na melhoria do equilíbrio e na redução do risco de queda nesta faixa etária.

Cada sessão de treino incluía seis componentes-chave de exercício: treino multissensorial (visual, somatossensorial e sistema vestibular); treino de controlo do centro de gravidade; treino de estratégia postural proactiva e reativa, treino de marcha, fortalecimento e exercícios de resistência e treino de flexibilidade durante 12 semanas.

Após o programa, os dois grupos (intervenção e controlo) foram avaliados, em relação ao equilibrio, e - grupo submetido ao programa obteve significativamente melhores resultados: $5,15 \quad(2,81)$ para o grupo de intervenção e de $\pm 1,45(2,80)$ para o grupo de controlo na escala FAB (Fullerton Advanced Balance). Os autores também referem que após um período de inatividade, a perda de equilibrio está mais evidente.

Este estudo demonstrou que o programa de enfermagem de reabilitação baseado em programa de exercicios para a prevenção de queda é eficaz na melhoria do equilíbrio e na redução do risco em grupos de idosos com equilíbrio comprometimento.

0 artigo número 7 (14), é investigado o efeito de um programa de exercícios complexos no equilíbrio, na marcha, nos sentidos vestibulares e nos sentidos propriocetivos quando o sentido visual é bloqueado, dirigido a idosos que já sofreram uma queda. O grupo de participantes foi dividido em grupo de visão bloqueada e o grupo de visão permitida. Os intervenientes iniciavam o treino com exercícios de aquecimento muscular (cerca de 10 minutos de alongamentos e 20 minutos de marcha). Após descanso de três minutos, iniciavam um percurso de obstáculos, treino propriocetivo, durante 10 minutos, com ajuda de um assistente.

Ocorreram melhorias significativas no teste 10MWT (10 meter walking test), no teste vestibular (VST) e no teste propriocetivo (PT) realizados pelo grupo com visão bloqueada após a intervenção $(p<0,05)$ comparativamente ao grupo com visão permitida. Não foi identificada uma diferença significativa no teste SUDT (stair up/down test) e na escala de equilíbrio de Berg (BBS) dentro de cada grupo entre antes e depois da intervenção.

Os autores deste artigo concluem que o programa de exercícios aplicado ao grupo com visão bloqueada contribuiu para a melhoria significativa da capacidade de equilíbrio e de marcha e aprimorou o sentido vestibular dos idosos intervenientes.

O complexo programa de exercícios de treino vestibular e propriocetivo para idosos ajudou a melhorar a capacidade de equilíbrio e de marcha bem como melhorou o sentido vestibular dos participantes. Quando os sentidos visuais são bloqueados, a resposta muscular é principalmente organizada e o controlo postural é feito mais rapidamente, porque a manutenção de função vestibular e propriocetiva aumenta as capacidades do controlo postural.

Apraz referir que este será um programa de exercícios para a prevenção de quedas útil para melhorar o equilíbrio e capacidade de marcha de pessoas idosas que já vivenciaram queda.

Em balanço dos estudos anteriores referidos, é evidente e recomendado que na prescrição de um programa de exercícios para a prevenção de quedas é fundamental a continuidade da prática física por parte da população idosa, pois um declínio no equilíbrio é verificado após um período de inatividade física, bem como a respetiva supervisão do profissional para diminuir quedas e lesões associadas.

Alguns artigos da nossa pesquisa referem-se a exercícios de equilíbrio específicos.

O estudo número 1 (9) aborda o exercício Dinâmico do Flamingo. Este exercício consiste em ficar de pé na posição ortostática numa só perna de olhos abertos durante um minuto, três vezes por dia durante seis meses. O objetivo deste estudo foi determinar os efeitos do exercício de equilíbrio na prevenção de quedas e de fraturas em pessoas idosas com equilíbrio comprometido.

O grupo de intervenção, diferenças significativas foram observadas no aumento do tempo de permanência em uma perna com os olhos abertos (foi aumentado aproximadamente 3 vezes), o peso corporal diminuiu; houve uma melhoria na independência na vida diária das mulheres.

Um maior número de fraturas ocorreu no grupo sem exercício (10-mulheres e 1-homem) que no grupo exercitado (3-mulheres e 1-homem). O número foi maior no grupo sem exercício, mas não houve diferença significativa, segundo os autores deste estudo. $\mathrm{O}$ número de fraturas foi não 
significativamente diferente para homens ou mulheres.

O exercício dinâmico de flamingo conduz a ganhos no aumento do tempo de permanência em pé, em uma só perna e também na diminuição do peso corporal, mas não foi demonstrada nenhuma diferença significativa na prevenção de fraturas em mulheres idosas com equilíbrio diminuído.

No artigo número 9 (16), os fisioterapeutas analisaram os efeitos dos exercícios de equilíbrio e exercícios de resistência elástica sobre a força muscular e o equilíbrio dos idosos com mais de 75 anos, num programa de oito semanas, com o objetivo de prevenção de quedas. Os idosos foram divididos em três grupos, de intervenção 1 (INT 1), intervenção 2 (INT 2) e grupo controlo (CON). O grupo INT 1 realizou exercícios de equilíbrio e o grupo INT 2 realizou exercícios de resistência elástica e o grupo CON realizou os exercícios após oito semanas, já o período de intervenção tinha terminado.

As sessões consistiam em uma hora, cinco vezes por semana durante oito semanas, num total de 40 sessões. Os idosos realizaram os exercícios em grupo, sob supervisão, duas vezes por semana. Nos restantes dias realizaram os exercícios em casa, sozinhos. As sessões de treino de uma hora consistiram em 10 minutos de aquecimento e alongamento, 40 minutos de exercício principal e 10 minutos de alongamento final. Os exercícios foram realizados em três séries, com 10 repetições por série, e houve um período de descanso de 30 segundos entre cada conjunto e um período de três a cinco minutos de descanso entre cada exercício. Os exercícios de equilíbrio consistiam em seis tipos de exercício: passo lateral, andar péante-pé, andar para trás, mancha em oito, posição em uma só perna com os braços cruzados anteriormente e aplicação de uma perturbação externa. Os oito exercícios resistidos consistiam em: agachamento, elevação do calcanhar, flexão e extensão da anca, flexão e extensão do joelho e dorsiflexão e flexão plantar do tornozelo.

O grupo INT 1 apresentou melhoria estatisticamente significativa na força muscular de cinco dos sete grupos musculares, mas não ao nível dos flexores do joelho e flexores plantares do tornozelo, sendo melhor no grupo INT 2 em que melhorou em todos os sete grupos musculares.

Ambos os grupos INT 1 e INT 2 apresentaram melhorias no índice de queda, obtendo melhores resultados que no grupo CON, bem com este não apresentou diferenças nas forças de qualquer grupo muscular após as oito semanas.

Os grupos INT 1 e INT 2 mostraram melhorias significativas após a intervenção, o que prova que ambos os exercícios de equilíbrio e de resistência são eficazes em melhorar o equilíbrio. Embora os exercícios de resistência elástica demonstraram ser mais eficazes do que exercícios de equilíbrio no fortalecimento dos flexores plantares do tornozelo, não houve uma grande diferença na eficácia dos dois tipos de exercícios.
Os autores concluíram que os dois tipos de exercício (de equilíbrio e de resistência elástica) mostraram melhorias, estatisticamente significativas nos grupos musculares após a intervenção, bem como com melhoria no índice queda, sendo assim aceitáveis como exercícios de prevenção de quedas para os idosos.

Em 2013, foi realizada uma revisão sistemática (artigo número 5) (12), sobre os efeitos de diferentes intervenções de exercício, habilidade de marcha e equilíbrio em idosos na prevenção do risco de queda.

O objetivo desta revisão foi recomendar estratégias de treino que otimizassem a capacidade funcional em idosos fisicamente frágeis, focando especialmente em programas de exercícios supervisionados que melhoram a força muscular, o equilíbrio e a habilidade de marcha e reduzir o risco de queda. Os investigadores defendem que os programas de intervenção de exercício (treino de força, resistência e equilíbrio), serão a melhor estratégia para melhorar todos estes componentes, bem como diminuir a taxa de quedas em idosos. A maioria dos estudos incluídos na revisão sistemática (12) descrevem melhorias na marcha, no equilíbrio e no risco de queda após a aplicação de um programa de treino físico multicomponente.

No entanto, os estudos em que o treino resistido sistemático foi realizado (sozinho ou como parte de componentes múltiplos exercícios físicos) revelaram maiores ganhos de força em idosos com fragilidade física ou graves declínios funcionais.

A ausência de alterações nos resultados funcionais e de força que foram medidos em algumas das investigações indica que a prescrição do exercício deve ser cuidadosamente adaptada e fornecer um estímulo suficiente para melhorar a capacidade de sujeitos frágeis. Além disso, a presente revisão focou apenas nos domínios da função física, dos conceitos fragilidade e fragilidade física. Assim, esta revisão sistemática é apenas capaz de recomendar estratégias para melhorar a função de indivíduos fisicamente frágeis.

Com base nas recentes evidências, estratégias de exercícios para melhorar a parâmetros cardiovasculares e desempenho funcional em idosos frágeis devem incluir o seguinte:

1. Programas de treino de resistência devem ser realizados três vezes por semana, com três séries de 8 a 12 repetições em uma intensidade que começa em 20\% -30\% e progride para $80 \%$ :

2. Para otimizar a capacidade funcional dos indivíduos, a resistência, os programas de treino devem incluir exercícios simuladores de atividades diárias como o exercício sit-to-stand.

3. Treino de resistência deve incluir caminhada com mudanças em ritmo e direção, andar em passadeiras, step-ups, escalada de degraus e bicicleta estática. Exercício de resistência podem começar em 5 a 10 minutos durante as primeiras semanas de treino e progressão para 15-30 minutos para o restante programa. A escala de taxa de esforço percebido é 
um método alternativo para a prescrição da intensidade do exercício, e uma intensidade de 12-14 na escala de Borg parece que seja bem tolerado.

4. O treino de equilíbrio deve incluir vários estímulos de exercício, como o pé ante pé, peso multidirecional em bicos de pés (elevadores), caminhar em calcanhares/ponta dos pés, caminhando sobre a linha, de pé em uma perna, transferências de peso (de uma perna para o outro) e exercícios modificados de Tai Chi.

(tandem foot standing, multi-directional weight lifts, heel-toe walking, line walking, stepping practice, standing on one leg, weight transfers (from one leg to the other), and modified Tai Chi exercises)

5. Programas de treino com múltiplos componentes devem incluir aumentos graduais no volume, intensidade e complexidade dos exercícios, juntamente com 0 desempenho simultâneo de resistência e exercícios de equilíbrio.

Em todos os estudos selecionados nesta scoping review, de uma forma global e descrita pelos autores nas conclusões dos seus estudos, o treino propriocetivo e de equilíbrio são de uma maior valia para a promoção da saúde e prevenção da queda na pessoa idosa.

Para além do treino propriocetivo e de equilíbrio, em três estudos é abordado o medo de cair.

No artigo número 4 (11), foram abordados os efeitos a longo prazo de um programa progressivo e específico, baseado em treino de equilíbrio em idosos saudáveis, com risco aumentado de queda, estabelecendo a relação entre o medo de cair e o treino de equilíbrio. Este tipo de programa progressivo e específico descrito pelos autores, baseado em treino de equilíbrio com tarefas duplas e múltiplas para idosos em risco de queda, proporcionou importantes benefícios positivos a curto prazo para a marcha, função de equilíbrio e medo de cair.

A velocidade de marcha rápida, a dupla execução da tarefa e medo de cair foram melhoradas no grupo de treino aos nove meses de seguimento. Apenas o medo autopercebido de cair permaneceu significativamente melhor aos 15 meses de seguimento. Embora a velocidade da marcha rápida tenha diminuído para o nível basal no grupo de treino $(1,49 \mathrm{~m} / \mathrm{s})$ permaneceu significativamente maior do que no grupo controlo $(1,37 \mathrm{~m} / \mathrm{s})$ no final do estudo.

Esse novo programa progressivo e específico, baseado em grupos de equilíbrio, com tarefas duplas e múltiplas para idosos em risco de queda, proporcionou importantes benefícios positivos a curto prazo para a marcha, função de equilíbrio e medo de cair. Esses benefícios diminuíram com o tempo, sugerindo que a participação periódica no treino de equilíbrio deve ser encorajada.

No artigo número 8 (15) foi analisado o medo de cair em idosos com défices de auto perceção de equilíbrio. O objetivo foi avaliar os efeitos de um programa de treino de equilíbrio de 12 semanas sobre a função autoavaliada e incapacidade em idosos saudáveis residentes na comunidade com déficits de equilíbrio e o medo de cair.

O grupo de intervenção relatou melhoria na função global ( $p=0,016)$, bem como na função básica ( $p=$ $0,044)$ e função avançada dos membros inferiores ( $p=$ 0,025 ) em comparação com o grupo controlo. O estudo não mostrou melhoria na função dos membros superiores.

Neste estudo, os autores concluem que um programa de treino de equilíbrio baseado em exercícios de equilíbrio estático e dinâmico, com recurso a perturbações na marcha, melhora a auto perceção dos défices de equilíbrio e o medo de cair nos idosos.

O artigo número 6 (13) compara os efeitos de um programa de exercícios com a componente física e psicológica do risco de queda, abordando o equilíbrio, a força, a função e o medo de cair. 0 teste Timed Up and Go (TUG), o teste de cadeira de cinco repetições (CST) e o teste de Romberg modificado (mod Rom) foram usados para avaliação física do risco de queda. Para os resultados psicológicos, foi usada a versão alemã da Falls Efficacy Scale - Internacional (FES-I).

Os idosos que participaram no grupo de intervenção mostraram uma melhoria no teste Timed-Up-and-Go (TUG): 1,5 segundos maior do que o mostrado pelo grupo controlo, equivalente a um efeito pequeno a moderado. Para o equilíbrio, foi alcançada uma melhoria relativa de 0,8 segundos, e a ansiedade sobre quedas foi reduzida em 3,7 pontos na Escala de Eficácia das Quedas-Internacional (FES-I), no grupo de intervenção em relação ao grupo controlo.

Os autores deste estudo concluíram que a intervenção com exercícios complexos para a prevenção de quedas, melhorou efetivamente o equilíbrio, a condição física e levou a uma redução do medo de cair na população idosa estudada.

Nestes três artigos (4-6-8), as respetivas conclusões ressalvam que 0 treino de equilíbrio deve ser encorajado e mantido para minimizar o medo de cair do idoso.

Um equilíbrio estável, maior força muscular e resistência elástica, leva a uma melhoria considerável na marcha e redução do medo de cair, que por consequência contribui para a redução do risco de queda. 


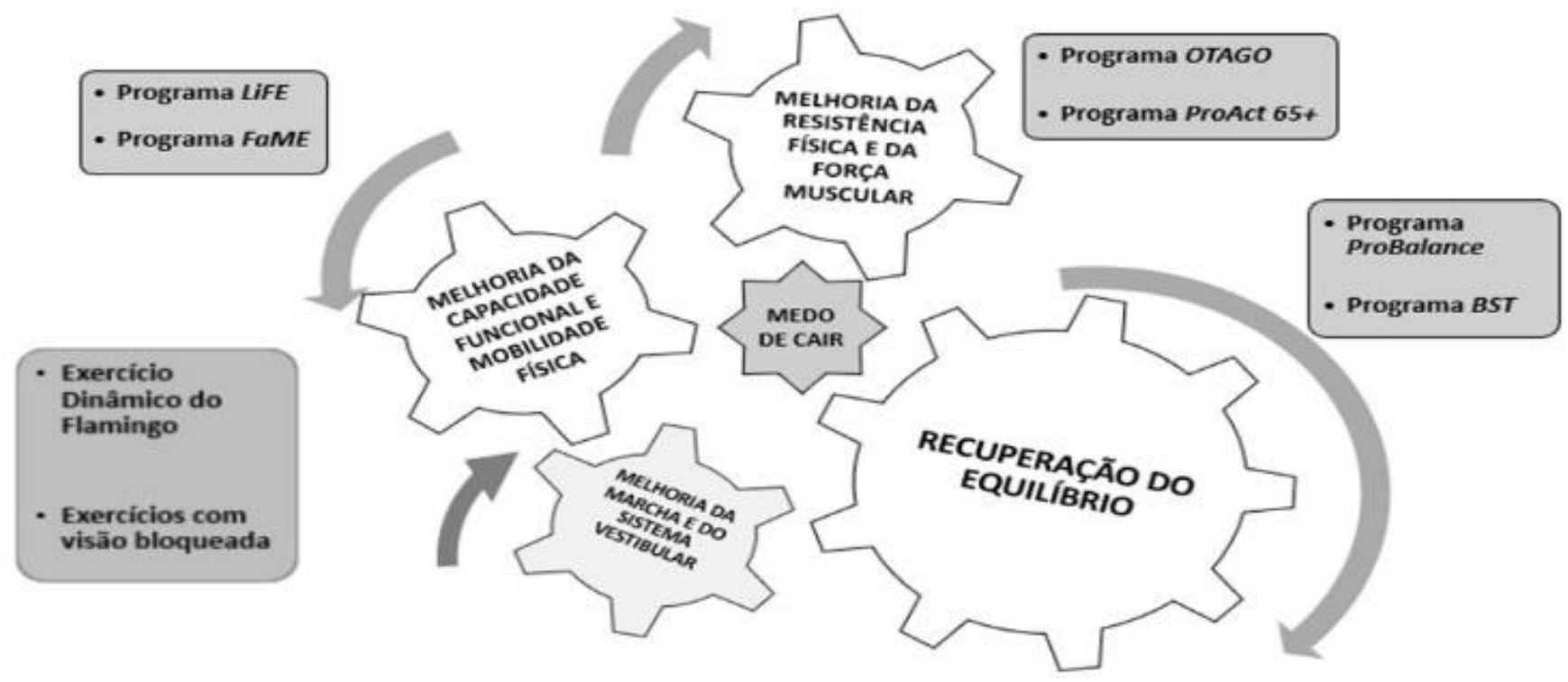

Figura 2 - Esquema representativo dos tipos de treino presentes nos estudos selecionados

\section{CONCLUSÃO}

Após a análise detalhada dos artigos selecionados, verifica-se que, maioritariamente, são abordados programas de treino ou exercícios específicos para a recuperação do equilíbrio e da força muscular na prevenção de quedas no idoso. Outros artigos abordam programas de treino com intervenção na melhoria da capacidade funcional e mobilidade física, através da implementação de programas mais específicos. São também descritos programas de exercícios singulares para aumento da força muscular e do equilíbrio em que, uns intervêm na melhoria da marcha e no sistema vestibular e outros incidem em exercícios de equilíbrio e de resistência.

De uma forma genérica, todos eles consideram que a implementação de programas de treino desta natureza tem um impacto positivo e significativo na importância do treino propriocetivo e do equilíbrio postural no idoso, assumindo um papel de referência significativa na prevenção de quedas.

São vários os autores que defendem a continuidade do exercício físico e dos programas de treino de equilíbrio e de proprioceção, pois na ausência destes, o risco de queda nos idosos aumenta substancialmente.

Em suma, a prescrição de um programa de treinos de exercícios para a prevenção da queda na população idosa deve ter em atenção a individualidade de cada pessoa e o tipo de exercícios (de equilíbrio, força, resistência). 0 medo de cair, nesta população mais frágil, está sempre presente, sendo fundamental a supervisão e a presença do profissional de saúde, não só para prevenir a queda pela segurança transmitida, mas também para incentivar a continuidade da prática do exercício físico.

\section{Limitação dos estudos}

Consideram-se as limitações para este estudo, o número reduzido de artigos com exercícios de treino sem recurso a tecnologia e/ou equipamentos tecnológicos, uma vez que um dos objetivos seria transpor estes treinos para o domicílio assim como apenas um artigo realizado por Enfermeiros Especialistas em Enfermagem de Reabilitação.

\section{Implicações para a investigação}

Dada a importância descrita sobre os benefícios do treino propriocetivo e de equilíbrio postural na prevenção de quedas no idoso, considera-se a realização de mais estudos, particularmente por Enfermeiros Especialistas em Enfermagem de Reabilitação, em contexto diário dos intervenientes (contexto domiciliar) e sem o recurso a tecnologia para reforçar o benefício da implementação desses mesmos programas.

\section{REFERÊNCIAS BIBLIOGRÁFICAS}

1. OMS. Relatório Mundial de Envelhecimento e Saúde. Suiça: OMS; 2015.

2. Marques-Vieira, C. e Sousa, L. Cuidados de enfermagem de reabilitação à pessoa ao longo da vida. $1^{\text {a }}$ Edição. Loures: Lusodidata, 2017.

3. Lelard T, Ahmaidi S. Effects of physical training on age-related balance and postural control. Clin Neurophysiol. 2015 Nov 1;45(4-5):357-69.

4. Yang XJ, Hill K, Moore K, Williams S, Dowson L, Borschmann K et al. Effectiveness of a targeted exercise intervention in reversing older people's mild balance dysfunction: a randomized controlled trial. Phys Ther. 2012 Jan 1;92(1):24-37.

5. Montoito, A. Fiabilidade de Testes de Proprioceptividade em Pessoas Idosas. Dissertação de Mestrado em Exercício e Saúde. Escola de Ciência e Tecnologia. Universidade de Évora. 2016.

6. Marques, L. Quedas são a principal causa de morte acidental dos idosos. [ed.] Jornal de Notícias. 15 de Novembro de 2017.

7. República, Diário da. Regulamento n. ${ }^{\circ} 392 / 2019$. Regulamento das competências específicas do enfermeiro especialista em Enfermagem de Reabilitação. $2^{\mathrm{a}}$ série, 3 de Maio de 2019, 85. 
8. Peters, M., Godfrey, C., Mclnerney, P., Baldini Soares, C., Khalil, H., \& Parker, D. Methodology for JBI scoping reviews. Adelaide : The Joanna Briggs Insitute, 2015.

9. Sakamoto K, Endo N, Harada A, Sakada T, Tsushita K, Kita K, Hagino H, Sakai A, Yamamoto N, Okamoto T, Liu M. Why not use your own body weight to prevent falls? A randomized, controlled trial of balance therapy to prevent falls and fractures for elderly people who can stand on one leg for $\leq 15 \mathrm{~s}$. J Orthop Sci. 2013 Jan 1;18(1):110-20.

10. Clemson L, Singh MA, Bundy A, Cumming RG, Manollaras K, O'Loughlin P, et al. Integration of balance and strength training into daily life activity to reduce rate of falls in older people (the LiFE study): randomised parallel trial. Bmj. 2012 Aug 7;345:e4547.

11. Halvarsson A, Franzén E, Farén E, Olsson E, Oddsson L, Ståhle A. Long-term effects of new progressive group balance training for elderly people with increased risk of falling-a randomized controlled trial. Clin Rehabil. 2013 May;27(5):450-8.

12. Cadore EL, Rodríguez-Mañas L, Sinclair A, Izquierdo M. Effects of different exercise interventions on risk of falls, gait ability, and balance in physically frail older adults: a systematic review. Rejuvenation Res. 2013 Apr 1;16(2):105-14..

13. Freiberger E, Blank WA, Salb J, Geilhof B, Hentschke C, Landendoerfer $\mathrm{P}$, Halle $M$, Siegrist $M$. Effects of a complex intervention on fall risk in the general practitioner setting: a cluster randomized controlled trial. Clin Interv Aging. 2013;8:1079-88.

14. Kim JY, Park SD, Song HS. The effects of a complex exercise program with the visual block on the walking and balance abilities of elderly people. J Phys Ther Sci. 2014;26(12):2007-9..

15. Roaldsen KS, Halvarsson A, Sahlström T, Ståhle A. Task-specific balance training improves self-assessed function in communitydwelling older adults with balance deficits and fear of falling: a randomized controlled trial. Clin Rehabil. 2014 Dec;28(12):118997.

16. Cho SI, An DH. Effects of a fall prevention exercise program on muscle strength and balance of the old-old elderly. J Phys Ther Sci. 2014;26(11):1771-4.

17. Kim WJ, Chang M, An DH. Effects of a community-based fall prevention exercise program on activity participation. J Phys Ther Sci. 2014;26(5):651-3. .

18. Gouveia BR, Jardim HG, Martins MM, Gouveia ÉR, de Freitas DL, Maia JA, Rose DJ. An evaluation of a nurse-led rehabilitation programme (the ProBalance Programme) to improve balance and reduce fall risk of community-dwelling older people: A randomised controlled trial. Int J Nurs Stud. 2016 Apr 1;56:1-8.

19. Gawler S, Skelton DA, Dinan-Young S, Masud T, Morris RW, Griffin $M$, Kendrick D, lliffe $S$. Reducing falls among older people in general practice: The ProAct65+ exercise intervention trial. Arch Gerontol Geriatr. 2016 Nov 1;67:46-54..

20. Lacroix A, Kressig RW, Muehlbauer T, Gschwind YJ, Pfenninger $B$, Bruegger O, Granacher U. Effects of a supervised versus an unsupervised combined balance and strength training program on balance and muscle power in healthy older adults: a randomized controlled trial. Gerontol. 2016;62(3):275-88. 


\title{
PREVENÇÃO DAS CONSEQUÊNCIAS DA IMOBILIDADE NA PESSOA EM SITUAÇÃO CRÍTICA
}

\author{
PREVENCIÓN DE LAS CONSECUENCIAS DE LA INMOVILIDAD EN ENFERMO CRÍTICO
}

\author{
PREVENTION OF THE IMOBILITY CONSEQUENCES IN CRITICALLY ILL PATIENTS
}

DOI 10.33194/rper.2019.v2.n1.10.4574 | Submetido 12.05.2019 | Aprovado 27.06.2019

\author{
Ana Vanessa Barroso Cerqueira ${ }^{1}$; (i) Eugénia Nunes Grilo² \\ 1 - Centro Hospitalar Universitário - Algarve; 2 - Escola Superior de Saúde Dr. Lopes Dias, Instituto Politécnico de Castelo Branco
}

\section{RESUMO}

Este artigo resultou de um projeto de intervenção que teve como objetivo prevenir as consequências da imobilidade na pessoa em situação crítica. A revisão da literatura salienta que programas de reabilitação precoce minimizam as repercussões da imobilidade com grandes benefícios na funcionalidade e qualidade de vida das pessoas. Para estudar e descrever este problema foi utilizada metodologia de estudo de casos.

Participaram quatro pessoas, internadas numa unidade de cuidados intensivos, a quem foi implementado um projeto de intervenção que incluía um conjunto sistematizado de cuidados no âmbito da prevenção de úlceras por pressão e da reabilitação motora e respiratória. A avaliação dos resultados permitiu concluir que as pessoas que integraram o projeto mantiveram ou melhoraram a amplitude do movimento; não desenvolveram úlceras por pressão nem complicações respiratórias. Conclui-se que um planeamento adequado e individualizado de cuidados de enfermagem de reabilitação previne as consequências da imobilidade nos doentes em estado crítico.

Desccritores: Enfermagem em Reabilitação; pessoas acamadas; estado crítico

\section{RESUMEN}

Este artículo resultó de un proyecto de intervención cuyo objetivo fue prevenir las consecuencias de la inmovilidad en enfermos críticos. La revisión de la literatura subraya que los programas de rehabilitación precoz minimizan las repercusiones de la inmovilidad con grandes beneficios en la funcionalidad y calidad de vida de las personas. Para estudiar y describir este problema se utilizó la metodología de estudio de casos.

Cuatro personas, hospitalizadas en una unidad de cuidados intensivos, participaron del proyecto de intervención que incluía un conjunto sistematizado de cuidados del ámbito de la prevención de úlceras por presión y de la rehabilitación motora y respiratoria. La evaluación de los resultados permitió concluir que las personas que integraron el proyecto mantuvieron o mejoraron la amplitud del movimiento; no desarrollaron úlceras por presión ni complicaciones respiratorias. Se concluye que una planificación adecuada e individualizada de cuidados de enfermería de rehabilitación previene las consecuencias de la inmovilidad en enfermos críticos.

Palabras Clave: Enfermería en Rehabilitación; personas encamadas; enfermedad crítica

\section{ABSTRACT}

This article resulted from an intervention project that aimed to prevent the immobility consequences in critically ill patients. The literature review emphasizes that early rehabilitation programs minimize the immobility repercussions with great benefits in people's functionality and quality of life. To study and describe this problem was used the case study methodology.

Four hospitalized persons in an intensive care unit participated on an intervention project that included a systematized nursing care in the scope of pressure ulcers prevention and motor and respiratory rehabilitation. The results evaluation allowed to conclude that people who participated in the project maintained or improved the range of motion; did not develop pressure ulcers or respiratory complications. It is concluded that adequate and individualized rehabilitation nursing care planning prevents immobility consequences in critically ill patients.

Keywords: Rehabilitation Nursing; bedridden persons; critical illness

\section{INTRODUÇÃO}

Nas Unidades de Cuidados Intensivos $(\mathrm{UCl})$ o repouso prolongado no leito é utilizado como uma medida terapêutica necessária à estabilização clínica das pessoas internadas. No entanto, os efeitos deletérios da imobilidade podem ser mais graves do que a situação clínica geradora da mesma, transformando uma redução da capacidade funcional temporária em incapacidade $^{1}$ reconhecendo-se que a imobilidade compromete a qualidade de vida das pessoas ${ }^{2}$. Além disso, atualmente verifica-se um aumento do número de sobreviventes da doença crítica com sequelas de 
disfunção neuromuscular e deficiência física, relacionadas com o seu internamento nas $\mathrm{UCl}^{3,4}$.

Os efeitos nocivos da imobilidade prolongada nas pessoas em situação crítica, têm como consequência, entre outras, disfunções severas no sistema osteomioarticular ${ }^{5}$, como o desenvolvimento de contraturas articulares ${ }^{6}$. Outro estudo ${ }^{7}$, afirmam que a fraqueza muscular generalizada é uma consequência comum nas pessoas que se encontram imobilizadas e particularmente nas que necessitam de suporte ventilatório invasivo. Nestas pessoas a fraqueza muscular associada à ineficácia do revestimento ciliar reduz a efetividade da tosse, o que contribui para o aumento da acumulação de secreções e risco acrescido de infeções respiratórias ${ }^{1}$. A ventilação e a perfusão pulmonar também ficam afetadas, o que se traduz em episódios de hipoxémia, capacidade de reserva ventilatória reduzida, aumento da dispneia e maior dificuldade no processo de desmame ventilatório ${ }^{8}$. Outro problema associado à imobilidade é o aparecimento de úlceras por pressão que representam um grave problema de saúde, com repercussões na pessoa, ao nível da mortalidade e morbilidade e os valores de prevalência destas tendem a aumentar nas populações de risco, nomeadamente as pessoas em estado crítico ${ }^{1}$.

Estas são algumas das razões que que justificam o investimento na prevenção das consequências da imobilidade e é fundamental encontrar evidência e evidência que aborde intervenções de enfermagem eficazes na prevenção e redução do problema 9 .

Neste sentido, os enfermeiros especialistas em enfermagem de reabilitação (EEER), que exercem funções nas $\mathrm{UCl}$, possuem um papel fulcral na elaboração e implementação de programas de reabilitação que visem a minimização das consequências da imobilidade. A prevenção de complicações, com 0 intuito de evitar as incapacidades ou minimizando as mesmas é um dos aspetos chave de atuação da Enfermagem de Reabilitação ${ }^{10}$, que ganha maior relevo em contexto de $\mathrm{UCl}$, visto que uma das finalidades da prestação de cuidados de Enfermagem de Reabilitação às pessoas em situação crítica consiste em evitar e reduzir complicações decorrentes da imobilidade no leito ${ }^{11}$, nomeadamente as respiratórias, motoras e funcionais $^{12}$. Sublinha-se que um dos contributos essenciais para prevenção das consequências da imobilidade é o planeamento adequado de cuidados de Enfermagem de Reabilitação, que inclua intervenções promotoras da mobilidade e subsequente do autocuidado ${ }^{1}$. Outros autores ${ }^{13}$ reforçam a importância dos programas de reabilitação e mobilização precoce, direcionados para as pessoas em situação crítica, com início precoce, ou seja, imediatamente após a estabilização das funções vitais, normalmente nos primeiros dois a cinco dias de internamento das pessoas nas $\mathrm{UCl}$.

Além disso, a promoção da segurança das pessoas cuidadas é um objetivo importante na prática da Enfermagem de Reabilitação ${ }^{14}$ e a prestação de cuidados de Enfermagem de Reabilitação na prevenção das consequências da imobilidade das pessoas em situação crítica permite que sejam evitadas situações e efeitos adversos que comprometam a sua segurança.

$\mathrm{O}$ internamento na $\mathrm{UCl}$ e as consequências que daí advêm, como a imobilidade, são eventos que desencadeiam várias transições nas pessoas, mais concretamente transições de saúde/ doença e situacionais $^{15}$. Na medida em que os enfermeiros possuem um papel preponderante na facilitação das transições, esse papel ganha um significado particular nos processos de transição saúde/doença e nestes, é fundamental que adotem uma postura de escuta e aceitação do outro, educação e orientação, promoção do autocuidado e conforto ${ }^{16}$, podendo também intervir nos períodos antecipatórios, de preparação para a mudança de papéis, de prevenção dos efeitos negativos da doença sobre as pessoas ${ }^{17}$, como é o caso das consequências da imobilidade.

Através da revisão da literatura, constatou-se que os estudos desenvolvidos por enfermeiros na área da prevenção das consequências da imobilidade na pessoa em situação crítica são escassos, comparativamente com os estudos desenvolvidos por outros profissionais da área de reabilitação.

Com o intuito de poder contribuir para a prevenção das consequências da imobilidade, e descrever esses contributos, foi desenvolvido um projeto de intervenção precoce de Enfermagem de Reabilitação que incidiu sobre as pessoas em situação crítica acometidas à imobilidade, internadas numa $\mathrm{UCl}$, às quais foram prestados cuidados de Enfermagem de Reabilitação organizados e sistematizados.

O foco é por definição da Classificação Internacional da Prática de Enfermagem (CIPE $囚)$ uma área de intervenção que é pertinente para a enfermagem ${ }^{18}$ e no contexto deste projeto os focos identificados como relevantes foram a limpeza das vias aéreas, a ventilação, a rigidez articular e a úlcera por pressão, associados às consequências respiratórias, articulares e tegumentares da imobilidade.

O projeto de intervenção apresenta como objetivo geral prevenir as consequências da imobilidade das pessoas internadas numa $\mathrm{UCl}$ e como objetivos específicos, realizar uma avaliação inicial das pessoas que inclua a avaliação da função ventilatória e dos mecanismos de limpeza das vias aéreas, avaliação da integridade cutânea e do risco de compromisso e a avaliação da amplitude articular, através da observação direta e da aplicação de instrumentos de avaliação adaptados à população portuguesa; identificar o risco de desenvolvimento de alterações respiratórias, tegumentares, e músculo-esqueléticas e formular diagnósticos associados; implementar um programa de intervenção de Enfermagem de Reabilitação respiratória e motora; descrever os contributos do programa de intervenção através da reavaliação da pessoa, incluindo a função ventilatória e os mecanismos de limpeza das vias aéreas, integridade cutânea e amplitude articular. 


\section{MÉTODO}

Para a elaboração do projeto de intervenção foi adotada a metodologia de estudos de caso, uma vez que esta estratégia de pesquisa destina-se sobretudo a descrever, compreender e explicar ${ }^{19}$, permitindo estudar um fenómeno (neste caso as consequências da imobilidade nas pessoas em situação critica) numa perspetiva holística e num contexto real, com diversas fontes de evidência, obtendo uma riqueza de informações descritivas, permitindo também a reflexão e a procura de alternativas para a solução dos problema ${ }^{20}$. Apesar de apresentar como limitação a impossibilidade de generalizar os resultados obtidos na enfermagem, possibilita conhecer em profundidade os aspetos do fenómeno em estudo ${ }^{21}$.

0 presente projeto descreve os casos de pessoas internadas numa $\mathrm{UCl}$ de um Centro Hospitalar de Lisboa, que apresentavam potencial risco para desenvolverem alterações tegumentares, músculoesqueléticas e respiratórias, associadas à imobilidade, critério de selecção para a participação no projeto de intervenção. Realizou-se no período de outubro a novembro de 2018, após a sua aprovação pela Comissão de Ética para a Saúde e autorização do Conselho de Administração do referido Centro Hospitalar.

A importância da enfermagem enquanto ciência teórico-prática deve ser sensível aos múltiplos focos de interesse e intervir no processo de transição e essa intervenção prática basear-se-á na facilitação das transições dos doentes e famílias onde a saúde e o bem-estar são percebidas como resultados ${ }^{16,17}$. Por isso, o projeto de intervenção baseou-se na metodologia do processo de enfermagem.

Com base nos quatro focos de enfermagem definidos e critérios sustentados no Padrão Documental dos Cuidados de Enfermagem da Especialidade de Enfermagem de Reabilitação ${ }^{22}$ e outros considerados relevantes e descritos na literatura, da avaliação inicial das pessoas constou a avaliação dos parâmetros vitais, monitorização da integridade cutânea, auscultação pulmonar e a avaliação do reflexo de tosse e do padrão respiratório, através da observação direta; a avaliação do estado de consciência através da aplicação da Escala de Coma de Glasgow (ECG) ${ }^{23}$; avaliação do risco de desenvolvimento de úlceras por pressão, com a aplicação da escala de Braden ${ }^{24}$. Foi também avaliada a amplitude do movimento (ADM) das articulações ao nível dos ombros, cotovelos, joelhos e tornozelos, através da goniometria. A utilização de instrumentos, de avaliação uniformizados, permite a documentação dos cuidados especializados, a sua continuidade e também o desenvolvimento de projetos de investigação que se possam assumir como boas práticas e serem replicados 25 .

Após a identificação dos problemas reais e potenciais a partir dos dados colhidos na avaliação inicial, foram elaborados diagnósticos de Enfermagem de Reabilitação relacionados com cada foco de enfermagem, recorrendo à linguagem $\quad \mathrm{CIPE} \circledast \quad$ e estratificaram-se intervenções baseadas na evidência científica e explanadas no Padrão Documental dos Cuidados de Enfermagem da Especialidade de Enfermagem de Reabilitação, no âmbito da Reeducação Funcional Motora (RFM), prevenção de úlceras por pressão e Reeducação Funcional Respiratória(RFR).

Foi definido que a avaliação dos focos de enfermagem limpeza das vias aéreas e ventilação seria realizada no início e no final de cada sessão de RFR, uma vez que se espera que as intervenções realizadas em cada sessão promovam, em princípio, uma melhoria imediata. Relativamente à avaliação dos focos de enfermagem rigidez articular e úlcera por pressão definiu-se que seria realizada em três momentos do plano de intervenção - inicial, intermédio e final - uma vez que a visibilidade dos resultados ocorre num período mais alargado, por contraponto com os focos anteriores.

Para garantir a integridade da investigação, todas as fases do presente projeto apresentam-se fundadas nos princípios éticos defendidos pela enfermagem, respeitando e salvaguardando a confidencialidade e o anonimato, quer da instituição na qual decorreu o projeto, quer dos participantes, tendo sido representados por letras. Foram também tomadas todas as medidas necessárias para se proceder a um consentimento informado, esclarecido e livre

\section{RESULTADOS}

A informação obtida foi sujeita a procedimentos de análise de natureza descritiva, que possibilitam descrever as características dos casos estudados e os valores obtidos pela medida das variáveis ${ }^{26}$.

\section{Descrição dos Casos}

Procede-se à descrição de cada caso, salvaguardando que durante as sessões de RFM verificou-se que todos os participantes mantiveram estabilidade hemodinâmica, tendo sido assegurada a segurança das intervenções efetuadas nas pessoas. Antes de cada sessão de RFR procedeu-se à visualização das radiografias de tórax dos participantes com a finalidade de detetar possíveis alterações que comprometessem a sua função respiratória.

\section{Caso da pessoa A}

Pessoa de 44 anos de idade, do sexo masculino, casado. Foi admitido na $\mathrm{UCl}$ com os diagnósticos de traumatismo crânio encefálico (edema cerebral difuso com fina lâmina de hematoma subdural frontal direito); fratura de C2 e de D9; pneumotórax à direita; fratura dos metacarpos da mão esquerda. Durante o internamento apresentou diversos problemas clínicos, como trombose venosa profunda do membro inferior esquerdo. Este problema ainda não se encontrava resolvido no momento da avaliação inicial que ocorreu no $30^{\circ}$ dia de internamento (Quadro n. ${ }^{\circ} 1$ ), pelo que se 
optou por não avaliar nesse momento a ADM do membro inferior esquerdo, devido ao risco de agravamento da situação.

\begin{tabular}{|c|c|}
\hline $\begin{array}{l}\text { Estado de consciência } \\
\text { (pontuação da ECG) }\end{array}$ & $\begin{array}{l}\text { Pontuação de } 11 \mathrm{~T} \text { (abertura ocular } \\
\text { espontânea-4; resposta verbal } \\
\text { ausente pela presença do tubo } \\
\text { endotraqueal (TET) - } 1 \text { e obedece a } \\
\text { ordens-6) }\end{array}$ \\
\hline Integridade Cutânea & $\begin{array}{l}\text { Ausente } \\
\text { - Úlcera por pressão categoria } 3 \text { na } \\
\text { região occipital, associada à } \\
\text { utilização permanente do colar } \\
\text { cervical; } \\
\text { - Úlcera por pressão categoria } 3 \text { na } \\
\text { região sagrada. }\end{array}$ \\
\hline $\begin{array}{l}\text { Risco de úlcera por } \\
\text { pressão } \\
\text { (pontuação da escala } \\
\text { de Braden) }\end{array}$ & $\begin{array}{l}\text { Risco elevado de úlcera por pressão } \\
\text { (13 pontos) }\end{array}$ \\
\hline $\begin{array}{l}\text { Avaliação do } \\
\text { movimento articular }\end{array}$ & $\begin{array}{l}\text { - Mantido repouso prolongado no } \\
\text { leito. } \\
\text { - Avaliada a ADM de forma passiva nos } \\
\text { membros superiores e membro } \\
\text { inferior direito com movimento } \\
\text { articular e muscular diminuído. } \\
\text { - Na flexão do cotovelo esquerdo } \\
\text { apresentou fácies de dor, no } \\
\text { momento final do movimento. }\end{array}$ \\
\hline Ventilação & $\begin{array}{l}\text { - Ventilação espontânea, com } \\
\text { oxigenioterapia por peça em } \mathrm{T} \text { com } \\
\text { fração de oxigénio inspirado }\left(\mathrm{FiO}_{2}\right) \text { de } \\
28 \% \text {. } \\
\text {-Padrão respiratório regular, } \\
\text { superficial, de predominância } \\
\text { abdominal (com expansão torácica } \\
\text { mínima), simetria torácica mantida e } \\
\text { sem utilização dos músculos } \\
\text { acessórios. Sem esfoço respiratório. } \\
\text { - Auscultação pulmonar com ruídos } \\
\text { adventícios }\end{array}$ \\
\hline $\begin{array}{l}\text { Mecanismos de } \\
\text { Limpeza das vias } \\
\text { aéreas } \\
\text { (Reflexo de tosse) }\end{array}$ & $\begin{array}{l}\text { Reflexo de tosse diminuído; mobiliza } \\
\text { as secreções até ao TET. Aspiração de } \\
\text { secreções frequentes. }\end{array}$ \\
\hline
\end{tabular}

Quadro 1 - Avaliação Inicial da pessoa A

Fonte: elaboração própria.

Na sequência da avaliação inicial efetuada, foram estabelecidos os seguintes diagnósticos de enfermagem:

- Diagnóstico 1 - Risco de rigidez articular;

- Diagnóstico 2 - Risco de úlcera por pressão em grau elevado; Diagnóstico 3 - Limpeza das vias aéreas ineficaz;

- Diagnóstico 4 - Ventilação comprometida.

Ao longo do período de intervenção a pessoa $A$ manteve o mesmo estado de consciência. Realizaram- se 7 sessões de RFM, tendo sido sempre realizadas mobilizações passivas, com aumento do número de repetições por movimento a partir da $5^{\mathrm{a}}$ sessão. Por questões de segurança, os exercícios de mobilização passiva do membro inferior esquerdo foram apenas introduzidos na $4^{\text {a }}$ sessão, momento em que se avaliou a ADM do membro inferior esquerdo.

Nas primeiras sessões apresentou fácies de dor durante a rotação externa do ombro esquerdo, flexão do cotovelo esquerdo e na supinação do antebraço esquerdo, pelo que se realizaram movimentos de menor amplitude. Foi sugerida e administrada terapêutica analgésica. Nas restantes sessões não apresentou dor durante as mobilizações. Salienta-se que, por ter havido um maior tempo de contato com a pessoa $A$, foram realizados três momentos de avaliação da ADM, enquanto que os restantes participantes foram submetidos a dois momentos avaliativos. Assim, a avaliação intermédia da ADM ocorreu na $3^{a}$ sessão e no final da $7^{a}$ sessão foi reavaliada a $A D M$.

Das articulações avaliadas nos três períodos verificouse que houve um aumento linear da ADM ao nível da abdução do ombro direito, flexão do cotovelo direito e flexão do joelho direito. A ADM da abdução do ombro esquerdo e da dorsiflexão do tornozelo direito aumentou da avaliação inicial para a intermédia e manteve-se na avaliação final.

Observou-se uma diferença nas ADM dos membros inferiores, em que as articulações do membro inferior direito apresentam maior amplitude, o que é compreensível visto que o membro inferior esquerdo esteve mais tempo imobilizado, no entanto apresentou aumento da ADM ao nível da flexão do joelho e dorsiflexão do tornozelo.

$\mathrm{Na}$ flexão dos ombros e na flexão plantar do tornozelo direito houve uma diminuição da ADM da avaliação intermédia para a avaliação final. Também se verificou uma diminuição da $A D M$ ao nível da flexão plantar do tornozelo esquerdo entre as duas avaliações efetuadas. A ADM da flexão do cotovelo esquerdo apresentou um decréscimo linear desde a primeira avaliação. É de ressalvar que durante as primeiras sessões foi um dos movimentos onde a pessoa A apresentou dor.

Quanto às medidas preventivas de úlcera por pressão, além da aplicação de creme hidratante e manutenção da pele seca, foi reforçada a alternância de decúbitos, com ajuda total, e a remoção do colar cervical uma vez dia (no mínimo), para inspecionar e limpar a pele; para prevenir a úlcera por pressão no mento, devido ao colar cervical, foram realizados cuidados à pele e aplicada compressa redutora de pressão em silicone que abrange a região do mento até à região supraclavicular.

Nas três avaliações efetuadas a pessoa A manteve a mesma pontuação na escala de Braden, o que se traduz num elevado risco de úlcera por pressão, no entanto, não desenvolveu mais nenhuma úlcera por pressão. 
No âmbito da RFR foram realizadas 6 sessões. A partir da $2^{\mathrm{a}}$ sessão foi aumentado o número de repetições na reeducação costal inferior, pela diminuição do murmúrio vesicular nas bases pulmonares, e na $3^{\text {a }}$ sessão foi aumentado o número de repetições dos restantes exercícios respiratórios.

Importa referir que no período em que decorreu o projeto de intervenção a pessoa A foi extubada endotraquealmente (um dia antes da $3^{a}$ sessão), no entanto por descompensação respiratória procedeu-se a uma nova reentubação endotraqueal (antes da $4^{\mathrm{a}}$ sessão) e na $6^{a}$ sessão tinha sido removido o TET no turno anterior.

Antes e após de cada sessão foram avaliados os parâmetros vitais. Os valores de frequência cardíaca e de pressão arterial média apresentaram ligeiras variações, verificando-se que na $3^{a}$ sessão houve um aumento da pressão arterial média após a sessão de RFR, contudo não comprometeram a estabilidade hemodinâmica da pessoa.

$\mathrm{Na} 3^{\mathrm{a}}$ e a $4^{\mathrm{a}}$ sessão observou-se um aumento da frequência respiratória, no entanto os seus valores encontraram-se circunscritos ao intervalo de referência da frequência respiratória. Além disso, ao aumento da frequência respiratória esteve associado um aumento da amplitude da onda da frequência respiratória, com melhoria do padrão respiratório.

Ao longo de todas as sessões de RFR avaliou-se a ventilação e a presença de esforço respiratório, verificando-se que a pessoa A não apresentou sinais de esforço respiratório, com melhoria na amplitude e no tipo de respiração. Destacamos que na sessão $n^{\circ} 4$ houve um retrocesso em termos do padrão respiratório que poderá estar associado ao período de descompensação prévio e que culminou na reentubação da pessoa. Apesar disso, e a partir dessa sessão a evolução foi favorável.

Os valores de $\mathrm{spO}_{2}$ aumentaram nas primeiras três sessões, mantiveram- se constantes na $4^{\mathrm{a}}$ e $6^{\mathrm{a}}$ sessão e na $5^{a}$ sessão diminui ligeiramente de $100 \%$ para $96 \%$. É de salientar que durante as sessões o débito de oxigénio oscilou, de acordo com as necessidades de oxigenioterapia da pessoa A.

A auscultação pulmonar realizou-se antes e após de todas as sessões, verificando-se que a pessoa A não apresentou ruídos adventícios (RA) no final das sessões e o murmúrio vesicular (MV) nas bases pulmonares apesar de se manter diminuído tornou-se mais audível.

Apesar de na $1^{\text {a }}$ sessão ter apresentado um acesso de tosse vigoroso, quando desconectado de fonte de oxigénio, tendo sido capaz de expulsar pelo TET secreções, na globalidade das sessões, enquanto esteve entubado endotraquealmente, a pessoa $A$ apresentou reflexo de tosse diminuído, mobilizando as secreções até ao TET, sendo necessária a aspiração de secreções.

$\mathrm{Na} 3^{a}$ sessão e na última sessão encontrava-se extubado, apresentando reflexo de tosse diminuído, contudo após a realização das técnicas de RFR planeadas, foi capaz de expelir as secreções. Quando incentivado a tossir, ficou mais sonolento tendo sido necessário aspirar as secreções.

\section{Caso da pessoa B}

Pessoa de 60 anos de idade, do sexo masculino e divorciado, vivendo sozinho. Admitido na UCI por AVC isquémico cerebeloso direito. Realizou-se a avaliação inicial no $7^{\circ}$ dia de internamento (Quadro n. ${ }^{\circ} 2$ ).

\begin{tabular}{|c|c|}
\hline $\begin{array}{l}\text { Estado de consciência } \\
\text { (pontuação da ECG) }\end{array}$ & $\begin{array}{l}\text { Pontuação de } 10 \text { T (abertura } \\
\text { ocular ao som-3; resposta verbal } \\
\text { ausente pela presença do TET - } 1 \\
\text { e obedece a ordens- } 6 \text { ) }\end{array}$ \\
\hline Integridade Cutânea & Presente \\
\hline $\begin{array}{l}\text { Risco de úlcera por } \\
\text { pressão } \\
\text { (pontuação da escala de } \\
\text { Braden) }\end{array}$ & $\begin{array}{l}\text { Risco elevado de úlcera por } \\
\text { pressão } \\
\text { (12 pontos) }\end{array}$ \\
\hline $\begin{array}{l}\text { Avaliação movimento } \\
\text { articular }\end{array}$ & $\begin{array}{l}\text { - Mantido repouso no leito. } \\
\text {-Avaliada a ADM de forma passiva } \\
\text { nos membros superiores e } \\
\text { inferiores com movimento } \\
\text { articular e muscular diminuído. } \\
\text { - Dor ausente no movimento } \\
\text { articular }\end{array}$ \\
\hline Ventilação & $\begin{array}{l}\text {-Sob ventilação mecânica } \\
\text { invasiva, em modo ventilatório de } \\
\text { pressão controlada. } \\
\text {-Padrão respiratório superficial, } \\
\text { misto, com simetria torácica } \\
\text { mantida; sem ciclos respiratórios } \\
\text { próprios, realizando aqueles } \\
\text { previamente regulados no } \\
\text { ventilador. } \\
\text { - Auscultação pulmonar com RA }\end{array}$ \\
\hline $\begin{array}{l}\text { Mecanismos de Limpeza } \\
\text { das vias aéreas } \\
\text { (Reflexo de tosse) }\end{array}$ & $\begin{array}{l}\text { Reflexo de tosse diminuído; não } \\
\text { mobiliza as secreções até ao TET. } \\
\text { Aspiração de secreções } \\
\text { frequentes. }\end{array}$ \\
\hline
\end{tabular}

Quadro 2 - Avaliação Inicial da pessoa B

Fonte: elaboração própria.

De acordo com a avaliação inicial, foram elaborados os seguintes diagnósticos de enfermagem:

- Diagnóstico 1- Risco de rigidez articular;

- Diagnóstico 2 - Risco de úlcera por pressão em grau elevado;

- Diagnóstico 3 - Limpeza das vias aéreas ineficaz;

- Diagnóstico 4 - Ventilação comprometida.

A pessoa B apresentou uma melhoria do estado de consciência ao longo do projeto de intervenção, apresentando no último dia uma pontuação na ECG de 14 (abertura ocular espontânea, discurso confuso, cumprindo ordens).

Realizaram-se 4 sessões de RFM, tendo sido efetuadas, numa primeira fase, mobilizações passivas. A partir da $3^{a}$ sessão o doente estava mais desperto e quando 
incentivado era o próprio a iniciar o movimento, pelo que se iniciaram exercícios de mobilização ativa assistidas.

Nas primeiras duas sessões apresentou fácies de dor à mobilização da região cervical, pelo que se suspendeu a mobilização da mesma. Nas restantes sessões sem queixas álgicas. No final da $4^{a}$ sessão reavaliou-se a ADM, de modo passivo, para serem comparados os resultados obtidos com os da avaliação inicial.

Globalmente a ADM foi mantida ou aumentada, observando-se uma diminuição da $\mathrm{ADM}$ ao nível da abdução do ombro direito, flexão do cotovelo direito e da flexão plantar de ambos os tornozelos.

Durante o projeto de intervenção a pessoa $B$ manteve a integridade cutânea, no entanto, devido à fricção (descaía constantemente no leito) apresentou rubor na região sagrada. Foi aplicado creme hidratante e adotados como posicionamentos preferenciais os decúbitos semi-dorsais e laterais. No turno anterior à última sessão, o sr. B tinha realizado o primeiro levante que decorreu sem intercorrências. Na última sessão a pessoa $B$ apresentava a pele da região sagrada íntegra. Apesar de manter um risco elevado de úlcera por pressão, aumentou a pontuação na Escala de Braden de 12 para 15 pontos.

Foram realizadas 5 sessões de RFR. $\mathrm{Na} 1^{\mathrm{a}}$ sessão a pessoa $B$ encontrava-se submetida a ventilação mecânica invasiva e foi extubada no final desse dia. Nas restantes sessões manteve-se em ventilação espontânea, contudo houve necessidade de aumentar o oxigénio, permanecendo desde a $3^{\mathrm{a}}$ sessão, inclusive, com máscara de venturi com $\mathrm{FiO}_{2}$ de $50 \%$, o que coincidiu com 0 momento em que foram observadas radiografias do tórax com imagem sugestiva de derrame pleural direito.

De modo a melhorar a ventilação e a prevenir a estase de secreções brônquicas, foram reforçados os ensinos relativos ao controlo respiratório com dissociação dos tempos respiratórios e ensino da tosse. Uma vez que havia a suspeita de derrame pleural direito, foram reforçados os posicionamentos terapêuticos que promovessem drenagem dessa área.

No início e no final de cada sessão foram avaliados os parâmetros vitais. A pessoa B manteve estabilidade hemodinâmica durante as sessões de RFR.

Globalmente as frequências respiratórias diminuíram após a sessão, evidenciando-se a sessão $n^{\circ} 3$ na qual a frequência respiratória prévia à sessão era superior ao valor máximo de referência da frequência respiratória. Quanto aos valores de $\mathrm{spO}_{2}$ ou mantiveram-se iguais (superior a 90\%) ou aumentaram.

Avaliada a ventilação e a presença de esforço respiratório no início e no final de todas as sessões de RFR, constatando-se que a pessoa $B$ na $2^{a}$ sessão apresentou padrão respiratório alterado e na $3^{a}$ sessão esforço respiratório a pequenos esforços e padrão respiratório alterado com adejo nasal e tiragem, não tendo sido possível modificar padrão respiratório, no entanto foi possível reduzir a frequência respiratória com as intervenções implementadas. $\mathrm{Na} 4^{\mathrm{a}}$ e $5^{\mathrm{a}}$ sessão houve melhoria na amplitude e no tipo de respiração, após incentivo no controlo respiratório com dissociação dos tempos respiratórios.

Verificou-se que, ao nível da auscultação pulmonar, antes das sessões apresentava Ruídos Adventícios, que estavam ausentes no final das sessões.

Durante as sessões de RFR a pessoa B manteve reflexo de tosse diminuído. A partir da $2^{a}$ sessão encontravase extubado endotraquealmente, apresentando dificuldade em expelir as secreções. Apesar de ensino de tosse dirigida manteve necessidade de aspiração de secreções, uma vez que apresentava secreções em moderada a grande quantidade.

\section{Caso da pessoa $\mathrm{C}$}

Pessoa de 50 anos de idade, do sexo masculino e casado. Tinha como antecedente pessoal hipertensão arterial. Foi admitido na UCIP por Aneurisma roto da artéria comunicante anterior. A avaliação inicial realizou-se no $1^{\circ}$ dia de internamento (Quadro n. $\left.{ }^{\circ} 2\right)$.

\begin{tabular}{|l|l|}
\hline $\begin{array}{l}\text { Estado de } \\
\text { consciência } \\
\text { (pontuação da } \\
\text { ECG) }\end{array}$ & Pontuação de 15 \\
\hline $\begin{array}{l}\text { Integridade } \\
\text { Cutânea }\end{array}$ & Presente \\
\hline $\begin{array}{l}\text { Risco de úlcera } \\
\text { por pressão } \\
\text { (pontuação da } \\
\text { escala de } \\
\text { Braden) }\end{array}$ & $\begin{array}{l}\text { Baixo risco de úlcera por pressão } \\
\text { (17 pontos) }\end{array}$ \\
\hline $\begin{array}{l}\text { Avaliação } \\
\text { movimento } \\
\text { articular }\end{array}$ & $\begin{array}{l}\text { - Indicação terapêutica de manter } \\
\text { repouso no leito. } \\
\text {-Avaliada a ADM de forma ativa nos } \\
\text { membros superiores e inferiores } \\
\text { com movimento articular e } \\
\text { muscular diminuído. } \\
\text { - Dor ausente no movimento } \\
\text { articular } \\
\text { - Não executa técnicas de } \\
\text { exercício muscular e articular }\end{array}$ \\
\hline $\begin{array}{l}\text {-Ventilação espontânea, com } \\
\text { oxigenioterapia por sonda binasal a } \\
\text { 3 L/min } \\
\text { - Padrão respiratório regular, de } \\
\text { média amplitude, misto, simétrico, } \\
\text { sem utilização dos músculos } \\
\text { acessórios } \\
\text {-Cansaço fácil a esforços } \\
\text { moderados, com aumento da } \\
\text { frequência respiratória, alteração } \\
\text { do padrão respiratório e } \\
\text { dificuldade em controlar a sua } \\
\text { respiração } \\
\text { - Auscultação pulmonar com MV }\end{array}$ \\
\hline
\end{tabular}




\begin{tabular}{|l|l|} 
& presente e sem RA \\
\hline $\begin{array}{l}\text { Mecanismos de } \\
\text { Limpeza das vias } \\
\text { aéreas } \\
\text { (Reflexo de }\end{array}$ & \\
tosse) & Sem acessos de tosse \\
\hline
\end{tabular}

Quadro 3-Avaliação Inicial da pessoa C

Fonte: elaboração própria.

Com base na avaliação inicial foram delineados os seguintes diagnósticos de enfermagem:

- Diagnóstico 1: Risco de rigidez articular;

- Diagnóstico 2: Potencial para melhorar capacidade para executar técnicas de exercício muscular e articular;

- Diagnóstico 3: Potencial para melhorar conhecimento sobre autocontrolo do padrão respiratório;

- Diagnóstico 4: Potencial para melhorar conhecimento sobre técnica respiratória;

- Diagnóstico 5: Potencial para melhorar capacidade para autocontrolo do padrão respiratório;

- Diagnóstico 6: Potencial para melhorar capacidade para usar técnicas respiratórias.

Ao longo do projeto de intervenção esteve consciente e orientado. Durante as 4 sessões de RFM a pessoa $C$ não referiu dor.

$\mathrm{Na} 1^{\text {a }}$ sessão foi demonstrado, através das mobilizações passivas, os movimentos polisegmentares que podia efetuar para manter ou melhorar a ADM. A pessoa $C$ foi capaz de assimilar e executar as técnicas demonstradas de forma independente, realizando-as várias vezes ao longo do dia. A partir da $2^{\mathrm{a}}$ sessão iniciou transferência para cadeirão, duas vezes por dia, com carga total, que decorreu sem intercorrências. $\mathrm{Na} 3^{\mathrm{a}}$ sessão foram introduzidos exercícios musculares e articulares ativo-resistidos ao nível dos membros superiores e inferiores, utilizando bandas elásticas, com boa assimilação dos mesmos por parte da pessoa $C$, que os executou de forma independente. No final da $4^{a}$ sessão foi reavaliada a ADM, com aumento das ADM avaliadas previamente. Considera-se que o fato da pessoa $C$ ter tido um papel mais ativo no seu processo de reabilitação poderá ter contribuído para os ganhos obtidos ao nível da ADM.

No âmbito da RFR (realizada uma sessão), a pessoa C não tinha conhecimentos sobre o autocontrolo do padrão respiratório e as técnicas respiratórias utilizadas para otimizar a ventilação (técnica de relaxamento; posições de descanso; dissociação dos tempos respiratórios; respiração abdominodiafragmática), pelo que foram efetuados ensinos relativos aos mesmos. A pessoa $C$ demonstrouse recetiva à informação fornecida, sendo capaz de descrever a importância e as vantagens do autocontrolo do padrão respiratório e das técnicas respiratórias.
Além disso, após instrução de técnica de autocontrolo do padrão respiratório e restantes técnicas respiratórias, a pessoa $C$ foi capaz de assimilá-las e realizá-las de modo independente, nomeadamente durante os exercícios. A pessoa $C$ referiu que a utilização das referidas técnicas o auxiliaram a tolerar melhor os exercícios mais intensos, que exigiam mais esforço.

\section{Caso da pessoa D}

Pessoa de 49 anos de idade, do sexo feminino e casada, foi admitida na UCIP no pós-operatório de craniectomia descompressiva urgente por edema cerebral com desvio das estruturas da linha média, associado a um enfarte isquémico em território da artéria cerebral média esquerda. A avaliação inicial decorreu no $3^{\circ}$ dia de internamento (Quadro n. ${ }^{\circ} 4$ ).

\begin{tabular}{|c|c|}
\hline $\begin{array}{l}\text { Estado de consciência } \\
\text { (pontuação da ECG) }\end{array}$ & $\begin{array}{l}\text { Pontuação de } 9 \mathrm{~T} \text { (abertura ocular ao } \\
\text { som -3; a resposta verbal ausente, } \\
\text { pela presença do TET - } 1 \text { e localiza a } \\
\text { dor -5) }\end{array}$ \\
\hline Integridade Cutânea & Presente \\
\hline $\begin{array}{l}\text { Risco de úlcera por } \\
\text { pressão } \\
\text { (pontuação da escala de } \\
\text { Braden) }\end{array}$ & $\begin{array}{l}\text { Risco elevado de úlcera por pressão } \\
(10 \text { pontos })\end{array}$ \\
\hline $\begin{array}{l}\text { Avaliação movimento } \\
\text { articular }\end{array}$ & $\begin{array}{l}\text { - Mantido repouso no leito. } \\
\text {-Avaliada a ADM de modo passivo } \\
\text { nos membros superiores e inferiores } \\
\text { com movimento articular e muscular } \\
\text { diminuído. } \\
\text { - Dor ausente no movimento } \\
\text { articular. }\end{array}$ \\
\hline Ventilação & $\begin{array}{l}\text {-Ventilação espontânea a realizar } \\
\text { oxigenioterapia a 0,5 L/min por } \\
\text { peça em T. } \\
\text { - Padrão respiratório regular, } \\
\text { superficial e de predominância } \\
\text { abdominal, com expansão torácica } \\
\text { reduzida mas simétrica, sem } \\
\text { utilização dos músculos acessórios. } \\
\text { - Auscultação pulmonar com RA }\end{array}$ \\
\hline $\begin{array}{l}\text { Mecanismos de Limpeza } \\
\text { das vias aéreas } \\
\text { (Reflexo de tosse) }\end{array}$ & $\begin{array}{l}\text { Reflexo tosse diminuído, dificuldade } \\
\text { na mobilização de secreções; } \\
\text { aspiração de secreções frequentes }\end{array}$ \\
\hline
\end{tabular}

Quadro 4 - Avaliação Inicial da pessoa D

Fonte: elaboração própria.

A partir da avaliação inicial foram formulados os seguintes diagnósticos de enfermagem:

- Diagnóstico 1- Risco de úlcera por pressão em grau elevado;

- Diagnóstico 2 - Risco de rigidez articular;

- Diagnóstico 3 - Limpeza das vias aéreas ineficaz;

- Diagnóstico 4 - Ventilação comprometida. 
Durante a implementação do projeto de intervenção a pessoa $D$ melhorou $o$ estado de consciência, apresentando um aumento da pontuação na ECG de 9 para 11T (abria os olhos espontaneamente e cumpria ordens simples).

Durante as 5 sessões de RFM a pessoa $D$ não manifestou dor, tendo sido sempre realizados exercícios de mobilização passiva. No final da $5^{a}$ sessão foi reavaliada a ADM. Na generalidade a ADM manteve-se ou aumentou, contudo houve uma diminuição na ADM ao nível da flexão dos ombros e na flexão do cotovelo direito.

Relativamente às medidas preventivas de úlcera por pressão instituídas, foi reforçada a alternância de decúbitos, com ajuda total, a aplicação de creme hidratante e a manutenção da pele seca e na $4^{a}$ sessão foi realizada a transferência para o cadeirão sem carga (utilizado elevador). No final da $5^{a}$ sessão mantinha um elevado risco de úlcera por pressão, contudo passou de 10 para 12 pontos na Escala de Braden. Durante o projeto de intervenção manteve a pele íntegra.

O projeto de intervenção contemplou 5 sessões de RFR, verificando-se que a pessoa manteve estabilidade hemodinâmica. As intervenções de RFR permitiram diminuir as frequências respiratórias o que se pode traduzir num maior controlo da respiração. Os valores de $\mathrm{spO}_{2}$ foram sempre constantes, mantendo-se no valor máximo possível (100\%), estando a pessoa $D$ submetida a oxigenioterapia por peça em T a $1 \mathrm{~L} / \mathrm{min}$.

Ao longo de todas as sessões de RFR avaliou-se a ventilação e a presença de esforço respiratório. A pessoa $D$ antes das sessões apresentava um padrão respiratório regular, superficial e predominantemente abdominal, com expansão torácica diminuída. Após as sessões, e a partir da $3^{a}$ sessão, houve uma melhoria da amplitude da respiração e após a $5^{\mathrm{a}}$ sessão apresentou uma respiração mista. Quanto ao esforço respiratório, foi apenas observado na $1^{\text {a }}$ sessão após moderados esforços (associado à abertura costal seletiva).

Relativamente à auscultação pulmonar foi efetuada antes e após de todas as sessões, verificando-se que foi eliminada a presença de Ruídos Adventícios com as intervenções de RFR realizadas. O Murmúrio Vesicular que inicialmente se encontrava diminuído nas bases pulmonares nas primeiras três sessões, após a $3^{a}$ sessão de RFR esteve mantido em todos os campos pulmonares.

Durante as sessões a pessoa $D$ apresentou o reflexo de tosse diminuído, com necessidade de aspiração de secreções na orofaringe e no TET. As características das secreções, quer na orofaringe quer no TET, variaram de sessão para sessão, no entanto no final da $4^{\mathrm{a}}$ sessão apresentavam-se em menor quantidade.

\section{DISCUSSÃO}

Depois da avaliação inicial das quatro pessoas participantes no projeto foram formulados os diagnósticos de Enfermagem de Reabilitação, e realizadas as intervenções que melhor se adaptavam à situação de cada pessoa, tendo em conta a revisão da literatura efetuada. Verificou-se que os diagnósticos de Risco de úlcera por pressão em grau elevado; Limpeza das vias aéreas ineficaz e Ventilação comprometida estavam presentes nas pessoas A, B e D. O diagnóstico de Risco de rigidez articular era comum aos quatro participantes do presente projeto.

No total foram realizadas 37 sessões, 17 no âmbito da RFR e 20 de RFM como resultado da identificação dos diagnósticos. Paralelamente foi estabelecido um plano de cuidados de prevenção das úlceras de pressão, às pessoas que apresentaram um risco elevado.

Relativamente ao risco de rigidez articular, na pessoa $C$ as intervenções de enfermagem instituídas contribuíram para atingir o resultado esperado, ou seja, a manutenção ou melhoria da ADM dos movimentos ao nível das articulações dos ombros, cotovelos, joelhos e tornozelos. Nas pessoas A, B e D constatou-se que a ADM manteve-se ou melhorou em alguns dos movimentos das articulações avaliadas.

Estes resultados alinham-se com casos semelhantes descritos na literatura, nomeadamente o estudo de Modragon-Barrera (27), cujos participantes eram pessoas internadas em $\mathrm{UCl}$ e onde também se verificou que após a realização de um programa de mobilizações articulares, houve um acréscimo da ADM ao nível da abdução e flexão dos ombros, abdução das ancas e dorsiflexão dos tornozelos, comprovando o defendido já algum tempo por outros autores ${ }^{28}$ sobre os benefícios da realização de exercícios de mobilização passiva, ativo-assistida nas pessoas em situação crítica.

Não obstante o resultado na pessoa A foi diferente do esperado, uma vez que este doente apresentou diminuição da ADM ao nível da flexão dos ombros, flexão do cotovelo e flexão plantar dos tornozelos; a pessoa $B$ apresentou um decréscimo na $A D M$ ao nível da abdução do ombro direito, flexão do cotovelo direito e flexão plantar dos tornozelos e a pessoa $D$ também diminuiu a ADM ao nível da flexão dos ombros e na flexão do cotovelo direito. A diferença entre os resultados esperados e os obtidos nos programas de ER pode ser justificada a partir de múltiplos fatores entre eles o fato de as articulações do cotovelo, do tornozelo e ombro apresentarem uma maior predisposição para o desenvolvimento de contraturas ${ }^{6}$, e que o estudo de Nepomuceno Júnior, Martinez, Neto $^{29}$ também comprovou mesmo com um programa de exercícios de mobilização articular nestas articulações. De um modo geral, nas pessoas que integraram o projeto de intervenção as amplitudes articulares foram mantidas ou melhoradas atestando a importância dos exercícios de amplitude de movimento e do posicionamento terapêutico, nas pessoas em situação crítica, já que estas intervenções contribuem para a prevenção dos efeitos deletérios da imobilidade prolongada e para a manutenção ou melhoria da funcionalidade motora das pessoas ${ }^{28,30,31}$.

No que se refere ao risco de úlcera por pressão, no período em que decorreu o projeto de intervenção as pessoas $B$ e $D$ diminuíram o risco (avaliado com a 
escala de escala de Braden) e o da pessoa A mantevese constante. As intervenções antecipatórias que englobam a avaliação sistemática da integridade cutânea e avaliação do risco, o reposicionamento e utilização de superfícies de apoio e apósitos terapêuticos adequados, a par da promoção da hidratação cutânea e da redução da humidade na pele revelaram-se eficazes porque, apesar de manterem um risco elevado de úlcera por pressão nenhuma das pessoas desenvolveu esta consequência da imobilidade. Estes resultados vão de encontro a outros já descritos ${ }^{32-35}$, comprovando que a monitorização sistematizada deste problema precedida da tomada de consciência do mesmo por parte de toda a equipa de enfermagem e a sua valorização, sobretudo por parte dos EEER, permitiu intervir individualmente nas pessoas e impedir o aparecimento de novas úlcera por pressão, confirmando tal como recomendado por parte da National Pressure Ulcer Advisory Panel, European Pressure Ulcer Advisory Panel and Pan Pacific Pressure Injury Alliance ${ }^{36}$ que a abordagem estruturada da avaliação do risco, que inclua uma avaliação da atividade/mobilidade e a condição da pele, que tem força de Evidência $B$ deve ser fortemente recomendada.

Na globalidade, após as sessões de RFR, as pessoas A, $B$ e $D$ melhoraram o padrão respiratório, com aumento da amplitude respiratória e da expansão torácica, verificando-se que nas sessões finais apresentaram um padrão respiratório regular, de média amplitude e misto. Verificámos também que os episódios de esforço respiratório evidentes em algumas sessões (uma sessão da pessoa B e uma sessão da pessoa $D$ ), foram resolvidos, não tendo sido visível nas sessões subsequentes. Ainda que as pessoas A e B tenham apresentado pontualmente (no final de uma ou várias sessões) aumento da frequência respiratória, observámos que na maioria das sessões as frequências respiratórias diminuíram em todas as pessoas, após as intervenções de RFR. Estes resultados demonstram que os objetivos pretendidos com a intervenção de enfermagem na área da RFR foram alcançados, na medida em que as assinergias e deficiências ventilatórias foram corrigidas e prevenidas, o que poderá ter contribuído para uma melhoria da função respiratória, tal como é explanado por diversos autores 28, 37-39.

No que diz respeito ao parâmetro de $\mathrm{spO}_{2}$, as percentagens nas pessoas $A, B$, e $D$ mantiveram-se constantes após as intervenções de RFR, ou aumentaram ligeiramente. Apesar dos participantes do projeto não estarem ventilados, os resultados obtidos coadunam-se com os descritos na literatura, verificando-se que a implementação de um plano de intervenção no âmbito da RFR nas pessoas em situação crítica promove uma ventilação mais eficaz, sendo este efeito visível através do aumento da $\mathrm{SpO}_{2}{ }^{40-44}$.

Ao longo de todas as sessões de RFR as pessoas mantiveram o reflexo de tosse diminuído, situação que pode estar associada à presença de uma via aérea artificial (TET) ${ }^{45}$, ou à diminuição da força muscular devido à própria condição crítica e à imobilidade ${ }^{7}$. Verificou-se ainda que no início das sessões as pessoas apresentavam presença de RA (roncos) na auscultação pulmonar, indicativa da presença de secreções ${ }^{46}$. Assim, a associação de várias manobras de higiene brônquica contribuiu para que os resultados esperados fossem atingidos, evidenciada pela ausência de RA no final das sessões. Pode-se atestar que um plano de cuidados que conjugue distintas técnicas de mobilização e eliminação de secreções promovem uma maior limpeza das vias aéreas, como também foi constatado nos estudos efetuados por Avena, Duarte, Cravo, Sologuren, Gastaldi ${ }^{40}$ e Naue, Forgiarini Junior, Dias, Vieira ${ }^{47}$, minimizando a estase de secreções e consequentemente os episódios de obstrução brônquica que precipitam a atelectasia ${ }^{48}$.

A pessoa designada por $\mathrm{C}$, ao contrário das restantes pessoas, estava consciente e orientada, apresentando capacidade para assimilar a informação e a instrução das técnicas implementadas no plano de intervenção. Além disso demonstrou estar motivada para adquirir novos conhecimentos que possibilitassem prevenir as complicações que advêm da imobilidade e maximizar as suas capacidades em termos funcionais motores e respiratórios, o que foi essencial para que a nossa intervenção fosse bem-sucedida. Os diagnósticos de enfermagem potencial para melhorar capacidade para executar técnicas de exercício muscular e articular; potencial para melhorar conhecimento sobre autocontrolo do padrão respiratório; potencial para melhorar conhecimento sobre técnica respiratória; potencial para melhorar capacidade para autocontrolo do padrão respiratório e potencial para melhorar capacidade para usar técnicas respiratórias foram apenas identificados nesta pessoa. Assim, ao longo do projeto de intervenção a pessoa $\mathrm{C}$ assimilou os conhecimentos transmitidos e as técnicas instruídas, sendo capaz de realizar de modo independente os exercícios de amplitude do movimento e empregar de modo adequado as técnicas respiratórias ensinada, confirmando o que refere $\mathrm{Habel}^{49}$, que os EEER ao apostarem na educação das pessoas promovem o seu empowerment, uma vez que thes são fornecidos os conhecimentos e as capacidades necessárias para gerirem os seus próprios cuidados e controlarem as suas vidas, ou seja, para serem o mais independentes possível.

Os resultados deste projeto de intervenção também permitiram verificar que o planeamento precoce da prestação de cuidados de enfermagem de reabilitação de forma adequada e individualizada, nas áreas da Reeducação Funcional Motora, da prevenção de úlceras por pressão e da Reeducação Funcional Respiratória, podem contribuir para a prevenção das consequências motoras, tegumentares e respiratórias da imobilidade nas pessoas em situação crítica. A Enfermagem de Reabilitação tem um papel crucial na promoção de práticas de cariz preventivo no seio da equipa multidisciplinar. Essas práticas orientadas para a segurança do doente vão ao encontro da primeira competência especifica dos EEER que é serem capazes de cuidar de pessoas com necessidades especiais em todos os contextos da prática e cuidados ${ }^{22}$ e que estão impossibilitadas de executar atividades básicas de forma independente, identificando as necessidades de intervenção especializada, implementando e avaliando 
programas que visem a redução dos riscos. E as suas formas de intervir são a execução, o ensino e a demonstração de técnicas promotoras do autocuidado.

Em síntese, de uma forma geral, os resultados obtidos neste projeto de intervenção comprovam a importância dos cuidados antecipatórios ${ }^{17}$, uma vez que o planeamento e uma intervenção de ER precoce previnem a ocorrência de eventos negativos, neste caso as consequências da imobilidade, que podem comprometer uma transição saúde/doença bemsucedida, vivenciada pelas pessoas em situação crítica, o que vai de certa forma ao encontro ao que é defendido por Ludin, Arbon, Parker ${ }^{15}$, que afirmam que as pessoas em situação crítica necessitam de um planeamento de transição mais abrangente, que implica um enfoque maior na sua antecipação e dos seus efeitos.

\section{CONCLUSÃO}

Os resultados obtidos neste projeto de intervenção permitiram verificar que os participantes mantiveram ou melhoraram amplitude do movimento, e, apesar do risco elevado, não desenvolveram úlceras por pressão, tendo também melhorado a sua condição respiratória. Apesar de não se poderem generalizar os resultados, por limitações metodológicas, os resultados esperados derivaram das intervenções planeadas implementadas, com a colaboração dos restantes elementos da equipa de enfermagem e foram alcançados.

A limitação do tempo para a implementação do projeto também foi uma limitação. Considera-se que numa replicação futura deste projeto seria pertinente alargar o seu tempo de implementação, possibilitando um maior número de casos.

Apesar das suas limitações, o presente projeto de intervenção pode ser um contributo para o desenvolvimento do conhecimento em Enfermagem de Reabilitação e um propulsor para que outros estudos sejam criados, uma vez que também demonstra a importância da intervenção do EEER direcionada às pessoas internadas na $\mathrm{UCl}$.

\section{REFERÊNCIAS BIBLIOGRÁFICAS}

1. Ordem dos Enfermeiros. Guia Orientador de Boas Práticas Cuidados à pessoa com alterações da mobilidade . posicionamentos, transferências e treino de deambulação. Lisboa: Ordem dos Enfermeiros; 2013 [citado em 201921 março]. Disponível na Internet: https://www.ordemenfermeiros.pt/arquivo/publicacoes/Docum ents/GOBP_Mobilidade_VF_site.pdf

2. Nascimento GIF, Silva ECB, Oliveira YSB, Pereira TMF, Cabral RMC. Atuação da fisioterapia na síndrome do imobilismo no idoso: uma revisão de literatura [Apresentação no $1^{\circ}$ Congresso Nacional do Envelhecimento Humano; 2016 nov 23-25; NatalRN, Brasil] Disponível na Internet: http://www.editorarealize.com.br/revistas/cneh/trabalhos/tra balho_ev054_md4_sa5_id1824_07102016203957.pdf

3. Hashem MD, Parker AM, Needham DM. Early mobilization and rehabilitation of patients who are critically ill. Chest [revista em linha]. 2016 [citado em 2019 mar 21];150(3):722-31. Disponível na

Internet:https://www.ncbi.nlm.nih.gov/pmc/articles/PMC60262 $60 / \mathrm{pdf} / \mathrm{main}$.pdf

4. Denehy L, Lanphere J, Needham DM. Ten reasons why ICU patients should be mobilized early. Intensive Care Med [revista em linha]. 2017 [citado em 2019 mar 21]; 43(1): 86-90. Disponível na Internet: https://eds.a.ebscohost.com/eds/pdfviewer/pdfviewer?vid=1\&s id=7f43a33f-83f1-4145-8df2-24754352d0dc\%40sdc-v-sessmgr06

5. Rodrigues GS, Gonzaga DB, Modesto ES, Santos FDO, Silva BB, Bastos VPD. Mobilização precoce para pacientes internados em unidade de terapia intensiva: revisão integrativa. Rev Inspirar Mov Saude [revista em linha]. 2017 [citado em 2019 mar 21]; 13(2): 27-31. Disponível na Internet: https://www.inspirar.com.br/revista/mobilizacao-precocepara-pacientes-internados-em-unidade-de-terapia-intensivarevisao-integrativa/

6. Clavet H, Hébert PC, Fergusson D, Doucette S, Trudel G. Joint contracture following prolonged stay in the intensive care unit. CMAJ [revista em linha].2008 [citado em 2019 mar 21]; 178(6): 691-697. Disponível na Internet: https://www.ncbi.nlm.nih.gov/pmc/articles/PMC2263098/pdf/ 20080311s00017p691.pdf

7. Silva APP, Maynard K, Cruz MR. Efeitos da fisioterapia motora em pacientes críticos: revisão de literatura. Rev Bras Ter Intensiva [revista em linha]. 2010 [citado em 2019 mar 21]; 22(1): 85-91. Disponível na Internet: http://www.scielo.br/pdf/rbti/v22n1/a14v22n1.pdf

8. Winkelman C. Bed rest in health and critical illness: A body systems approach. AACN Adv Crit Care [revista em linha]. 2009 [citado em 2019 mar 21]; 20(3):254-66. Disponível na Internet: https://www.researchgate.net/publication/26701683_Bed_Rest _in_Health_and_Critical_Illness

9. Azevedo PMS, Gomes BP. Efeitos da mobilização precoce na reabilitação funcional em doentes críticos: uma revisão sistemática. Referência. [revista em linha]. 2015 [citado em 2019 mar 21]; ser IV (5): 129-138. Disponivel na Internet: http: //www.scielo.mec.pt/pdf/ref/vserlVn5/serIVn5a15.pdf

10. Ordem dos Enfermeiros. Regulamento dos padrões de qualidade dos cuidados especializados em enfermagem de reabilitação. [publicação online]; 2011 [consult. Em 19 mar 2019]. Disponível na Internet: https://www.ordemenfermeiros.pt/arquivo/colegios/Document s/PQCEEReabilitacao.pdf

11. Santos A, Oliveira I, Silveira T. Mobilização precoce em UCI. Salutis Scientia [revista em linha]. 2010 [citado em 2019 mar 21]; (2):19 $\quad-24 . \quad$ Disponível na Internet: http: / /docplayer.com.br/46526065-Mobilizacao-precoce-emuci-early-mobilization-in-icu.html

12. Severino S. Enfermagem de Reabilitação à Pessoa Submetida a Ventilação Mecânica. In: Marques-Vieira C, Sousa L, coordenadores. Cuidados de Enfermagem de Reabilitação à pessoa ao longo da vida. $1^{\text {a }}$ ed. Loures: Lusodidacta; 2016. p. 365-380

13. Mejía ASC, Martínez NGM, Nieto ORP, Camacho MAM, Tomas ED, Martínez BP. Movilización temprana como prevención y tratamiento para la debilidad adquirida en la unidad de cuidados intensivos en pacientes en ventilación mecánica. Experiencia en un hospital de segundo nível. ESJ [revista em linha]. 2018 [citado em 2019 Mar 21]; 21(14): 19-30. Disponível na Internet: https://www. researchgate.net/publication/326808245 Moviliza cion_Temprana_Como_Prevencion_Y_Tratamiento_Para_La_Debi lidad_Adquirida_En_La_Unidad_De_Cuidados_Intensivos_En_Paci entes_En_Ventilacion_Mecanica_Experiencia_En_Un_Hospital_De Segundo_Nivel

14. Nelson A. Segurança para Doentes com Incapacidades. In: Hoeman S, editor. Enfermagem de reabilitação: Prevenção, intervenção e resultados esperados. $4^{\mathrm{a}}$ ed. Loures: Lusodidacta; 2011. p. $169-176$

15. Ludin SM, Arbon P, Parker S. Patients' transition in the Intensive Care Units: Concept analysis. Intensive Crit Care Nurs [revista em linha]. 2013 [citado em 2019 mar 21]; 29: 187-192. Disponível na Internet: http://dx.doi.org/10.1016/j.iccn.2013.02.001

16. Santos E, Marcelino L, Abrantes L, Marques C, Correia R, Coutinho E, Azevedo I. O Cuidado Humano Transicional Como Foco da Enfermagem: Contributos das Competências Especializadas e Linguagem Classificada CIPE ${ }^{\circledR}$. Millenium [revista em linha]. 2015 [citado em 2019 mar 21]; 49: 153-171. Disponível na Internet: http://www.ipv.pt/millenium/Millenium49/9.pdf 
17. Zagonel IPS. O cuidado humano transicional na trajetória de enfermagem. Rev.latino-am. enfermagem [revista em linha]. 1999 [citado em 2019 mar 21]; 7 (3): 25-32. Disponível na Internet: http://www.scielo.br/pdf/rlae/v7n3/13473.pdf.

18. International Council of Nurses. CIPE versão 2015: Classificação Internacional para a Prática de Enfermagem. Lisboa: Ordem dos Enfermeiros; 2015 [citado em 201922 março]. Disponível na Internet:

https://futurosenf.files.wordpress.com/2017/04/cipe_2015.pdf

19. Grilo EN, Mendes F. O estudo de caso como estratégia de investigação em enfermagem. Poster apresentado em: Congresso de Investigação Ibero-Americano de Países de Língua Oficial Portuguesa, $3^{\mathrm{a}}$ edição, 2012 jun 12-15, Coimbra. Disponível na Internet: Disponível em http://hdl.handle.net/10400.11/1744

20. Gautério-Abreu DP, Ávila JA, Santos SSC, Ilha S, Silva BT. Contribuições do estudo de caso para o cuidado de enfermagem: um relato de experiência. Rev enferm UFPE on line [revista em linha]. 2016 [citado em 2019 mar 21]; 10(3): 1149-1154. Disponível na Internet: https://doil.org/10.5205/1981-8963v10i3a11070p1149-1154-2016

21. Silva LAGP, Mercês NNA. Estudo de casos múltiplos aplicado na pesquisa de enfermagem: relato de experiência. Rev Bras Enferm [revista em linha]. 2018 [citado em 2019 mar 21]; 71(3): 1194-1197. Disponível na Internet: http://dx.doi.org/10.1590/0034-7167-2017-0066

22. Ordem dos Enfermeiros. Padrão Documental dos Cuidados de Enfermagem da Especialidade de Enfermagem de Reabilitação. [publicação online]; 2015 [consult. em 19 mar 2019]. Disponível na

Internet: https://www.ordemenfermeiros.pt/arquivo/colegios/Document s/2015/MCEER_Assembleia/PadraoDocumental_EER.pdf

23. Teasdale G. Recording the Glasgow Coma Scale. [publicação online]; 2014 [consult. em 19 mar 2019]. Disponível na Internet: http: //www.glasgowcomascale.org/recording-gcs/

24. Direção Geral da Saúde. Orientação da Direção-Geral da Saúde, Escala de Braden: Versão Adulto e Pediatrica (Braden Q). Orientação $n^{\circ}$ 17/2011 de 19/05/2011[publicação online]; 2014 [consult. Em 19 mar 2019]. Disponível na Internet: https://www.dgs.pt/departamento-da-qualidade-nasaude/ficheiros-anexos/orientacao_ulceraspdf-pdf.aspx.

25. Ordem dos Enfermeiros. Enfermagem de Reabilitação, Instrumentos de recolha de dados para a documentação dos Cuidados especializados em Enfermagem de Reabilitação. [publicação online]; 2016 [consult. em 19 mar 2019]. Disponível na http://www.ordemenfermeiros.pt/publicacoes/Documents/Inst RecolhaDadosDocumentacaoCuidEnfReabilitacao_Final_2017.pdf

26. Fortin MF. O processo de investigação: da concepção à realização. $2^{\mathrm{a}}$ ed. Loures: Lusociência; 1999

27. Mondragón-Barrera MA. Condición física y capacidad funcional en el paciente críticamente enfermo: efectos de las modalidades cinéticas. Rev CES Med [revista em linha]. 2103 [citado em 2019 mar 21]; 27(1): 53-66. Disponível na Internet: http://www.scielo.org.co/pdf/cesm/v27n1/v27n1a06.pdf

28. Gosselink R, Bott J, Johnson M, Dean E, Nava S, Norrenberg M et al. Physiotherapy for adult patients with critical illness: recommendations of the European Respiratory Society and European Society of Intensive Care Medicine Task Force on Physiotherapy for Critically III Patients. Intensive Care Med. [revista em linha]. 2008 [citado em 2019 mar 21]; 34(7):1188$99 . \quad$ Disponível na Internet: https: //eds.a.ebscohost.com/eds/pdfviewer/pdfviewer?vid=8\&s id=428da056-0222-4ea8-b756-0d8164b11f7a\%40sessionmgr4006

29. Nepomuceno Júnior BV, Martinez BP, Gomes Neto M. Impacto do internamento em unidade de cuidados intensivos na amplitude de movimento de pacientes graves: estudo piloto. Rev. bras. ter. intensiva [revista em linha]. 2014 [citado em 2019 mar 21]; 26(1): 65-70. Disponível na Internet: http://www.scielo.br/pdf/rbti/v26n1/0103-507X-rbti-26-010065.pdf

30. Dantas CM, Silva PFS, Siqueira FHT, Pinto RMF, Matias S, Maciel $C$ et al. Influência da mobilização precoce na força muscular periférica e respiratória em pacientes críticos. Rev. bras. ter. intensiva [revista em linha]. 2012 [citado em 2019 mar 21]; 24(2): 173-178. Disponível na Internet: http://www.scielo.br/pdf/rbti/v24n2/13.pdf
31. França EET, Ferrari F, Fernandes $P$, Cavalcanti R, Duarte A, Martinez BP et al. Fisioterapia em pacientes críticos adultos: recomendações do Departamento de Fisioterapia da Associação de Medicina Intensiva Brasileira. Rev. bras. ter. intensiva [revista em linha]. 2012 [citado em 2019 mar 21]; 24(1): 6-22. Disponível na Internet: http: / /www.scielo.br/pdf/rbti/v24n1/03.pdf

32. Gill EC. Reducing hospital acquired pressure ulcers in intensive care. BMJ Qual Improv Rep. [revista em linha]. 2015 [citado em 2019 mar 21]; 4(2): u205599.w3015. Disponível na Internet: https://bmjopenquality.bmj.com/content/bmjqir/4/1/u205599 .w3015.full.pdf [DOI: 10.1136/bmjquality.u205599.w3015

33. Rios BL, Oliveira JSF, Torres MT, Souza NO, Marques PF, Reis UOP. Prevenção de úlceras por pressão em unidade de terapia intensiva: um relato de experiência. Rev enferm UFPE on line [revista em linha]. 2016 [citado em 2019 mar 21]; 10(6): 49594964.

Disponível

na Internet:https://periodicos.ufpe.br/revistas/revistaenfermagem /article/download/11278/12923

34. Swafford K, Culpepper R, Dunn C. Use of a Comprehensive Program to Reduce the Incidence of Hospital-Acquired Pressure Ulcers in an Intensive Care Unit. Am J Crit Care [revista em linha]. 2016 [citado em 2019 mar 21]; 25(2): 152-155. Disponível na Internet: http://ajcc. aacnjournals.org/content/25/2/152.full.pdf+html

35. Thorpe E. Prophylactic use of dressings for pressure ulcer prevention in the critical care unit. $\mathrm{Br} \mathrm{J}$ Nurs. [revista em linha]. 2016 [citado em 2019 mar 21];25(12): S6-S12. Disponível na Internet: https://doi.org/10.12968/bjon.2016.25.12.S6

36. National Pressure Ulcer Advisory Panel, European Pressure Ulcer Advisory Panel and Pan Pacific Pressure Injury Alliance. Prevention and Treatment of Pressure Ulcers: Quick Reference Guide. Osborne Park, Australia: Cambridge Media; 2014 [citado em 201921 março]. Disponível na Internet: https: / /www.npuap.org/wpcontent/uploads/2014/08/Updated-10-16-14-Quick-ReferenceGuide-DIGITAL-NPUAP-EPUAP-PPPIA-160ct2014.pdf

37. Branco PS, Barata S, Barbosa J, Cantista M, Lima A, Maia J. Temas de Reabilitação - Reabilitação Respiratória. Porto: Medesign; 2012 [citado em 201921 março]. Disponível na Internet:http://repositorio.chlc.minsaude.pt/bitstream/10400.1 7/765/1/Temas\%20Reabilita\%C3\%A7\%C3\%A3o_Reab\%20Respirat\% C3\%B3ria.pdf

38. Cordeiro MC, Menoita EC. Reeducação Funcional Respiratória In: Cordeiro MC, Menoita EC, editores. Manual de Boas Práticas na Reabilitação Respiratória: Conceitos, Princípios e Técnicas. $1^{\text {a }}$ ed. Loures: Lusociência; 2012. p. 61-115

39. Spapen HD, De Regt J, Honoré PM. Chest physiotherapy in mechanically ventilated patients without pneumonia-a narrative review. J Thorac Dis. [revista em linha]. 2017 [citado em 2019 mar 21]; 9(1): E44-E49. Disponível na Internet: https://www.ncbi.nlm.nih.gov/pmc/articles/PMC5303101/pdf/j td-09-01-E44.pdf

40. Avena KM, Duarte AM, Cravo SD, Sologuren MJ, Gastaldi AC. Efeitos da tosse manualmente assistida sobre a mecânica do sistema respiratório de pacientes em suporte ventilatório total. J. bras. pneumol [revista em linha]. 2009 [citado em 2019 mar 21]; 34(6): 380-386. Disponível na Internet: http://www.scielo.br/pdf/jbpneu/v34n6/v34n6a08

41. Fadaii A, Bagheri B, Pirsalehi A, Taherkhanchi B, Abbasi, MA. Effect of pulmonary rehabilitation program on patients admitted to ICU: a comparative cross sectional study. JPS [revista em linha]. 2015 [citado em 2019 mar 21]; 6(3): 18-21. Disponível na Internet:

https://www.researchgate.net/publication/298272039_Effect_o f_pulmonary_rehabilitation_program_on_patients_admitted_to_I CU_a_comparative_cross_sectional_study

42. Guimarães FS, Lopes AJ, Constantino SS, Lima JC, Canuto P, de Menezes SL. Expiratory Rib Cage Compression in Mechanically Ventilated Subjects: a Randomized Crossover Trial. Respir Care [revista em linha]. 2014 [citado em 2019 mar 21]; 59(5): 678$685 . \quad$ Disponível na Internet: http://rc.rcjournal.com/content/respcare/59/5/678.full.pdf

43. Moreira FC, Teixeira C, Savi A, Xavier R. Alterações da mecânica ventilatória durante a fisioterapia respiratória em pacientes ventilados mecanicamente. Rev. bras. ter. intensiva [revista em linha]. 2015 [citado em 2019 mar 21]; 27(2): 155-160. Disponível 
na Internet: http://www.scielo.br/pdf/rbti/v27n2/0103-507Xrbti-27-02-0155.pdf

44. Santos FA, Schneider Júnior LC, Forgiarini Junior LA, Veronezi J. Efeitos da compressão torácica manual versus a manobra de PEEP-ZEEP na complacência do sistema respiratório e na oxigenação de pacientes submetidos à ventilação mecânica invasiva. Rev. bras. ter. intensiva [revista em linha]. 2009 [citado em 2019 mar 21]; 21(2): 155-161. Disponível na Internet: http://www.scielo.br/pdf/rbti/v21n2/07.pdf

45. Araújo S, Machado MG. Aspiração eotraqueal. In: Machado MG, coordenador. Bases da Fisioterapia Respiratória: Terapia Intensiva e Reabilitação. Rio de Janeiro: Guanabara Koogan; 2008. p. 66-77

46. Naue WS, Forgiarini Junior LA, Dias AS, Vieira SR. Compressão torácica com incremento da pressão em ventilação com pressão de suporte: efeitos na remoção de secreções, hemodinâmica e mecânica pulmonar em pacientes em ventilação mecânica. J. bras. pneumol [revista em linha]. 2014 [citado em 2019 mar 21]; 40(1): 55-60. Disponível na Internet: http://www.scielo.br/pdf/jbpneu/v40n1/pt_1806-3713-jbpneu40-01-00055.pdf

47. Cordeiro MC, Menoita EC. Semiologia Clínica. In: Cordeiro MC, Menoita EC, editores. Manual de Boas Práticas na Reabilitação Respiratória: Conceitos, Princípios e Técnicas. $1^{\text {a }}$ ed. Loures: Lusociência; 2012. p. 21-28

48. Ntoumenopoulos G, Hammond N, Watts NR, Thompson K, Hanlon G, Paratz JD, Thomas P (2018). Secretion clearance strategies in Australian and New Zealand Intensive Care Units. Aust Crit Care [revista em linha] 2018 [citado em 2019 mar 21]; 31(4): 191 196. Disponível na Internet: https://doi.org/10.1016/j.aucc.2017.06.002

49. Habel M. Educação do doente e da família orientada para resultados. In: Hoeman S, editor. Enfermagem de reabilitação: Prevenção, intervenção e resultados esperados. $4^{\text {a }}$ ed. Loures: Lusodidacta; 2011.p. 61-72 


\title{
INTERVENÇÃO DO ENFERMEIRO ESPECIALISTA EM REABILITAÇÃO NA MOBILIDADE DA PESSOA IDOSA INSTITUCIONALIZADA - PROGRAMA TEIA
}

\author{
INTERVENCIÓN DEL ENFERMERO ESPECIALISTA EN RBEHABILITACIÓN EN LA MOVILIDAD DE LA PERSONA IDOSA \\ INSTITUCIONALIZADA - PROGRAMA TEIA
}

\section{INTERVENTION OF THE SPECIALIST NURSE IN REHABILITATION ON THE MOBILITY OF THE INSTITUTIONALIZED ELDERLY PERSON - TEIA PROGRAM}

DOI 10.33194/rper.2019.v2.n1.11.4557 | Submetido 31.01.2019 | Aprovado 25.06.2019

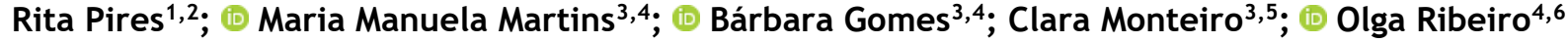 \\ 1 - Curso Mestrado em Enfermagem de Reabilitação - ESEP; 2 - Instituto de Ação Social das Forças Armadas - CASP; 3 - Escola \\ Superior de Enfermagem do Porto; 4 - Centro de Investigação em Tecnologias e Serviços de Saúde (CINTESIS); 5 - Centro \\ Hospitalar Póvoa de Varzim/Vila do Conde, EPE; 6 - Escola Superior de Saúde de Santa Maria (ESSSM)
}

\section{RESUMO}

Introdução: 0 envelhecimento produz alterações fisiológicas, anatómicas, comportamentais, sociais e culturais. Indiscutivelmente, o enfermeiro especialista em reabilitação, assume cada vez mais um papel importante nos cuidados prestados durante o envelhecimento, através da elaboração de planos de cuidados especializados que maximizem a funcionalidade do idoso, capacitando-o para uma maior autonomia e independência no autocuidado, incrementando desta forma a sua qualidade de vida. Nesta perspetiva, apresentamos o programa TEIA que se foca no treino do equilíbrio, da continência urinaria e a cognição em idosos ativos.

Objetivo: Avaliar o impacto do programa de 12 semanas, em idosos ativos institucionalizados, sobre o estado de equilíbrio, cognição, sintomatologia de incontinência urinária e qualidade de vida.

Método: Estudo quasi-experimental, antes-depois, com grupo de controlo. Amostra total de 30 idosos, 16 no grupo de programa e 14 no grupo de controlo. Foram aplicados vários instrumentos de avaliação funcional, na versão portuguesa, nomeadamente: Falls Efficacy Scale Internacional (FES I); Teste de Tinetti; Escala de Equilíbrio de Berg (EEB); Teste Timed Up and Go (TUG); International Consultation on Incontinence Questionnaire - Short Form (ICIQSF); Índice de Lawton-Brody; Escala Geriátrica de Depressão de 15 questões (GDS15); Teste de Declínio Cognitivo de 6 itens (6CIT); e Questionário de vida associado à saúde (SF-36).

Resultados: Os idosos do grupo de programa melhoraram no equilíbrio, estático e dinâmico, no medo cair e na execução da marcha (Tinetti, $Z=-3,126 ; p=0,002$; EEB, $Z=-3,304 ; p=0,001$; FES I, $Z=-3,059$; $p=0,002$ e TUG, $Z=-3,516$; $\mathrm{p}=0,0001)$. Trouxe-lhes benefícios no desempenho da cognição $(6 \mathrm{CIT}, \mathrm{Z}=-3,088 ; \mathrm{p}=0,002)$ e na perceção da qualidade de vida associada à incontinência urinária (ICIQ-SF, Z=-2,680; $p=0,007$ ).

Conclusão: A implementação do Programa TEIA traduz-se em ganhos significativos para a saúde dos idosos, melhorando o equilíbrio, a competência dos músculos do assoalho pélvico e no desempenho da cognição potenciado a qualidade de vida dos participantes.

Descritores: Envelhecimento, Equilíbrio, Incontinência Urinária, Cognição, Enfermagem de Reabilitação

\section{RESUMEN}

Introducción: El envejecimiento produce alteraciones fisiológicas, anatómicas, comportamentales, sociales y culturales. Indiscutiblemente, el enfermero especialista en rehabilitación, asume cada vez más un papel importante en los cuidados prestados durante el envejecimiento, a través de la elaboración de planes de cuidados especializados que maximicen la funcionalidad del anciano, capacitándolo para una mayor autonomía e independencia en el autocuidado, incrementando de esta forma su calidad de vida. En esta perspectiva, presentamos el programa TEIA que se enfoca en el entrenamiento del equilibrio, de la continencia urinaria y la cognición en ancianos activos.

Objetivo: Evaluar el impacto del programa de 12 semanas, en ancianos activos institucionalizados, sobre el estado de equilibrio, cognición, sintomatología de incontinencia urinaria y calidad de vida.

Método: Estudio cuasi-experimental, antes-después, con grupo de control. Muestra total de 30 ancianos, 16 en el grupo de programa y 14 en el grupo de control. Varias herramientas de evaluación funcional se aplicaron en la versión portuguesa, a saber: Falls Efficacy Scale Internacional (FES I); Prueba de Tinetti; Escala de Equilibrio de Berg (EEB); Prueba Timed Up and Go (TUG); Internacional Consultation on Incontinence Questionnaire - Short Form (ICIQ-SF); Índice de Lawton-Brody; Escala Geriátrica de Depresión de 15 preguntas (GDS15); Prueba de Declinación Cognitiva de 6 elementos (6CIT); y Cuestionario de vida asociado a la salud (SF-36). 
Resultados: En el caso de los ancianos del grupo de programa mejoraron en el equilíbrio, estático y dinámico, en el miedo a caer y en la ejecución de la marcha (Tinetti, $Z=-3,126 ; p=0,002 ; E E B, Z=3,304 ; p=0,001 ; F E S I, Z=-3,059$; $p=0,002$ e TUG, $Z=-3,516 ; p=0,0001)$. Les traen beneficios en el desempeño de la cognición $(6 C I T, Z=-3,088$; $\mathrm{p}=0,002$ ) y en la percepción de la calidad de vida asociada a la incontinencia urinaria (ICIQ-SF, Z=-2,680; $p=0,007$ ).

Conclusión: La implementación del Programa TEIA se traduce en ganancias significativas para la salud de los ancianos, mejorando el equilibrio, la competencia de los músculos del piso pélvico y en el desempeño de la cognición potenciada la calidad de vida de los participantes.

Palabras clave: Envejecimiento, Equilibrio, Incontinencia Urinaria, Cognición, Enfermería de Rehabilitación

\section{ABSTRACT}

Introduction: Aging produces physiological, anatomical, behavioral, social and cultural changes. Arguably, the nurse specialist in rehabilitation, assumes an increasingly important role in the care provided during the aging, through the elaboration of specialized care plans that maximize the functionality of the elderly, enabling them to have greater autonomy and independence in self-care, such that they can have a better quality of life. In this work, we present the TEIA program that focuses on the training of balance, urinary continence and cognition in active elderly.

Objective: To assess the impact of the 12-week program on institutionalized elderly individuals on the state of balance, cognition, symptoms of urinary incontinence and quality of life.

Method: Quasi-experimental study, before-after, with control group. A total sample of 30 elderly, 16 in the program group and 14 in the control group. Several functional evaluation instruments were applied in the Portuguese version, namely: Falls Efficacy Scale International (FES I); Tinetti's test; Berg Balance Scale (BBS); Timed Up and Go Test (TUG); International Consultation on Incontinence Questionnaire - Short Form (ICIQ-SF); LawtonBrody Index; Geriatric Depression Scale of 15 questions (GDS15); Cognitive Decline Test of 6 items (6CIT); and Health-related Life Questionnaire (SF-36).

Results: Elderlies in the program group improved their static and dynamic balance, fear of falling and gait execution (Tinetti, $Z=-3,126, p=0,002$; BBS, $Z=-3,304, p=0,001$; FES I, $Z=-3,059, p=0,002$; and TUG, $Z=-3,516$, $p=0,0001)$. Additionally, the program brought them benefits in the performance of cognition $(6 \mathrm{CIT}, \mathrm{Z}=-3,088$, $\mathrm{p}=0,002)$ and in the perception of quality of life associated with urinary incontinence (ICIQ-SF, $Z=-2,680, p=0,007$ ).

Conclusion: The implementation of the TEIA Program led to significant gains on the health of the elderly, improving the balance, competence of the pelvic floor muscles and the performance of cognition, resulting in enhanced the participants' quality of life.

Keywords: Aging, Balance, Urinary Incontinence, Cognition, Nursing Rehabilitation

\section{INTRODUÇÃO}

A melhoria da qualidade de vida na velhice é um dos maiores desafios da atualidade. Mas envelhecer com qualidade de vida, requer medidas e intervenções que permitem que o idoso esteja integrado na sociedade, na família, nas instituições, com meios de subsistência e apoios necessários. É de salientar que são tão importantes os cuidados de saúde e os apoios sociais, como a participação ativa do indivíduo para atingir este objetivo ${ }^{(1,2)}$.

Dada a tendência demográfica da população portuguesa, caracterizada pelo aumento da longevidade do ser humano e pela diminuição da natalidade ${ }^{(3,4)}$, torna-se necessário adequar os cuidados que prestamos, ao longo da vida, em especial os cuidados específicos na velhice onde a enfermagem de reabilitação tem um papel fundamental, não só na conceção de evidências científicas que sustentem a elaboração de planos de cuidados específicos e especializados como também na sua execução.

Para alcançar este fim é essencial compreender que o envelhecimento pode levar à deterioração de várias capacidades fisiológicas (tais como, a força muscular, a capacidade aeróbica, a coordenação neuromuscular, a flexibilidade, entre outras) que por sua vez podem levar à decadência do desempenho físico e mental, acarretando consequências para a qualidade de vida, bem-estar e para a realização dos autocuidados, das atividades de vida diária e das atividades instrumentais da vida diária ${ }^{(5)}$.

Deste modo, o conceito de capacidade funcional tem atraído preocupação crescente aos profissionais de saúde, em especial aos enfermeiros em reabilitação, procurando permanentemente estratégias para melhorar e/ou manter as habilidades funcionais dos idosos.

O envelhecimento faz parte do ciclo da vida e como tal, é lógico valorizá-lo, até porque constitui uma oportunidade para uma sociedade mais enriquecida. Amiúde, o envelhecimento, é relacionado com o declínio das faculdades físicas e mentais, aspeto que o associa a uma imagem pejorativa, que a todo custo deve ser evitada, similarmente associado a doenças, perda de autonomia e independência e ao consequente afastamento dos papeis sociais ${ }^{(6)}$.

Envelhecer não pode ser visto como um processo só de perdas, sendo possível por ação de intervenções comportamentais, sociais, económicas e ambientais, 
as pessoas poderem envelhecer ativamente vivendo mais anos com melhor qualidade de vida, diminuindo a sua dependência e potenciando a sua autonomia ${ }^{(7-9)}$.

A capacidade de preservar e/ou potenciar a autonomia e a independência, aumentando a qualidade de vida, nos idosos, relaciona-se com a vigilância do estado de saúde, o tipo de cuidados de saúde vivenciados, os ambientes em viveram, bem como a adoção de estilos de vida ${ }^{(10)}$.

No último relatório do Sistema EVITA do Instituto Nacional de Saúde Doutor Ricardo Jorge, os mecanismos de lesão que mais contribuíram para o número de Acidentes Domésticos e Lazer ( $A D L)$ são as quedas $(68,7 \%)$, destacando-se de forma pronunciada como a maior causa de ADL. Enfatiza-se que o grupo com maior ocorrência de quedas é do sexo feminino com idade igual ou superior a 75 anos ${ }^{(11)}$.

Segundo Swift e Iliffe (2014) existem alguns fatores de risco que poderão contribuir para as quedas em idosos, nomeadamente: histórico de quedas; instabilidade postural; problemas de mobilidade; problemas de equilíbrio; problemas de continência; comprometimento cognitivo; problemas de saúde; medicação; síndrome da síncope; e deficiência visual (12). Constata-se que alterações no equilíbrio, continência urinária e cognição, são determinantes para ocorrência de quedas nos idosos.

São várias as evidências que sustentam os efeitos benéficos do treino de equilíbrio, tais como: a redução no medo de cair; a redução do número de quedas; o aprimoramento da performance do equilíbrio; a melhoria da execução da marcha; e o decorrente aumento da qualidade de vida ${ }^{(13-15)}$.

Associado às vantagens do treino de equilíbrio, o treino dos músculos do assoalho pélvico, em situações de incontinência urinária é essencial. A incontinência urinária pode ser um sintoma muito limitante. 0 facto de o idoso poder ter, por exemplo, incontinência urinária de urgência, obriga-o a ter uma rápida resposta física para alcançar a casa de banho antes de ocorrer a perda de urina. Este tipo de situações pode levar a perdas de equilíbrio e consequentemente a quedas ${ }^{(16-18)}$.

A cognição e o controlo motor estão intimamente relacionados, o movimento corporal na generalidade não é realizado na ausência de intenção, por isso os processos cognitivos são essenciais para o controle motor $(5,19)$, desempenham um papel vital nas atividades de vida diárias e nas atividades instrumentais de vida diária, bem como, na combinação de várias atividades de vida diária e atividades instrumentais da vida diária em paralelo (20).

A construção do Programa TEIA em idosos ativos teve em consideração estas três variáveis, equilíbrio corporal, continência urinária e cognição. Atendendo às componentes que integra, este programa é essencial para fortalecer a funcionalidade nos idosos, habilitando-os para preservar a independência e autonomia. Neste sentido, este estudo tem como objetivo avaliar o impacto da implementação do programa TEIA sobre o estado de equilíbrio, sintomatologia da incontinência urinária, cognição e qualidade de vida em idosos ativos institucionalizados.

\section{MÉTODO}

Este foi um estudo quasi-experimental, antes-depois, com grupo de controlo. Com duração de 12 semanas, o grupo de programa teve duas sessões semanais de treino de equilíbrio e treino muscular do assoalho pélvico e uma sessão semanal de estimulação cognitiva intercaladas (Figura 1) e grupo de controlo não foi sujeito à intervenção.

A técnica de amostragem usada foi não probabilística, acidental. Os critérios de inclusão foram: indivíduos com mais de 65 anos, com marcha preservada e institucionalizados. Os critérios de exclusão: indivíduos com: (i) doença do foro mental que limitasse a compreensão do objeto de estudo, bem como, do conteúdo das sessões do programa; (ii) ou com comorbilidade que impedisse o exercício físico.

Obteve-se autorização das duas Instituições, o Instituto de Ação Social das Forças Armadas (IASFA) Centro de Apoio Social do Porto (CASP) e a Santa Casa da Misericórdia do Porto - Lar da Nossa Senhora da Misericórdia. Neste estudo foram atendidos e garantidos todos os requisitos éticos e deontológicos respeitantes à investigação científica.

Participaram neste estudo, um total de 32 idosos institucionalizados, tendo sido divididos em grupo de programa e grupo de controlo, 17 e 15 respetivamente. Houve uma desistência no grupo de programa e ocorreu um óbito no grupo de controlo. No final do estudo o grupo de programa teve 16 participantes e o grupo de controlo teve 14 participantes (Figura 2). 


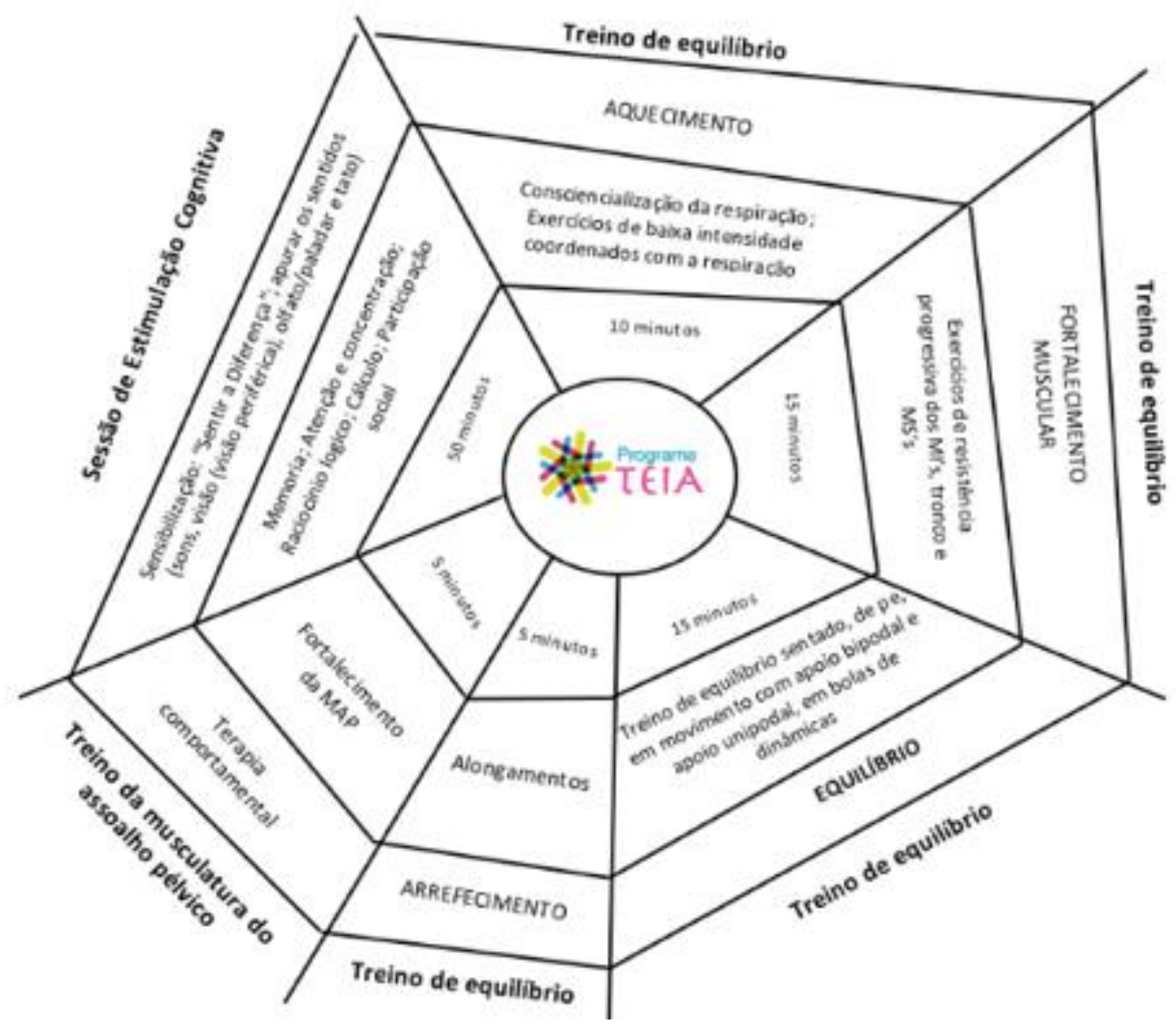

Figura 1 - Estrutura Programa TEIA
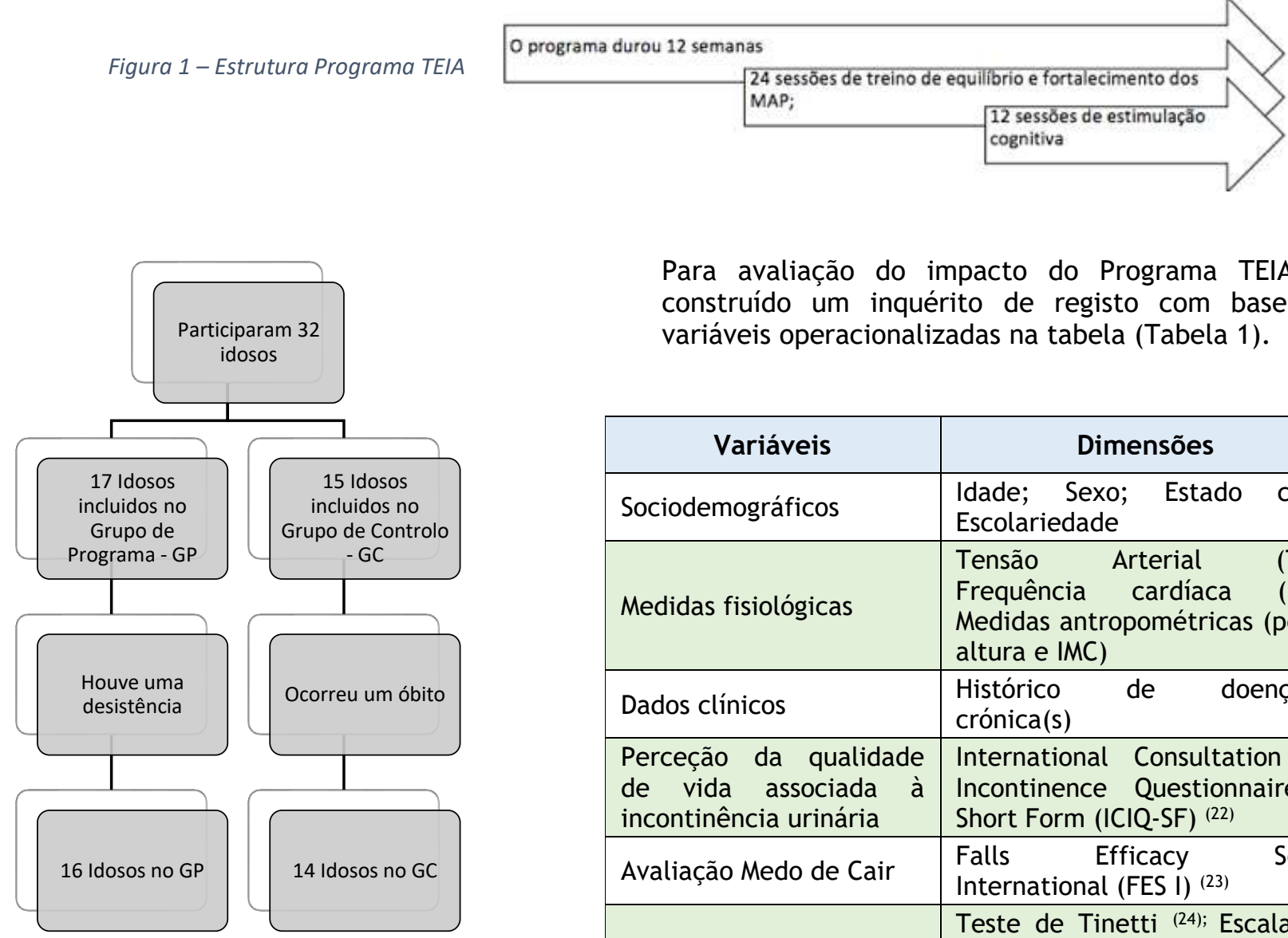

Para avaliação do impacto do Programa TEIA foi construído um inquérito de registo com base nas variáveis operacionalizadas na tabela (Tabela 1).

\begin{tabular}{|c|c|}
\hline Variáveis & Dimensões \\
\hline Sociodemográficos & $\begin{array}{l}\text { Idade; Sexo; Estado civil; } \\
\text { Escolariedade }\end{array}$ \\
\hline Medidas fisiológicas & $\begin{array}{lcc}\text { Tensão } & \text { Arterial } & \text { (TA); } \\
\text { Frequência } & \text { cardíaca } & (\mathrm{FC}) ; \\
\text { Medidas antropométricas } & \text { (peso, } \\
\text { altura e IMC) } & \end{array}$ \\
\hline Dados clínicos & $\begin{array}{l}\text { Histórico de doença(s) } \\
\text { crónica(s) }\end{array}$ \\
\hline $\begin{array}{l}\text { Perceção da qualidade } \\
\text { de vida associada à } \\
\text { incontinência urinária }\end{array}$ & $\begin{array}{l}\text { International Consultation on } \\
\text { Incontinence Questionnaire - } \\
\text { Short Form (ICIQ-SF) }{ }^{(22)}\end{array}$ \\
\hline Avaliação Medo de Cair & $\begin{array}{lll}\text { Falls } \quad \text { Efficacy } & \text { Scale } \\
\text { International (FES I) }\end{array}$ \\
\hline Alterações no equilíbrio & $\begin{array}{l}\text { Teste de Tinetti (24); Escala de } \\
\text { Equilíbrio de Berg (EEB) } \\
\text { Teste Time Up and Go (TUG) }\end{array}$ \\
\hline Independência nas AIVD & Índice de Lawton- Brody (27) \\
\hline Estado depressivo & $\begin{array}{l}\text { Escala Geriátrica de Depressão } \\
\text { de } 15 \text { questões (GDS15)(28) }\end{array}$ \\
\hline
\end{tabular}




\begin{tabular}{|l|l|}
\hline Cognição & $\begin{array}{l}\text { Teste de Declínio Cognitivo de } \\
6 \text { itens }(6 \mathrm{CIT})^{(29)}\end{array}$ \\
\hline $\begin{array}{l}\text { Perceção da qualidade } \\
\text { de vida associada à saúde }\end{array}$ & $\begin{array}{l}\text { Questionário de vida associado } \\
\text { à saúde }(\mathrm{SF}-36)^{(30)}\end{array}$ \\
\hline
\end{tabular}

Tabela 1 - Variáveis e instrumentos de colheita

Foi realizada uma análise estatística descritiva e inferencial, com recurso a testes paramétricos, nomeadamente o teste $t$ de Student, para avaliação intersujeitos e o teste $\mathrm{t}$ Amostras Emparelhadas na análise intrasujeitos, e em certos casos, os respetivos testes não paramétricos, o teste de Mann-Whitney e o teste de Wilcoxon. 0 nível de significância adotado foi de $0,05^{(21)}$. O software utilizado para o tratamento de dados e análise estatística foi o IBM $®$ SPSS $\circledast$ Statistics versão 24 .

\section{RESULTADOS E DISCUSSÃO}

A amostra total $(n=30)$, caracterizou-se com uma média de idades de 83,3 anos, a mediana de 84 anos. A idade variou dos 67 anos aos 93 anos, com um desvio padrão de 6,32 anos. Com uma representação igual entre os sexos, $50 \%$ homens e $50 \%$ mulheres, quer na amostra quer nos e grupos. Relativamente ao estado civil os grupos com mais representatividade são os casados e viúvos quer na amostra (40\% casados e 43,3 viúvos) quer nos grupos (grupo do programa - 43,8\% casados e 43,8\% viúvos; grupo de controlo - 35,7\% casados e $42,9 \%$ viúvos). Relativamente às habilitações literárias, aquela com maior representatividade na amostra foi o $1^{\circ}$ ciclo $(40,0 \%)$ seguindo-se o $3^{\circ}$ ciclo $(30,0 \%)$. Nos grupos a tendência foi a mesma (Tabela 2).

\begin{tabular}{|c|c|c|c|c|c|c|c|}
\hline \multicolumn{2}{|c|}{$\begin{array}{c}\text { Características } \\
\text { sociodemográficas }\end{array}$} & \multicolumn{2}{|c|}{$\begin{array}{l}\text { Grupo de } \\
\text { Programa } \\
\text { (GP) }\end{array}$} & \multicolumn{2}{|c|}{$\begin{array}{l}\text { Grupo de } \\
\text { Controlo } \\
\text { (GC) }\end{array}$} & \multicolumn{2}{|c|}{$\begin{array}{l}\text { Total da } \\
\text { Amostra }\end{array}$} \\
\hline & & $\mathrm{n}$ & $\%$ & $\mathrm{n}$ & $\mathrm{n}$ & $\mathrm{n}$ & $\%$ \\
\hline \multicolumn{2}{|c|}{ Participantes } & 16 & 53,3 & 14 & 46,7 & 30 & 100 \\
\hline \multicolumn{2}{|c|}{$\begin{array}{l}\text { Média de Idade } \\
\qquad(\sigma)\end{array}$} & \begin{tabular}{|c|}
83 \\
$(5,56)$ \\
\end{tabular} & -- & \begin{tabular}{|c|}
83 \\
$(7,32)$ \\
\end{tabular} & - & $\begin{array}{c}83 \\
(6,33)\end{array}$ & -- \\
\hline \multirow{2}{*}{ Sexo } & Feminino & 8 & 50,0 & 7 & 50,0 & 15 & 50,0 \\
\hline & Masculino & 8 & 50,0 & 7 & 50,0 & 15 & 50,0 \\
\hline \multirow{4}{*}{$\begin{array}{c}\text { Estado } \\
\text { Civil }\end{array}$} & Solteiro & 0 & 0 & 2 & 14,3 & 2 & 6,7 \\
\hline & Casado & 7 & 43,8 & 5 & 35,7 & 12 & 40,0 \\
\hline & $\begin{array}{l}\text { Separado/ } \\
\text { Divorciado }\end{array}$ & 2 & 12,5 & 1 & 7,1 & 3 & 10,0 \\
\hline & Viúvo & 7 & 43,8 & 6 & 42,9 & 13 & 43,3 \\
\hline \multirow{5}{*}{$\begin{array}{l}\text { Habilita- } \\
\text { ções } \\
\text { Literárias }\end{array}$} & $1^{\circ}$ Ciclo & 5 & 31,3 & 7 & 50,0 & 12 & 40,0 \\
\hline & $2^{\circ}$ Ciclo & 4 & 25,0 & 1 & 7,1 & 5 & 16,7 \\
\hline & $3^{\circ}$ Ciclo & 5 & 31,3 & 4 & 28,6 & 9 & 30,0 \\
\hline & Secundário & 1 & 6,3 & 0 & 0,0 & 1 & 3,3 \\
\hline & $\begin{array}{l}\text { Ensino } \\
\text { Superior }\end{array}$ & 1 & 6,3 & 2 & 14,3 & 3 & 10,0 \\
\hline
\end{tabular}

Tabela 2 - Caraterização da Amostra

Análise da implementação do Programa TEIA

\section{Antes do Programa}

$\mathrm{Na}$ avaliação realizada antes do programa verificou-se que em todas as variáveis, exceto o índice de massa corporal médio e a perceção da qualidade de vida associada à saúde na dimensão desempenho físico, o $p$ value teve um valor superior a 0,05 , significando que não existiam diferenças estatisticamente significativas entre o grupo de programa e controlo, inferindo a similaridade dos grupos.

\section{Após o Programa}

Sobre as Medidas Fisiológicas: No grupo de programa, da $1^{\circ}$ para a $2^{\mathrm{a}}$ avaliação, o valor sistólico médio de $139 \mathrm{mmHg}$ passou para um valor de $127 \mathrm{mmHg}$ e o valor diastólico médio passou de $77 \mathrm{mmHg}$ para $72 \mathrm{mmHg}$. A frequência cardíaca média de $81 \mathrm{bpm}$ passou para $74 \mathrm{bpm}$.

No grupo de programa e de controlo, houve um peso médio de 73,069 $\mathrm{Kg}$ e $68,585 \mathrm{Kg}$ respetivamente, na $1^{\mathrm{a}}$ avaliação. $\mathrm{Na} 2^{\mathrm{a}}$ avaliação, o peso médio passou para $72,025 \mathrm{Kg}$ no grupo de programa, e $70,000 \mathrm{Kg}$ no grupo de controlo.

Estas diferenças de valores refletiram-se no valor de IMC. Na $1^{\text {a }}$ avaliação, o grupo de programa, teve um valor de 28,30 e na $2^{\text {a }}$ avaliação um valor de 27,93 . 0 grupo de controlo, na $1^{\text {a }}$ avaliação teve um valor de 25,39 e na $2^{\mathrm{a}}$ avaliação um valor de 25,89 .

Estas alterações de peso e consequentemente do valor de IMC, levaram a um reposicionamento relativamente à categorização do IMC, houve uma variação do número de pessoas, do grupo de programa, que passou da categoria obeso grau I para pré-obeso, ou seja, na $1^{\text {a }}$ avaliação $43,8 \%$ eram pré-obesos e $31,3 \%$ eram obesos grau I. Na $2^{\mathrm{a}}$ avaliação a percentagem de préobesos passou para $56,3 \%$ e a percentagem de obesos grau I passou para $18,8 \%$. No grupo de controlo, na $1^{\text {a }}$ avaliação, $50 \%$ eram pré-obesos, $41,9 \%$ normal e $7,1 \%$ obeso grau I e na $2^{\mathrm{a}}$ avaliação $42,9 \%$ pré-obesos, $35,7 \%$ normal e $21,9 \%$ obeso grau 1 .

$\mathrm{Na}$ análise intrasujeitos, no grupo do programa, todas as medidas fisiológicas tiveram um decréscimo, havendo alterações estatisticamente significativas para os valores da tensão arterial, valor sistólico ( $t$ (15) $=4,522 ; p=0,0001$ ) e valor diastólico (t (15) $=2,698 ; p=0,017$ ); da frequência cardíaca (t (15) $=3,335 ; p=0,005)$; do peso (t $(15)=2,427 ; p=0,028)$ e do índice de massa corporal (t (15) $=2,318 ; p=0,035$ ). O mesmo não se comprova no grupo de controlo, já que nas variáveis tensão arterial (diastólica e sistólica) e frequência cardíaca o $p$ value é superior a 0,05 , logo não houve alterações estatisticamente significativas nos seus valores da $1^{a}$ para a $2^{\circ}$ avaliação $(t(13)=-$ 2,649; $\mathrm{p}=0,020)$. Em relação ao índice de massa corporal $(t(13)=-2,370 ; p=0,034)$, neste grupo, houve alterações estatisticamente significativas mas com tendência oposta ao grupo do programa. Quando 
realizada avaliação intersujeitos verificou-se que não houve alterações estatisticamente significativas.

Sobre a Perceção da qualidade de vida associada à incontinência urinária (ICIQ-SF): A média de pontuação da $1^{\mathrm{a}}$ avaliação no grupo do programa, comparativamente com a $2^{\mathrm{a}}$ avaliação decresceu significativamente, de um valor médio de 4,19 pontos para um valor de 2,44 pontos. Já no grupo de controlo, houve um aumento no valor médio de 4,93 pontos para 6,50 pontos. Nesta variável como a distribuição não é normal, recorreu-se ao teste de Wilcoxon e verificou-se que houve diferenças estatísticas da $1^{\mathrm{a}}$ para a $2^{\mathrm{a}}$ avaliação, quer para 0 grupo do programa $(Z=-2,680 ; p=0,007)$, quer para o grupo de controlo $(Z=-2,375 ; p=0,018)$. Quando realizada a análise intersujeitos verificou-se que houve diferenças estatísticas significativas entre o grupo do programa e 0 grupo de controlo relativamente à $2^{\mathrm{a}}$ avaliação $(U=44,000 ; \mathrm{p}=0,004)$ (tabela 3).

Sobre a Cognição (6CIT): O valor médio de pontuação, no grupo do programa, passou de 7 para 4 pontos, os valores máximos de 19 para 14 pontos e o desvio padrão de 6 passa para 5 pontos. Já no grupo de controlo, a pontuação média passou de 5 para 7 pontos, mantendo o valor máximo e desvio de padrão. $\mathrm{Na}$ avaliação intrasujeitos constatou-se que no grupo do programa houve diferenças estatísticas significativas $(Z=-3,088 ; p=0,002)$ mas no grupo de controlo não ocorreu diferenças estatísticas $(Z=-1,901$; $\mathrm{p}=0,57)$. Na avaliação intersujeitos averiguou-se que não houve diferenças estatísticas $(U=72,500 ; p=0,101)$ (tabela3).

\begin{tabular}{|c|c|c|c|c|c|c|c|c|}
\hline \multirow[b]{2}{*}{ Variável } & \multirow[b]{2}{*}{ Outcomes } & \multicolumn{3}{|c|}{$G P(n=16)$} & \multicolumn{3}{|c|}{$\mathrm{GC}(\mathrm{n}=14)$} & \multirow{2}{*}{$\begin{array}{c}p \text { value } \\
\text { a entre } \\
\text { os } \\
\text { grupos }\end{array}$} \\
\hline & & $\begin{array}{c}1^{\mathrm{a}} \\
\text { avaliação }\end{array}$ & $\begin{array}{c}2^{\mathrm{a}} \\
\text { avaliação }\end{array}$ & $\begin{array}{c}p \text { value } \\
1^{\text {a }} \text { e } 2^{\text {a }} \\
\text { avaliação }\end{array}$ & $\begin{array}{c}1^{\mathrm{a}} \\
\text { avaliação }\end{array}$ & $\begin{array}{c}2^{\mathrm{a}} \\
\text { avaliação }\end{array}$ & $\begin{array}{c}p \text { value } \\
1^{\text {a }} \text { e } 2^{\mathrm{a}} \\
\text { avaliaçãao }^{\text {ava }}\end{array}$ & \\
\hline $\begin{array}{l}\text { Perceção da qualidade } \\
\text { de vida associada à } \\
\text { incontinência urinária } \\
\text { Pontuação média } \\
(\sigma)\end{array}$ & $\begin{array}{l}\text { ICIQ-SF } \\
\text { Max: } 21 \\
\text { Min: } 0 \\
\end{array}$ & $\begin{array}{c}4,19 \\
(5,09)\end{array}$ & $\begin{array}{c}2,44 \\
(5,02)\end{array}$ & 0,007 & $\begin{array}{c}4,93 \\
(5,48)\end{array}$ & $6,50(5,26)$ & 0,018 & 0,004 \\
\hline $\begin{array}{c}\text { Cognição } \\
\text { Pontuação média } \\
(\sigma)\end{array}$ & $\begin{array}{c}\text { 6CIT } \\
\text { Max:28 } \\
\text { Min: } 0 \\
\end{array}$ & $\begin{array}{c}7 \\
(6)\end{array}$ & $\begin{array}{c}3,56 \\
(4,99)\end{array}$ & 0,002 & $\begin{array}{l}5 \\
(7)\end{array}$ & $6,79(7,13)$ & 0,573 & 0,101 \\
\hline
\end{tabular}

Sobre o Medo de Cair (FES-I) e Equilíbrio (Teste de Tinetti, Escala de Equilíbrio de Berg, Teste Timed Up and Go): No que se refere à variável "medo de cair" analisada através da escala FES-I, no grupo de programa, a média de pontuação inicial foi de 75 pontos e a final de 85 pontos e no grupo de controlo a pontuação média passou de 82 pontos para 78 pontos. Quando realizada a análise intrasujeitos, verificou-se que no grupo do programa houve diferenças estatísticas entre a $1^{\text {a }}$ avaliação e a $2^{\mathrm{a}}$ avaliação $(Z=-$ $3,059 ; p=0,002)$, já no grupo de controlo não houve diferenças estatísticas $(Z=-2,366 ; p=0,18)$. Também não houve diferenças significativamente estatísticas entre os grupos, após a implementação do programa $(U=111,000 ; p=0,966)$.

Sobre a avaliação do equilíbrio, como se pode verificar pela tabela 4 , no grupo do programa na $1^{\text {a }}$ avaliação a pontuação média foi de 23 pontos, passando na $2^{\mathrm{a}}$ avaliação para 26 pontos. Já no grupo de controlo a pontuação média foi de 24 pontos passando para 23 pontos na $2^{\mathrm{a}}$ avaliação. Analisando a pontuação do Teste de Tinetti, na avaliação intrasujeitos, tendo em conta o seu valor total, verificou-se que houve diferenças significativas entre a $1^{\mathrm{a}}$ e a $2^{\mathrm{a}}$ avaliação, no grupo do programa $(Z=-3,126 ; p=0,002)$, mas não no grupo de controlo $(Z=-2,271 ; p=0,23)$. Na avaliação intersujeitos verificou-se que na $1^{\text {a }}$ avaliação não houve diferenças entre os grupos $(U=101,000$; $p=0,667)$, mas na $2^{a}$ avaliação, houve diferenças estatisticamente significativas entre o grupo de programa e o grupo de controlo $(U=60,000 ; p=0,031)$.

A pontuação segundo a escala de equilíbrio de Berg, no grupo de programa, passou de uma média de 44 pontos para uma média de 49 pontos. O grupo de controlo passou de 42 pontos para 39 pontos médios. Verificou-se também a alteração da moda das pontuações da $1^{\mathrm{a}}$ para a $2^{\mathrm{a}}$ avaliação, no grupo de programa foi de 50 para 52 pontos, no grupo de controlo passou de 49 para 42 pontos. Transpondo para a avaliação intrasujeitos, verificou-se que houve diferenças estatisticamente significativas, quer para o grupo do programa $(Z=-3,304 ; p=0,001)$, quer para o grupo de controlo $(Z=-3,203 ; p=0,001)$. Na avaliação intersujeitos, verificou-se que também houve diferenças estatísticas significativas, na $2^{\mathrm{a}}$ avaliação, confirmado pelo teste Mann-Whitney $(U=36,000 ; p=$ 0,001) (tabela4).

Em relação ao tempo necessário para realizar o teste Timed Up and Go, verificou-se que no grupo do programa de um valor médio de 20,16 seg., um valor máximo de 44,17 seg. e um valor mínimo de 9,74seg., passou-se para um valor médio de $16,66 \mathrm{seg}$., um valor máximo de 40,20 seg. e um valor mínimo de 7,71 seg. No grupo de controlo, passou-se de um valor médio de 20,66 seg., para 24,07 seg., o valor máximo passou de 44,19 seg. para 45,20 seg. e o valor mínimo de 11,39 seg. para 12,27 seg.. Na avaliação intrasujeitos 
verificou-se que houve diferenças estatisticamente significativas da $1^{\mathrm{a}}$ para a $2^{\mathrm{a}}$ avaliação, quer no grupo do programa $(Z=-3,516 ; p=0,0001)$, quer no grupo de controlo $(Z=-3,296 ; \quad p=0,001) . \quad \mathrm{Na}$ avaliação intersujeitos verificou-se que houve alterações estatisticamente significativas na $2^{\mathrm{a}}$ avaliação $(U=55,000 ; p=0,017)$ (tabela 4).

\begin{tabular}{|c|c|c|c|c|c|c|c|c|}
\hline \multirow[b]{2}{*}{ Variável } & \multirow[b]{2}{*}{ Outcomes } & \multicolumn{3}{|c|}{ GP $(n=16)$} & \multicolumn{3}{|c|}{$\mathrm{GC}(\mathrm{n}=14)$} & \multirow{2}{*}{$\begin{array}{l}p \text { value } \\
\text { a entre os } \\
\text { grupos }\end{array}$} \\
\hline & & $\begin{array}{c}1^{\mathrm{a}} \\
\text { avaliação }\end{array}$ & $\begin{array}{c}2^{\mathrm{a}} \\
\text { avaliação }\end{array}$ & $\begin{array}{c}p \text { value } \\
1^{\mathrm{a}} \text { e } 2^{\mathrm{a}} \\
\text { avaliação }\end{array}$ & $\begin{array}{c}1^{\mathrm{a}} \\
\text { avaliação }\end{array}$ & $\begin{array}{c}2^{\mathrm{a}} \\
\text { avaliação }\end{array}$ & $\begin{array}{c}p \text { value } \\
1^{\mathrm{a}} \text { e } 2^{\mathrm{a}} \\
\text { avaliação }\end{array}$ & \\
\hline \multirow{3}{*}{$\begin{array}{l}\text { Pontuação } \\
\text { média } \\
(\sigma)\end{array}$} & $\begin{array}{c}\text { Teste de } \\
\text { Tinetti } \\
\text { Max: } 28 \\
\text { Min: } 0\end{array}$ & $\begin{array}{l}23 \\
(4)\end{array}$ & $\begin{array}{l}25,88 \\
(3,01)\end{array}$ & 0,002 & $\begin{array}{l}24 \\
(4)\end{array}$ & $\begin{array}{l}23,07 \\
(4,34)\end{array}$ & 0,231 & 0,031 \\
\hline & $\begin{array}{c}\text { EEB } \\
\text { Max: } 56 \\
\text { Min: } 0\end{array}$ & $\begin{array}{l}44 \\
\text { (7) }\end{array}$ & $\begin{array}{l}49,00 \\
(6,46)\end{array}$ & 0,001 & $\begin{array}{l}(42 \\
(8)\end{array}$ & $\begin{array}{l}39,00 \\
(8,73)\end{array}$ & 0,001 & 0,001 \\
\hline & $\begin{array}{l}\text { Teste TUG } \\
\text { Seg. }\end{array}$ & $\begin{array}{l}20,16 \\
(9,93)\end{array}$ & $\begin{array}{l}16,67 \\
(9,68)\end{array}$ & 0,0001 & $\begin{array}{l}20,60 \\
(9,49)\end{array}$ & $\begin{array}{c}24,07 \\
(11,31)\end{array}$ & 0,001 & 0,017 \\
\hline $\begin{array}{l}\text { Medo de } \\
\text { Cair } \\
\text { Pontuação } \\
\text { média } \\
(\sigma)\end{array}$ & $\begin{array}{c}\text { FES I } \\
\text { Max:100 } \\
\text { Min: } 0\end{array}$ & $\begin{array}{l}75 \\
(24)\end{array}$ & $\begin{array}{c}85,19 \\
(14,76)\end{array}$ & 0,002 & $\begin{array}{c}82 \\
(28)\end{array}$ & $\begin{array}{c}78,07 \\
(32,15)\end{array}$ & 0,018 & 0,984 \\
\hline
\end{tabular}

Tabela 4- Resultados para o Teste Tinetti, Escala de Equilibrio de Berg, teste Timed Up and Go e FES-I.

$\mathrm{Na}$ análise da Independência nas atividades instrumentais de vida diária (Índice de Lawton-Brody): Para a pontuação do Índice de Lawton-Brody a média de valores manteve-se da $1^{\text {a }}$ para a $2^{\circ}$ avaliação em ambos os grupos. Analisando cada item da escala, para - grupo de programa, verificou-se que, no item "Cuidar da casa", 37,5\% "cuida da casa sem ajuda" e manteve pontuação na $2^{a}$ avaliação; na resposta "faz tudo exceto o trabalho pesado", de $12,5 \%$ passou-se para $18,8 \%$, e na resposta "só faz tarefas leves", de $43,8 \%$ passou-se para $37,5 \%$ na $2^{a}$ avaliação. No item "Preparar comida", de 50\% passou-se para 62,5\% na resposta "planeia, prepara e serve sem ajuda" e 37,5\% passou-se para $25 \%$ na resposta "prepara se lhe derem os ingredientes". No item "Ir às compras", 43,8\% referiu que era "incapaz de ir às compras" e na $2^{\text {a }}$ avaliação diminui para $37,5 \%$; na resposta "faz as compras acompanhado" de $18,8 \%$ passou-se para $25 \%$. No item "uso de transporte" verificou-se que, de $25 \%$ passou-se para 18,8\% na resposta "necessita de acompanhamento" e na proporção inversa, de 18,8\% passou-se para $25 \%$ na resposta "só anda de táxi".

Nesta variável não houve diferenças estatisticamente significativas quer na avaliação intrasujeitos quer na avaliação intersujeitos. Esta evidência é confirmada pela análise intrasujeitos, onde não houve diferenças estatisticamente significativas da $1^{\text {a }}$ para a $2^{\text {a }}$ avaliação, no grupo de programa $(Z=-1,633 ; p=0,102)$ e no grupo de controlo $(Z=-1,342 ; p=0,180)$ e em consonância, na avaliação intersujeitos também não houve diferenças estatísticas entre na $2^{a}$ avaliação $(U=99,500 ; p=0,608)$.

Sobre o Estado depressivo (Escala Geriátrica de Depressão de 15 questões): 0 grupo de programa teve uma média de 4 pontos, quer na $1^{\mathrm{a}}$, quer na $2^{\mathrm{a}}$ avaliação. Através da frequência de percentagens cumulativas verificou-se que, o número de participantes dentro dos pontos de corte de 0-5 pontos, neste grupo, passou de $56,3 \%$ para $68,8 \%$, da $1^{\text {a }}$ para a $2^{\text {a }}$ avaliação. 0 grupo de controlo teve uma pontuação média de 5 pontos na $1^{\text {a }}$ avaliação e passou para 6 pontos na $2^{a}$ avaliação. Constata-se, nesta variável, que na avaliação intrasujeitos, segundo o teste Wilcoxon, no grupo do programa não houve diferenças estatísticas $(Z=-1,121 ; p=0,262)$, e no grupo de controlo ocorreu diferenças estatísticas $(Z=-2,232$; $p=0,026)$, uma vez que, houve acréscimo na pontuação da Escala Geriátrica de Depressão de 15 questões. Na avaliação intersujeitos verificou-se que não houve diferenças estatísticas significativas entre os grupos na $2^{a}$ avaliação $(U=71,500 ; p=0,091)$.

Da análise da Perceção da qualidade de vida associada à saúde (Questionário de vida associado à saúde SF36): Quando agrupamos as dimensões do Questionário de vida associado à saúde, SF-36, em componente física (função física, desempenho físico, dor e saúde em geral) e em componente mental (vitalidade, função social, desempenho emocional e saúde mental), constatou-se que na amostra, ocorreu uma variação da $1^{\mathrm{a}}$ para a $2^{\mathrm{a}}$ avaliação. 0 valor médio de $54 \%$ passou para $66 \%$ para componente física, e na componente mental, passou de um valor médio de $68 \%$ para $78 \%$. Na avaliação intersujeitos podemos afirmar que houve diferenças estatisticamente significativas, no grupo de programa, quer na componente física $(Z=-$ $3,077 ; \mathrm{p}=0,002)$, quer na componente mental ( $\mathrm{Z}=$ $2,552 ; p=0,011)$. No grupo de controlo não houve diferenças na componente física $(Z=-1,454 ; p=0,146)$, e na componente mental houve diferenças estatísticas, mas no sentido contrário, ou seja, houve perdas $(Z=-2,805 ; p=0,005)$. Na avaliação intersujeitos 
verificou-se que houve diferenças entre os grupos na componente mental na $2^{\mathrm{a}}$ avaliação $(\mathrm{U}=62,000$; $p=0,038)$ que não existiu na $1^{\text {a }}$ avaliação $(U=103,500$; $p=0,728)$. Na componente física não houve diferenças estatisticamente significativas entre os grupos, nem na $1^{\mathrm{a}} \quad(U=95,500 ; \mathrm{p}=0,498)$ nem na $2^{\mathrm{a}}$ avaliação $(U=81,000 ; p=0,208)$.

\section{Avaliação intersujeitos ( $1^{\text {a }}$ avaliação)}

No que diz respeito à avaliação intersujeitos na $1^{\circ}$ avaliação importa ressalvar alguns dados.

Relativamente à distribuição da variável sexo, quer na amostra total, quer nos dois grupos que a constituem, a distribuição foi igual e com uma representação de $50 \%$ para cada um dos sexos, ao contrário da maioria dos estudos onde houve maior representatividade do sexo feminino $(34,35)$, bem como, na população portuguesa, entre a faixa etária 80-84 anos, média de idades no nosso estudo, onde cerca de $62 \%$ da população é do sexo feminino(3).

Quanto ao estado civil, são os casados e viúvos com maior expressão, seguiu-se estado civil separado/divorciado e solteiro em ambos os grupos do estudo, análogo ao estudo de Possamai Menezes et al. (36). A distribuição das habilitações literárias demonstrou que $50 \%$ ou mais dos participantes, em ambos os grupos possuíam habilitações literárias superiores ao $1^{\mathrm{a}}$ ciclo, coincidente com outro estudo. (33).

Relativamente às restantes variáveis, nas análises intersujeitos na $1^{\text {a }}$ avaliação, comprovados com os respetivos testes estatísticos, verificou-se que os grupos não houve diferenças estatisticamente significativas, excetuando no valor de índice de massa corporal e na dimensão desempenho físico do questionário de vida associado à saúde SF-36. Isto permitiu-nos concluir que os grupos antes da implementação do programa TEIA eram muito equivalentes, contribuindo desta forma, para a garantia da validade interna do estudo. Dado que quanto mais semelhantes forem os grupos programa e de controle no recrutamento e quanto mais essas semelhanças forem confirmadas pelos testes da $1^{\text {a }}$ avaliação mais efetivo será esse controle ${ }^{(21)}$.

\section{Avaliação intrasujeitos (grupo de programa)}

Foram vários os achados que se encontraram com a implementação do programa, nomeadamente: a redução da tensão arterial, a diminuição da frequência cardíaca, o decréscimo do peso e consequentemente do índice de massa corporal e reposicionamento nas categorias do índice de massa corporal. Assim como, a alteração da perceção da qualidade de vida associada com a incontinência urinária; a diminuição do medo de cair; melhor performance no equilíbrio; melhoria da aptidão cognitiva e variação da perceção da qualidade de vida associada à saúde.

O valor sistólico e diastólico, no grupo do programa, sofreu um decréscimo estatisticamente significativo. Tendo por base a norma sobre hipertensão arterial definida pela Direção Geral de Saúde (2013), os valores sistólicos passaram de uma classificação normal alta, para a classificação normal. Já os valores diastólicos mantiverem uma classificação ótima ${ }^{(37)}$. 0 valor da frequência cardíaca em repouso da $1^{a}$ para a $2^{\mathrm{a}}$ avaliação decresceu, este achado está em concordância com a relação que existe entre o efeito da atividade física e a diminuição da FC em repouso (38).

Abordando agora a avaliação do peso e índice de massa corporal, verificou-se que na avaliação intrasujeitos do grupo do programa houve perda de peso, em média de $1 \mathrm{~kg}$ e consequentemente o índice de massa corporal também diminuiu levando a um reposicionamento da categoria do IMC. Apesar deste valor médio manter esta subamostra na categoria do pré-obeso é de salientar que, houve uma variação do número de pessoas que passaram da categoria obeso grau I para pré-obeso. Mais uma vez comprovou-se a relação que existe entre a atividade física e a redução do peso e índice de massa corporal (39).

A perceção da qualidade de vida associada à incontinência urinária foi avaliada através do questionário International Consultation on Incontinence Questionnaire - Short Form, verificou-se que houve uma diminuição da pontuação média do questionário. Contribuindo para esta redução de pontuação, esteve a tendência de diminuição de pontuação em todas as perguntas do questionário que contribuem para a pontuação final. Esta variação de resultados pode ser atribuída à análise que foi realizada à pergunta $n^{\circ} 6$, na primeira avaliação, que desta forma, permitiu compreender quais os tipos de incontinência urinária mais frequente, na subamostra, e assim adaptar a estratégias mais eficazes para reduzir a frequência, a quantidade e o impacto da incontinência urinária, comprovando a relação do treino muscular do assoalho pélvico e da terapia comportamental como preditores de melhoria da qualidade de vida associada à incontinência urinária $(40,41)$.

Analisando agora a pontuação da Falls Efficacy Scale I verificou-se que houve diferenças entre a $1^{\mathrm{a}}$ e $2^{\mathrm{a}}$ avaliação no grupo do programa, sendo que a pontuação média aumentou. Através destes valores verificou-se que o medo de cair diminuiu, uma vez que, os participantes mostram-se mais confiantes em executar as 10 tarefas que a escala inclui, potenciando desta forma a associação entre o treino de equilíbrio e o medo de cair $(35,42)$.

A pontuação do teste de Tinetti, da Escala de Equilíbrio de Berg e do teste Timed Up and Go, também sofreram alterações da $1^{\mathrm{a}}$ para a $2^{\mathrm{a}}$ avaliação. No Teste de Tinetti e na Escala de Equilíbrio de Berg a pontuação média aumentou e a moda das pontuações também foi a favor da tendência de aumento da pontuação. O tempo médio do teste Timed Up and Go diminuiu da $1^{\mathrm{a}}$ para a $2^{\mathrm{a}}$ avaliação. Através destes resultados podemos atestar que os participantes do grupo de programa, melhoraram a mobilidade e consequentemente melhoram a performance da marcha, do equilíbrio, estático e dinâmico, podendo 
ser um preditor de diminuição do risco de queda em idosos $(31,33,43)$.

Ao analisarmos a performance dos participantes em relação à execução das atividades instrumentais de vida diárias, verificou-se que, não houve diferenças estatisticamente significativas, entre a $1^{\text {a }}$ e a $2^{\text {a }}$ avaliação, e a média de pontuação do Índice de Lawton-Brody manteve-se. No entanto, na análise da variação de pontuação a cada item do Índice, verificou-se que houve diferenças estatísticas às respostas dos itens "Cuidar da casa", "Preparar comida", "Ir às compras" e "Uso de transporte", ou seja, as respostas que conferem maior independência tiveram um aumento da $1^{\mathrm{a}}$ para a $2^{\mathrm{a}}$ avaliação. 0 referido leva-nos a depreender que os participantes sentiram maior confiança em desempenhar tarefas domésticas, como cuidar da casa e preparar comida, bem como, nas saídas ao exterior.

A relação entre o medo de cair, a qualidade de vida e da execução das atividades instrumentais de vida diárias foi estabelecida nos estudos de Jahana e Diogo (2007) e Fhon et al. (2012). Efetivamente, o Programa TEIA, contribuiu para a diminuição do medo de cair, mas apesar de em termos médios de pontuação não ter sofrido alterações, evidenciou-se que em certas atividades instrumentais de vida diárias houve uma melhoria na confiança para a execução das mesmas, nomeadamente, nas atividades instrumentais acima referidas. Resultados semelhantes foram obtidos noutros estudos $(44,45)$.

Também na análise da Escala Geriátrica de Depressão de 15 questões verificou-se que não houve alterações estatísticas na análise intrasujeitos. Verificou-se que no grupo de programa a pontuação média dos participantes manteve-se nos pontos de coorte sugestivos de "sem sintomatologia depressiva". Aliado a este dado, esteve o facto de ter ocorrido um aumento na percentagem do número de participantes, que passaram para esta classificação.

O medo de cair e a frequência de quedas pode levar a que o idoso fique mais ansioso e mais deprimido, por conseguinte leva ao isolamento social, diminuição da atividade física, permanecendo mais tempo sentado ou deitado, prejudicando a mobilidade e a independência nos autocuidados Como já verificamos com a implementação do Programa TEIA, os participantes diminuíram o medo de cair e este fator pode refletir-se na sintomatologia depressiva. ${ }^{(44-46)}$.

A decadência da função cognitiva pode levar ao aumento do número de quedas nos idosos, e por este motivo, a estimulação cognitiva foi incluída na estrutura do Programa TEIA. A pontuação média da escala Teste de Declínio Cognitivo de 6 itens, da $1^{\text {a }}$ para a $2^{\mathrm{a}}$ avaliação no grupo de programa, decresceu, sugestivo de melhor desempenho cognitivo, o que traduz que a implementação de um programa de estimulação cognitiva a idosos contribui para um melhor desempenho nas funções cognitivas ${ }^{(32)}$.

Guszman et al. (2015) estabeleceu a relação entre o medo de cair e a cognição, ou seja, quando o primeiro aumenta a segunda está em declínio, havendo relação intrínseca entre a cognição e o nível da atividade física, que pode levar à limitação da mobilidade, ou seja, a mobilidade é afetada pela cognição se esta limitar a atividade física ${ }^{(47)}$. Comprovou-se que o Programa TEIA melhorou a confiança, a mobilidade, performance da marcha e equilíbrio levando à diminuição do medo de cair. Melhorou também o desempenho da cognição, logo prosperaram as funções cognitivas, nomeadamente as relacionadas com 0 medo de cair. Evidenciou-se a relação que há entre o treino da cognição com o medo de cair.

Foi nossa intenção compreender como o Programa TEIA interferia com a qualidade de vida associada à saúde dos participantes. Através das pontuações da Questionário de vida associado à saúde SF-36, nas suas várias dimensões, verificou-se que na avaliação intrasujeitos, do grupo de programa, houve diferenças estatísticas significativas, quer na componente física (função física, desempenho físico, dor e saúde geral) quer na componente mental (vitalidade, função social desempenho emocional e saúde mental). 0 mencionado comprova que o Programa TEIA teve implicações positivas na qualidade de vida dos participantes ${ }^{(31,48)}$.

Relativamente às avaliações intrasujeitos do grupo de programa, validou-se que o Programa TEIA introduziu alterações estatisticamente significativas, na qualidade de vida associada com a incontinência urinária, no medo de cair, na performance do equilíbrio, seja estático ou dinâmico, na mobilidade, na marcha, em algumas atividades instrumentais de vida diárias, na sintomatologia depressiva, na função cognitiva e na qualidade de vida associada à saúde. Em todas estas variáveis, verificou-se uma melhoria na sua performance, 0 que se traduz num melhor desempenho físico e mental, bem como em benefícios na perceção da qualidade de vida. 0 treino permitiu ganhos secundários, tais como, a diminuição dos valores tensionais, frequência cardíaca, peso e índice de massa corporal.

\section{Avaliação intersujeitos $2^{\mathrm{a}}$ avaliação}

No que concerne à avaliação intersujeitos, após a implementação do Programa TEIA, verificou-se que na perceção da qualidade de vida associada com a incontinência urinária houve diferenças estatisticamente significativas, achados concordantes com o estudo de Berlezi et al. (2013) ${ }^{(49)}$ evidenciando mais uma vez, a relação entre o treino muscular do assoalho pélvico e terapia comportamental e a perceção da qualidade de vida associada à incontinência urinária.

Relativamente à avaliação do medo de cair verificouse que apesar de ter havido diminuição do medo de cair após a implementação do Programa TEIA no grupo de programa, não houve diferenças estatisticamente significativas entre o grupo de programa e o grupo de controlo, resultado muito idêntico ao encontrado em outros estudos $(31,42)$, podendo este facto estar relacionado com o tamanho da amostra.

Quando examinada a pontuação do teste de Tinetti, da Escala de Equilíbrio de Berg e do tempo de 
execução teste Timed Up and Go, atestou-se que houve diferenças estatisticamente significativas. Podemos concluir que o Programa TEIA, na sua componente de treino de equilíbrio, conseguiu melhorar o equilíbrio estático e dinâmico, a mobilidade, a marcha, a estabilidade na deambulação, que de forma indireta produziu a diminuição do risco de queda concordante com os achados de outros estudos ${ }^{(13,33,42)}$, contribuindo para a evidência da relação entre o treino de equilíbrio e a diminuição do risco de quedas em idosos.

$\mathrm{Na}$ avaliação da dependência nas atividades instrumentais de vida diária e depressão, validou-se que não houve diferenças entre os grupos. Num estudo sobre estimulação cognitiva de Apóstolo et al. (2011) achados foram os mesmos, apesar de terem evidenciado os ganhos na avaliação intrasujeitos no grupo do programa, tal como aconteceu após a implementação do Programa TEIA (11), atribuindo-se este dado ao tamanho da amostra.

$\mathrm{Na}$ variável cognição, apesar das diferenças estatísticas significativas, na avaliação intrasujeitos no grupo de programa, apurou-se que não houve ganhos estatisticamente significativos entre os grupos. Podemos inferir que esta análise pode estar relacionada com o do facto da amostra ser pequena para sustentar esta diferença. Não foram encontrados estudos que tenham utilizado apenas a escala Teste de Declínio Cognitivo de 6 itens, de modo a relacionar os resultados.

As diferenças estatísticas significativas observadas na avaliação intrasujeitos, no que concerne à perceção da qualidade de vida associada à saúde, não se comprovaram na avaliação intersujeitos para a componente física. Evidência oposta à encontrada no estudo de Kyrdalen et al. (2013), onde ocorreram diferenças entre grupos na componente física, mas não na componente mental (31).

Em suma, na $2^{\mathrm{a}}$ avaliação evidenciou-se diferenças intergrupais na perceção da qualidade de vida associada à incontinência urinária, na performance do equilíbrio, na marcha, na perceção da qualidade de vida associada à saúde na componente mental. Não foram evidenciadas alterações estatisticamente significativas na variável cognição, podendo estar relacionado com o facto de a amostra do estudo ser pequena.

\section{CONCLUSÃO}

O envelhecimento enriquece o Ser Humano com as experiências de vida, aumento da resiliência e de capacidade para enfrentar vicissitudes que vão surgindo. Mas o envelhecimento também traz a maturação dos órgãos e consequentes alterações fisiológicas e anatómicas do corpo, que se pode ou não, traduzir em dependência e/ou em perda de autonomia. Estas alterações podem interferir, com o comportamento na marcha, na rapidez das mudanças posturais, na capacidade de adotar mecanismos compensatórios de manutenção de equilíbrio, no desempenho do equilíbrio, na competência da musculatura do assoalho pélvico e no desempenho da cognição.

O Programa TEIA foi desenhado para contemplar várias dimensões, desde o treino de equilíbrio, o treino muscular do assoalho pélvico até à estimulação cognitiva. Verificamos que estas três dimensões, se trabalhadas em conjunto, produzem efeitos positivos na qualidade de vida, relacionando-se com a diminuição do risco de queda, privilegiando assim a independência, ou baixos níveis de dependência e a autonomia nos idosos.

A implementação deste programa, não só, deu o seu contributo à população idosa ajudando a elevar o seu potencial funcional, como também, à comunidade de enfermagem nomeadamente, aos enfermeiros de reabilitação. 0 enfermeiro de reabilitação tem um papel muito importante na adoção de atitudes para promover um envelhecimento ativo, na medida em que, otimiza o potencial funcional, promove a independência e autonomia dos idosos, incrementa a sua qualidade de vida e fortalece aptidões físicas e mentais que possibilitam ultrapassar as limitações que o envelhecimento produz, o que permite racionalizar os recursos humanos e financeiros.

Sendo o Programa TEIA, um programa de atividade física e comportamental específico para as três dimensões já descritas, verificou-se que a sua implementação permitiu obter ganhos primários e secundários. Como ganhos secundários, verificou-se que o ensino e consciencialização dos tempos respiratórios, parte constituinte das sessões de treino de equilíbrio, permitiu aumentar a capacidade aeróbia e a tolerância ao esforço cardiovascular, originando uma descida do valor médio da tensão arterial e frequência cardíaca.

Um outro ganho secundário foi a perda de peso, provavelmente relacionado com a contínua prática da atividade física. Os participantes do grupo de programa perderam em média um quilograma e consequentemente diminuíram o valor de índice de massa corporal. Outro fator secundário está relacionado com a qualidade de vida, de um modo geral melhorou, pois verificou-se que houve diferenças estatísticas na perceção da qualidade de vida associada à saúde na componente mental.

Como ganhos primários, validou-se a eficácia da performance do equilíbrio, estático e dinâmico, a melhoria da mobilidade, o aperfeiçoamento na habilidade da marcha, no melhoramento do desempenho e competência muscular do assoalho pélvico, que em associação à terapia comportamental, potenciou o aumento da qualidade de vida associada à incontinência urinária, bem como no desempenho das funções cognitivas.

Todos estes benefícios permitiram comprovar a importância deste tipo de programa de exercícios neste tipo de população, sendo o Programa TEIA uma mais valia para o idoso e para os profissionais que cuidam deles.

Uma limitação fundamental do estudo, prendeu-se com o facto da amostra ser pequena, que poderá ter 
limitado certos achados estatísticos. Considerou-se também uma limitação, o facto de não ter havido uma $3^{\mathrm{a}}$ avaliação, a ser realizada num período após a conclusão da implementação do programa, por forma, a evidenciar ainda mais a necessidade de atividade física frequente, direcionada para o treino das dimensões, equilíbrio, continência urinária e cognição.

Como trabalho futuro, seria importante atestar as conclusões desde estudo com outros estudos com amostras maiores, por forma a corroborar os benefícios da implementação deste tipo de programa. Também seria importante proceder a uma reavaliação dos participantes após um período sem as atividades inerentes ao programa, no sentido de averiguar a existência de complicações intrínsecos à falta de treino.

\section{REFERÊNCIAS BIBLIOGRÁFICAS}

1. São José J. de, Teixeira A. Envelhecimento ativo: contributo para uma discussão crítica. análise social, Revista do Instituto de Ciências Sociais da Universidade de Lisboa. 2014;210. ISSN:00032573

2. Paúl M, Ribeiro O. Manual de envelhecimento ativo. 2nd ed. Lisboa: Lidel; 2018. ISBN:978-989-752-333-5

3. Instituto Nacional de Estatística. Instituto Nacional de Estatística - Statistics Portugal. [Web page] Lisboa: Instituto Nacional de Estatística, 2017. [Updated 2019; cited 201909 Janeiro] Available from: https://ine.pt/xportal/xmain?xpid=INE\&xpgid=ine_bdc tree\&co ntexto=bd\&selTab=tab2.

4. Eurostat. Estrutura populacional e envelhecimento. Eurostat Statistics Explained. [Web page]: Eurostat; 2018 [Updated 2018; cited 201909 Janeiro] Available from: https://ec.europa.eu/eurostat/statisticsexplained/index.php?title=Population structure and ageing/pt\# A_percentagem_de_idosos_continua_a_aumentar.

5. Kalsait, A., Lakshmiprabha, R., Iyyar, S. e Mehta, A. Correlation of Cognitive Impairment with funcional Mobility \& Risk of Fall in Elderly Individuals. Indian J Physiother Occup Ther. 2017; 11(2): pp7-11.

6. Schneider, R. e Irigaray, T. O envelhecimento na atualidade: aspetos cronológicos, biológicos, psicológicos e sociais. Campinas. Estud Psicol. 2008; 25(4): pp.585-593.

7. Sequeira, C. Cuidar de idosos com dependência física e mental. 1ed. Lisboa: Lidel; 2010. ISBN: 978-972-757-717-0.

8. Saúde, Organização Mundial de. Relatório Mundial de Envelhecimento e Saúde. 1ed. Genebra: World Health Organization; 2015.

9. Saúde, Direção Geral de. Estratégia Nacional para o Envelhecimento Ativo e Saudável 2017-2025, Proposta do Grupo de trabalho Interministerial (Despacho $\left.n^{\circ} 12427 / 2016\right)$. Lisboa: DGS; 2017.

10. Firmino, H., Simões, M. e Cerejeira, J. Saúde Mental das Pessoas Mais Velhas. 1ed. Lisboa: Lidel; 2016. ISBN: 978-989-752-147-8.

11. Jorge, Instituto Nacional de Saúde Doutor Ricardo. EVITA-Epidemiologia e Vigilância dos Traumatismos e Acidentes: relatório 2009-2012. 1ed. Lisboa: INSA,IP; 2014. ISBN: 978-9898794-00-0.

12. Swift CG, Iliffe S. Assessment and prevention of falls in older people-concise guidance. Clin Med. [Internet]. 2014 Dec 1 [cited 17 June 2019]; 14(6):658-62. Available from: https://www.ncbi.nlm.nih.gov/pmc/articles/PMC4954140/

13. Gouveia BR, Jardim HG, Martins MM, Gouveia ÉR, de Freitas DL, Maia JA, Rose DJ. An evaluation of a nurse-led rehabilitation programme (the ProBalance Programme) to improve balance and reduce fall risk of community-dwelling older people: A randomised controlled trial. Int J Nurs Stud. 2016 Apr 1;56:1-8..

14. Barban F, Annicchiarico R, Melideo M, Federici A, Lombardi M,
Giuli S, et al. Reducing fall risk with combined motor and cognitive training in elderly fallers. Brain Sci. 2017 Feb 10;7(2):19.

15. Marques EA, Figueiredo P, Harris TB, Wanderley FA, Carvalho J. Are resistance and aerobic exercise training equally effective at improving knee muscle strength and balance in older women?. Arch Gerontol Geriatr. 2017 Jan 1;68:106-12.

16. Madill SJ, Pontbriand-Drolet S, Tang A, Dumoulin C. Effects of PFM rehabilitation on PFM function and morphology in older women. Neurourol Urodyn. 2013 Nov;32(8):1086-95..

17. Abrams $\mathrm{P}$, Andersson KE, Birder L, Brubaker L, Cardozo L, Chapple C, et al. Fourth International Consultation on Incontinence Recommendations of the International Scientific Committee: Evaluation and treatment of urinary incontinence, pelvic organ prolapse, and fecal incontinence. Neurourol Urodyn. 2010 Jan;29(1):213-40.

18. Kim $H$, Yoshida $H$, Suzuki $T$. The effects of multidimensional exercise on functional decline, urinary incontinence, and fear of falling in community-dwelling elderly women with multiple symptoms of geriatric syndrome: a randomized controlled and 6 month follow-up trial. Arch Gerontol Geriatr. 2011 Jan 1;52(1):99-105.

19. Shumway-Cook, A. e Woollacott, M. Motor Control Traslating research into clinical pratice. 3 ed. Filadelfia: Lipincot Williams \& Wilkins; 2007.

20. Apóstolo, J., Cardoso, D., Marta, L. e Amaral, T. Efeito da estimulação cognitiva em Idosos. Referência. 2011; III (5):193201.

21. Fortin, M. F. Fundamentos e Etapas do Processo de Investigação. 1ed. Loures: Lusodidata; 2009. ISBN: 978-972-8383-10-7.

22. Orientações sobre Incontinência Urinária [Internet]. Apurologia.pt. 2019 [cited 22 May 2019]. Available from: https://www.apurologia.pt/guidelines/Incont-Urinaria.pdf

23. Melo CA. Adaptação cultural e validação da escala "Falls Efficacy Scale" de Tinetti. Ifisionline [Internet]. 2011 [cited 22 May 2019]; 1 (3): 33-43..

24. Petiz E. A atividade física, equilíbrio e quedas um estudo com idosos institucionalizados. Mestrado em Ciência do Desporto, na área de especialização de Atividade Física para a Terceira Idade, pela Faculdade de Ciências do Desporto e de Educação Física -Universidade do Porto (não publicado); 2002.

25. Santos AP, Ramos NC, Estevão PC, Lopes AM, Pascoalinho J. Instrumentos de medida úteis no contexto da avaliação em fisioterapia. Re (habilitar)[Internet]. 2005 [cited 22 May 2019];(1): 131-156.

26. Podsiadlo D, Richardson S. The timed "Up \& Go": a test of basic functional mobility for frail elderly persons. J Am Geriatr Soc. 1991 Feb;39(2):142-8.

27. Sequeira C. Cuidar de idosos dependentes. Coimbra: Quarteto Editora; 2007.

28. Alves Apóstolo JL, Batista Cardoso DF, Gonçalves Marta LM, de Oliveira Amaral TI. Efeito da estimulação cognitiva em Idosos. Referência. 2011;II(5)..193-201.

29. Paiva DD, Apóstolo JL. Cognição e Envelhecimento: Estudo de Adaptação Transcultural e Validação do Six Item Cognitive Impairment Test (6-Cit). Escola Superior de Enfermagem de Coimbra, Coimbra. 2013.

30. Ferreira PL. Criação da versão portuguesa do MOS SF-36. Parte I Adaptação cultural e linguística. Acta Med Port. 2000 Jan Abr; 13(1-2): 55-66.

31. Kyrdalen, Ingebjørg L. et al. The Otago Exercise Program Performed as Group Training Versus Home Training in Fall-prone Older People: A Randomized Controlled Trial. Physiother Res Int. 2013; 19(2):108-116.

32. Apóstolo JL, Cardoso DF, Rosa Al, Paúl C. The effect of cognitive stimulation on nursing home elders: A randomized controlled trial. J Nurs Scholarsh. 2014 May 1;46(3):157-66..

33. Mulasso A, Roppolo M, Liubicich ME, Settanni M, Rabaglietti E. A multicomponent exercise program for older adults living in residential care facilities: direct and indirect effects on physical functioning. J Aging Phys Act. 2015 Jul;23(3):409-16.

34. Zelinski EM, Spina LM, Yaffe K, Ruff R, Kennison RF, Mahncke HW, Smith GE. Improvement in memory with plasticity-based adaptive cognitive training: Results of the 3-month follow-up. J 
Am Geriatr Soc. 2011 Feb;59(2):258-65..

35. Gawler S, Skelton DA, Dinan-Young S, Masud T, Morris RW, Griffin M, Kendrick D, Iliffe S. Reducing falls among older people in general practice: The ProAct65+ exercise intervention trial. Arch Gerontol Geriatr. 2016 Nov 1;67:46-54.

36. Possamai Menezes, L., Stamm, B., Tambara Leite, M., Hildebrandt, L. e Kirchner, R. Cair faz parte da vida: Fatores de risco para quedas em idosos. Rev Pesqui Cuid Fundam. 2016; 8(4):5080

37. Saúde, Direção Geral de. Hipertensão Arterial: definição e classificação. 1ed. Lisboa: DGS; 2013.

38. Brum, P., Forfaz, C., Tinucci, T. e Negrão, C. Adaptações agudas e crônicas do exercício físico no sistema cardiovascular. Rev Bras Educ Fís Esp. 2004; 18:21-31.

39. Nelson, M., Rejeski, W., Blair, S., Duncan, P. e Judge, J. Physical Activity and Public Health in Older Adults: Recommendation From the American College of Sports Medicine and the American Heart Association. Circulation. 2007; 116(9):1094-1105.

40. Rosqvist, E., Aukee, P., Kallinen, M. e Rantanen, T. Feasibility and acceptability of the pelvic floor muscle and bladder training programme. Int J Urol Nurs. 2008; 2(3):113-118.

41. Pereira, V., Correia, G. e Driusso, P. Individual and group pelvic floor muscle training versus no treatment in female stress urinary incontinence: a randomized controlled pilot study. Eur J Obstet Gynecol Reprod, 2011; 159(2):465-471.

42 Kapan A, Luger E, Haider S, Titze S, Schindler K, Lackinger C, Dorner TE. Fear of falling reduced by a lay led home-based program in frail community-dwelling older adults: A randomised controlled trial. Arch Gerontol Geriatr. 2017; 68: pp.25-32.

43. Emilio EJ, Hita-Contreras $F$, Jiménez-Lara PM, Latorre-Román $P$, Martínez-Amat A. The association of flexibility, balance, and lumbar strength with balance ability: risk of falls in older adults. J Sports Sci Med. 2014 May;13(2):349-357.

44. Jahana KO, Diogo MJ. Quedas em idosos: principais causas e conseqüências. Saúde Colet. 2007; 4(17):148-153.

45. Fhon JR, Fabrício-Wehbe SC, Vendruscolo TR, Stackfleth R, Marques S, Rodrigues RA. Accidental fails in the elderly and their relation with functional capacity. Rev Latino-Am Enferm. 2012; 20(5):1-8.

46. Yardimci, B., Aran, S., Ozkaya, I., Aksoy, S., Demir, T., Tezcan, G. e Kaptanoglu, A. The role of geriatric assessment tests and anthropometric measurements in identifying the risk of falls in elderly nursing home residents. Saudi Med J. 2016; 37(10):11011108.

47. Guzman $A B$, Lacampuenga PE, Lagunsad AP. Examining the structural relationship of physical activity, cognition, fear of falling, and mobility limitation of Filipino in nursing homes. Educ Gerontol. 2015; 41(7):527-542.

48. Riva N, Faccendini S, Lopez ID, Fratelli A, Velardo D, Quattrini $A$, et al. Balance exercise in patients with chronic sensory ataxic neuropathy: a pilot study. Journal of the Peripheral Nervous System. 2014; 19:145-151.

49. Berlezi EM, Martins M, Dreher DZ. Programa individualizado de exercícios para incontinência urinária executado no espaço domiciliar. Sci Med. 2013 Oct 1;23(4),232-238. 


\title{
IMPACTO DE UM TREINO PROPRIOCETIVO NA CAPACIDADE FUNCIONAL DOS IDOSOS
}

\author{
IMPACTO DE UN ENTRENAMIENTO PROPIOCEPTIVO EN LA CAPACIDAD FUNCIONAL DE LOS ANCIANOS
}

\author{
IMPACT OF A PROPRIOCEPTIVE TRAINING ON THE FUNCTIONAL CAPACITY OF THE ELDERLY
}

DOI 10.33194/rper.2019.v2.n1.12.4560 | Submetido 03.03.2019 | Aprovado 27.06.2019

\author{
Sérgio Garcia ${ }^{1,2}$; Marisa Cunha ${ }^{2,3}$; (i) Eugénia Mendes ${ }^{4}$; (i) Leonel Preto ${ }^{4}$; (i) André Novo ${ }^{4,5}$ \\ 1 - ACES Tâmega II - Vale do Sousa Sul - UCC Paredes Rebordosa; 2 - Reabilita.Lar; 3 - ACES Tâmega II - Vale do Sousa Sul - UCC \\ Cuidar Penafiel; 4 - Escola Superior de Saúde do Instituto Politécnico de Bragança; 5 - NurselD - CINTESIS
}

\section{RESUMO}

Introdução: O envelhecimento humano acarreta uma diminuição da capacidade funcional dos idosos, sendo o exercício físico fundamental para a melhorar.

Objetivo: Avaliar os efeitos de um programa de Enfermagem de Reabilitação de treino propriocetivo na capacidade funcional num grupo de idosos.

Método: Estudo quasi-experimental com avaliação antes e após intervenção. A amostra é constituída por 24 idosos distribuídos pelo grupo de intervenção $(n=12)$ e grupo de controlo (12). 0 programa de intervenção incluiu 24 sessões ao longo de 12 semanas de implementação. Foram utilizados como instrumentos de medida o teste de equilíbrio unipodal, o Índice de Tinetti para equilíbrio e marcha e aptidão física pela bateria de testes de Rikli \& Jones.

Resultados: No grupo de intervenção houve evolução positiva relativamente a todas as variáveis avaliadas, com diferenças estatisticamente significativas nos dois momentos de avaliação. No grupo de controlo não se verificaram alterações com significado estatístico.

Conclusão: Este programa de treino propriocetivo demonstrou ganhos na capacidade funcional dos idosos.

Palavras chave: enfermagem de reabilitação; proprioceção; envelhecimento; capacidade funcional

\section{RESUMEN}

Introducción: El envejecimiento humano acarrea una disminución de la capacidad funcional de los ancianos, siendo el ejercicio físico fundamental para mejorarla.

Objetivo: Evaluar los efectos de un programa de Enfermería de Rehabilitación de entrenamiento propicio en la capacidad funcional en un grupo de ancianos.

Método: Estudio cuasi-experimental con evaluación antes y después de intervención. La muestra está constituida por 24 ancianos distribuidos por el grupo de intervención $(n=12)$ y el grupo de control (12). El programa de intervención incluyó 24 sesiones a lo largo de 12 semanas de aplicación. Se utilizaron como instrumentos de medida la prueba de equilibrio unipodal, el Índice de Tinetti para equilibrio y marcha, y aptitud física por la batería de pruebas de Rikli \& Jones.

Resultados: En el grupo de intervención hubo una evolución positiva en todas las variables evaluadas, con diferencias estadísticamente significativas en los dos momentos de evaluación. En el grupo de control, no hubo cambios significativos en el significado estadístico.

Conclusión: Este programa de entrenamiento propuesto ha demostrado ser determinante en la mejora de la capacidad funcional de los ancianos.

Palabras clave: enfermería de rehabilitación; propiocepción; envejecimiento; capacidad funcional

\section{ABSTRACT}

Introduction: Human aging implies a reduction in the functional capacity of the elderly, and physical exercise is fundamental to improve it.

Objective: To evaluate the effects of a Rehabilitation Nursing program of self-training on functional capacity in a group of elderly people.

Method: Quasi-experimental study with evaluation before and after intervention. The sample consisted of 24 elderly people distributed by the intervention group (12) and the control group $(n=12)$. The intervention program 
included 24 sessions over 12 weeks of implementation. The unipodal balance test, the Tinetti index for balance and gait, and physical fitness by the Rikli \& Jones test battery were used as measuring instruments.

Results: In the intervention group there was a positive evolution in relation to all variables evaluated, with statistically significant differences in the two moments of evaluation. In the control group, there were no statistically significant changes.

Conclusion: This program of proprioceptive training demonstrated gains in the functional capacity of the elderly.

Keywords: rehabilitation nursing; proprioception; aging; functional capacity

\section{INTRODUÇÃO}

Com o aumento da idade o corpo humano passa por um período de alterações que levam ao declínio das capacidades físicas, tais como a diminuição da flexibilidade, agilidade, coordenação, mobilidade articular e, principalmente, o equilíbrio(1).

Há uma diminuição progressiva na capacidade funcional que acompanha o processo de envelhecimento mas que não deve ser fator de exclusão social, de dependência ou de outras limitações que levam a situações de solidão ou institucionalização(2).

0 envelhecimento compromete a habilidade do sistema nervoso central em realizar o processamento dos sinais vestibulares, visuais e propriocetivos responsáveis pela manutenção do equilíbrio corporal $^{(3)}$.

Os idosos apresentam perdas propriocetivas que diminuem a capacidade de deteção do movimento e dificultam a reprodução precisa de movimentos articulares, ou seja, dificultam a proprioceção( ${ }^{(4)}$.

O termo proprioceção deriva do latim (re)ceptus (ato de receber) e proprios (nós próprios).

A proprioceção pode ser definida como o input neural proveniente das terminações nervosas denominadas de mecanorrecetores (recetores sensoriais para a proprioceção) localizados na pele, tendões, músculos, cápsulas articulares e ligamentos, que são responsáveis pelo envio de informação sobre o movimento, posição ou deformação que ocorre nestas estruturas ao SNC. Este processa, organiza e comanda o corpo de forma adequada a manter o controlo e postura correta do corpo $^{(5,6)}$.

Rossato et al., em 2013, afirmam que através da proprioceção ocorrem estímulos nos recetores das cápsulas articulares, músculos e ligamentos, que além de assegurarem uma boa integridade das sensações propriocetivas, melhoram a força muscular, equilíbrio e marcha ${ }^{(7)}$.

O processo de envelhecimento é acompanhado de alterações do sistema nervoso, locomotor e sensorial que podem provocar alterações na postura, equilíbrio e marcha ${ }^{(8)}$. Bulksman e Vilela, em 2004, referem que nos idosos as respostas motoras aos estímulos propriocetivos, visuais e auditivos estão mais lentos, podendo interferir na qualidade da marcha e na realização das atividades de vida diárias (AVD) ${ }^{(9)}$.

A capacidade funcional pode ser representada pela capacidade de um indivíduo em realizar as AVD sem dificuldades ${ }^{(10)}$, além de estar associada a alterações clínicas provocadas pelo envelhecimento. Alterações nas AVD podem ser úteis para indicar futuras complicações relacionadas com a saúde do idoso, como incapacidade física, fragilidade, institucionalização e mortalidade ${ }^{(11)}$.

As variáveis da capacidade funcional que se consideraram pertinentes para avaliar neste estudo foram o equilíbrio e a aptidão física, fundamentais para a capacidade funcional dos idosos e que se tornaram foco importante dos profissionais de saúde pelo seu elevado impacto na vida dos idosos.

Este estudo teve como objetivo avaliar o impacto de um programa de Enfermagem de Reabilitação de treino propriocetivo na capacidade funcional dos idosos. Foi formulada a seguinte pergunta de investigação: Qual o impacto de um programa de Enfermagem de Reabilitação de treino propriocetivo na capacidade funcional em idosos?

\section{MÉTODO}

Foi realizado um estudo quasi-experimental, com grupo de intervenção e grupo de controlo.

\section{População e amostra}

Foi solicitado aos médicos de família a sua colaboração na referenciação dos participantes. A amostra, de conveniência, é constituída por 24 idosos, dos quais 12 integraram o grupo de intervenção (idosos inscritos nas USF de Lordelo) e 12 o grupo de controlo (idosos inscritos nas USF de Rebordosa).

Foram definidos os seguintes critérios de inclusão: idade igual ou superior a 65 anos de idade, clinicamente estáveis, com capacidades músculoesqueléticas para a realização dos exercícios que constavam no programa de intervenção e nos dois momentos de avaliação, com capacidade para entender e cumprir ordens simples. Como critério de exclusão foi definida a contraindicação para a prática de exercício físico pelo médico de família. Todos os participantes no estudo faltaram a 4 ou a menos sessões de treino.

\section{Instrumentos de avaliação}

Para avaliar o impacto decorrente da implementação do programa de Enfermagem de Reabilitação de treino propriocetivo na capacidade funcional dos idosos, foram utilizados o Indice de Tinetti (avaliação do 
equilíbrio e da marcha), o teste de equilíbrio unipodal (avaliação do equilíbrio estático) e a bateria de testes de Rikli-Jones (avaliação da aptidão física).

Todos os testes foram realizados nos dois grupos de idosos participantes no estudo, com 12 semanas de intervalo entre os dois momentos de avaliação. No grupo de intervenção as avaliações foram efetuadas antes do início do programa e no final do mesmo.

As avaliações foram realizadas nos dois grupos no mesmo horário e na mesma semana e foi pedido a todos os participantes que utilizassem roupa desportiva e cómoda.

Foram avaliadas as variáveis da capacidade funcional, nomeadamente equilíbrio estático e dinâmico, equilíbrio unipodal e aptidão física.

\section{Protocolo de intervenção}

O programa foi realizado durante 12 semanas, com 2 sessões por semana de 60 minutos cada. Todos os exercícios foram realizados pelos participantes sem calçado, de forma a potenciar o efeito propriocetivo dos exercícios nos participantes, com a exceção de alguns exercícios em que os idosos não se sentiam tão confortáveis sem calçado. As sessões foram constituídas por 3 partes como Brower (2003) e Eyigor et al. (2007) descreveram ${ }^{(12,13)}$ :

- Aquecimento/alongamento (10 min);

- Exercícios propriocetivos (40 min);

- Alongamento/relaxamento (10 min).

Na Figura 1 pode-se observar o Programa de Exercício Propriocetivo de forma esquemática.

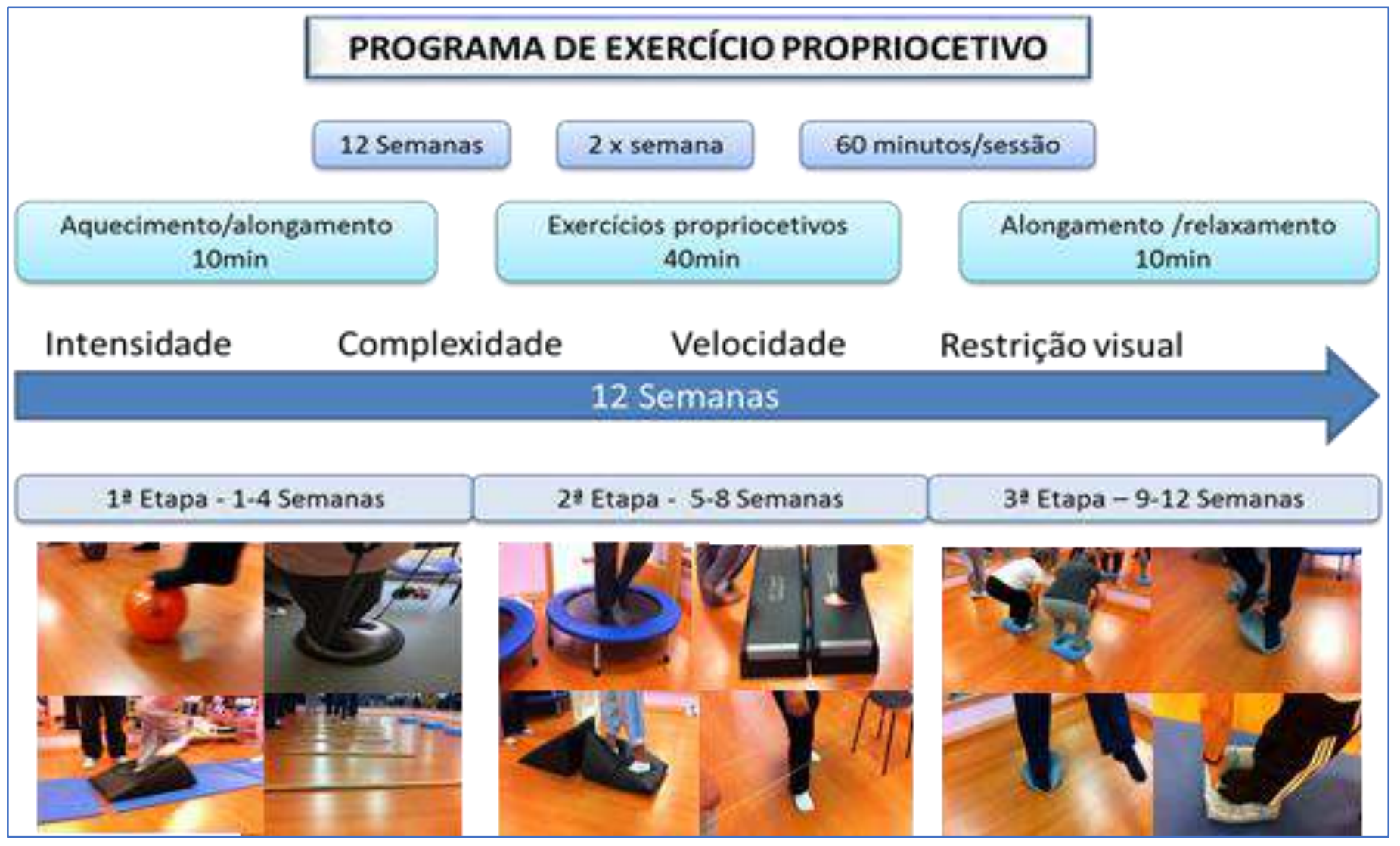

Figura 1 - Programa de exercício propriocetivo

Etapas do programa de exercícios propriocetivos

Foram realizados ao longo das 12 semanas 54 exercícios diferentes, criados e adaptados para os idosos, que foram aumentando de intensidade, complexidade, velocidade e alguns com restrição visual, tendo em conta se os participantes tinham capacidade para os executar sem queixas ou desconforto. Foram formados circuitos com várias estações com exercícios diferentes nas várias sessões, com a duração de 2 a 3 minutos em cada exercício ${ }^{(14)}$. Os exercícios foram realizados por fases, divididos por 3 etapas de evolução dos idosos (18 exercícios em cada), tendo em conta a adaptação aos exercícios, resistência, força muscular e equilíbrio apresentados. Sumariamente, as primeiras 4 semanas representaram a $1^{\text {a }}$ etapa, da $5^{\mathrm{a}}$ à $8^{\mathrm{a}}$ semana considerámos a $2^{\mathrm{a}}$ etapa e da $9^{a}$ à $12^{a}$ semana a $3^{a}$ etapa.

\section{Análise e tratamento dos dados}

O tratamento estatístico dos dados foi efetuado com recurso ao programa informático IBM SPSS (Statistical Pachage for the Social Sciences) Statistics, versão 20, apresentando-se a estatística descritiva mediante o valor média desvio padrão e valores mínimos e máximos. O número de indivíduos determinados pelas avaliações é indicado pelo $\mathrm{n}$ amostral.

Para o estudo da comparação entre os dois momentos de avaliação de cada grupo, recorreu-se à aplicação do teste de diferenças de médias intrasujeitos não- 
paramétrico Wilcoxon. O nível de significância para este estudo foi estabelecido para $p \leq 0,05$.

\section{Considerações éticas}

Todos os participantes assinaram o consentimento informado de forma livre e esclarecida, tendo sido explicados em detalhe os objetivos do estudo e a natureza da sua participação, bem como foi pedida autorização para a utilização de imagem e vídeo. 0 estudo obteve autorização por parte do ACeS Tâmega II - Vale de Sousa Sul e o parecer favorável pela Comissão de Ética para a Saúde da ARS Norte (Parecer $\left.n^{\circ} 51 / 2013\right)$.

\section{RESULTADOS}

0 género feminino predominou tanto no grupo de intervenção $(66,7 \%)$, como no grupo de controlo $(75 \%)$, tendo assim uma distribuição semelhante relativamente ao género em ambos os grupos.

Relativamente à média de idades, verificou-se uma homogeneidade dos dois grupos, tendo o grupo de intervenção uma média de $67,25 \pm 2,01$ anos e o grupo de controlo $68,08 \pm 1,73$ anos, sendo que o mínimo de idade é 65 anos e o máximo é de 71 anos (nos dois grupos).

No Quadro 1 podem-se observar os resultados das avaliações (intrasujeitos) antes e após a implementação do programa de intervenção, nos grupos de intervenção e de controlo (Teste Wilcoxon, Z).

\begin{tabular}{|c|c|c|c|c|c|c|c|}
\hline & & & & \multirow{2}{*}{\multicolumn{2}{|c|}{ Grupo de Intervenção }} & & \\
\hline & & & \multirow[b]{2}{*}{$\mathrm{N}$} & & & \multicolumn{2}{|c|}{ Grupo Controlo } \\
\hline & & & & Média & $p$ & Média & $p$ \\
\hline \multirow{10}{*}{$\begin{array}{c}\text { APTIDÃO } \\
\text { FÍSICA }\end{array}$} & \multirow{2}{*}{ Levantar e sentar na cadeira (repetições) } & Antes & 12 & $9,08 \pm 2,10$ & \multirow{2}{*}{$\underline{0,002}$} & $10,42 \pm 3,37$ & \multirow{2}{*}{0,357} \\
\hline & & Após & 12 & $17,17 \pm 5,02$ & & $10,08 \pm 3,55$ & \\
\hline & \multirow{2}{*}{ Flexão do cotovelo (repetições) } & Antes & 12 & $11,33 \pm 3,91$ & \multirow{2}{*}{$\underline{0,002}$} & $15,58 \pm 6,14$ & \multirow{2}{*}{0,196} \\
\hline & & Após & 12 & $21,33 \pm 6,91$ & & $15,08 \pm 5,79$ & \\
\hline & \multirow{2}{*}{ Sentado e alcançar (cm) } & Antes & 12 & $11,92 \pm 12,06$ & \multirow{2}{*}{$\underline{0,002}$} & $7,92 \pm 7,79$ & \multirow{2}{*}{0,621} \\
\hline & & Após & 12 & $0,33 \pm 8,13$ & & $8,25 \pm 8,04$ & \\
\hline & \multirow{2}{*}{ Alcançar atrás das costas (cm) } & Antes & 12 & $26 \pm 5,87$ & \multirow{2}{*}{$\underline{0,002}$} & $32,25 \pm 9,72$ & \multirow{2}{*}{0,072} \\
\hline & & Após & 12 & $18,33 \pm 6,27$ & & $33,5 \pm 10,20$ & \\
\hline & \multirow{2}{*}{ Levantar, caminhar $2,44 \mathrm{~m}$ e voltar a sentar (segundos) } & Antes & 12 & $11,5 \pm 2,46$ & \multirow{2}{*}{$\underline{0,002}$} & $11 \pm 3,46$ & \multirow{2}{*}{0,272} \\
\hline & & Após & 12 & $6,08 \pm 1,50$ & & $11,7 \pm 4,68$ & \\
\hline \multirow{6}{*}{ EQUILÍBRIO } & \multirow{2}{*}{ Teste Unipodal (segundos) } & Antes & 12 & $12,75 \pm 12,37$ & \multirow{2}{*}{$\underline{0,002}$} & $4,92 \pm 6,59$ & \multirow{2}{*}{$\underline{0,034}$} \\
\hline & & Após & 12 & $29,75 \pm 21,75$ & & $3,75 \pm 3,86$ & \\
\hline & \multirow{2}{*}{ Índice de Tinetti - Equilíbrio } & Antes & 12 & $14,08 \pm 2,02$ & \multirow{2}{*}{$\underline{0,011}$} & $14,67 \pm 2,38$ & \multirow{2}{*}{$\underline{0,046}$} \\
\hline & & Após & 12 & $15,67 \pm 1,15$ & & $14,33 \pm 2,27$ & \\
\hline & \multirow{2}{*}{ Índice de Tinetti - Marcha } & Antes & 12 & $9,75 \pm 1,13$ & \multirow{2}{*}{$\underline{0,003}$} & $10,83 \pm 0,93$ & \multirow{2}{*}{0,564} \\
\hline & & Após & 12 & $11,83 \pm 0,57$ & & $10,75 \pm 1,13$ & \\
\hline
\end{tabular}

Quadro 1 - Resultados das avaliações antes e após programa de intervenção (intrasujeitos), nos grupos de intervenção e de controlo (Teste Wilcoxon, Z).

\section{DISCUSSÃO}

Relativamente aos testes da bateria de Rikli \& Jones de aptidão física, verificou-se melhoria estatisticamente significativa em todos os parâmetros avaliados. No teste flexão do cotovelo houve uma melhoria de 11,33 para 21,33 repetições, em média. No teste levantar e sentar da cadeira, de 9,08 para 17,17 repetições, no teste sentado e alcançar de $-11,92$ para $-0,33 \mathrm{~cm}$, no teste atrás das costas de $26 \mathrm{~cm}$ para $-18,33 \mathrm{~cm}$ e no teste levantar, caminhar durante $2,44 \mathrm{~m}$ e voltar a sentar houve uma melhoria de 11,5 para 6,08 segundos.

Avelar, em 2013, num estudo cujo objetivo foi avaliar um programa de 12 semanas de circuitos sensoriais, verificou uma melhoria na aptidão física dos idosos participantes. No estudo e Kim et al., em 2010, concluíram que a implementação de um programa de equilíbrio resultou num aumento da força muscular nos membros inferiores e superiores ${ }^{(14,15)}$.

A melhoria do desempenho do "levantar, caminhar durante $2,44 \mathrm{~m}$ e voltar a sentar" é consistente com os resultados de estudos que aplicaram exercícios semelhantes aos deste estudo e com o mesmo número de sessões ${ }^{(4,13,14,16,17)}$.

Não foram encontrados estudos de treino propriocetivo que avaliassem diretamente a flexibilidade, mas podemos discutir que as diferenças estatisticamente significativas do presente programa se devem à diversidade de exercícios de componente propriocetiva com base noutro tipo de exercícios, que 
implicam alongamentos e aumento da flexibilidade dos idosos.

Sousa, em 2012, num estudo que decorreu durante 20 semanas com idosos, tendo como objetivo a avaliação de um programa de atividade física multicomponente, verificou melhoria significativa da flexibilidade dos membros superiores e inferiores ${ }^{(18)}$.

No presente estudo houve também uma melhoria significativa no equilíbrio unipodal, equilíbrio estático e dinâmico/marcha, segundo o Índice de Tinetti.

No teste de equilíbrio unipodal, no grupo de intervenção, em média, o tempo em equilíbrio passou de 12,75 segundos antes da intervenção para 29,75 segundos após o programa. No grupo de controlo houve uma ligeira diminuição entre as duas avaliações. Os resultados estão de acordo com a literatura consultada. Lustosa et al., em 2010, num estudo que decorreu durante 8 semanas com a participação de 7 idosas, com o objetivo de testar um treino funcional, verificaram uma melhoria significativa no equilíbrio unipodal ${ }^{(19)}$.

No que se refere ao equilíbrio estático, no grupo de intervenção, houve melhoria estatisticamente significativa da média do score entre as avaliações, de 14,08 para 15,67. Quanto ao equilíbrio dinâmico/marcha, no grupo de idosos que realizou este programa, houve uma melhoria com significância estatística do score entre as avaliações, de 9,75 para 11,83. Os resultados obtidos são corroborados por vários estudos na literatura.

Nascimento et al., em 2012, num estudo de 4 semanas de treino propriocetivo em 9 idosos, verificaram melhoria significativa no equilíbrio postural dos idosos$^{(20)}$. Silva et al., em 2018, verificaram uma melhoria do equilíbrio de mulheres idosas após programa propriocetivo(21), tal como Costa et al., em 2009, que estudaram o efeito de um circuito de exercícios multisensoriais em 26 idosos durante 10 sessões, com resultados com significativa melhoria ${ }^{(22)}$.

\section{CONCLUSÃO}

Sociedades ditas civilizadas têm que ter a consciência que a aposta em idosos saudáveis e independentes durante o maior número de anos de vida possível, é uma aposta não só de qualidade em saúde, mas também de sustentabilidade económica.

Os Enfermeiros de Reabilitação podem e devem ter um papel interventivo e sustentado no seu corpo de conhecimentos e competências específicas e implementar programas de exercício que visem uma melhoria na capacidade funcional dos idosos, dotandoos de skills que os tornem mais independentes na realização das suas atividades diárias. Este estudo insere-se neste contexto, sendo o treino propriocetivo o nosso foco de atenção prioritário, por ser um treino de exercícios específicos e ainda pouco usado na população idosa, mas com grande potencial de utilização como ficou demonstrado neste estudo.

Podemos agora afirmar que o programa de Enfermagem de Reabilitação de treino propriocetivo implementado teve um efeito determinante na melhoria da capacidade funcional dos idosos, o que permite responder em pleno ao objetivo delineado.

Houve melhoria estatisticamente significativa em todos os parâmetros avaliados no grupo de intervenção, enquanto no grupo de controlo não houve melhoria significativa em nenhum parâmetro avaliado, sendo que ainda se verificou uma diminuição com significado estatístico no parâmetro equilíbrio unipodal neste último grupo.

A implementação de programas de exercício físico é atualmente uma área de atuação dos Enfermeiros de Reabilitação, sendo de todo o interesse aumentar o nosso corpo de competências específicas que nos permita intervir de uma forma mais criteriosa, rigorosa e científica nos idosos das nossas comunidades. A implementação de programas de exercício propriocetivo pelos enfermeiros de reabilitação, tendo como alvo a população mais vulnerável, na qual se inclui os idosos, tem que se constituir uma prática sistemática e sistematizada profissionalizada - promovendo ganhos em saúde e, em simultâneo,-contribuir para a nossa posição enquanto elementos fundamentais no sistema de saúde, social e económico.

Como limitações deste estudo apontamos o curto período de tempo em que decorreu o programa de treino, o reduzido tamanho da amostra e a escassez de artigos científicos sobre a temática em estudo. Como sugestões futuras apontamos para a necessidade de replicar este programa com um maior número de idosos e de o implementar em diferentes programas de saúde da Direção Geral da Saúde, no âmbito do aumento dos níveis de atividade física e da melhoria do equilíbrio

\section{REFERÊNCIAS}

1. Manna L, Mota CB, Lopes LFD, Rossi AG, Teixeira CS, Kleinpaul JF. Investigação do equilíbrio corporal em idosos. Rev Bras Geriatr Gerontol [Internet]. 2008;11(2):155-65. Available from: http: //www.redalyc.org/pdf/4038/403838778003.pdf

2. Cabral MV, Ferreira PM. Envelhecimento activo em Portugal: trabalho, reforma, lazer e redes sociais [Internet]. Fundação Francisco Manuel dos Santos; 2014 [cited 2019 Feb 24]. 141 p. Available from: http://repositorio.ul.pt/handle/10451/23416

3. Zanardini FH, Zeigelboim BS, Jurkiewicz AL, Marques JM, Bassetto JM. Reabilitação vestibular em idosos com tontura. Pro-Fono Rev Atualização Cient. 2007;19(2):1-7.

4. Marcon Alfieri, Fábio; Leite de Moraes MC. Envelhecimento e o controle postural. Saúde Colet [Internet]. 2008 [cited 2019 Feb 24];4(19):30-3. Available from: https://www.redalyc.org/html/842/84201907/

5. Silvestre MV, Lima WC de. Importância do treinamento proprioceptivo na reabilitaçäo de entorse de tornozelo. Fisioter Mov. 2003;16(2):27-34.

6. Sayuri Tookuni K, Bolliger Neto R, Martins Pereira CA, Rúbio de Souza D, Greve JMD, Ayala AD. Análise comparativa do controle postural de indivíduos com e sem lesão do ligamento cruzado anterior do joelho. Acta Ortop Bras. 2005;13(3).

7. Rossato CE, Lemos LFC, Teixeira CS, Pranke GI, Mota CB. Proprioceção no esporte: uma revisão sobre a prevenção e recuperação de lesões desportivas. Saúde (Santa Maria). 2013;39(2):57-70.

8. Sanglard RCF, Pereira JS. A influência do isostretching nas alterações dos parâmetros da marcha em idosos. Fisioter Bras. 2005;6(4):255-60. 
9. Buksman S, Vilela AL. Instabilidade postural e quedas. In: Saúde do idoso: a arte de cuidar. $2^{\mathrm{a}}$ ed. Rio de Janeiro (RJ): Interciência; 2004:208-18.

10. Arena R, Myers J, Williams MA, Gulati M, Kligfield P, Balady GJ, et al. Assessment of functional capacity in clinical and research settings: a scientific statement from the American Heart Association Committee on Exercise, Rehabilitation, and Prevention of the Council on Clinical Cardiology and the Council on Cardiovascular N. Circulation. 2007;116(3):329-43.

11. Coelho $C$ de F, Burini RC. Atividade física para prevenção e tratamento das doenças crônicas não transmissíveis e da incapacidade funcional. Rev Nutr. 2009;937-46.

12. Brouwer BJ, Walker C, Rydahl SJ, Culham EG. Reducing fear of falling in seniors through education and activity programs: a randomized trial. J Am Geriatr Soc. 2003;51(6):829-34.

13. Eyigor S, Karapolat H, Durmaz B. Effects of a group-based exercise program on the physical performance, muscle strength and quality of life in older women. Arch Gerontol Geriatr. 2007;45(3):259-71.

14. Avelar BP. Efeitos de um circuito de exercícios sensoriais na força muscular, equilíbrio e desempenho funcional de mulheres idosas. Dissertação (Mestrado em Educação Física)-Universidade de Brasília, Brasília; 2013.

15. Kim K, Piao Y-J, Kim N-G, Kwon T-K. Characteristic analysis of the isokinetic strength in lower limbs of the elderly on training for postural control. Int J Precis Eng Manuf. 2010;11(6):955-67.

16. Donat H, Özcan A. Comparison of the effectiveness of two programmes on older adults at risk of falling: unsupervised home exercise and supervised group exercise. Clin Rehabil. 2007;21(3):273-83.

17. Fu S, Low Choy N, Nitz J. Controlling balance decline across the menopause using a balance-strategy training program: a randomized, controlled trial. Climacteric. 2009;12(2):165-76.

18. Sousa FLG de. Academia Sénior: um contributo para a aptidão funcional dos idosos Tese Mestrado Gerontologia Social. Centro de Tecnologias de Saúde. Funcha; 2014.

19. Lustosa LP, de Oliveira LA, da Silva Santos L, de Cássia Guedes R, Parentoni AN, Pereira LSM. Efeito de um programa de treinamento funcional no equilíbrio postural de idosas da comunidade. Fisioter e Pesqui. 2010;17(2):153-6.

20. Nascimento LCG do, Patrizzi LJ, Oliveira C. Efeito de quatro semanas de treinamento proprioceptivo no equilíbrio postural de idosos. Fisioter mov. 2012;25(2):325-31.

21. Silva C, Silva B, Pimentel T, Souza J, Januário P, Cruz A. Análise do equilíbrio em idosas após a realização dos exercícios de Frenkel. Rev Saúde e Desenvolv. 2018;12(10):210-23.

22. Costa JNA, Gonçalves CD, Rodrigues GBA, Paula AP, Pereira MM, Safons MP. Exercícios multissensoriais no equilíbrio e na prevenção de quedas em idosos. EFDeportes com. 2009; 
